\title{
Regulation of thrombin formation via the protein C pathway in normal and hypercoagulable states
}

Citation for published version (APA):

Nicolaes, G. A. F. (1997). Regulation of thrombin formation via the protein $C$ pathway in normal and hypercoagulable states. [Doctoral Thesis, Maastricht University]. Universiteit Maastricht. https://doi.org/10.26481/dis.19970529gn

Document status and date:

Published: 01/01/1997

DOI:

10.26481/dis.19970529gn

Document Version:

Publisher's PDF, also known as Version of record

\section{Please check the document version of this publication:}

- A submitted manuscript is the version of the article upon submission and before peer-review. There can be important differences between the submitted version and the official published version of record. People interested in the research are advised to contact the author for the final version of the publication, or visit the DOI to the publisher's website.

- The final author version and the galley proof are versions of the publication after peer review.

- The final published version features the final layout of the paper including the volume, issue and page numbers.

Link to publication

\footnotetext{
General rights rights.

- You may freely distribute the URL identifying the publication in the public portal. please follow below link for the End User Agreement:

www.umlib.nl/taverne-license

Take down policy

If you believe that this document breaches copyright please contact us at:

repository@maastrichtuniversity.nl

providing details and we will investigate your claim.
}

Copyright and moral rights for the publications made accessible in the public portal are retained by the authors and/or other copyright owners and it is a condition of accessing publications that users recognise and abide by the legal requirements associated with these

- Users may download and print one copy of any publication from the public portal for the purpose of private study or research.

- You may not further distribute the material or use it for any profit-making activity or commercial gain

If the publication is distributed under the terms of Article $25 \mathrm{fa}$ of the Dutch Copyright Act, indicated by the "Taverne" license above, 
Regulation of Thrombin Formation via the

\section{Protein C Pathway in}

Normal and Hypercoagulable states 
Nicolaes, Gerardus A.F.

Regulation of thrombin formation via the protein $C$ pathway in normal and hypercoagulable states by Gerardus A.F. Nicolaes - Maastricht:

Thesis Universiteit Maastricht, 1997

ISBN 90-5681-016-2

NUGI 732

Omslag: Stella Thomassen

Druk: Unigraphic Maastricht

(C) G.A.F. Nicolaes, Maastricht 1997

All rights reserved. No part of this publication may be reproduced or transmitted in any form or by any means, electronic or mechanical, including photocopy, recording or any information storage and retrieval systems, without permission of the copyright owner. 


\section{Regulation of Thrombin Formation via the Protein C Pathway in}

Normal and Hypercoagulable states

\section{PROEFSCHRIFT}

ter verkrijging van de graad van doctor aan de Universiteit Maastricht, op gezag van de Rector Magnificus, Prof. Mr. M.J. Cohen, volgens het besluit van het College van Decanen, in het openbaar te verdedigen op donderdag 29 mei 1997 om 16:00 uur.

door

Gerardus Anna Franciscus Nicolaes 
Promotor: Prof. Dr. H.C. Hemker

Co-promotores: Dr. J.Rosing

Dr. G. Tans

Beoordelingscommissie: Prof. Dr. F.C.S. Ramaekers (voorzitter)

Prof. Dr. R.M. Bertina (Rijksuniversiteit Leiden)

Prof. Dr. B. Dahlbäck, (University of Lund, Sweden)

Prof. Dr. J.L.H. Evers

Prof. Dr. J.A. Knottnerus

Prof. Dr. H.P. Schwarz (University of Vienna, Austria)

Financial support by the Netherlands Heart Foundation and by the Foundation

Dr. Ir. J.H.J. v.d. Laar for the publication of this thesis is greatly acknowledged. 
Studieknóbbelknee

Dao zag "nen dokter "in spé": "Studere? Dat hoof neet perse.

De loup vaan t blood

Dee weit iech al good,

En thart höb lech oonder de knee!"

Fons Otten, 1988 in 'ABC in Mestreech'

Voor mijn moeder en vader,

Voor Silvie 
मे

की

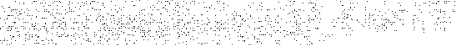

मे

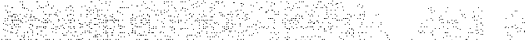

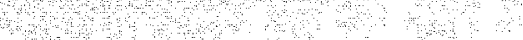

अ मे का 


\section{Contents}

Contents

page

vii

Abbreviations

viii

Chapter 1: Blood Coagulation, Factor $V$ and Thrombosis

Chapter 2: $\quad$ Activation of Human Factor V by Meizothrombin

Chapter 3 Molecular Events in the Cleavage of FVa and FVaLeiden by Activated Protein C

Chapter 4 A Prothrombinase-Based Assay for Detection of APC Resistance

Chapter 5

Effect of Activated Protein $\mathrm{C}$ on Thrombin Generation and on the Thrombin Potential in the plasma of normal and APC-resistant individuals

Chapter 6

Different Sensitivities to Activated Protein $C$ in Women Using Second and Third Generation Oral Contraceptives

Chapter $7 \quad$ General Discussion and Conclusions

Summary

Samenvatting

Curriculum Vitae

List of Publications 


\section{Abbreviations}

\begin{tabular}{|c|c|}
\hline$\alpha 2 M$ & $\alpha 2$ macroglobulin \\
\hline$\alpha 2 M-11 a$ & thrombin complexed to $\alpha 2$ macroglobulin \\
\hline Ala & Alanine \\
\hline APC & activated protein $\mathrm{C}$ \\
\hline APC-sr & APC sensitivity ratio \\
\hline APTI & activated partial thromboplastin time \\
\hline Arg & Arginine \\
\hline ATIII & antithrombin III \\
\hline$B C A$ & bicinchoninic acid \\
\hline BSA & bovine serum albumin \\
\hline DNA & deoxyribonucleic acid \\
\hline DOPC & 1,2-dioleoyl-sn-glycero-3-phosphocholine \\
\hline DOPE & 1,2-dioleoyl-sn-glycero-3-phosphoethanolamine \\
\hline DOPS & 1,2-Dioleoyl-sn-glycero-3-phosphoserine \\
\hline EDTA & ethylenediaminetetraacetic acid \\
\hline ETP & endogenous thrombin potential \\
\hline factor $\mathrm{Va}{ }^{\mathrm{P} 506 \mathrm{Q}}$ & abnormal factor Va in which $\mathrm{Arg}^{506}$ is replaced by Gln \\
\hline FPLC & fast protein liquid chromatography \\
\hline FV & coagulation factor $V$ \\
\hline FVa & activated coagulation factor $V$ \\
\hline Fva int & FVa cleaved at $\mathrm{Arg}^{506}$ \\
\hline $\mathrm{FVi}$ & APC-catalyzed inactivated coagulation factor $V$ \\
\hline FX & coagulation factor $X$ \\
\hline FXa & activated coagulation factor $X$ \\
\hline Giln & Glutamine \\
\hline Glu & Glutamic acid \\
\hline HEPES & hydroxyethylpiperazineethanesulfonic acid \\
\hline 12581 & $\begin{array}{l}\mathrm{N} \text {-dansyl-(p-guanidino)-phenylalanine-piperidide } \\
\text { hydrochloride }\end{array}$ \\
\hline lla & $\alpha$-thrombin \\
\hline$K_{1 / 2 X a}$ & $\begin{array}{l}\text { apparent } K_{d} \text { for the dissociation of the membrane-bound } \\
\text { factor } X a-V a \text { complex }\end{array}$ \\
\hline$k_{\text {cat }}$ & catalytic constant, \\
\hline$K_{m}$ & Michaelis constant \\
\hline Mr & relative molecular weight \\
\hline$M w$ & molecular weight \\
\hline APC-sr & normalized APC sensitivity ratio \\
\hline
\end{tabular}




$\begin{array}{ll}\text { OC } & \text { oral contraceptives } \\ \text { PC } & \text { phosphatidyicholine } \\ \text { PCR } & \text { polymerase chain reaction } \\ \text { PE } & \text { phosphatidylethanolamine } \\ \text { Phe } & \text { Phenylalanine } \\ \text { PL } & \text { phospholipid, phospholipid vesicles } \\ \text { pNA } & \text { para-nitroaniline } \\ \text { p-NPGB } & \text { p-nitrophenyl-p'-guanidino-benzoate hydrochloride } \\ \text { PPACK } & \text { D-Pro-Phe-Arg-CH2Cl } \\ \text { Pro } & \text { Proline } \\ \text { PS } & \text { phosphatidylserine } \\ \text { PT } & \text { prothrombin } \\ \text { rAPC } & \text { recombinant human APC } \\ \text { RVV-X } & \text { purified factor X activator from Russel's viper venom } \\ \text { S2238 } & \text { D-Phe-(pipecolyl)-Arg-pNA } \\ \text { S2366 } & \text { L-pyroGlu-Pro-Arg-pNA } \\ \text { SDS } & \text { sodium dodecyl sulfate } \\ \text { SDS-PAGE } & \text { polyacrylamide gel electrophoresis in the presence of } \\ & \text { SDS } \\ \text { SEM } & \text { standard error of the mean } \\ \text { TF } & \text { tissue factor } \\ \text { V } & \text { maximal initial rate of substrate conversion } \\ & \text { expressed in terms of total amount of enzyme present }\end{array}$




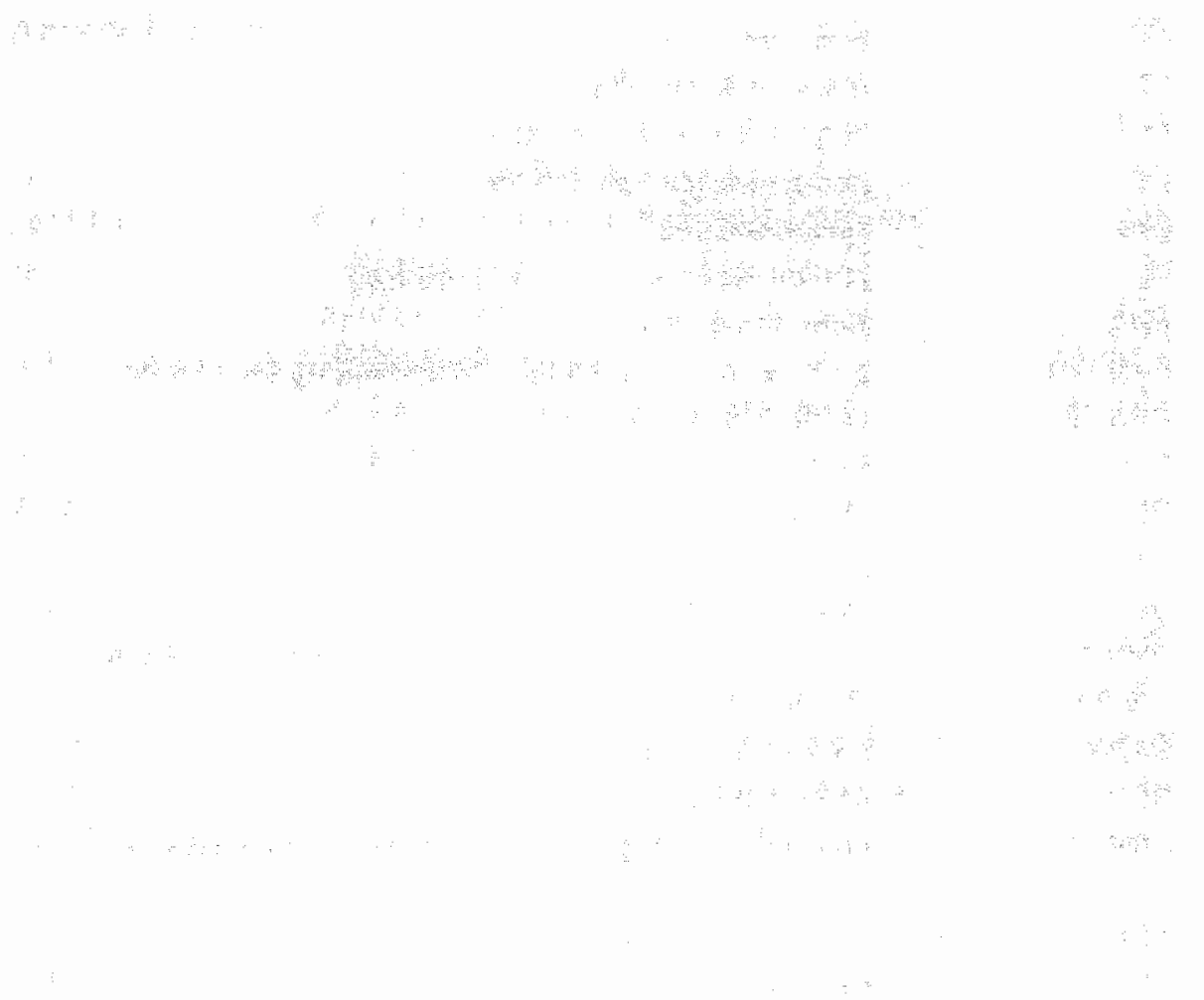


Chapter 1

\section{Blood Coagulation, Factor V and Thrombosis}

a general introduction to this thesis 


\subsection{Introduction}

\section{Haemostasis and Thrombosis}

The vascular system in higher organisms constitutes the vital transport system between the various tissues and organs. This function is performed in cooperation with a pump and a carrier-medium, known to us as the heart and the blood, respectively. Poor maintenance of this system can be hazardous to the entire organism and vascular damage would cause fatal blood loss without a system that has the potency to repair the damaged blood vessels at the site of the injury: the haemostatic system.

Haemostasis is intimately associated with other host-defense systems such as the inflammatory response ${ }^{1}$ and works in concert with physiological processes such as vasoconstriction in order to limit vascular damage and repair damaged bloodvessels.

Two prime events are essential to prevent blood loss after vascular injury: formation of an unstable primary platelet plug that is subsequently stabilized by the formation of a fibrin network ${ }^{2-3}$.

Haemostasis is capable of locally transforming the physical properties of the blood dramaticaily: an apparent fluid phase is changed into an apparent solid phase (clot). The haemostatic system thus also inherently possesses a dangerous capacity for clogging up the vessel system. Therefore, several mechanisms exist, that strictly control the process of clot formation and/or that can remove a clot once it has become redundant. It is generally believed that in healthy individuals in the absence of tissue injury, these pro- and antithrombotic processes, proceed simultaneously at a low, vigilant, level in a dynamic equilibrium that is shifted in favour of anticoagulation ${ }^{4}$.

In the case of thrombosis, a commonly observed pathological condition, it is hypothesized that loss of control over the haemostatic system induces a socalled hypercoagulable state that contributes at least in part to the pathogenesis of this disease ${ }^{5}$. As a result, undesirable formation of thrombi and their accumulation can lead to obstruction of the circulation. Due to obstruction ischemia occurs, which may cause necrosis or gangrene in underlying tissues and/or organs.

Both in normal haemostasis and in the pathological condition of thrombosis the generation of a proteolytic enzyme, thrombin, as well as the regulation of the functional activity of a cofactor protein, Factor $V$, play a pivotal role (see 1.2 and 1.3). Disproportionate activity of either protein can impose both a bleeding or a thrombotic tendency. 
The following sections of this chapter contain information on some basic events in the blood coagulation process. The role of factor $V$ (FV), especially its function in the control over and expression of procoagulant activities, will be discussed in more detail.

\subsection{The Biochemistry of the Coagulation Cascade}

As was stated in section 1.1 above, bleeding is put an halt to by the concerted actions of both platelets and plasma proteins. Platelet action and plasma protein activation are two inseparable processes, acting simultaneously both in temporal and spatial respects. Platelet action and function will be briefly discussed from a enzymological point of view (for excellent reviews on the histological/ cytological properties or signal transduction in platelets see refs. ${ }^{6-7}$ ).

\section{Platelets}

Platelets, or thrombocytes, are small cells that are abundantly present in human blood $\left(3 \times 10^{11} \text { cells/l) }\right)^{8}$. Since most platelets circulate for $8-10$ days in the blood, their number is constantly replenished by continuous production, presumably by the "budding" of giant bone marrow precursor cells, the megakaryocytes ${ }^{9}$. Although platelets contain various cell organelles and granules, they are anucleate and are therefore sometimes considered as cell fragments, rather than entire cells.

Apart from their role in inflammation ${ }^{10}$, platelets play a major role in the arrest of bleeding. Upon exposure to subendothelial structures in damaged vessels (e.g. collagen or basement membrane), platelets are activated by a series of interactions, of which receptor-mediated interaction is most important. The result of this activation process is that platelets adhere to the subendothelium at the site of a vessel damage and simultaneously adhere to each other. By this mechanism they form a lose plug that prevents the loss of blood. In the course of platelet activation two further processes are important. Firstly, the phospholipid content of the platelet outer-membrane is changed by active and passive redistribution of phospholipids between the inner and outer leaflets of the platelet membrane. Most importantly, glycerophosphoryl-Lserine (PS) is exposed, which is essential for the binding of vitamin $K$ dependent proteins of coagulation and the formation of enzymatically active membrane complexes involved in the haemostatic mechanism (see section 1.3 below $)^{11-12}$. 
Secondly, the contents of internal stores are released ( $\alpha$-granules, dense bodies) which contain coagulation factors and low molecular weight platelet activation/aggregation-agonists. The released molecules contribute to the initiation and maintenance of coagulation at the site of the injury. The physiological importance of this release is underscored by the fact that patients in which the release reaction is impaired or absent show a bleeding tendency (e.g. Gray platelet syndrome, Storage pool deficiency) ${ }^{8}$. Factor Vauebec, a bleeding disorder which was for long ascribed to the qualitative deficiency in platelet FV, has recently been hypothesized to be associated with a general defect that leads to degradation (and therefore inactivation) of most proteins of the $\alpha$-granules, including $\mathrm{FV}^{13}$. This again, stresses the importance of $\alpha$-granule release for haemostasis.

\section{General outline of reactions leading to thrombin formation}

In 1964 it was recognized that the reactions of coagulation occur in an organized manner and are closely linked and sequential. Fibrin formation was hypothesized to be the result of a waterfall (cascade) of reactions ${ }^{14-15}$. Via a complex series of reactions, fibrin is formed from its soluble precursor protein, fibrinogen. For an accurate coagulation response the following properties of the cascade are required:

1. No fibrin deposition may take place under normal conditions

2. Response to injury must be fast

3. The response must be limited to the site of injury

Nature's elegant solution for these requirements embody the essential characteristics that make the clotting system so powerful. Clotting factors (indicated by Roman numbers I to XIII) ${ }^{4}$ are plasma proteins circulating in the blood as inactive precursor molecules. Many of them are synthesized in the liver and in a number of cases vitamin $K$ is required for the formation of functionally active proteins.

Initiation of coagulation is still a matter of debate. It is, however, generally accepted that exposure of tissue factor, a transmembrane glycoprotein that is located in many cell types including cells of the adventitia, to blood is essential for efficient triggering of coagulation ${ }^{16-20}$. Since tissue factor is not expressed in intact endothelium, initiation of coagulation only occurs after vascular damage.

In most factors limited proteolysis converts the inactive profactor into an active form, which either is a non-enzymatic cofactor molecule or a serine

\footnotetext{
"By convention, the activated form of a coagulation factor is indicated by a small "a" added to the roman number
} 
protease. These activation reactions occur preferably on suitable phospholipid surfaces, i.e. membranes containing negatively charged phospholipids, such as PS. In vivo these surfaces are most likely presented by platelets or by small platelet particles, which expose negatively charged phospholipid molecules in their outer leafllet only upon activation. This mechanism ensures that activated platelet surfaces provide docking places for the assembly of enzyme complexes and that coagulation is localized to the site of injury (platelet). On these membranes, activated coagulation factors (serine proteases) form an active enzyme complex with a non-enzymatically cofactor molecule, that has an improved overall catalytic efficiency due to its organization at a surface (lowering of $K_{m}$ ). The importance of the cofactor presence needs to be stressed here, since their presence alone improves overall catalytic efficiency of the complex by 3 to 4 orders of magnitude. Newly formed proteases are on their turn capable of converting numerous other zymogen molecules into active clotting factors, thus resulting in an amplification of the clotting process.

Another way of amplification is the occurrence of positive feedback reactions in the coagulation cascade: many products promote their own formation by activation of other clotting factors acting "earlier' in the coagulation process. The general outcome of all these processes is the obligatory massive formation of thrombin, the enzyme that is capable of transforming fibrinogen to its insoluble derivative fibrin. Since 1964 many researchers have shaped the cascade and a simplification of the current view on the blood coagulation cascade is given in Figure 1.1 below.

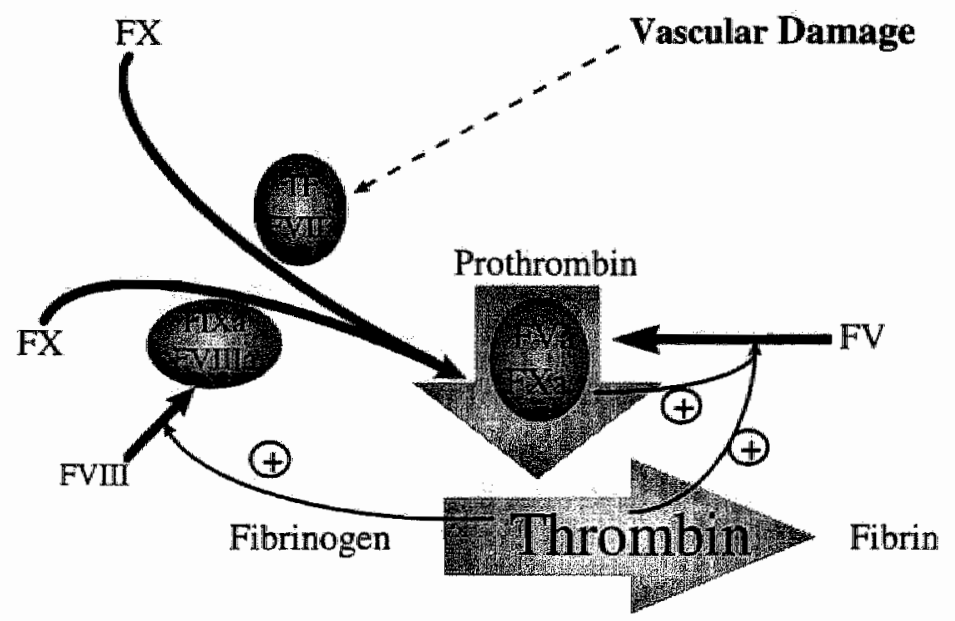

Fig 1.1 Schematic representation of the coagulation cascade. Solid arrows indicate proteolytic activations, clotting factors organized in owals indicate membrane bound complexes of clotting factors, $\oplus$ indicates positive feedback reaction. 'TF' is tissue factor, 'F' stands for coagulation factor 


\section{Clinical relevance}

The physiological relevance of the presence of the majority of the clotting factors is underscored by the association of a bleeding tendency with clotting factor deficiencies (it is only the FXII, prekaliikrein- and high molecular weight kininogen-deficiencies that have not been related to excessive bleeding ${ }^{21}$ ). Historically, haemophilia $A$, a hereditary bleeding disorder, showed for the first time that deficiency of a coagulation factor (FVIII) can be associated with severe and sometimes lethal symptoms. Although partial deficiencies are mostly asymptomatic ${ }^{22}$, deficiencies of coagulation factors $(<5-10 \%$ functional activities) are often accompanied by a variety of bleedings, including joint-, muscle- or retroperitoneal hemorraghes which can be life-threatening ${ }^{23-24}$.

\section{Anticoagulant reactions counteracting thrombin formation}

Two general mechanisms exist for the limitation of thrombin formation. These include 1) the actions of plasma inhibitors and 2) of proteases that convert active clotting factors into inactive products. These two systems are essentially different with the first being a constitutive and the second being a reactive inhibitory system. Inhibition by circulating plasma inhibitors results in the formation of enzyme-inhibitor complexes that have no biological activity. In contrast, each protease molecule catalyzes the inactivation of many clotting factor molecules. Moreover, the activity of the proteases is subject to control by their activation from inactive proenzymes and by their inhibition by plasma inhibitors. In both systems complex formation with cofactor molecules provides a mean of fine-tuning of activity and/or reactivity (e.g. heparin in case of plasma inhibitors or protein $S$ for the activated form of the anticoagulant serine protease protein $\mathrm{C}$ ).

\section{Plasma inhibitors}

Human plasma contains a number of inhibitors, fast- and slow acting, that are in a great surplus relative to the amount of active proteases they are to inhibit. Among these the serpins antithrombin III (ATIII), heparin cofactor II $(\mathrm{HCII})$, protein $\mathrm{C}$ inhibitor $(\mathrm{PCl})$ and $\alpha_{1}$-antitrypsin, as well as $\alpha_{2}$-macroglobulin $(\alpha 2 M)$, belonging to the $\alpha$-macroglobulin family, are the most prominent. Inhibition by the serpins is fairly selective and reversible, although the dissociation rate of the complexes are so slow that for practical purposes inhibition is considered to be irreversible. The actions of ATIII and $\mathrm{HCll}$ are greatly potentiated by the presence of heparin. The inhibitory capacity of $\alpha 2 \mathrm{M}$ is mechanistically different from the active-site directed serpins and shows 
almost universal specificity. Binding of a protease to $\alpha 2 \mathrm{M}$ results in a conformational change following protease reaction, covalently anchoring the protease by transacylation, that appears to physically entrap the protease molecule and is therefore irreversible ${ }^{25}$. The $\alpha 2 \mathrm{M}$-protease complex retains activity towards small oligopeptide substrates (e.g. chromogenic substrates), but is almost completely inactive towards larger protein substrates $(>30 \mathrm{KD})^{26}$ The major physiological inhibitors of thrombin, the central enzyme in haemostasis, are ATIII and $\alpha 2 \mathrm{M}$.

In recent years, interest in tissue factor pathway inhibitor (TFPI), a Kunitztype protease inhibitor has been revived by many researchers. TFPI directly inhibits FXa and forms a complex with FXa that on its tum inhibits the FVlla/tissue factor (TF) complex ${ }^{27-29}$.

\section{The protein $\mathrm{C}$ pathway}

Thrombin, when assembled after high affinity binding with the integral membrane protein thrombomodulin (TM), changes from a procoagulant into an anticoagulant protein. Binding to TM modulates the substrate specificity of thrombin. As a result, fibrinogen, platelets, factors V, VIII and XIII can no longer be activated ${ }^{30-32}$. TM is present on the vascular surface of endothelial cells in almost all blood vessels and in a great variety of tissues (including the brain). Formation of the thrombin-TM complex not only diminishes the amount of available procoagulant thrombin but what is more important, this complex converts protein $\mathrm{C}$, a vitamin $\mathrm{K}$ dependent zymogen with a normal plasma concentration of 48-81 nM, into activated protein $C(A P C)^{33-35}$. The activation rate of protein $C$ by thrombin is increased by more than 4 orders of magnitude ${ }^{36}$ upon binding of thrombin to TM.

Activated protein $\mathrm{C}$ is capable of proteolytically inactivating both the activated and non-activated forms of factors $\mathrm{V}$ and VIII, by cleavage of multiple peptide bonds. Another vitamin $K$ dependent protein, protein $S$, serves as a cofactor for the inactivation of factors Va and VIIla by APC. The cofactor activity of protein $S$ is in its tum regulated by C4b-binding protein (C4BP), a multi-domain protein of the classical complement pathway. Protein $S$ bound to C4BP (in 1:1 complex) lacks cofactor activity in the protein $C$ pathway ${ }^{36}$. Furthermore, APC is slowly neutralized in vivo by at least three protease inhibitors: the protein $\mathrm{C}$ inhibitor (PCl), $\alpha 1$-antitrypsin and $\alpha_{2}$ macroglobulin ${ }^{37-42}$.

Recently, it has been shown by Shen et al. and by Varadi et al. that FV can act as cofactor for the inactivation of FVIIla by APC in purified systems and in plasma respectively ${ }^{43-44}$. 
APC-catalyzed inactivations of factors $V(a)$ and VIII(a) occur in the absence of a phospholipid membrane. However, in the absence of phosphollipids reaction rates are too slow to be considered important. The presence of a catalytic surface has an influence on both the order of consecutive peptide bond cleavages in factor V/Na and on the rate constants of these cleavages, stimulations of up to 1000 -fold are reported by us (see chapter 3). Furthermore, it has been reported that incorporation of phosphatidylethanolamine into the lipid surface selectively enhances the $\mathrm{FVa}$ inactivation by $\mathrm{APC}^{45}$.

Aside from their inactivation by APC, factors V and VIII have been reported to be cleaved by proteases such as plasmin and FXa. The physiological importance of these interactions have not yet been fully understood ${ }^{46-47}$.

\section{Clinical relevance}

The physiological relevance of the anticoagulant pathways is dramatically exemplified by the association of deficiencies of ATIII, protein C or protein S with thrombosis. In case of homozygous deficiencies, or combined heterozygous deficiencies, these thrombotic tendencies can be severe and the affected patients may develop purpura fulminans (a disease involving clotting of the microvasculature of the skin, and the uncontrolled coagulation generally leads to death in infancy unless treated $)^{48-49}$. Recently, a hereditary disorder has been described, that is called APC resistance, that is associated with thrombosis and in which a DNA mutation renders FVa resistant to inactivation by APC ( $F V_{\text {Leiden }}{ }^{50}$, see section 1.5 below).

Since the formation of thrombin and the regulation of FV cofactor activity are topics of the research described in this thesis, the general concepts of thrombin generation will be described in more detail in the following sections.

\subsection{The Prothrombinase Complex}

Proteolytic activation of prothrombin is catalyzed by an enzyme complex (the prothrombinase complex, PTase) composed of the serine protease FXa that is noncovalently and reversibly associated with the cofactor FVa on membranes containing negatively charged phospholipids. The overall acceleration of prothrombin activation that is achieved by the assembled PTase, as compared to the activation by $F X a$ alone, is $>1,000,000$ fold $^{51}$. 


\section{Prothrombin}

Human prothrombin (factor II, PT), the zymogen of the active products thrombin and meizothrombin, is a plasma glycoprotein that has a molecular weight of $72 \mathrm{kD}$ and a plasma concentration of $1.48 \mu \mathrm{M}^{52}$. Prothrombin synthesis primarily occurs in the liver and the resulting protein shows several types of structural motifs or domains: fragment 1 (F1) and fragment 2 (F2) and the proteinase module (see fig 1.2 below). Synthesis of biologically active $\mathrm{F} 1$ domain is dependent upon the presence of vitamin $K$, which acts as a cofactor in the post-translational $\gamma$-carboxylation of 10 Glu residues in the F1 domain into Gla residues ${ }^{53}$. The Gla-residues function in the $\mathrm{Ca}^{2+}$-dependent binding of PT to negatively charged phospholipids.

\section{Prothrombin}

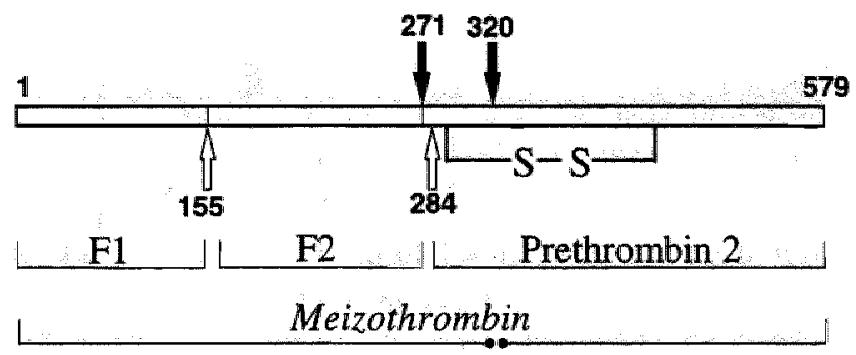

$\alpha$-thrombin

Figure 1.2 Schematic representation of prothrombin and several of its activation products. Cleavage sites by FXa are indicated by solid arrows, the cleavages catalyzed by thrombin are indicated by the open arrows. Enzymatically active products are indicated in italics.

Recently it was shown that $\mathrm{PT}_{\text {, }}$ apart from being the substrate for the PTase complex, actively contributes to the assembly of this complex ${ }^{54}$.

\section{Factor Xa}

Factor $\mathrm{Xa}$ is a vitamin $\mathrm{K}$ dependent heterodimeric serine protease with a molecular mass of $45 \mathrm{kD}$ that is formed after activation of its $59 \mathrm{kD}$ plasma precursor factor $X^{55}$, which has a plasma concentration of $\sim 170 \mathrm{nM}^{55}$. FXa is generated from its inactive zymogen, $\mathrm{FX}$, by proteolytic removal of a 52 amino acid activation peptide ${ }^{55}$ by either an extrinsic (TF-FVlla complex) or an intrinsic FX-activating complex (FIXa-FVIIla complex). FXa consists of a $27 \mathrm{kD}$ heavy chain and a $18 \mathrm{kD}$ light chain that are linked via a disulfide bridge ${ }^{56-57}$. While lipid binding is considered to be mediated by the $11 \gamma$-carboxyglutamic 
acid residues in the Gla-domain ${ }^{57}$, located in the N-terminal part of the light chain of FXa, interaction with FVa and substrate (PT) are thought to be mediated by regions located in the heavy chain domain of $\mathrm{FXa}$, that also contain the His-Asp-Ser catalytic triad ${ }^{58}$.

\section{Phospholipid Surface}

Although FVa and FXa can assemble in the absence of a phospholipid surface (PL) and can activate PT, assembly of a fully functional PTase requires the presence of a suitable membrane surface. The phospholipid membrane adds the protein-lipid interaction to the protein-protein and proteinmetal ion interactions already present in the FVa-FXa complex in free solution. As an overall result the $\mathrm{K}_{d}$ for the FVa-FXa interaction drops from $\sim 10^{-5}-10^{-6} \mathrm{~mol} / 1$ to $10^{-9} \mathrm{~mol} / 1$ in the presence of a membrane surface ${ }^{51,59-62}$. However, not only the enzyme and its cofactor bind to the PL-surface, but also the substrate, PT which contains a Gla-domain (see above).

It is generally accepted that for efficient lipid activity the polar headgroup of a phospholipid molecule needs to contain a net negative electric charge. Factors, other than the polar headgroups that influence the activity of lipid membranes in prothrombin activation are the organization of the phospholipids (e.g. small unilamellar vesicles, or monolayers, macroscopic surfaces), the membrane fluidity (largely dependent upon the kind of fatty acyl side chains and temperature) and the stereochemical configuration of the phospholipid headgroup ${ }^{63-67}$.

In vivo, the procoagulant surface for PTase assembly and function is most likely provided by the PS that is exposed on the outer membranes of activated platelets ${ }^{68}$. Endothelial cells ${ }^{69}$, viruses ${ }^{70}$ and monocytes/ macrophages ${ }^{19,71 \cdot 73}$ have however also been hypothesized to provide surfaces for haemostatic and thrombotic processes. Furthermore, in vitro experiments show that microvesicles, that are released from the platelet membrane upon activation and that also contain PS, might form a suitable surface for in vivo PT activation ${ }^{74-76}$. Reports on the physiological importance of procoagulant microvesicles are contradictory however (see ref. ${ }^{77}$ ).

\section{Factors $V$ and Va}

Factor $\mathrm{Va}$ is the heterodimeric non-enzymatic cofactor that is formed after activation of its inactive pro-cofactor $\mathrm{FV}$ ( activity $<0.27 \%,{ }^{60}$ ) by limited proteolysis (see also section 1.4 below). FV is a $330 \mathrm{kD}$ single chain 
glycoprotein with a plasma concentration of $-21 \mathrm{nM}^{78}$. It is synthesized mainly in the liver and in megakaryocytes where it is being transcribed from a 6672 base pair stretch of DNA located in the chromosome $1 \mathrm{q} 21-25^{79}$. The resulting procofactor consists of 2224 amino acids, which includes a 28 -amino acid leader peptide, that after translation subsequently undergoes post-ribosomal modification. These include at least glycosilations ${ }^{80-84}$, phosphorylations ${ }^{82}$ and sulphations ${ }^{83-84}$. The FV molecule shows a distinct multi-domain structure that resembles that of FVIII (see fig 1.3 below).

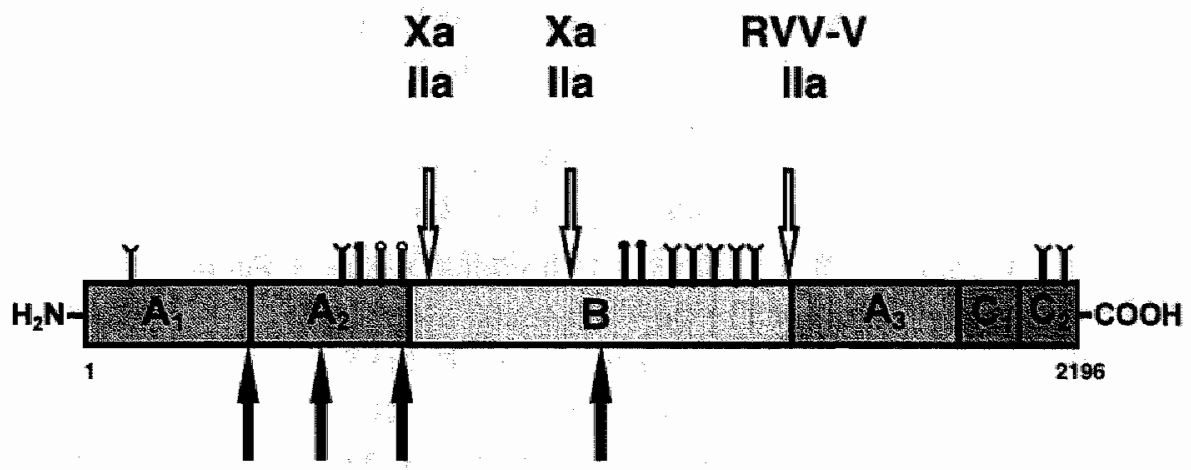

Figure 1.3 Schematic diagram of the multi domain structure of FV. Cleavage sites at $\operatorname{Arg}^{709}$, Arg $^{1018}$ and Arg $^{1545}$ are indicated by open arrows ${ }^{\text {refs.85-88 }}$. Closed arrows indicate the reported cleavage sites for the inactivation of Factor $V$ by activated protein $C^{\text {ret.89. }}$. $Y$ ' indicates the presence of carbohydrate side chains in the A1-A2 domain, the fragment $T \mathrm{hr}^{1009}-\mathrm{Arg}^{1545}$ of

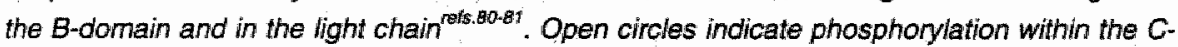
terminal part of the heavy chain rot.82, filled circles indicate sulphations in the heavy chain region and in the Thr $^{\text {1019 }}$-Arg ${ }^{1545}$ fragment.

The homology between the $A 1, A 2, A 3, C 1$ and $C 2$ domains of $F V$ and the corresponding domains in FVIII is $-40 \%$ on basis of the amino acid sequence. The B-domains of FV and FVIII show no homology ${ }^{90}$. The Adomains of FV further show $\sim 40 \%$ amino acid sequence homology with the three highly conserved domains in ceruloplasmin, a plasma copper-binding transport protein. It has been suggested that FV, FVIII and ceruloplasmin form a family of structurally related proteins that stem from a common ancestral gene ${ }^{91}$.

Human FVa consists of a $105 \mathrm{kD}$ heavy chain (A1-A2, fig.3) and a 71-74 $\mathrm{kD}$ light chain (A3-C1-C2, fig. 3) that are noncovalently linked by a calcium ${ }_{i o n}{ }^{88}$. Since two different forms of the light chain region exist, FVa can occur in two forms in plasma, named FVa1 and FVa2. FVa1 and FVa2 differ in their binding properties to phospholipid membranes ${ }^{92}$, the basis for this 
heterogeneity has been shown to be resulting from differential glycosylation of Asp ${ }^{2181}$ in the $\mathrm{C} 2$ domain (see fig. 1.3, ref. ${ }^{81}$ ). The heavy chain domain of the FVa molecule is largely responsible for the interactions with $\mathrm{PT}^{93-96}$, while several patches of the light chain, located near the C-terminal end, have been shown to be involved in phospholipid binding ${ }^{97-101}$. It is noteworthy to mention that the $\mathrm{C}$ domains of FVa are approximately $70 \%$ identical to the duplicated C domains present in a murine breast epithelial cell protein of unknown function $^{102}$. Both heavy and light chain contain regions that mediate interaction with $\mathrm{FXa}^{103-104}$.

The large B-domain that is released from the FV molecule on thrombincatalyzed activation was considered to fulfill no more functional role than separating the heavy and light chains until recently. It has been shown by Kaufman and coworkers that efficient thrombin activation of $\mathrm{FV}$ requires the presence of an acidic amino acid rich regions within the B-domain ${ }^{105}$. Furthermore, Lu et al. concluded that a portion of the B-domain is involved in the FV cofactor function for FVIII inactivation by APC $^{106}$.

Apart from circulating in the blood, $\sim 25 \%$ of the FV contained in the whole blood is present in platelet $\alpha$-granules and can be secreted along with other $\alpha$-granule proteins upon activation of the platelet ${ }^{73,78}$. A physiological necessity for the presence of platelet FV has not yet been shown, although it has been reported that platelet FV can support thrombin generation in patients with acquired immune inhibitors of plasma $F^{107-108}$. Platelet $F V$ is stored as a complex with multimerin, a $155 \mathrm{kD}$ specific binding protein of the light chain domain of $F V(a)$. A possible role for multimerin as a carrier protein for $\mathrm{FV}$ in platelets has been suggested. Regulation of platelet FVa activity might differ from that of its plasma equivalent ${ }^{109-110}$.

\section{Integration of Interactions in the Prothrombinase Complex}

What is it that makes the prothrombinase complex so efficient and the physiologically most relevant activator of PT? An insight into this can be effectively demonstrated by evaluating the influence of the individual components of the complex on the kinetic parameters of PT activation.

\begin{tabular}{|c|c|c|c|c|}
\hline $\begin{array}{l}\text { Activating } \\
\text { Component }\end{array}$ & $\begin{array}{l}\mathrm{Km} \\
(\mu \mathrm{M})\end{array}$ & $\left.\underset{\left(m o l ~ l l a ~ s^{-1 *}\right.}{V_{\max }}(\mathrm{mol} \mathrm{Xa})^{-1}\right)$ & $\begin{array}{l}\mathrm{k}_{\text {cat }} / \mathrm{K}_{\mathrm{m}} \\
\mathrm{M}^{-1} * \mathrm{~s}^{-1}\end{array}$ & $\begin{array}{l}\text { Time to convert } 1 \\
\text { PT molecule }\end{array}$ \\
\hline $\mathrm{Xa}$ & 84 & 0.011 & 131 & $1 \mathrm{hr} 26 \mathrm{~min} 24 \mathrm{~s}$ \\
\hline$X a-V a$ & 34 & 6.22 & $1.83^{*} 10^{5}$ & $3.8 \mathrm{~s}$ \\
\hline Xa-PL & 0.06 & 0.038 & 6. $33^{*} 10^{5}$ & $274 \mathrm{~s}$ \\
\hline$X a-V a-P L$ & 0.21 & 32.0 & $1.52^{*} 10^{8}$ & $0.036 \mathrm{~s}$ \\
\hline
\end{tabular}

Table 1.1 Kinetic properties of the prothrombinase complex. (Data adapted from references. $51_{0}(11)$. 
In table 1.1 it is shown that FXa alone has only a limited potency to activate PT. Addition of FVa alters the maximum capacity with which FXa activates PT. Addition of phospholipid alone, lowers the $K_{m}$ for PT activation some $\sim 1400$ times, whereas the combined addition of PL and FVa joins the beneficial effects brought about by each component alone and simultaneously lowers the $\mathrm{Km}$ for prothrombin activation and increases the maximum turnover rate $\left(k_{\text {cat }}\right)$ of the enzymatic complex. It is conceivable that each component contributes to the assembly, positioning and proteolytic activity of the PTase complex so that a more than million-fold increase in catalytic efficiency can be achieved.

The concept of the PTase, an enzyme-complex that is fully active only after the assembly of enzyme, cofactor and substrate at a phospholipid surface, further ensures a localization of thrombogenic response: complex assembly occurs only on suitable membranes and the catalyst is concentrated at the site of the injury. Also, through feedback reactions that influence the assembly and expression of activity in PTase, the complex can be modulated in various manners ${ }^{59}$.

\subsection{Control of Factor V Cofactor Activity}

Since FV has an extremely low cofactor activity ${ }^{60}$, activation to its active product is a prerequisite for the expression of prothrombinase activity. In fact, during in vitro coagulation, FV activation is the rate-limiting factor in prothrombin activation ${ }^{112}$.

\section{activation of the procofactor, Factor $V$}

FV can be activated by thrombin, as well as by FXa via multiple cleavages at positions $\mathrm{Arg}^{709}-\mathrm{Ser}^{710}, \mathrm{Arg}^{1018}-\mathrm{Thr}^{1019}$ and at $\mathrm{Arg}^{1545}-\mathrm{Ser}^{1546}$. Apart from these activations, a specific non-fysiological FV activator from Russels viper venom (RVV-V) can be used to activate FV (see fig 1.4 below $^{86,88,113,114}$ ). 


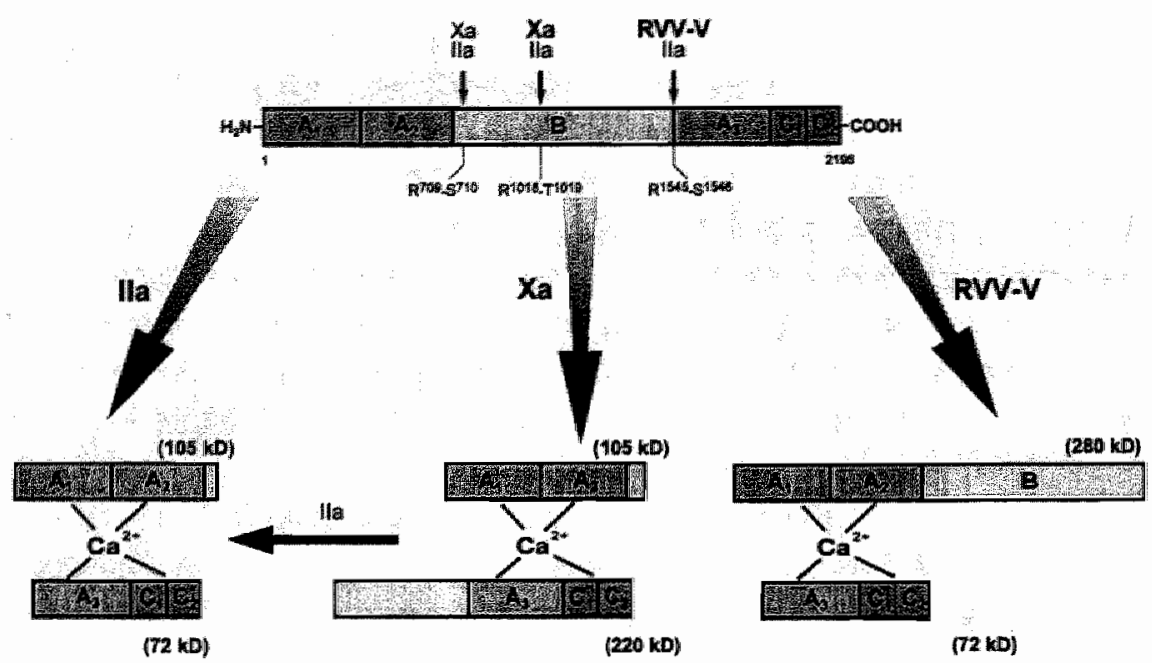

Figure 1.4 Activation of factor $V$ via limited proteolysis. Schematic representation of the thrombin, FXe and RVV-V mediated deavages of FV during activation of the procofactor molecule. Small arrows mark the positions of the proteolytic cleavages at the indicated scissile bonds. Fragment molecular masses are given. Forms of FVa that contain the $72 \mathrm{kD}$ or the 220 $k D$ fragment express cofactor activity.

Whereas FXa catalyzed activation is lipid-dependent, activation by thrombin is not. From the $k_{\text {cat }} / K_{m}$ values it is concluded that FXa is as efficient as thrombin in activating $\mathrm{FV}^{86}$. Thrombin-activated $\mathrm{FVa}$ expresses the same cofactor activity as FXa-activated FVa. As can be deduced from the domain structures of FV, FXa and thrombin ( $F V a$ and FXa contain phospholipid binding domains, while thrombin does not), FXa-catalyzed activation of $\mathrm{FV}$ is greatly stimulated by the presence of a phospholipid surface whereas thrombin-catalyzed activation occurs both in the presence and the absence of a phospholipid surface ${ }^{86}$.

\section{Downregulation of Factor $V$ cofactor activity}

Although $\mathrm{FVa}$ is proteolysed effectively by plasmin ${ }^{46}$ and $\mathrm{FXa}^{47}$, it is generally thought that proteolytic inactivation of $\mathrm{FVa}$ (and FV) under physiological conditions is regulated by activated protein C (APC, see section 1.2). APC inactivates FVa via three cleavages in the heavy chain region of the cofactor at $\mathrm{Arg}^{306}, \mathrm{Arg}^{506}$ and $\mathrm{Arg}^{679}$ respectively, resulting in loss of cofactor activity $^{89,115}$. No cleavage of the light chain is observed ${ }^{89}$. APC-catalyzed inactivation of $\mathrm{FVa}$ is stimulated by the presence of negatively charged membrane surfaces ${ }^{116-418}$ and by the vitamin $K$ dependent cofactor Protein $S^{118-120}$. Recently, we have shown that in a purified protein system the 
presence of FXa selectively inhibits the APC-catalyzed cleavage at $\mathrm{Arg}^{506}$, an inhibition that is independent of the presence of a catalytic triad in FXa ${ }^{121}$. In the same report it was shown that protein $S$ selectively enhances cleavage at Arg $^{306}$ some 20-fold.

\subsection{APC resistance}

\section{original observations}

In 1993, laboratory findings by Dahlbäck and coworkers indicated a poor anticoagulant response to APC in the plasma of a group of patients with a family history of familial thromboembolic disease ${ }^{122-123}$. The phenomenon was termed 'APC resistance' and it was recognized to be an important cause for familial thrombosis, since it is found in $20-60 \%$ of patients documented with idiopathic thromboembolism. It was proposed that patients that were APC resistant, were missing a cofactor of the APC anticoagulant system. Similar findings by Griffin et al. ${ }^{124}$ and Koster et al. ${ }^{125}$ in the same year 1993 also showed the diminished response to APC in plasma and established the abnormality in the anticoagulant protein C pathway. In February 1994 Dahlbäck and Hildebrand showed that in vitro APC resistance could be corrected by the addition of purified $\mathrm{FV}$, thereby identifying $\mathrm{FV}$ as a cofactor for $\mathrm{APC}^{126}$. The 'cofactor' theory could explain earlier observations from plasma experiments which showed that the impaired APC response in plasma of APC-resistant individuals could be corrected with normal plasma ${ }^{127}$.

\section{Hereditary Factors Causing APC Resistance}

Shortly after the initial reports by Dahlbäck et al. and their suggestion of a hereditary nature for the defect ${ }^{123}$, Bertina et al. showed ${ }^{50}$, simultaneously with several other laboratories ${ }^{128-130}$, that APC resistance is linked to the occurrence of a $G \rightarrow A$ point mutation in the gene for $F V$ ( $F V_{\text {Leiden }}$ ). This causes the replacement of $\mathrm{Arg}^{506}$, located at an APC cleavage site, to Gin and as a result APC cannot cleave FVa at the 506-position. The mutation was estimated to occur in $\sim 4 \%$ of the Dutch population ${ }^{50,125}$, a percentage that was confirmed for several other western countries ${ }^{131}$. This occurrence rate is 10 times higher than that of the sum of all other known hereditary causes of familial thrombophilia. Epidemiological studies have shown that heterozygosity for the $F V_{\text {Leiden }}$ mutation results in a $\sim 7$ fold increase in the risk of thrombosis, homozygosity in a $50-100$ fold increase ${ }^{125.132}$. In over $95 \%$ of APC-resistance cases, this molecular cause of resistance to APC is found ${ }^{132}$ 
A general mechanism for the occurrence of thrombosis has not been reported so far. It is likely though that as well a) hampered downregulation of FVa activity, due to the R506Q mutation, as b) the reported anticoagulant cofactor activity of FV in the APC-catalyzed FVIIla-inactivation ${ }^{43,133}$, which is lower in case of $F V_{L e i d e n}$, are of major influence in the development of thrombosis in APC resistant individuals. Homozygous APC resistance appeared to be a mild risk factor for venous thrombosis compared with homozygous and heterozygous protein $\mathrm{C}$ and protein $\mathrm{S}$ deficiency. Therefore, it was deduced that multiple manifestations of heretic defects besides the FV Leiden mutation ('double hits') play an important role in the manifestation of thrombosis related to the $\mathrm{FV}_{\text {Leiden }}$ mutation.

Thromboses that develop generally are venous by nature. Several investigators however, have associated APC resistance with the development of stroke and arterial thrombosis ${ }^{134-137}$, whether this holds true remains to be clarified.

\section{Acquired APC Resistance}

As detection of functional APC resistance requires plasma testing, reduction of clotting factors is likely to interfere with the outcome of an APC resistance assay and hence constitutes a problem to clinical laboratory testing. This is particularly true in the case of use of oral anticoagulant drugs or heparin which largely interfere with functional tests for APC resistance. When testing for APC resistance via functional assay systems, several different plasmas give assay outcomes which would qualify the plasmas tested as stemming from APC resistant individuals.

The presence of such 'acquired APC resistant' factors are generally observed in plasmas containing anti-phospholipid antibodies or lupus anticoagulants. Other known (hereditary) causes, resulting in the phenotype of APC resistance include protein $\mathrm{S}$ deficiency or protein $\mathrm{C}$ deficiency (depending on APC resistance assay).

Another acquired type of APC resistance is encountered in healthy women that are pregnant, or that are on contraceptive (OC) therapy. Assay outcomes for these groups of women have been reported to overlap with heterozygous $F V_{\text {Leidan }}$ carriers. To some extent, both conditions (pregnancy, OC use) present hormonal and metabolic similarities, and both have reported influence on the haemostatic system which in general shifts in the direction of both an increased prothrombotic tendency and increased fibrinolytic activity ${ }^{138-142}$. The net outcome of these changes in the haemostatic system are thought to balance each other. However, thromboembolic disease is a leading cause of 
obstetric morbidity and mortality and accounts for a major percentage of matemal deaths ${ }^{143}$. Recent (revived) concern about the association of $O C$ use with thromboembolic disease (in particular those containing the third generation progestagens desogestrel, gestodene and norgestimate) has been a great impulse to retro- and prospective studies on this subject. The molecular etiology of the correlation between pregnancy/OC use and thrombosis remains, however, to be clarified.

For all of the above mentioned acquired causes of APC resistance modification of functional assays or use of DNA-based assay systems have so far overcome all of these false positive APC resistances. Whether a falsepositive APC resistance test outcome reflects merely an interference with the APC resistance assay or gives information on the in vivo development of thrombosis in APC resistant patients is not known. Using this shortcoming of functional testing, several new assays have been developed that are intended to be sensitive for more than one component of the protein $\mathrm{C}$ pathway.

Shortly after the onset of the work that is described in this dissertation in 1993, Dahlbäck and coworkers firstly described the APC resistance. Since in our laboratory FV regulation in general and APC catalyzed inactivations in particular were subjects of investigation, research focused on the APC resistance using model systems with purified proteins, as well as in plasmabased systems. This thesis describes the research that was performed in this, for 'Factor V researchers', turbulent times in the period March 1993 to March1997. It can roughly be divided into three parts with the chapters 2 and 3 describing the activation and inactivation mechanisms of human FV in purified protein systems and the chapters 5 and 6 describing downregulation of thrombin formation by APC in plasma-based systems, with chapter 4 being an intermediate between the model- and the plasma-based systems. 


\section{References}

1. Esmon CT, Schwarz HP. An update on clinical and basic aspects of the protein C anticoagulant pathway. Trends Cardiovasc Med 1995; 5: 141-148.

2. Ratnoff $O D$. The development of knowledge about haemostasis and thrombosis. In: Bloom AL, Forbes CD, Thomas DP, Tuddenham EGD, eds. Haemostasis and Thrombosis - Volume 1, 3rd ed. Edinburgh: Churchill Livingstone, 1994: 3 28 .

3. Hemker HC. Thrombin generation, an essential step in haemostasis and thrombosis. In: Bloom AL, Forbes CD. Thomas DP. Tuddenham EGD, eds. Haemostasis and Thrombosis, 3rd ed. Edinburgh: Churchill Livingstone, 1994: $477-490$.

4. Dahlbäck B, Stenflo J. A natural anticoagulant pathway: protein C,S, C4bbinding protein and thrombomodulin. In: Bloom AL, Forbes CD, Thomas DP. Tuddenham EGD, eds. Haemostasis and Thrombosis, 3rd ed. Edinburgh: Churchill Livingstone, 1994: 671-698.

5. Thomas DP. Pathogenesis of venous thrombosis. In: Bloom $A L$, Forbes $C D$, Thomas DP, Tuddenham EGD, eds. Haemostasis and Thrombosis, 3rd ed. Edinburgh: Churchill Livingstone, 1994: 1335-1347.

6. Bevers EM, Rosing J, Zwaal RFA. Platelets and Coagulation. In: Maclntyre, Gordon, eds. Platelets in Biology and Pathology III, Amsterdam: Elsevier Science Publishers B.V. 1987: 127-160.

7. Heemskerk JWM, Sage SO. Calcium signaling in platelets and other cells. Platelet 1994; 5: 295-316.

8. Beck WS, Robinson SH, Bunn HF, et al. Hematology. Cambridge, Massachusetts: MIT Press, 1990"1 1-496.

9. Akkerman $\mathrm{JN}_{\text {, Detwiller TC }}$, Gear ARL, et all. Platelet responses and metabolism - volume I: Responses. Boca Raton: CRC Press, 1986;

10. Barnetson RSC, Beverley PCL, Bradley JE, et al. Immunology. London: Mosby, $1996 ; 1.1-28.15$.

11. Bevers EM, Comfurius P, Van Rijn JLM, Hemker HC, Zwaal RFA. Generation of prothrombin-converting activity and the exposure of phosphatidylserine at the outer surface of platelets. Eur J Biochem 1982; 122: 429-436.

12. Bevers EM, Comfurius $P$. Zwaal RFA. Changes in membrane phospholipid distribution during platelet activation. Biochim Biophys Acta 1983; 736:57-66.

13. Janeway $C M$, Rivard $G E$, Tracy $P B$, Mann $K G$. Factor $V$ Quebec revisited. Blood 1996; 87: 3571-3578.

14. Davie EW, Ratnoff OD. Waterfall sequence for intrinsic blood clotting. Science 1964; 145: 1310-1312.

15. MacFarlane RG. An enzyme cascade in the blood clotting mechanism, and its function as a biological amplifier. Nature 1964; 202: 498-499.

16. Osterud B, Rapaport SI. Activation of factor $\mathrm{X}$ by the reaction product of tissue factor and factor VII: additional pathway for initiating coagulation. Proc Natl Acad Sci USA 1977; 74: 5260-5264.

17. Nemerson $Y$, Repke D. Tissue factor accelerates the activation of coagulation factor VII: the role of a bifunctional coagulation factor. Thromb Res 1985; 40: 351-358.

18. Nemerson $Y$. Tissue factor and haemostasis. Blood 1988; 71: 1-8.

19. Fuster V. Plaque rupture, thrombosis and therapeutic implications. Haemostasis $1996 ; 26$ (suppl 3): 438a(Abstract)

20. Banner DW, D'Arcy A, Chène $C$, Winkler FK, Guha A, Konigsberg WH, Nemerson $Y$, Kirchhofer D. The crystal structure of the complex of blood coagulation factor Vlla with soluble tissue factor. Nature 1996; 380: 41-46. 
21. Saito $H$. The contact phase of blood coagulation. In: Bloom $A L$, Forbes $C D$ Thomas DP, Tuddenham EGD, eds. Haemostasis and Thrombosis, 3rd ed. Edinburgh: Churchill Livingstone, 1994: 289-307.

22. Rotoli B, D Avino R, Chiurazzi F. Combined Factor V and Factor VII deficiency Report of a case with a record on combined defects and considerations on the relevance of partial deficiency of coagulation factors. Acta Haematol 1983; 69: $117-122$.

23. Bloom AL. The management of patients with inherited blood coagulation disorders. In: Bloom AL, Forbes CD, Thomas DP, Tuddenham EGD, eds. Haemostasis and Thrombosis, 3rd ed. Edinburght: Churchill Livingstone, 1994: 897-917.

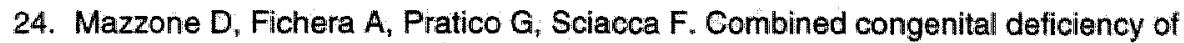
factor V and factor VIII. Acta Haematol 1982; 68: 337-338.

25. Barret AJ, Starkey PM. The interaction of $\alpha 2$-macroglobulin with proteinases. Biochem J 1973; 133: 709-715.

26. Starkey PM. The physiological inhibitors of coagulation and fibrinolysis. Amsterdam: Elsevier, 1979; 221-230.

27. Broze GJ, Warren LA; Novotny WF, Higuchi DA, Girrard JJ, Miletich JP. The lipoprotein-associated coagulation inhibitor that inhibits the factor Vlla-tissue factor complex, also inhibits factor Xa: insight into possible mechanisms of action. Blood 1988; 71: 335-343.

28. Broze GJ, Jr. The tissue factor pathway of coagulation: factor VII, tissue factor, and tissue factor pathway inhibitor. In: Bloom AL, Forbes CD, Thomas DP, Tuddenham EGD, eds. Haemostasis and Thrombosis, 3rd ed. Edinburgh: Churchill Livingstone, 1994: 349-377.

29. Lindhout $T$, Franssen J, Willems GM. Kinetics of the inhibition of tissue factorfactor VIla by the tissue factor pathway inhibitor. Thromb Haemostas 1995; 74: 910-915.

30. Esmon NL, Carroll RC, Esmon CT. Thrombomodulin blocks the ability of thrombin to activate platelets. J Biol Chem 1983; 258: 12238-12242.

31. Esmon CT, Esmon NL, Harris $\mathrm{KW}$. Complex formation between thrombin and thrombomodulin inhibits both thrombin catalyzed fibrin formation and factor $V$ activation. J Biol Chem 1982; 257: 7944-7947.

32. Polgar J, Lerant I, Muszbek L, Machovic R. Thrombomodulin inhibits the activation of factor XIII by thrombin. Thromb Haemostas $1987 ; 58$ : $506 a($ Abstract)

33. Esmon CT, Owen WG. Identification of an endothelial cell cofactor for thrombin catalyzed activation of protein C. Proc Natl Acad Sci USA 1981; 78: 2249-2252.

34. Esmon CT. The regulation of natural anticoagulant pathways. Science 1987; 235: 1348-1352.

35. Esmon CT. The roles of protein $\mathrm{C}$ and thrombomodulin in the regulation of blood coagulattion. J Biol Chem 1989; 264: 4743-4746.

36. Dahibäck $B$, Stenflo J. A natural anticoagulant pathway: Protein $C_{i n} S$ C4Bbinding protein and thrombomodulin. In: Bloom AL, Forbes CD, Thomas DP, Tuddenham EGD, eds. Haemostasis and Thrombosis, 3rd ed. Edinburgh: Churchill Livingstone, 1994: 671-698.

37. Heeb MJ, Griffin JH. Physiologic inhibition of human activated protein $\mathrm{C}$ by $\propto 1$ antitrypsin. J Biol Chem 1988; 263: 11613-11616.

38. Heeb MJ, España F, Griffin $\mathrm{JH}$. Inhibition and complexation of activated protein $C$ by two major inhibitors in plasma. Blood 1989; 73 : 446-454.

39. Suzuki K, Deyashiki $Y$, Nishioka J, Toma K. Protein $C$ inhibitor: structure and function. Thromb Haemostas $1989 ; 61$ : $337-342$. 
40. Van der Meer $J_{\text {, Van Tilburg }} N_{\text {, }}$ Van Wijngaarden $A$, Van der Linden $I K$, Briet $E_{\text {" }}$ Bertina RM. A second plasma inhibitor of activated protein C: $\propto 1$-antitrypsin. Thromb Haemostas 1989; 62: 756-757.

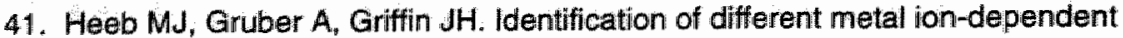
inhibition of activated protein $C$ by $\alpha 2$-macroglobulin and $\alpha 2$-antiplasmin in blood and comparisons to inhibition of factor $\mathrm{Xa}$, thrombin, and plasmin. $\mathrm{d}$ Biol Chem $1991 ; 266: 17606-17612$.

42. Hoogendoom $H_{y}$ Toh $\mathrm{CH}$, Nesheim ME, Giles AR. $\alpha 2$-macroglobulin binds and inhibits activated protein C. Blood 1991; 78: 2283-2290.

43. Shen $L$, Dahlback $B$. Factor $V$ and protein $S$ as synergistic cofactors to activated protein $\mathrm{C}$ in degradation of factor VIlla. J Biol Chem 1994; 269: 18735-18738.

44. Váradi K, Rosing J, Tans G, Pabinger I, Keil B, Schwarz HP. Factor V enhances the cofactor function of protein S in the APC-mediated inactivation of factor VIII: influence of the Factor VR506Q mutation. Thromb Haemostas 1996; 76(2): 208214

45. Smirnov MD, Triplett DT, Comp PC, Esmon NL, Esmon CT. On the role of phosphatidylethanolamine in the inhibition of activated protein $\mathrm{C}$ activity by antiphospholipid antibodies. J Clin invest 1995; 95: 309-316.

46. Omar MN, Mann KG. Inactivation of Factor Va by Plasmin. J Biol Chem 1987; 262:20:9750-9755.

47. Odegaard B, Mann KG. Proteolysis of Factor Va by Factor Xa and Activated Protein C. J Biol Chem 1987; 262:23: 11233-11238.

48. Seligsohn $U$, Berger A, Abend M, Rubin L, Attias D, Zivelin A, Rapaport SI. Homozygous protein $C$ deficiency manifested by massive thrombosis in the newborn. N Engl J Med 1984; 310: 559-562.

49. Marlar RA, Neumann A. Neonatal purpura fulminans due to homozygous protein $C$ or protein S deficiency. Semin Thromb Hemost 1990; 16: 299-309.

50. Bertina RM, Koeleman BPC, Koster T, Rosendaal FR, Diven RJ, de Ronde $H_{\text {, }}$ van der Velden PA, Reitsma PH. Mutation in blood coagulation factor V associated with resistance to activated protein C. Nature 1994; 369: 64-67.

51. Rosing $\mathrm{J}$, Tans G, Govers-Riemslag JWP, Zwaal RFA, Hemker HC. The role of phospholipids and factor $\mathrm{Va}$ in the prothrombinase complex. J Biol Chem 1980; 255: 274-283.

52. Kisiel W, Hanahan PJ. Purification and characterization of human factor II. Biochim Biophys Acta 1973; 304: 103-113.

53. Magnusson S, Petersen TE, Sottrup-Jenssen L, Claeys H. Complete primary structure of prothrombin: Isolation, structure, and reactivity of ten carboxylated glutamic acid residues and regulation of prothrombin activation by thrombin. In: Reich E, Rifkin DB, Shaw E, eds. Proteases and Biological Control, Cold Spring Harbor Laboratory: Cold Spring Harbor, NY, 1975: 123

54. Billy D, Willems GM, Hemker HC, Lindhout T. Prothrombin contributes to the assembly of the factor Va-factor Xa complex at phosphatidylserine-containing phospholipid meimbranes. J Biol Chem 1995; 270: 26883-26889.

55. DiScipio RG, Hermadson MA, Yates SG, Davie EW. A comparison of human prothrombin, factor IX (Christmas factor), factor X (Stuart factor) and Protein $S$. Biochemistry 1977; 16: 698-706.

56. Steinberg $M$, Nemerson $Y$. Activation of factor $X$. In: Colman $W$, Hirsch J, Marder VJ, Sakman EW, eds. Hemostasis and Thrombosis, 2nd ed.

Philadelphia: Lippincott Company, 1987: 112-119.

57. McMullen BA, Fujikawa $K_{4}$ Kisiel W, Sasagawa $T$, Howald WN, Kwa EY, Weinstein $B$. Complete amino acid sequence of the light chain of human blood coagulation factor $X$ : evidence for identification of residue 63 as $\beta$ hydroxyaspartic acid. Biochemistry 1983; 22: 2875-2884. 
58. James HL. Physiology and biochemistry of factor $X$. In: Bloom AL, Forbes CD, Thomas DP, Tuddenham EGD, eds. Haemostasis and Thrombosis, 3rd ed. Edinburgh: Churchill Livingstone, 1994, 439-464.

59. Mann KG, Nesheim ME, Church WR, Haley P, Krishnaswamy S. Surfacedependent reactions of the vitamin K-dependent enzyme complexes. Blood 1990; 76(1): 1-16.

60. Nesheim ME, Taswell JB, Mann KG. The contribution of bovine factor $V$ and factor $\mathrm{Va}$ to the activity of the prothrombinase. J Biol Chem 1979; 254: 1095210962.

61. Krishnaswamy S. Prothrombinase Complex assembly Contributions of ProteinProtein and Protein-Membrane interactions toward complex formation. J Biol Chem 1990; $7: 3708-3718$.

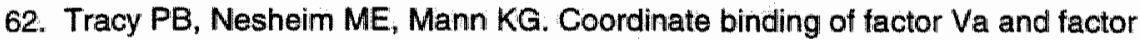
$X a$ to the unstimulated platelet. $J$ Biol Chem 1981; 256: 743-751.

63. Higgins DL, Callahan P.J, Prendergast FG, Nesheim ME, Mann KG. Lipid mobility in the assembly and expression of the activity of the prothrombinase complex. J Biol Chem 1985; 260: 3604-3612.

64. Sterzing PR, Barton PG. The influence of cholesteral on the activity of phospholipid in blood coagulation: requirement for a lipid crystalline lipid phase. Chem Phys Lipids 1973; 10: 137-148.

65. Billy D, Speijer H, Willems GM, Hemker HC, Lindhout T. Prothrombin activation by prothrombinase in a tubular flow reactor. J Biol Chem 1995; 270: 1029-1034.

66. Govers-Riemslag JWP, Janssen MP, Zwaal RFA, Rosing J. Effect of membrane fluidity and fatty acid composition on the prothrombin-converting activity of phospholipid vesicles. Biochemistry 1992; 31: 10000-10008.

67. Comfurius P, Smeets EF, Willems GM, Bevers EM, Zwaall RFA. Assembly of the prothrombinase complex on lipid vesicles depends on the stereochemical configuration of the polar headgroup of phosphatidylserine. Biochemistry 1994; 33: 10319-10324.

68. Bevers EM, Comfurius P, Van Rijn JLM, Hemker HC, Zwaal RFA. Generation of prothrombin-converting activity and the exposure of phosphatidylserine at the outer surface of platelets. Eur J Biochem 1982; 122: 429-436.

69. Sugo T, Nakamikawa $\mathrm{C}$, Tanabe S, Matsuda M. Activation of prothrombin by factor Xa bound to the membrane surface of human umbilical vein endothelial cells: Its catalytic efficiency is similar to that of prothrombinase complex on platelets. J Biochem 1995; 117: 244-250.

70. Pryzdial ELG, Wright JF. Prothrombinase assembly on an enveloped virus: Evidence that the cytomegalovirus surface contains procoagulant phospholipid. Blood 1994; 84: 3749-3757.

71. McGee MP, Foster S, Wang X. Simultaneous expression of tissue factor and tissue factor pathway inhibitor by human monocytes. A potential mechanism for localized control of blood coagulation. J Exp Med 1994; 179: 1847-1854.

72. Tracy PB, Allen DH, Worfolk LA, Lawler RR. Monocyte macrophage regulation of coagulant events. Haemostasis 1996; 26 Suppl. 1: 6-11.

73. Tracy $P B$, Eide $L L$, Mann KG. Human prothrombinase complex assembly and function on isolated peripheral blood cell populations. J Biol Chem 1985; 260: 2119-2124.

74. Sandberg $H$, Andersson $L$, Hoglund.S. Isolation and characterization of lipidprotein particles containing platelet factor 3 released from human platelets. Biochem J 1982; 203: 303-311.

75. Sims PJ, Wiedmer T, Esmon CT, Weiss HJ, Shattil SJ. Assembly of the platelet prothrombinase complex is linked to vesiculation of the platelet plasma membrane. J Biol Chem 1989; 264: 17049-17057. 
76. Tans G, Rosing $d$, Thomassen MCLGD, Heeb MJ, Zwaal RFA, Griffin JH. Comparison of anticcagulant and procoagulant activities of stimulated platelets and platelet-derived microparticles. Blood 1991; 77: 2641-2648.

77. Dachary-Prigent $J$, Tot F, Satta N, Pasquet JM, Uzan A, Freyssinet JM. Physiopathological significance of catalytic phospholipids in the generation of thrombin. Semin Thromb Hemostasis ER - 1996; 22: 157-164.

78. Tracy $P B$, Eide LL, Bowie EJ. Radioimmunoassay of factor $V$ in human plasma and platelets. Blood 1982, 60, 59-63.

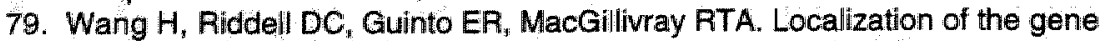
encoding human factor $V$ to chromosome 1q21-25. Genomics 1988; $2: 324-8$

80. Bruin $\pi$, Sturk $A$, Ten Cate JW, Cath $M$. The function of the human factor $V$ carbohydrate molety in blood coagulation. Eur J Biochem 1987; 170:305-310.

81. Ortel Th, Yoo L, Quinn-Allen MA, Kane WH. Partial glycosylation at asparagine2181 of the second $C$-type domain of human factor $V$ is the structural basis of the light chain doublet. Blood 1994; 84 , no.10 suppl.1: 387 a(Abstract)

82. Kalafatis M, Rand MD, Jenny JJ, Ehrlich $\mathrm{YH}$, Mann KG. Phosphorylation of Factor Va and Factor Villa by Activated Platelets. Blood 1993; 81: 704-719.

83. Pittman DD, Tomkinson KN, Michnick DA, Seligsohn U, Kaufman RJ. Posttranslational sulfation of factor $V$ is required for efficient thrombin cleavage and activation and for full procoagulant activity. Biochemistry 1994; 33: 69526959.

84. Hortin GL. Sulfation of tyrosine residues in coagulation factor V. Blood 1990; 76(5): 946-952.

85. Jenny RJ, Pittman DD, Toole JT, Kriz RW, Aldape RA, Hewick RM, Kaufman RJ, Mann KG. Complete cDNA and derived amino acid sequence of human factor V. Proc Natl Acad Sci USA 1987; 84: 4846-4850.

86. Monkovic D, Tracy P. Activation of Human Factor $V$ by Factor $X a$ and Thrombin. Biochemistry 1990; 29: 1118-1128.

87. Nesheim ME, Foster WB, Hewick RM. Characterization of factor V activation intermediates. J Biol Chem 1984; 259: 3187-3196.

88. Suzuki K, Dahlbäck B, Stenflo J. Thrombin-Catalyzed Activation of Human Coagulation Factor V. J Biol Chem 1982; 257-11: 6556-6564.

89. Kalafatis $M$, Rand MD, Mann KG. The mechanism of inactivation of human factor $V$ and human factor $V a$ by activated protein $C . J$ Biol Chem 1994; 269: 31869-31880.

90. Cripe LD, Moore KD, Kane WH. Structure of the Gene for Human Coagulation Factor V. Biochemistry 1992; 31: 3777-3785.

91. Church WR, Jernigan RL, Toole JT, Hewick RM, Knopf J, Knutson GJ, Nesheim ME, Mann KG, Fass DN. Coagulation factors $V$ and VIII and ceruloplasmin constitute a family of structural related proteins. Proc Natl Acad Sci USA 1984; 81: 6934-6937.

92. Rosing ل, Bakker HM, Thomassen MCLGD, Hemker HC, Tans G. Characterization of two Forms of Human Factor Va with different Cofactor Activities. J Biol Chem 1993; 268: 21130-21136.

93. Guinto $E R$, Esmon CT. Loss of prothrombin and of factor Xa-factor Va interactions upon inactivation of factor Va by activated protein $\mathrm{C}$. J Biol Chem 1984; 259: 13986-13992.

94. Luckow EA, Lyans DA, Ridgeway TM, Esmon CT, Laue TM. Interaction of Clotting Factor $V$ Heavy Chain with Prothrombin and Prethrombin 1 and Role of Activated Protein $C$ in Regulating This Interaction: Analysis by Analytical Uitracentrifugation. Biochemistry 1989; 28: 2348-2354. 
95. Bakker HM, Tans G, Thomassen MCLGD, et al. Functional properties of human factor Va lacking the $\mathrm{Asp}^{683}-\mathrm{Arg}^{709}$ domain of the heavy chain. J Biol Chem 1994; 269: 20662-20667.

96. Nicolaes GAF, Tans $\mathrm{G}_{\mathrm{i}}$ Thomassen MCLGD, et al. Peptide Bond Cleavages and Loss of Functional Activity during Inactivation of Factor Va and Factor VaR506Q by activated protein. J Biol Chem 1995 270(36): 21158-21166.

97. Van de Waart $P$, Bruls $H$, Hemker HC. Interaction of bovine blood clotting factor $\mathrm{Va}$ and its subunits with phospholipid vesicles. Biochemistry 1983;22:24272432.

98. Tracy PB, Mann KG. Prothrombinase complex assembly on the platelet surface is mediated through the 74,000 -dalton component of factor Va. Proc Natl Acad Sci USA 1983; 80: 2380-2384.

99. Ortel TL, Devore-Carter D, Quinn-Allen MA. Deletion analysis of recombinant human factor V. J Cell Biochem 1992; 267: 4189-4198.

100. Kalafatis M, Rand MD, Mann KG. Factor Va-Membrane Interaction is Mediated by Two Regions Located on the Light Chain of the Cofactor. Biochemistry 1994; 33: 486-493.

101. Lecompte M-F, Bouix G, Mann KG. Electrostatic and Hydrophobic Interactions are involved in Factor Va Binding to Membranes Containing Acidic Phospholipids. J Biol Chem 1994; 269-3: 1905-1910.

102. Stubbs ID, Lekutis C, Singer KL, et al. Proc Natl Acad Sci USA 1990; 87: 84178421.

103.Pryzdial ELG, Mann KG. The association of coagulation factor Xa and factor $\mathrm{Va}$. J Cell Biochem 1991; 266: 8960-8977.

104. Kalafatis M, Xue J, Lawler CM, Mann KG. Contribution of the heavy and light chains of factor $\mathrm{Va}$ to the interaction with factor $\mathrm{Xa}$. Blochemistry 1994; 33: 6538-6545.

105. Marquette KA, Pittman DD, Kaufman RJ. The factor V B-domain provides two functions to facilitate thrombin clleavage and release of the light chain. Blood 1995; 86: 3026-3034.

106.Lu DS, Kalafatis $M$, Mann KG, Long $G$. comparison of activated protein C/protein S-mediated inactivation of human factor VIII and factor V. Blood 1996; 87:11: 4708-4717.

107. Nesheim ME, Nichols WL, Cole TL. Isolation and study of an acquired inhibitor of human coagulation factor V. J Clin Invest 1986; 77: 405-415.

108.Chediak J, Ashenhurst JB, Garlick I. Succesful management of bleeding in a patient with factor $V$ inhibitor by platelet transfusions. Blood 1980; 56: 835-841.

109. Hayward CPM, Furmaniak-Kazmierczak E, Cieutat A-M, Moore JC, Bainton DF, Nesheim ME, Kelton $J G$, Cote $G$. Factor $V$ is complexed with multimerin in resting platelet lysates and colocalizes with multimerin in platelet $\alpha$-granules. J Biol Chem 1995; 270: 19217-19224.

110. Hayward CPM, Rivard GE, Kane WH, Drouin J, Zheng S, Moore JC, Kelton JG. An autosomal dominant, qualitative platelet disorder associated with multimerin deficiency, abnormalities in platelet factor $V$, thrombospondin, von Willebrand factor, and fibrinogen and an epinephrine aggregation defect. Blood 1996; 87: 4967-4978.

111. Bakker HM. Accelerin - The activated form(s) of human blood coagulation factor

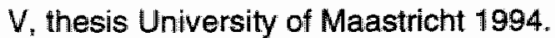

112.Pieters J, Hemker HC, Lindhout T. In situ generated thrombin is the only enzyme that effectively activates factor VIIII and factor $V$ in thromboplastinactivated plasma. Blood 1989; 74: 1021-1024.

113. Esmon CT, Jackson CM. Thromb Res 1974; 2: 509-524. 
114. Kane WH, Majerus PW. Purification and characterization of human coagulation factor V. J Blol Chem 1981; 256; 1002-1007.

115. Kalafatis M, Bertina $\mathrm{RM}$, Rand MD, Mann KG. Characterization of the molecular defect in factor $\mathrm{V}^{\mathrm{R} 360 \mathrm{O}}$. J Biol Chem $1995 ; 270: 4053-4057$.

116. Walker FJ, Sexton PW, Esmon CT. The inhibition of blood coagulation by activated protein $\mathrm{C}$ through selective inactivation of activated factor $\mathrm{V}$. Biochim Bjophys Acta 1979;571; 333-342.

117.Suzuki K, Stenflo J, Dahibaack B Teodorsson B. J Biol Chem 1983; 258: 19141920.

118. Bakker HM, Tans $\mathrm{G}$, Janssen-Claesen T, Thomassen MCLGD, Hemker HC, Griffiin $\mathrm{JH}$, Rosing $\mathrm{J}$. The effect of phospholipids, calcium ions and protein $\mathrm{S}$ on rate constants of human factor $\mathrm{Va}$ inactivation by activated human protein $\mathrm{C}$. Eur J Biochem 1992; 208: 171-178.

119. Walker FJ. Regulation of activated protein C by a new protein. A possible function for bovine protein S. J Biol Chem 1980; 255: 5521-5524.

120 . Solymoss S, Tucker MM, Tracy PB. Kinetics of inactivation of membrane-bound factor $\mathrm{Va}$ by activated protein $\mathrm{C}$. Protein $\mathrm{S}$ modulates factor Xa protection. J Bioll Chem 1988; 263: 14884-14890.

121.Rosing J, Hoekema L, Nicolaes GAF, Thomassen MCLGD, Hemker HC, Varadi $K$, Schwarz HP, Tans G. Effects of protein $S$ and factor $X a$ on peptide bond cleavages during inactivation of factor $\mathrm{Va}$ and factor $\mathrm{Va}{ }^{\mathrm{A} 506 \mathrm{C}}$ by activated protein C. J Biol Chem 1995; 270: 27852-27858.

122. Dahilbäck $B$, Carlsson $M$, Svensson PJ. Familial thrombophilia due to a previously unrecognized mechanism characterized by poor anticoagulant response to activated protein $\mathrm{C}$ : Prediction of a cofactor to activated protein $\mathrm{C}$. Proc Natl Acad Sci USA 1993; 90: 1004-1008.

123.Svensson PJ, Dahlbäck B. Resistance to Activated Protein $C$ as a Basis for Venous Thrombosis. N Engl $\mathbb{d}$ Med 1994; 330:8: 517-522.

124. Griffin $\mathrm{JH}$, Evatt $\mathrm{B}_{n}$ Wideman $\mathrm{C}_{\mathrm{y}}$ Fernández JA. Anticoagulant protein $\mathrm{C}$ pathway defective in a majority of thrombophilic patients. Blood 1993; 82: 1989-1993.

125. Koster T, Rosendaal FR, De Ronde H, Briët E, Vandenbroucke JP, Bertina RM. Venous thrombosis due to a poor anticoagulant response to activated protein $\mathrm{C}$ : Leiden Thrombophilia Study. Lancet 1993; 342: 1503-1506.

126: Dahlbäck $B$. Hildebrand $B$. Inherited resistance to activated protein $C$ is corrected by anticoagulant cofactor activity found to be a property of factor $\mathrm{V}$. Proc Natl Acad Sci USA 1994; 91 : 1396-1400.

127. Dahibäck B. Thromb Haemostas 1993; 69: 978 a(Abstract)

128. Sun X, Evatt B, Griffin JH. Blood Coagulation Factor Va Abnormality Associated With Resistance to Activated Protein $C$ in Venous Thrombophilia. Blood 1994; 83:11: 3120-3125.

129. Voorberg J, Roelse JC, Koopman R, Büller H, Berends F, ten Cate JW, Mertens $K_{b}$ van Mourik. JA. Association of idiopathic venous thromboembolism with single point-mutation at Arg $^{506}$ of factor $V_{\text {: }}$ Lancet 1994; 343: 1535-1536.

130.Zöller B, Svensson PJ, He X, Dahlbäck B. Identification of the same factor $V$ gene mutation in 47 out of 50 thrombosis-prone families with inherited resistance to activated protein $\mathrm{C}$. $J$ Clin Invest 1994; 94: 2521-2524.

131. Rees DC, Cox MJ, Clegg JB. World distribution of factor V Leiden. Lancet 1995; 346: $1133-1134$.

132. Dalhlbäck $B$. Inherited Thrombophilia: Resistance to Activated Protein $\mathrm{C}$ as a pathogenic Factor of Venous Thromboembolism. Blood 1995; 85:3: 607-614.

133. Váradi $K$, Rosing J, Tans G, Schwarz HP. Influence of factor $V$ and factor Va on APC-induced cleavage of human factor VIII. Thromb Haemost 1995; 73: 730731. 
134. Simioni P, De Ronde H, Prandoni P, Saladini M, Bertina RM, Girolami A. Ischemic stroke in young patients with activated protein $C$ resistance: $A$ report of three cases belonging to three different kindreds, Stroke 1995, 26: 885-890.

135. Halbmayer WM, Haushofer A, Schön $\mathrm{A}_{3}$ Fischer M. The Prevalence of Poor Anticoagulant Response to Activated Protein C (APC Resistance) among Patients Suffering from Stroke or Venous Thrombosis and among Healthy Subjects. Blood Coagul Fibrinol 1995* 5:51.

136. Montaruli B, Voorberg J, Tamponi G, Borchiellini A, Muleo G, Pannocchia A, van Mourik JA, Schinco P. Arterial and venous thrombosis in two Italian familles with the factor V Arg(506)-> GIn mutation. Eur J Haematol 1996, 57, 96-100,

137.Sakata T, Kario K, Katayama $Y$, Matsuyama T, Kato H, Miyata T. Clinical significance of activated protein $C$ resistance as a potential marker for hypercoagulable state. Thromb Res 1996; 82: 235-244.

138. Stirling $Y$, Woolf $L$, North WRS, Seghatchian MJ, Meade TW: Haemostasis in normal pregnancy. Thromb Haemostas 1984; 52(2): 176-182.

139. Van Wersch JWJ, Ubachs JMH. Blood coagulation and Fibrinolysis during normal pregnancy. Eur J Clin Chem Clin Biochem 1991; 29: 45-50.

140.Coata $G$, Ventura $F$, Lombardini $R_{s}$ Ciuffetti $G$, Cosmi EV, Di Renzo GC. Effect of low-dose oral triphasic contraceptives on blood viscosity coagulation and lipid metabolism. Contraception 1995; 52: 151-157.

141.Stubblefield $P G$. The effects on hemostasis of oral contraceptives containing desogestrel. Am J Obstet Gynecol 1993; 168(3): 1047-1052.

142.Speroff $L, D e C h e r n e y A$, The advisary board for the new progestins. Evaluation of a new generation of oral contraceptives. Obstet Gynecol 1993; 81: 1034-1047.

143.Forbes CD, Greer IA, Lowe GDO, et al. Haemostasis and Thrombosis in Obstetrics and Gynaecology. London: Chapman \& Hall, $1^{\text {st }}$, ed. 1992. 


\section{Chapter 2}

\section{Activation of Human Factor $\mathbf{V}$ by Meizothrombin}

Based on: Activation of human factor $V$ by meizothrombin. Joumal of Biological Chemistry 1994, 269 (23) 15969-15972

reprinted with permission of the publisher 


\subsection{Summary}

A recombinant human prothrombin was prepared in which $\operatorname{Arg}^{155}$ was replaced by Ala. The recombinant prothrombin was converted into a meizothrombin derivative (R155A meizothrombin) that was resistant to autocatalytic removal of the fragment 1 domain. R155A meizothrombin appeared to be a potent factor $\mathrm{V}$ activator in reaction mixtures that contained negatively charged phospholipid vesicles. Factor $\mathrm{V}$ activation by R155A meizothrombin was characterized by a second order rate constant of $0.06 \mathrm{x}$ $10^{6} \mathrm{M}^{-1} \mathrm{~s}^{-1}$ in the absence of phospholipid and $18 \times 10^{6} \mathrm{M}^{-1} \mathrm{~s}^{-1}$ in the presence of $60 \mu \mathrm{M}$ phospholipid vesicles composed of a $10 / 90(\mathrm{~mol} / \mathrm{mol})$ mixture of phosphatidylserine (PS) and phosphatidylcholine (PC). The rate constant for thrombin-catalyzed activation of factor $V$ was hardly affected by the presence of phospholipid vesicles and was $4.0 \times 10^{6} \mathrm{M}^{-1} \mathrm{~s}^{-1}$. The initial rate of activation of $3 \mathrm{nM}$ factor $\mathrm{V}$ by R155A meizothrombin was a function of the concentration of PS/PC vesicles present in the reaction mixture and the calculated rate constant reached a plateau value at $[\mathrm{PS} / \mathrm{PC}] \geq 50 \mu \mathrm{M}$. Gel electrophoretic analysis of factor $V$ activation showed that R155A meizothrombin and thrombin cleaved the susceptible peptide bonds in factor $V$ at different rates. However, both activators finally generated a factor $\mathrm{Va}$ molecule composed of a heavy chain with an $M_{r}=104,000$ and a light chain doublet with $M_{r}$ values of 74,000 and 71,000 . Since meizothrombin is one of the major reaction products formed during the initial phase of prothrombin activation, these findings are indicative of a significant contribution of meizothrombin to in vivo factor $\mathrm{V}$ activation.

\subsection{Introduction}

Human blood coagulation factor $V$ is a single chain glycoprotein ${ }^{1,2}$ that, during haemostasis, is converted into factor Va via limited proteolysis by enzymes (e.g. thrombin and factor $\mathrm{Xa}$ ) generated after the initiation of blood coagulation $^{1+6}$. Factor $\mathrm{Va}$ is the non-enzymatic cofactor of the prothrombinactivating complex, which also comprises the serine protease factor $\mathrm{Xa}$, calcium ions and a procoagulant membrane surface. Depending on the reaction conditions, factor $\mathrm{Va}$ accelerates prothrombin activation $10^{3.10^{5}}$. fold ${ }^{7-9}$

The important function of factor $\mathrm{Va}$ in haemostatic plug formation is further underscored by the observation that, during in vitro coagulation, factor $\mathrm{Va}$ is the rate-limiting factor in prothrombin activation ${ }^{10}$ and by the fact that the activity of factor $\mathrm{Va}$ is efficiently regulated by activated protein $\mathrm{C}^{11}$. Since 
factor $V$ is unable to act as a cofactor in the prothrombinase complex? activation of factor $V$ must be a key event in thrombin formation.

Here we report that meizothrombin, a reaction intermediate that accumulates during the initial phase of prothrombin activation ${ }^{12-15}$, may be an important factor $V$ activator. Meizothrombin exhibits full activity on chromogenic substrates, but compared with thrombin it has a reduced activity on macromolecular protein substrates ${ }^{12,16}$. Studies on the catalytic activities of meizothrombin are hampered, however, by the fact that it is autoproteolyzed to meizothrombin (desF 1$)^{12,17}$ or thrombin ${ }^{17}$. In this chapter the preparation of a recombinant human prothrombin is described in which Arg $^{155}$ is replaced by Ala. The recombinant prothrombin was converted into meizothrombin, which, due to the amino acid substitution, could not be converted to meizothrombin (desF1) and which was not measurably autolyzed to thrombin. This meizothrombin derivative is a powerful factor $V$ activator in the presence of phospholipids. Since its activity can even exceed that of thrombin, activation of factor $V$ by meizothrombin may be of prime importance for the initiation of prothrombin activation.

\subsection{Materials and Methods}

\section{Materials}

Ovalbumin, BSA, bovine brain PS and egg-yolk PC were purchased from Sigma. DOPC and DOPS were obtained from Avanti Polar Lipids (Pelham, AL). Small unilamellar phospholipid vesicles were prepared as described before $^{18}$. S2238 (D-Phe-pipecolyl-Arg p-nitroanilide) and 12581 ( $\mathrm{N}$-dansyl-(pguanidino)phenylalanine piperidide hydrochloride) were supplied by Chromogenix. Materials used for protein purification were purchased from Pharmacia Biotech Inc. The adenovirus transformed human kidney 293 cell line (ATCC CRL1573) was from Flow Laboratories, Inc. Escherichia coli 1061/P3 and plasmid pcDNA1 were from Invitrogen. Iscove's and Optimem1 medium were from Life Technologies, Inc. Vitamin $K_{1}$ was from Hoffman-La Roche. Human coagulation factors were prepared by earlier described procedures ${ }^{14,18}$. The prothrombin activator from Echis coloratus was purified from the crude venom (Latoxan) by gel permeation chromatography on Superdex 200 and ion-exchange chromatography on Mono Q and Mono S. The venom prothrombin activator was applied to a Mono $Q$ in $50 \mathrm{mM}$ Tris ( $\mathrm{pH}$ 7.9), $100 \mathrm{mM} \mathrm{NaCl}, 0.1 \mathrm{mM} \mathrm{CaCl} 2$ and to a Mono $S$ in $25 \mathrm{mM}$. Hepes (pH 7.7) $50 \mathrm{mM} \mathrm{NaCl}, 0.1 \mathrm{mM} \mathrm{CaCl}_{2}$ and eluted from the columns at $\mathrm{NaCl}$ 
concentrations between 150 and $200 \mathrm{mM}$. Details of the purification procedure will be described elsewhere.

\section{Cloning of prothrombin and construction of R155A prothrombin}

Full-length prothrombin CDNA was obtained as described before ${ }^{19}$. Mutagenesis was performed by the polymerase chain reaction overlap extension technique ${ }^{20}$, using two overlapping oligonucleotides (5: CGATGACTCCAGCGTCCGAAGGCTCC-3' and 5'-GGAGCCTTCGGACGCTGGAGTCATCG-3" (mutated sequence is underlined)), resulting in the replacement of $\operatorname{Arg}^{155}$ with Ala. The mutated fragment was used to substitute the wild type Xhol-BstEll fragment of prothrombin in pcDNA1 and the DNA sequence was confirmed for the entire fragment.

\section{Expression of recombinant prothrombin}

The prothrombin cDNAs obtained from the pcDNA1 plasmid by digestion with $E c O R I$ and $X b a l$ were inserted into the $B C A$ site of expression vector $p$ GTh (a gift of Dr. B.W. Grinnell, Lilly Research Laboratories, Indianapolis, USA). This vector enables high expression levels in the adenovirustransformed human kidney cell line 293 and selection of positive clones with hygromycin B since the vector contains the cistron for expression of hygromycin phosphotransferase.

Cells were grown in Optimem 1 medium supplemented with $5 \%$ fetal calf serum and $10 \mu \mathrm{g} / \mathrm{ml}$ vitamin $K_{1}$. The cells were transfected and colonies were selected as described by Walls et al. ${ }^{21}$. The selected cell line was grown in $175-\mathrm{cm}^{2}$ culture dishes in the medium described above. After reaching confluency, the cells were kept serum-free in Optimem 1 with $10 \mu \mathrm{g} / \mathrm{ml}$ vitamin $\mathrm{K}_{1}$ and the medium was collected and refreshed each $72 \mathrm{hr}$ during 8 weeks. The medium was centrifuged for $20 \mathrm{~min}$ at $14,000 \mathrm{xg}$ and the supernatant was stored at $-80^{\circ} \mathrm{C}$.

\section{Purification and characterization of R155A prothrombin}

In a typical purification, $0.5 \mathrm{~L}$ medium (to which $0.5 \mathrm{mg} / \mathrm{m} /$ ovalbumin was added to minimize protein losses during the first purification step) was loaded at $4^{\circ} \mathrm{C}$ on a $5-\mathrm{ml}$ fast flow Q-Sepharose column. The column was washed with $100 \mathrm{ml} 50 \mathrm{mM}$ Tris $\left(\mathrm{pH} 7.5\right.$ at $4^{\circ} \mathrm{C}$ ) and $150 \mathrm{mM} \mathrm{NaCl}$, and R155A prothrombin was eluted with a $100-\mathrm{ml}$ linear gradient of $150-1000 \mathrm{mM} \mathrm{NaCl}$ in the same buffer. R155A prothrombin-containing fractions were pooled and 
dilluted 5 -fold in $50 \mathrm{mM}$ Tris $\left(\mathrm{pH} 7.5\right.$ at $\left.20^{\circ} \mathrm{C}\right)$ and applied to a Mono Q column (HR 5/5) connected to a Pharmacia FPLC system. R155A prothrombin was eluted with a $30-\mathrm{ml}$ linear gradient of $100-1000 \mathrm{mM} \mathrm{NaCl}$ in the same buffer. R155A prothrombin containing fractions were pooled, dialyzed against $25 \mathrm{mM}$ Hepes (pH 7.5) and $175 \mathrm{mM} \mathrm{NaCl}$ at $4^{\circ} \mathrm{C}$, and stored at $-80^{\circ} \mathrm{C}$. R155A prothrombin appeared as a closely spaced doublet on non-reduced gels and as a single smeared band on reduced gels (Fig. 2.1) R155A prothrombin was fully carboxylated as determined by the method of Kuwada and Katayama ${ }^{22}$. Concentrations of $\mathrm{R} 155 \mathrm{~A}$ prothrombin were determined after complete activation with Echis carinatus venom and by enzyme-linked immunosorbent assay using a biotinylated rabbit polyclonal antibody to human prothrombin. Antigen/activity ratio's, initial rates of activation by the prothrombinase complex, and final levels of thrombin obtained were the same for R155A prothrombin and purified human plasma prothrombin.

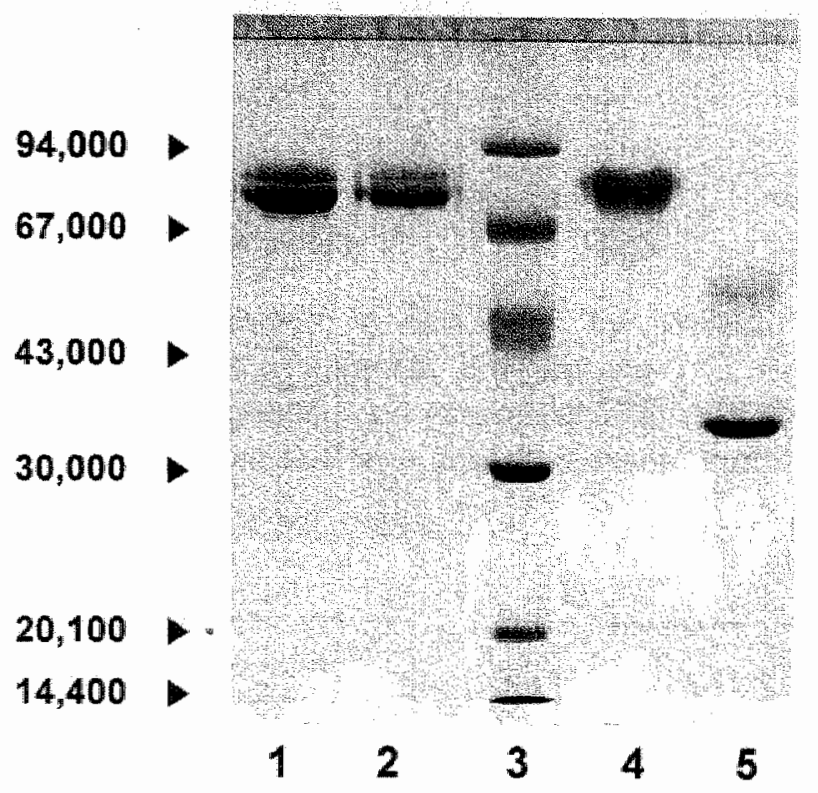

Fig. 2.1 Gelelectrophoretic analysis of R155A prothrombin and R155A melzothrombin. R155A prothrombin $(2.64 \mu \mathrm{M})$ was incubated at $37{ }^{\circ} \mathrm{C}$ with $65 \mathrm{ng} / \mathrm{ml}$ purified prothrombin activator from the venom of Echis coloratus in a reaction medium containing $25 \mathrm{mM}$ Hepes ( $\rho H$ 7.5), $175 \mathrm{mM} \mathrm{NaCl}, 5 \mathrm{mM} \mathrm{CaCl}$ and $20 \mu \mathrm{M}$ 12581. After 4 min the activation mixture was applied to a Mono-S column (HR5/5) that was equilibrated with $25 \mathrm{mM}$ Hepes (pH 7.7) and 50 $\mathrm{mM} \mathrm{NaCl}$. R155A meizothrombin passed through this column and 12581 was added to the meizothrombin-containing fractions to a final concentration of $20 \mu \mathrm{M}$. The $\mathrm{R} 155 \mathrm{~A}$ meizothrombin preparation was stored at $-80^{\circ} \mathrm{C}$. The gel represents SDSPAGE analysis of: 1) R155A prothrombin, 2) R155A meizothrombin, 3) molecular weight standards; 4) R155A prothrombin $+5 \%$-mercaptoethanol and 5) R155A meizothrombin $+5 \% \beta$-mercaptoethanol. 


\section{Protein concentrations}

R155A meizothrombin concentrations were determined with S2238, considering that the amidolytic activity/mole of R155A meizothrombin is the same as that of thrombin ${ }^{12,16}$.

Factor Va was quantitated by determining the rate of factor Xa-catalyzed prothrombin activation in reaction mixtures that contained a limiting amount of factor $V a$ and saturating concentrations phospholipid vesicles $(50 \mu \mathrm{M} P S / P C$, $10: 90, \mathrm{M} / \mathrm{M})$, factor $\mathrm{Xa}(5 \mathrm{nM})$ and prothrombin $(0.5 \mu \mathrm{M})^{18}$. The inhibitor I2581 $(20 \mu \mathrm{M})$ was present to prevent further activation of factor $V$ by thrombin generated in the assay mixture. 12581 did not interfere with the subsequent thrombin determination since it is a reversible inhibitor whose inhibitory action in the thrombin assay was essentially eliminated by dilution and by the presence of the $\$ 2238$. The molar factor Va concentration was calculated from the rate of prothrombin activation using a tumover number of $6000 \mathrm{~mol}$ prothrombin activated per $\mathrm{min} / \mathrm{mol}$ of factor Xa-Va complex ${ }^{14}$. 


\subsection{Results}

\section{Preparation of R155A Meizothrombin}

R155A prothrombin was converted into R155A meizothrombin with the purified prothrombin activator from Echis coloratus venom. R155A meizothrombin was separated from the venom activator on a Mono $\mathrm{S}$ column. This column material did not bind R155A meizothrombin, but retained the venom activator. Immediately after elution of R155A meizothrombin, the thrombin inhibitor 12581 (final concentration $20 \mu \mathrm{M}$ ) was added to prevent autocatalytic peptide bond cleavages. SDS-PAGE analysis of R155A prothrombin and of the R155A meizothrombin that eluted from the Mono $S$ column showed that R155A prothrombin was completely converted into R155A meizothrombin and that no further peptide bond cleavages had occurred. R155A meizothrombin was stored at $-80^{\circ} \mathrm{C}$. Before use, 12581 was removed by passage through a prepacked Sephadex G-25 (PD-10) column. The meizothrombin preparation thus obtained was diluted to $50 \mathrm{nM}$ and was stable for at least $12 \mathrm{hrs}$ at $0^{\circ} \mathrm{C}$.

\section{R155A meizothrombin-, meizothrombin(desF1)- and thrombin- catalyzed activation of factor $V$}

Time courses of factor $V$ activation by R155A meizothrombin, meizothrombin(desF1) and thrombin are presented in Fig. 2.2. In free solution, R155A meizothrombin and meizothrombin(desF1) were poor factor $V$ activators, with activities that were less than $5 \%$ of that of thrombin (Fig. 2.2A).
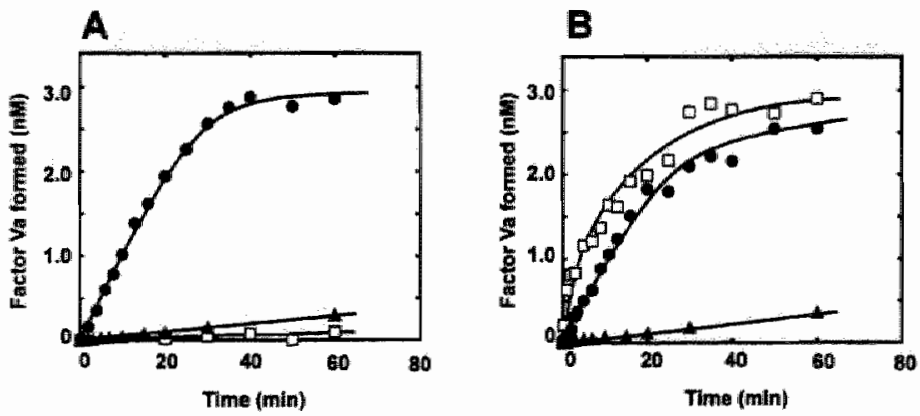

Fig. 2.2 Time courses of factor V activation by thrombin, R155A meizothrombin and meizothrombin(desF1). Human factor $V(3 \mathrm{nM})$ was activated at $37^{\circ} \mathrm{C}$ with $0.15 \mathrm{nM}$ thrombin (C), A155A meizothrombin ( $\square$ ) or meizothrombin(des $F$ 1) (A) in the absence (A) or presence (B) of $60 \mu M$ DOPS/DOPC $(10 / 90$, mol/mol) vesicles in a reaction mixture containing $25 \mathrm{mM}$ Hepes (pH 7.5), $175 \mathrm{mM} \mathrm{NaCl}, 5 \mathrm{mM} \mathrm{CaCl}$ and $5 \mathrm{mg} / \mathrm{ml} / \mathrm{BSA}$. After the time infervals indicated in the figure aliquots from the activation mixture were assayed for the presence of factor Va as described under "Materials and Methods". 
However, when negatively charged phospholipid vesicles were included in the activation mixture, there was a drastic increase of the rate of $\mathrm{R} 155 \mathrm{~A}$ meizothrombin-catalyzed activation of factor $V$, while there was hardly any effect on factor $V$ activation by thrombin or meizothrombin(desF1) (Fig. 2.2B). We verified that factor $V$ activation in reaction mixtures containing phospholipids and R155A meizothrombin was not due to $\alpha$-thrombin formed by autoproteolysis of $\mathrm{R} 155 \mathrm{~A}$ meizothrombin. This is concluded from the fact that $\mathrm{R} 155 \mathrm{~A}$ meizothrombin present in activation mixtures retained full amidolytic activity when incubated with antithrombin III + heparin, which shows that it is not converted into $\alpha$-thrombin since this would be readily inhibited by these inhibitors ${ }^{12}$.

Initial rates of factor $\mathrm{Va}$ generation were linear in time between 0 and $3 \mathrm{~min}$ and directly proportional to the concentrations of factor $V(0-5 \mathrm{nM})$ and activator (0-0.3 nM) present in the reaction mixture (data not shown). This shows that factor $V$ activation under these conditions is first-order in both factor $V$ and activator (R155A meizothrombin, meizothrombin(desF1) or thrombin), which allows the calculation of second-order rate constants for factor $V$ activation from the initial rates of factor $\mathrm{Va}$ formation. These rate constants are summarized in Table 2.1.

\section{Table 2.1}

\section{Second order rate constants of factor $V$ activation}

Rate constants of factor $\mathrm{V}$ activation by thrombin, meizothrombin(desF 1 ) or R155A meizothrombin were calculated from initial rates of factor Va formation obtained from the time courses of factor $V$ activation presented in Fig. 2.2.

\begin{tabular}{lcc} 
& \multicolumn{2}{c}{$k\left(\mathrm{M}^{-1} \mathrm{~s}^{-1}\right)$} \\
\cline { 2 - 3 } Factor V activator & no lipid & $+60 \mu \mathrm{M}$ DOPS/DOPC \\
\hline Thrombin & $4.0 \times 10^{6}$ & $3.6 \times 10^{6}$ \\
Meizothrombin(desF1) & $0.17 \times 10^{6}$ & $0.22 \times 10^{6}$ \\
R155A meizothrombin & $0.06 \times 10^{6}$ & $18 \times 10^{6}$ \\
\hline
\end{tabular}

Thrombin catalyzed factor $\mathrm{V}$ activation with a second-order rate constant of $4.0 \times 10^{6} \mathrm{M}^{-1} \mathrm{~s}^{-1}$ in the absence of phospholipid vesicles and $3.6 \times 10^{6} \mathrm{M}^{-1} \mathrm{~s}^{-}$

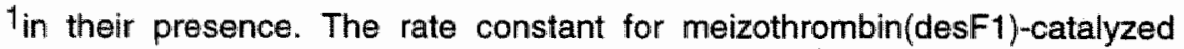
factor $V$ activation was -20 -fold lower $\left(k=0.17 \times 10^{6} \mathrm{M}^{-1} \mathrm{~s}^{-1}\right)$ and was also hardly affected by the presence of phospholipid. In free solution, R155A meizothrombin was the weakest factor $V$ activator $\left(k=0.06 \times 10^{6} \mathrm{M}^{-1} \mathrm{~s}^{-1}\right)$. However, the presence of $60 \mu \mathrm{M} \mathrm{PS} / \mathrm{PC}(10: 90, \mathrm{~mol} / \mathrm{mol})$ vesilcles caused a 
300 -fold increase in the initial rate of R155A meizothrombin-catalyzed factor $V$ activation, yielding a rate constant $\left(k=18 \times 10^{6} \mathrm{M}^{-1} \mathrm{~s}^{-1}\right)$ that even exceeds that of thrombin.

The initial rate of factor $V$ activation by $R 155 \mathrm{~A}$ meizothrombin was a function of the phospholipid concentration in the reaction mixture. The rate constant calculated from the initial phase of time courses of activation of $3 \mathrm{nM}$ factor $V$ by R155A meizothrombin increased from $0.06 \times 10^{6} \mathrm{M}^{-1} \mathrm{~s}^{-1}$ in the absence of phospholipid vesicles to an average plateau value of $19 \times 10^{6}$ $\mathrm{M}^{-1} \mathrm{~s}^{-1}$ at concentrations PS/PC $(10: 90, \mathrm{~mol} / \mathrm{mol})$ vesicles concentrations of $\geq$ $50 \mu \mathrm{M}$ (Fig. 2.3). Half-maximal rates of factor $\mathrm{V}$ activation were observed at $10 \mu \mathrm{M}$ PS/PC.

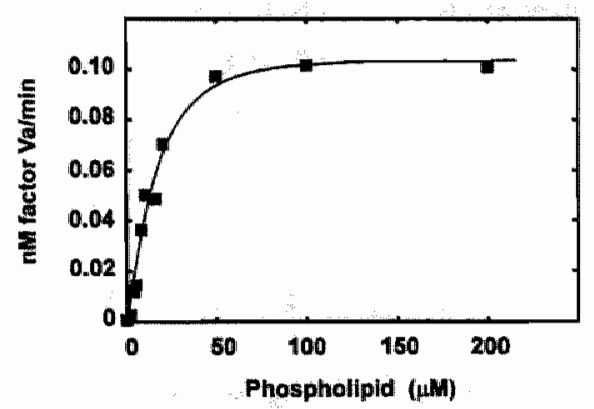

Fig. 2.3 Phospholipid dependence of R155A meizothrombin-catalyzed activation of factor $V$. Human factor $V(3 \mathrm{nM})$ was activated at $37^{\circ} \mathrm{C}$ with $0.03 \mathrm{nM}$ R155A meizothrombin in a reaction mixture containing $25 \mathrm{mM}$ Hepes (pH 7.5); $175 \mathrm{mM} \mathrm{NaCl}, 5 \mathrm{mM} \mathrm{CaCl} 2,5 \mathrm{mg} / \mathrm{ml}$ $B S A$ and concentrations of DOPS/DOPC (10/90, mol/mol) vesicles indicated in the figure. After appropriate time intervals aliquots were taken from the activation mixture and assayed for the presence of factor Va as decribed under "Materials and Methods". Initial rates of factor $\checkmark$ activation were obtained from the time courses of factor Va formation by linear regression.

A remark is due here regarding the equation that describes time courses of factor $\mathrm{V}$ activation such as those presented in Fig. 2.2. Theoretically, the time course of product generation of an enzyme-catalyzed reaction determined under pseudo first-order conditions is described by the equation $\mathrm{P}_{t}=\mathrm{S}_{\mathrm{o}}\left(1-\mathrm{e}^{-k . t}\right)$, in which $\mathrm{P}_{t}$ is the product concentration at time $t, \mathrm{~S}_{\mathrm{o}}$ is the substrate concentration at $t=0$ and $k$ is the pseudo first-order rate constant of the reaction. The second-order rate constant of the reaction is obtained after dividing the pseudo first-order rate constant by the enzyme concentration. The time courses of thrombin-catalyzed factor $V$ activation could be fitted with this equation and yielded a rate constant equal to that calculated from the initial rate of factor $\mathrm{Va}$ formation. However, the time course of R155A 
meizothrombin-catalyzed activation of factor $V$ (Fig. 2.2B) did not adhere to the equation for a pseudo first-order reaction. The experimental curve was biphasic, with a rapid initial phase ( $60 \%$ of the reaction) followed by a slower second phase that completes factor $V$ activation. Possible explanations for this biphasic behaviour are given in the discussion.

(A) Thrombin

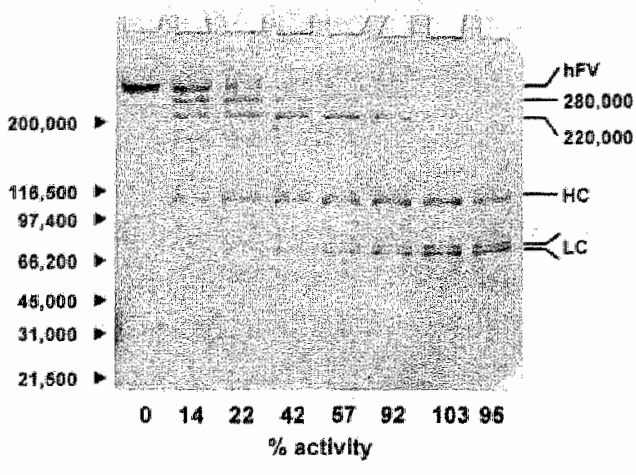

(B) R16.5A-Melzothrombin

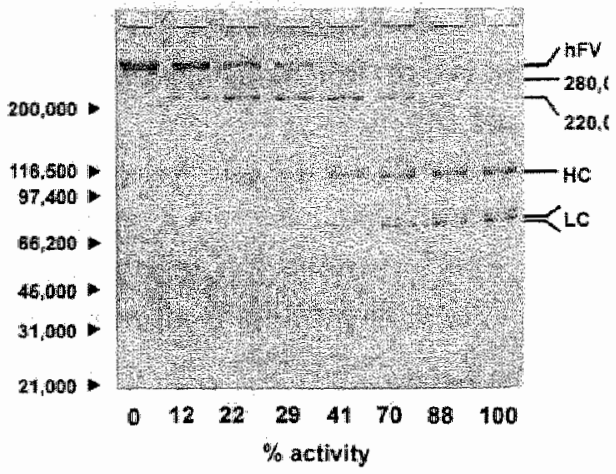

Fig. 2.4 Gelelectrophoretic analysis of factor $V$ activation by thrombin and R155A meizothrombin. Human factor $V(365 \mathrm{nM})$ was activated at $37^{\circ} \mathrm{C}$ with $2.5 \mathrm{nM}$ thrombin (A) or $2.5 \mathrm{nM}$ R155A meizothrombin in a reaction mixture containing $25 \mathrm{mM}$ Hepes $(\mathrm{pH} 7.5), 175$ $\mathrm{mM} \mathrm{NaCl}, 5 \mathrm{mM} \mathrm{CaCl} 2$ and $60 \mu \mathrm{M}$ DOPS/DOPC $(10 / 90$, mol/mol) vesicles. After different time intervals aliquots from the activation mixture were assayed for the presence of factor Va as described under "Materiais and' Methods". At the same times $10 \mu$ aliquots from the activation mixture were mixed with to $\mu$ f SDS- and mercaptoethanol-containing gelbuffer. To allow correlation of activation with product formation the gel represents SDS-PAGE analysis of samples which are matched as close as possible with respect to the factor Va activities generated in the reaction mixtures.

\section{SDS-PAGE analysis of factor $V$ activation by thrombin and $R 155 A$ meizothrombin}

Generation of reaction intermediates and products during factor $V$ activation by thrombin and R155A meizothrombin was analysed by SDSPAGE (Fig. 2.4A,B). In agreement with the literature ${ }^{1-6}$ thrombin-catalyzed activation of factor $\mathrm{V}$ proceeds via the characteristic high molecular weight intermediates with $M_{r}=280,000$ and 220,000 . The 280,000 intermediate was, however, hardly formed when factor $V$ was activated by R155A meizothrombin (Fig. 2.4B). This indicates differences in either the order or the 
rate of peptide bond cleavage during factor $\mathrm{V}$ activation by thrombin or R155A meizothrombin. Further processing of the high molecular weight intermediates resulted in both cases in the generation of activation fragments, which were hardly visible on the gel due to poor staining with Coomassie Blue ${ }^{5}$ and in the formation of a factor $\mathrm{Va}$ molecule that consisted of a heavy chain with an $M_{r}$ of 104,000 and a light chain doublet with $M_{r}$ values of 74,000 and 71,000 .

\subsection{Discussion}

Factor $\mathrm{V}$ activation is an important reaction in hemostatic plug formation. It results in the formation of factor $\mathrm{Va}$, the protein cofactor that greatly accelerates prothrombin activation and that regulates the rate of thrombin formation. Factor $\mathrm{V}$ is rapidly activated by thrombin ${ }^{1-6}$ and by factor $\mathrm{Xa}^{6}$, which are the proteases that are generally considered to be the physiological activators of factor $\mathrm{V}$.

In this chapter, it is reported that factor $V$ is also readily activated by meizothrombin, provided that negatively charged membranes are present as a catalytic surface. Meizothrombin is a reaction intermediate that accumulates in the early phase of prothrombin activation at concentrations that exceed those of thrombin ${ }^{12-15}$. Meizothrombin is a serine protease that, compared with thrombin, was reported to exhibit greatly reduced activity towards macromolecular thrombin substrates such as fibrinogen ${ }^{12.16}$, platelets $^{16}$ and factor $V^{16}$. Evaluation of the catalytic activity of meizothrombin is, however, hampered by the fact that it is further processed into meizothrombin-desF1 (fast) or $\alpha$-thrombin (slow) $)^{12,17}$ via an autocatalytic reaction. Removal of the fragment 1 domain, which contains the $\gamma$-carboxyglutamic acid residues that function in the binding of meizothrombin to procoagulant membranes, may especially influence those catalytic activities of meizothrombin that may occur on a phospholipid surface e.g. protein $C$ and/or factor $V$ activation. To enable activity studies of meizothrombin, we have prepared a recombinant human prothrombin in which Arg 155 was replaced by Ala. The recombinant prothrombin was converted into a meizothrombin derivative (R155A meizothrombin) that is resistant to autocatalytic removal of the fragment 1 domain. In free solution, R155A meizothrombin is a poor activator of factor $V$, and activates factor $V$ at a rate that is $<2 \%$ of that of thrombin $\left(k=0.06 \times 10^{6}\right.$ $\mathrm{M}^{-1} \mathrm{~S}^{-1}$ versus. $4.0 \times 10^{6} \mathrm{M}^{-1} \mathrm{~s}^{-1}$ ). However, when negatively charged phospholipid vesicles are included in the reaction mixture, there is a phospholipid-dependent increase of the rate of R155A meizothrombincatalyzed factor $V$ activation, reaching a plateau value with an average activation rate constant of $k=19 \times 10^{6} \mathrm{M}^{-1} \mathrm{~s}^{-1}$ at $\geq 50 \mu \mathrm{M}$ PS/PC. Since the 
activation of factor $\mathrm{V}$ by thrombin or meizothrombin(desF1) is hardly affected by the presence of phospholipid, we conclude that the stimulation in the case of R155A meizothrombin is due to the fact that both the enzyme (R155A meizothrombin) and the substrate (factor $V$ ) bind to the membrane surface. This simultaneous binding promotes the interaction between two poorly interacting components (R155A meizothrombin and factor $V$ ), which results in an increased rate of factor $V$ activation. Such a mechanism of action of membranes has also been proposed for other phospholipid-dependent coagulation factor activations ${ }^{23}$.

The final product of both thrombin- and R155A meizothrombin-catalyzed activation of factor $V$ is a factor Va molecule that consists of the characteristic heavy- and light chains. There are, however, some differences in the pattern of high molecular weight intermediate generation in the early phase of the activation reaction. Gel electrophoretic analysis (Fig. 2.4) shows that thrombin activates factor $V$ via $M_{1} 280,000$ and 220,000 intermediates (designated $A_{1}$ and $B$ in Ref. 1) by successive cleavage of peptide bonds 1, 2 and 3 (Fig. 2.5). The $M_{r} 280,000$ intermediate is, however, hardly formed during factor $V$ activation by R155A meizothrombin. This indicates that, under these conditions, there is a change in either the rate or the order of peptide bond cleavages during factor $V$ activation.

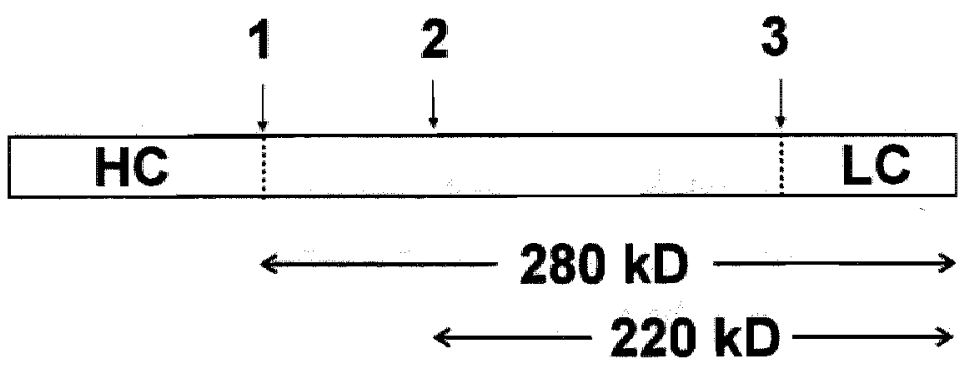

Fig. 2.5 Peptide bonds cleaved by thrombin during factor $V$ activation. The heavy and light chain of factor Va are indicated by $H C$ and $L C$, respectively.

Such an effect may be specific for situations in which membrane-bound factor $V$ is activated by a membrane-bound enzyme since a similar activation pattern (i.e. reduced $\mathrm{M}_{\mathrm{r}} 280,000$ intermediate formation) was also obsenved in the case of phospholipid-dependent activation of factor $\mathrm{V}$ by factor $\mathrm{Xa}^{6}$. A phenomenon like this may be caused by a steric or juxtaposing effect that results from coordinate binding of substrate and enzyme to the membrane surface. 
The observations that meizothrombin-catalyzed factor $V$ activation occurs at a membrane surface via a peptide bond cleavage pattern that differs from that of factor $V$ activation by thrombin may explain why time courses of factor $V a$ formation are biphasic in case of meizothrombin and monophasic in the case of thrombin. Recently, we reported that factor $V$ preparations contain two forms of factor $V$ with different affinities for negatively charged membranes ${ }^{18}$. Although there may be several explanations for biphasic time courses of product generation during pseudo first-order reactions, we would like to mention two possibilities that relate to the observations mentioned above: 1) fast generation of an activation intermediate with a cofactor activity that is lower than that of a slowly formed end product (factor $\mathrm{Va}$ ) or 2) fast activation of the factor $V$ that binds with high affinity to phospholipid, followed by slow activation of the factor $V$ molecules that have a low affinity for phospholipid.

The data presented in this chapter show that meizothrombin is a potent factor $V$ activator in the presence of phospholipids. The rate constant of R155A meizothrombin-catalyzed factor $V$ activation $\left(18 \times 10^{6} \mathrm{M}^{-1} \mathrm{~s}^{-1}\right)$ even exceeds those determined for activation by thrombin $\left(4 \times 10^{6} \mathrm{M}^{-1} \mathrm{~s}^{-1}\right.$, this chapter and ref. 6) or factor $\mathrm{Xa}\left(3.26 \times 10^{6} \mathrm{M}^{-1} \mathrm{~s}^{-1}\right.$, ref. 6). Since the first prothrombin molecules that are activated during coagulation in whole blood are likely converted into meizothrombin ${ }^{15}$, meizothrombin should be considered as a physiologically important factor $V$ activator with a major function during the phase of coagulation in which the prothrombinase complex is generated. 


\section{References}

1. Dahlback B. Human coagulation factor $\vee$ purification and thrombin-catalyzed activation. J Clin Invest 1980; 66, 583-591

2. Kane WH and Majerus PW. Purification and characterization of human coagulation factor $V$. J Biol Chem 1981; 256, 1002-1007

3. Esmon $C T$. The subunit structure of thrombin-activated factor $V$. Isolation of activated factor $V$, separation of subunits and reconstitution of biological activity. J Biol Chem 1979; 254, 964-973

4. Nesheim ME and Mann KG. Thrombin-catalyzed activation of single chain bovine factor $V$. I Biol Chem 1979, 254, 1326-1334

5. Suzuki $K$, Dahibäck $B$ and Stenflo J. Thrombin-catalyzed activation of human coagulation factor $V$. J Biol Chem 1982; 257, 6556-6564

6. Monkovic DD and Tracy PB. Activation of human factor $\mathrm{V}$ by factor $\mathrm{Xa}$ and thrombin. Biochemistry 1990;29,1118-1128

7. Nesheim ME, Taswell JB and Mann KG. The contribution of bovine factor $V$ and factor $\mathrm{Va}$ to the activity of the prothrombinase. J Biol Chem 1979; 254, 10952-10962

8. Rosing J, Tans G, Govers-Riemslag JWP, Zwaal RFA and Hemker HC. The role of phospholipids and factor $\mathrm{Va}$ in the prothrombinase complex. $\mathrm{J} \mathrm{Biol}$ Chem 1980; 255, 274-283

9. van Riljn JLML, Govers-Riemslag JWP, Zwaal RFA and Rosing J. Kinetic studies of prothrombin activation: effect of factor $\mathrm{Va}$ and phospholipids on the formation of the enzyme-substrate complex. Biochemistry 1984;23, 4557-4564

10.Pieters $\mathrm{J}$ and Lindhout $\mathrm{T}$. The limited importance of factor $\mathrm{Xa}$ inhibition to the anticoagulant property of heparin in thromboplastin-activated plasma. Blood $1988 ; 72,2048-2052$

11. Esmon $\mathrm{CT}$. The roles of protein $\mathrm{C}$ and thrombomodulin in the regulation of blood coagulation. J Biol Chem 1989; 4743-4746

12.Rosing J, Zwaal RFA and Tans G. Formation of meizothrombin as intermediate in factor Xa-catalyzed prothrombin activation. J Biol Chem 1986; $261,4224-4228$

13.Krishnaswamy S, Mann KG and Nesheim ME. The prothrombinase-catalyzed activation of prothrombin proceeds through the intermediate meizothrombin in an ordered, sequential reaction. J Biol Chem 1986; 261, 8977-8984

14.Tans $G$, Janssen-Claessen T, Hemker HC, Zwaal RFA and Rosing J. Meizothrombin formation during factor Xa-catalyzed prothrombin activation. Formation in a purified system and in plasma. J Biol Chem 1991; 266, 2186421873

15.Bovill EG, Tracy RP, Hayes T, Jenny RJ, Bushan F and Mann KG Thromb Haemostasis 1993;" 69, 779

16. Doyle EF and Mann KG. Multiple active forms of thrombin. IV. Relative activities of meizothrombin. J Bial Chem 1990; 265, 10693-10701

17. Rhee MJ, Morris S and Kosow DP. Role of meizothrombin and meizothrombin(des $\mathrm{F}_{1}$ ) in the conversion of prothrombin to thrombin by the Echis carinatus venom coagulant. Biochemistry 1982; $21,3437-3443$ 
18.Rosing J, Bakker HM, Thomassen MCLGD, Hemker HC and Tans G. Characterization of two forms of human factor Va with different cofactor activities. J Biol Chem 1993; 268, 21130-21136

19. Horrevoets AJG, Tans G, Smilde AE, van Zonneveld AJ and Pannekoek $H$. Thrombin-variable region 1 (VR1). Evidence for the dominant contribution of VR1 of serine proteases to their interaction with plasminogen activator inhibitor 1. J Biol Chem 1993; 268, 779-782.

20. Ho SN, Hunt HD " Horton RM mutagenesis by overlap extension using the polymerase chain reaction. Gene $1989 ; 77,51-59$

21. Walls JD, Berg DT, Yan SB and Grinnell BW. Amplificiation of multicystronic plasmids in the human 293 cell line and secretion of correctly processed recombinant human protein C. Gene 1989; 81, 139-149

22. Kuwada $\mathrm{M}$ and Katayama K. An improved method for the determination of gamma-carboxyglutamic acid in proteins, bone, and urine. Anal Blochem 1983; $131,173-179$

23.Mann KG, Nesheim M E, Church W R, Haley P and Krishnaswamy S. Surtace dependent reactions of the vitamin K-dependent enzyme complexes. Blood $1990 ; 76,1-16$. 


\section{Chapter 3}

\section{Molecular Events in the Cleavage of FVa and $\mathrm{FVa}_{\text {Leiden }}$ by Activated Protein $\mathrm{C}$}

Based on: Peptide Bond Cleavages and Loss of Functional Activity During Inactivation of Factor Va and Factor VaR506Q by Activated Protein C, Journal of Biological Chemistry 1995 , 270 (36), 21158-21166

reprinted with permission of the publisher 


\subsection{Summary}

Factor $V$ was purified from the plasma of an APC-resistant patient who is homozygous for the mutation Arg ${ }^{506} \rightarrow$ Gin (factor $V R 506 Q$ ). Factor $V R 506 Q$ was converted by thrombin into factor Va which was further purified yielding a factor Va preparation that had the same cofactor activity in prothrombin activation as normal factor $\mathrm{Va}$. Inactivation of low concentrations of normal factor $\mathrm{Va}(<5 \mathrm{nM})$ by $0.15 \mathrm{nM}$ activated protein $\mathrm{C}(\mathrm{APC})$ in the presence of phospholipid vesicles proceeded via a biphasic reaction that consisted of a rapid phase $\left(k=4.3 \times 10^{7} \mathrm{M}^{-1} \mathrm{~s}^{-1}\right)$, yielding a reaction intermediate with reduced cofactor activity that was fully inactivated during the subsequent slow phase $\left(\mathrm{k}=2.3 \times 10^{6} \mathrm{M}^{-1} \mathrm{~s}^{-1}\right)$. Inactivation of factor $\mathrm{Va} R 506 \mathrm{Q}$ proceeded via a monophasic reaction $\left(k=1.7 \times 10^{6} \mathrm{M}^{-1} \mathrm{~s}^{-1}\right.$ ). Immunoblot analysis showed that APC-catalyzed inactivation of factor $V a$ occurred via peptide bond cleavages in the heavy chain. The rapid phase of inactivation of normal factor $\mathrm{Va}$ was associated with cleavage at Arg 506 and full inactivation of factor $\mathrm{Va}$ required subsequent cleavage at $\mathrm{Arg}^{306}$. The slow monophasic inactivation of factor $\mathrm{Va} \mathrm{R} 506 \mathrm{Q}$ correlated with cleavage at $\mathrm{Arg}^{306}$. Cleavage at $\mathrm{Arg}^{506}$ in normal factor $\mathrm{Va}$ resulted in accumulation of a reaction intermediate that exhibited $40 \%$ cofactor activity in prothrombin activation mixtures that contained a high factor $\mathrm{Xa}$ concentration $(5 \mathrm{nM})$. Compared with native factor $\mathrm{Va}$, the reaction intermediate retained virtually no cofactor activity at low factor $\mathrm{Xa}$ concentrations $(0.3 \mathrm{nM})$. This demonstrates that factor $V a$ that is cleaved at Arg 506 is impaired in its ability to interact with factor Xa. MichaelisMenten kinetic analysis showed that cleavage at Arg 506 in membrane-bound factor $V a$ was characterized by a low $K_{m}$ for factor $V a(20 \mathrm{nM})$ and $\mathrm{k}_{\text {cat }}=$ $0.96 \mathrm{~s}^{-1}$. For cleavage at $\mathrm{Arg}^{306}$ in factor $\mathrm{VaR} 506 \mathrm{Q}$ the kinetic parameters were $\mathrm{Km}=196 \mathrm{nM}$ and $\mathrm{k}_{\mathrm{cat}}=0.37 \mathrm{~s}^{-1}$. This means that differences between APC-catalyzed inactivation of factors $\mathrm{Va}$ and $\mathrm{VaR506Q}$ will become much less pronounced at high factor $\mathrm{Va}$ concentrations. When factor $\mathrm{VaR} 506 \mathrm{Q}$ was inactivated by APC in the absence of phospholipids, cleavage at Arg679 of the heavy chain also contributed to factor Va inactivation. Comparison of rate constants for APC-catalyzed cleavage at $\mathrm{Arg}^{306}$, Arg 506 and $\mathrm{Arg}^{679}$ in the absence and presence of phospholipids indicated that phospholipids accelerated these cleavages to a different extent. This indicates that the binding of factor $\mathrm{Va}$ to phospholipids changes the accessibility of the cleavage sites and/or the sequence of peptide bond cleavage by APC. 


\subsection{Introduction}

Human blood coagulation factor $\mathrm{Va}$ is a heterodimeric glycoprotein ${ }^{1}$ that consists of a heavy chain $\left(M_{r}=105,000\right)$ associated via a single $\mathrm{Ca}^{2}+$ ion with a light chain $\left(M_{r}=74,000\right.$ or 72,000 , cf. ref $\left.{ }^{2}\right)$. Factor $V a$ is formed during hemostasis from the inactive procofactor $V$ after limited proteolysis. Factor $\mathrm{Va}$ is an essential nonenzymatic cofactor of the prothrombin-activating complex, which further comprises the serine protease factor $\mathrm{Xa}$, calcium ions and a procoagulant membrane surface. Depending on the reaction conditions factor $\mathrm{Va}$ accelerates prothrombin activation $10^{3-10^{5}} \mathrm{fold}^{3-5}$.

Proteolytic inactivation of factor Va by activated protein C (APC), is one of the key reactions in the regulation of thrombin formation. APC-catalyzed cleavage of factor $\mathrm{Va}$ is stimulated by the presence of negatively charged membrane surfaces ${ }^{6-8}$ and by the protein cofactor, protein $S^{8-10}$. The loss of cofactor activity of factor $\mathrm{Va}$ is associated with peptide bond cleavages in the heavy chain of factor $\mathrm{Va}$ at $\mathrm{Arg}^{306}, \mathrm{Arg}^{506}$ and $\mathrm{Arg}{ }^{679^{11,12}}$. The physiologic importance of the down-regulation of factor Va activity by APC is underscored by the abservation of recurrent thromboembolic events in individuals that are deficient in either protein $\mathrm{C}$ or protein $\mathrm{S}^{13-15}$.

Since a first publication by Dahlbäck et al. ${ }^{16}$, several laboratories have associated the occurrence of familial thrombophilia in a large group of patients with a poor anticoagulant response to APC (APC resistance). APC resistance is at least 10 times more common than all other known genetic thrombosis risk factors together and has an allelic frequency of $-2 \%$ in the Dutch population ${ }^{17}$. The molecular defect in APC-resistant patients was recently demonstrated ${ }^{78-21}$ to be linked to a single point mutation in the factor $V$ gene that causes an amino acid substitution (Arg506 $\rightarrow$ Gin) at a site that is cleaved during APC-catalyzed inactivation of factor $\mathrm{Va}^{11}$.

In this chapter we present a kinetic analysis of APC-catalyzed inactivation of human factor $V a$ that was either obtained from normal plasma or from the plasma of a patient who is homozygous for the mutation (Arg506 $\rightarrow$ Gln). Parallel experiments were performed in which changes of functional activity of factor Va during inactivation by APC were correlated with the cleavage of peptide bonds in the factor Va molecule. This study was undertaken in order to elucidate the consequences of the molecular defect in factor $V$ for the regulation of in vivo prothrombin activation. 


\subsection{Materials and Methods}

\section{Materials}

Hepes, Tris, bovine serum alburmin and Russel's viper venom were purchased from Sigma Chemical Co., USA. DOPC and DOPS were obtained from Avanti Polar Lipids, Pelham, AL., USA. The chromogenic substrates S2238 and S2366 were supplied by Chromogenix, Mölndal, Sweden. PPACK was obtained from Calbiochem and p-NPGB was from Nutritional Biochernicals. Micro BCA protein assay kits were from Pierce, Rockford, USA. FPLC equipment and column materials used for protein purification were purchased from Pharmacia, Uppsala, Sweden.

\section{Proteins}

Human coagulation factors used in this study were isolated from fresh frozen plasma. Human prothrombin and factor $\mathrm{X}$ were purified according to DiScipio et all. ${ }^{22}$. Human thrombin was prepared from prothrombin activation mixtures as described by Pletcher and Nelsestuen ${ }^{23}$. Human factor Xa was obtained from purified factor $X$ after activation with RVV-X and isolation from the activation mixture by affinity chromatography on soybean trypsin inhibitorSepharose ${ }^{24}$. RVV-X was purified from Russel's viper venom according to Schiffman et al. ${ }^{25}$. Protein $\mathrm{C}$ was purified and activated as described by Gruber et al. ${ }^{26}$. The first steps of the preparation of human factor $V$ and factor VR506Q were essentially as described by Dahlbäck ${ }^{27}$ with minor modifications ${ }^{28}$. The factor $V$ (in $25 \mathrm{mM}$ Hepes $\mathrm{pH} 7.5,50 \mathrm{mM} \mathrm{NaCl}, 5 \mathrm{mM}$ $\mathrm{CaCl}_{2}$ ) thus obtained was applied to a Resource $\mathrm{S}$ column and eluted with 20 $\mathrm{ml}$ of a linear gradient ( $50 \mathrm{mM}-1000 \mathrm{mM} \mathrm{NH}_{4} \mathrm{Cl}$ ) in $25 \mathrm{mM}$ Hepes (pH 6.5), 5 $\mathrm{mM} \mathrm{CaCl} 2$. Aliquots from column fractions were incubated for 15 min with 5 $\mathrm{nM}$ thrombin and factor Va-containing fractions were pooled. Factor Va was prepared by incubating factor $V(33 \mu \mathrm{g} / \mathrm{ml})$ for $20 \mathrm{~min}$ with $5 \mathrm{nM}$ thrombin in $25 \mathrm{mM}$ Hepes (pH 7.5), $175 \mathrm{mM} \mathrm{NaCl}$ and $5 \mathrm{mM} \mathrm{CaCl}_{2}$. After activation 15 nM PPACK was added to inhibit thrombin. Factor Va was further subjected to fast protein liquid chromatography (FPLC) on a Mono $S$ column (HR 5/5) at room temperature ${ }^{2}$. The factor $\mathrm{Va}$ bound to the Mono $\mathrm{S}$ column was eluted with $15 \mathrm{ml}$ of a linear gradient $\left(50 \mathrm{mM}-1000 \mathrm{mM} \mathrm{NH}_{4} \mathrm{Cl}\right)$ in $25 \mathrm{mM}$ Hepes $(\mathrm{pH} 7.5), 5 \mathrm{mM} \mathrm{CaCl}_{2}$. Factor $\mathrm{Va}$ activity eluted from the column in two wellseparated protein peaks containing factor Va with light chains of $M_{r}=74,000$ and $M_{r}=71,000$, respectively ${ }^{2}$. The two factor $V a$ containing peaks were pooled and brought into $25 \mathrm{mM}$ Hepes (pH 7.5), $175 \mathrm{mM} \mathrm{NaCl}, 5 \mathrm{mM} \mathrm{CaCl} 2$ 
by a buffer exchange on a PD-10 column. Factor $V$ and factor Va from an APC-resistant patient were purified by the same methods. The patient was a female with a history of deep vein thrombosis and pulmonary embolism. Plasma from the patient was obtained by plasmapheresis. The APCresistance ratio was 1.31 (Coatest APC-resistance kit, Chromogenix, Mölndal, Sweden). The patient was identified as homozygous for the substitution $\mathrm{G}^{1691} \rightarrow \mathrm{A}$ in the factor $\mathrm{V}$ gene (amino acid substitution Arg509 $\rightarrow$ Gin in factor V) by genetic analysis in genomic DNA samples isolated from peripheral blood $^{29}$.

\section{Protein Concentrations}

Protein concentrations were determined with the micro BCA protein assay $^{30}$. Molar thrombin and factor $X a$ concentrations were determined by active site titration with $\mathrm{p}-\mathrm{NPGB}^{31_{0} 32}$. Prothrombin concentrations were determined after complete activation of prothrombin with Echis carinatus venom and quantitation of thrombin with p-NPGB. APC concentrations were determined with S2366 using kinetic parameters reported by Sala et al. ${ }^{33}$ Factor $V$ and factor $V a$ were quantitated as described below.

\section{Phospholipid Vesicle Preparations}

Small unilamellar phospholipid vesicles were prepared as described earlier ${ }^{2}$. Phospholipid concentrations were determined by phosphate analysis $^{34}$.

\section{Gel Electrophoretic and Immunoblot Analysis}

Purity of protein preparations was analyzed by SDS-PAGE on $8 \%$ acrylamide slabgels ${ }^{35}$ and staining with Coomassie Brilliant Blue R-250. The inactivation patterns of factor $\mathrm{Va}$ were analyzed after SDS.PAGE, electrophoretic transfer of proteins from the gel to Immobilon-P membranes and visualization with a polyclonal rabbit-antibody directed against the heavy chain of factor $\mathrm{Va}$ and goat-anti-rabbit IgG conjugated with alkaline phosphatase as described by Blake et $\mathrm{al}^{38}$. 


\section{Factor Va Assay}

Factor $\mathrm{Va}$ cofactor activity was quantitated by determining the rate of factor Xa-catalyzed prothrombin activation in reaction mixtures that contained a limiting amount of factor $\mathrm{Va}$, a saturating concentration factor $\mathrm{Xa}(5 \mathrm{nM}), 50$ $\mu \mathrm{M}$ phospholipid vesicles (DOPS/DOPC, 10/90, mol/mol) and $0.5 \mu \mathrm{M}$ prothrombin $^{28}$. Rates of prothrombin activation were determined with the chromogenic substrate $\$ 2238^{4}$. The molar factor $\mathrm{Va}$ concentration in the assay mixture was calculated from the rate of prothrombin activation using a tumover number of 6000 moles prothrombin activated per min per mole of factor XaVa complex ${ }^{37}$. Factor $V$ was quantitated by the same method after activation with 5 nM thrombin.

\section{Kinetic Data Analysis}

The formation of a membrane-bound factor XaVa complex was determined by measuring rates of prothrombin activation in the presence of phospholipid vesicles at a fixed (limiting) concentration of factor $\mathrm{Va}$ and varying amounts of factor $\mathrm{Xa}$. Factor $\mathrm{Xa}$, factor $\mathrm{Va}$ and phospholipid vesicles were preincubated for $5 \mathrm{~min}$ at $37^{\circ} \mathrm{C}$ in $25 \mathrm{mM} \mathrm{Hepes}(\mathrm{pH} 7.5), 175 \mathrm{mM} \mathrm{NaCl}$, $2 \mathrm{mM} \mathrm{CaCl}_{2}$ and $5 \mathrm{mg} / \mathrm{ml} \mathrm{BSA}$. Prothrombin activation was started by the addition of prothrombin (preincubated at $37^{\circ} \mathrm{C}$ in the same buffer) and rates of prothrombin activation were determined with the chromogenic substrate $S 2238^{4}$. The apparent $K_{d}$ for dissociation of the membrane-bound factor $X a-$ Va complex $\left(\mathrm{K}_{1 / 2} \mathrm{Xa}_{\mathrm{a}}\right)$ was obtained from plots of the rate of prothrombin activation as function of the factor $X a$ concentration that were fitted to the equation for a single site binding isotherm (hyperbola) via non-linear least squares regression analysis..

The kinetic parameters $\left(\mathrm{K}_{\mathrm{m}}\right.$ and $\left.V_{\max }\right)$ for factor Xa-catalyzed prothrombin activation were determined by measuring the rate of thrombin formation at varying prothrombin concentrations in the presence of a fixed phospholipid concentration, a limiting amount of factor $\mathrm{Xa}$ and a saturating concentration of factor $\mathrm{Va}$ as described in the previous paragraph. The kinetic parameters were obtained by fitting the data to the Michaelis-Menten equation using non-linear least squares regression analysis. 


\section{Curve Fitting of Pseudo-first Order Time Courses of Factor Va Inactivation}

Time courses of factor $\mathrm{Va}$ or factor $\mathrm{VaR506 \textrm {Q }}$ inactivation by APC were determined by following the loss of cofactor activity of factor $\mathrm{Va}$ as a function of time. Data reported in literature ${ }^{11,12}$ and in this chapter demonstrate that the loss of factor Va cofactor activity can proceed via 2 pathways:

$$
\text { Factor } \mathrm{Va} \stackrel{\mathrm{k}_{1}}{\longrightarrow} \text { Factor } \mathrm{Va}_{\mathrm{int}} \stackrel{\mathrm{k}_{2}}{\longrightarrow} \text { Factor } \mathrm{Va}_{\mathrm{i}}
$$

$$
\text { Factor } \mathrm{Va} \stackrel{\mathrm{k}_{3}}{\longrightarrow} \text { Factor } \mathrm{Va}_{\mathrm{i}}
$$

in which factor $V a_{i n t}$ is a reaction intermediate with partial cofactor activity, factor $\mathrm{Va}_{\mathrm{i}}$ is a reaction product that has no cofactor activity, $\mathrm{k}_{1}$ is the second order rate constant for cleavage of peptide bond $1, k_{2}$ is the second order rate constant for cleavage of peptide bond 2 in factor $V a_{i n t}$ and $k_{3}$ is the second order rate constant for cleavage of peptide bend 2 in native factor $\mathrm{Va}$.

Under first order conditions, i.e. conditions at which the inactivation rate is directly proportional to the factor Va and APC concentrations, the loss of cofactor activity is described by equation $3^{38}$ :

$$
V a_{t}=V a_{0} * e^{-\left(k_{1}+k_{3}\right) * t}+B * V a o * \frac{k_{1} * e^{\left(-k_{2} * t\right)}}{\left(k_{1}+k_{3}-k_{2}\right)} *\left(1-e^{\left\{-\left(k_{1}+k_{3}-k_{2}\right) \cdot t\right\}}\right)
$$

in which $V a_{t}$ is the cofactor activity determined at time $t, V_{a}$ is the cofactor activity determined before APC is added, B is the cofactor activity of factor $\mathrm{Va}_{\text {int }}$ (expressed as fraction of the cofactor activity of native factor $\mathrm{Va}$ ) and $k_{1}, k_{2}$ and $k_{3}$ are the rate constants defined above. The rate constants and the cofactor activity of factor $V a_{\text {int }}$ were obtained by fitting the data to equation 3 using non-linear least squares regression analysis.

In the case of normal factor $\mathrm{Va}$ inactivation, $\mathrm{k}_{3}$ appeared to be associated with cleavage of the peptide bond at $\mathrm{Arg}^{306}$. Therefore, time courses of normal factor $V a$ inactivation were fitted with a fixed $k_{3}$, obtained from kinetic analysis of factor $\mathrm{Va}_{\mathrm{a}} \mathrm{R} 506 \mathrm{Q}$ inactivation. 
In some experiments (factor $\mathrm{Va}$ inactivation in free solution) there was a slow loss of factor Va cofactor activity in the absence of APC. In these cases the spontaneous loss of cofactor activity $(0.4 \% / \mathrm{min})$ was added to $\mathrm{k}_{3}$.

\subsection{Results}

\section{Peptide Bonds in Factor Va Susceptible to Proteolysis by APC}

Recently it was reported ${ }^{11}$ that APC can cleave 3 peptide bonds in the heavy chain of human factor $\mathrm{Va}$ that are located at $\mathrm{Arg}^{306}, \mathrm{Arg}^{506}$ and Arg679. Fig. 3.1 represents a schematic diagram of the heavy chain of factor $\mathrm{Va}$ in which we have depicted the sites that are susceptible to APC and the molecular weights of possible cleavage products. In the present chapter we will refer to the rate constants associated with the indicated peptide bond cleavages as $k_{306}, k_{506}$ and $k_{679}$, respectively.

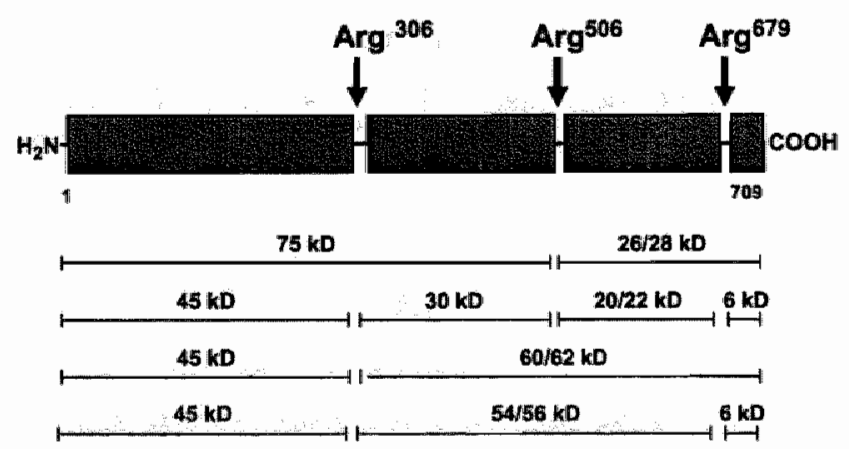

FiG. 3.1 Schematic representation of APC cleavage sites in the heavy chain of factor Va. The heavy chain of human factor Va contains three peptide bonds that can be cleaved by $A P C$ and that are located at $\mathrm{Arg}^{306}, \mathrm{Arg}^{506}$ and $\mathrm{Arg}^{679}$. The molecular weights of possible cleavage products correspond to those given in other publications ${ }^{11,12}$.

\section{Structural and Functional Properties of Factor Va Purified from Normal and from APC-Resistant Plasma}

Factor $V$ and thrombin-activated factor $V a$ were purified from normal and homozygous APC-resistant plasma as described in the Materials and Methods. The thrombin-activated factor $\mathrm{Va}$ and factor $\mathrm{Va}$ R506Q preparations had identical gel electrophoretic properties with the characteristic heavy chain 
with $M_{r}=105,000$ and a light chain doublet at $M_{r}=74,000$ and 71,000 (data not shown).

Factor $\mathrm{Va}$ and factor $\mathrm{VaA506Q}$ had similar cofactor activities in prothrombin activation. Kinetic analysis showed that prothrombin was activated in the presence of $25 \mu \mathrm{M}$ phospholipid vesicles (DOPS/DOPC, $10 / 90, \mathrm{~mol} / \mathrm{mol}$ ) with the following kinetic parameters: $K_{\mathrm{m}}$ for prothrombin $=$ $0.13 \mu \mathrm{M}, \mathrm{K}_{\text {cat }}=8570 \mathrm{~min}^{-1}$ and $\mathrm{K}_{1 / 2 \mathrm{Xa}_{\mathrm{a}}}$ of $\mathrm{XaVa}_{\mathrm{a}}$ complex formation $=0.083$ $\mathrm{nM}$ for prothrombinase complexes with normal factor $\mathrm{Va}$ and $\mathrm{K}_{\mathrm{m}}$ for prothrombin $=0.12 \mu \mathrm{M}, \mathrm{k}_{\text {cat }}=8450 \mathrm{~min}^{-1}$ and $\mathrm{K}_{1 / 2} \mathrm{Xa}$ of XaVa complex formation $=0.105 \mathrm{nM}$ for prothrombinase complexes with factor $\mathrm{Va} A 506 \mathrm{Q}$ (data not shown).

This means that the factor Va assay that we used, which measures the cofactor activity of factor $\mathrm{Va}$ in prothrombin activation, allows quantitative comparison of factor $\mathrm{Va}$ and factor $\mathrm{VaR} 506 \mathrm{Q}$.

\section{Kinetic Analysis of APC-Catalyzed Inactivation of Membrane-Bound Factor Va and Factor VaR506Q}

Time courses of APC-catalyzed inactivation of factor $\mathrm{Va}$ and factor $\mathrm{Va} R 506 \mathrm{Q}$ in the presence of phospholipid vesicles are shown in Fig. 3.2.
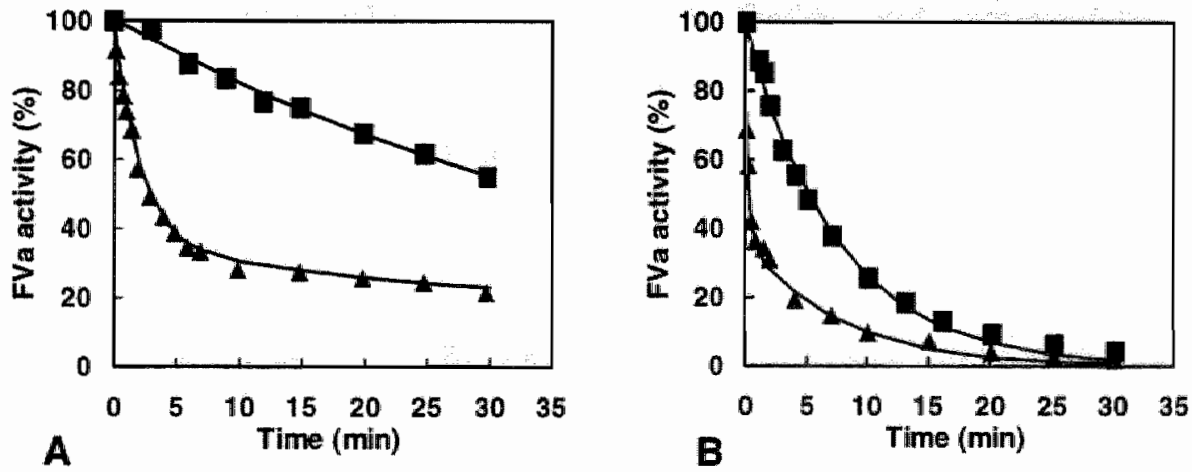

FIG. 3.2 Inactivation of factor Va and factor VaR5060 by $A P C$ in the presence of

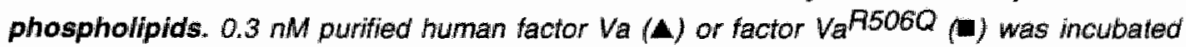
with (A) $0.15 \mathrm{nM} A P C$ or (B) $1.5 \mathrm{nM} A P C$ and $25 \mu \mathrm{M}$ phospholipid vesicles (DOPS/DOPC, 10/90, mol/mol) in $25 \mathrm{mM}$ Hepes (pH 7.5), $175 \mathrm{mM} \mathrm{NaCl}, 3 \mathrm{mM} \mathrm{CaCl} / 2$ and $5 \mathrm{mg} / \mathrm{ml} \mathrm{BSA}$ at 37 ${ }^{\circ} \mathrm{C}$. At the indicated time points factor $\mathrm{Va}$ activity was determined as described in the "Materials and Methods". The solid lines represent exponential curves obtained after fitting the data using equation 3 given in the "Materials and Methods". The rate constants and activity of the reaction intermediate were determined by nonlinear least-squares regression of the data. 
At a low APC concentration $(0.15 \mathrm{nM})$ normal factor $V a$ was inactivated via a biphasic reaction during which $50 \%$ of the factor Va activity was lost within $3 \mathrm{~min}$. Factor $\mathrm{Va} R 506 \mathrm{Q}$ is inactivated at a considerably lower rate requiring more than $45 \mathrm{~min}$ for $50 \%$ loss of cofactor activity (Fig. 3.2A). When a similar experiment was performed at a high APC concentration (1.5 $\mathrm{nM}$ ) inactivation of factor $\mathrm{VaR506Q}$ appeared to occur via a monophasic reaction (the data points could be fitted with a single exponential), whereas the inactivation of normal factor Va still proceeded via a biphasic reaction (fig. 3.2B).

The time courses of factor $\mathrm{Va}$ and $\mathrm{Va} \mathrm{R} 506 \mathrm{Q}$ inactivation (\% factor $\mathrm{Va}$ activity $v s$. time) were not affected by varying the concentrations of factor $\mathrm{Va}$ or $\mathrm{VaR506Q}$ between 0 and $5 \mathrm{nM}$. Since the rates of factor $\mathrm{Va}$ inactivation were also directly proportional to the arnount of APC present (0.05- $5 \mathrm{nM})$ we concluded that factor $\mathrm{Va}$ and $\mathrm{Va} \mathrm{R} 506 \mathrm{Q}$ inactivation were first-order in both factor $\mathrm{Va}(\mathrm{VaR506Q})$ and $\mathrm{APC}$. This allows calculation of apparent secondorder rate constants for factor $\mathrm{Va}$ inactivation from time courses such as shown in Fig. 3.2.

On the basis of literature data ${ }^{11,12}$ and experiments presented below it can be postulated that the biphasic time courses of inactivation of normal factor Va presented in Fig. 3.2 result from rapid cleavage at Arg 506 yielding a reaction intermediate that possesses partial cofactor activity in prothrombin activation. This reaction intermediate is fully inactivated by subsequent slow cleavage at $\mathrm{Arg}^{306}$. Inactivation of factor $\mathrm{Va} \mathrm{R} 506 \mathrm{Q}$ likely proceeds via a monophasic reaction that is the result of slow cleavage at Arg 306 .

The time courses of inactivation could indeed be fitted (Fig. 3.2, solid lines) using an equation that describes the time-dependent loss of cofactor activity when factor $\mathrm{Va}$ is inactivated via the random ordered two-step reaction model described in the "Materials and Methods". The fits of the particular experiment presented in Fig. 3.2 yielded the following second-order rate constants: $k_{506}$ $=4.7 \times 10^{7} \mathrm{M}^{-1} \mathrm{~s}^{-1}, \mathrm{k}_{306}=1.7 \times 10^{6} \mathrm{M}^{-1} \mathrm{~s}^{-1}$ and $40 \%$ cofactor activity for the reaction intermediate (factor Va cleaved at $\mathrm{Arg}{ }^{506}$ ) in the case of normal factor $V a$ inactivation and $k_{306}=1.4 \times 10^{6} \mathrm{M}^{-1} \mathrm{~s}^{-1}$ and a reaction product that has virtually lost its cofactor activity in the case of factor $\mathrm{Va}_{a} \mathrm{R} 506 \mathrm{Q}$ inactivation.

\section{Immunoblot Analysis of APC-Catalyzed Inactivation of Membrane- Bound Factor Va and Factor VaR506Q}

Generation of heavy chain fragments during APC-catalyzed factor Va and factor $\mathrm{VaR506Q}$ inactivation was analyzed by SDS-PAGE, transfer to Immobilon-P membranes and visualization of the reaction products with a 
polyclonal antibody directed against the heavy chain domain of human factor Va (Fig. 3.3).

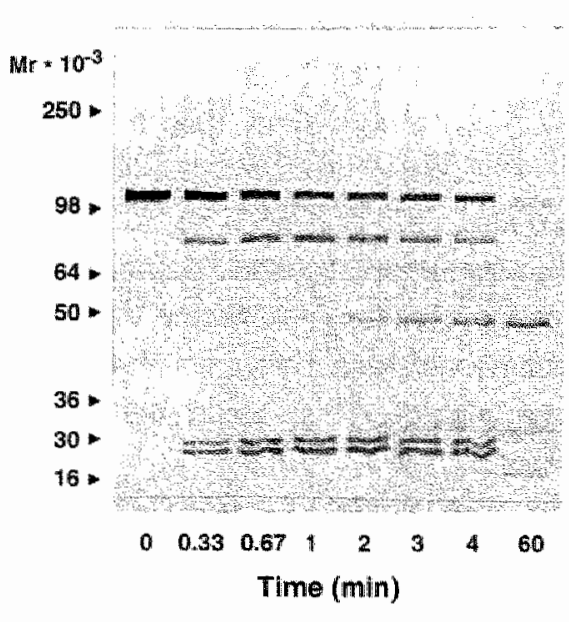

A

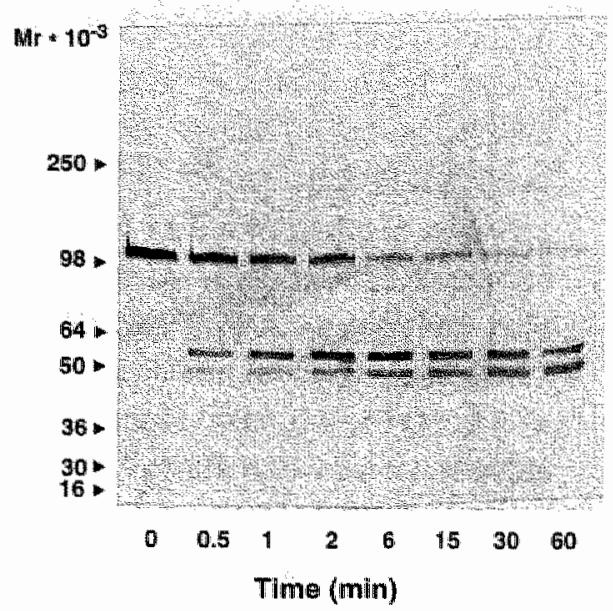

B

FIG. 3.3 Immunoblot analysis of factor $V a$ and factor $V a R 506 Q$ inactivation by APC in the presence of phospholipids. (A) 6 nM purified human factor Va and $1 \mathrm{nM} A \mathrm{APC}$ or (B) 15 $n M$ factor $V_{a} R 506 Q$ and $5 n M A P C$ were incubated with $25 \mu M$ phospholipid vesicles (DOPS/DOPC, 10/90, mol/mol) in $25 \mathrm{mM}$ Hepes ( $p \mathrm{H} 7.5$ ), $175 \mathrm{mM} \mathrm{NaCl}, 3 \mathrm{mM} \mathrm{CaCl}$ and 0.1 mg/ml BSA at $37^{\circ} \mathrm{C}$. In the case of normal factor Va (A) the APC concentration was increased to $110 \mathrm{nM}$ after $5 \mathrm{~min}$. At the indicated time intervals samples from the inactivation mixture were subjected to SDS-PAGE. After transfer to Immobilon-P membranes, the heavy chain and derived fragments were visualized' with a polyclonal antibody directed against the heavy chain of factor Va. The positions of the molecular weight markers are indicated at left of Panels $\mathrm{A}$ and $\mathrm{B}$. The percentages cofactor activity at the indicated time points were (A) 100,63,46, 40, $25,19,17$, and $0 \%$ and (B) $100,80,67,43,12,3,2$, and $1 \%$. Further experimental details are described under "Materials and Methods".

In the description of the gell patterns presented below, the formation of reaction products was associated with peptide bond cleavages at $\operatorname{Arg}^{306}$, Arg 506 or Arg 679 on the basis of molecular weights of heavy chain fragments indicated in Fig. 3.1.

During the initial phase of inactivation of normal factor $\mathrm{Va}$, reaction products with $M_{r}$ of 75,000 and $26,000 / 28,000$ were formed, which is indicative of cleavage at $\mathrm{Arg}^{506}$ (Fig. 3.3A). Prolonged incubation of factor Va with a high APC concentration resulted in the disappearance of the $M_{r}=$ 75,000 reaction intermediate (cleavage at $\mathrm{Arg}^{306}$ ) and formation of reaction products with $M_{r}$ of 45,000 and 30,000 , respectively. The fragment with $M_{r}=$ 30,000 stains poorly with our polyclonal antibody and was hardly visible on 
the gel. During the final stage of the inactivation reaction the peptide bond at Arg679 was also cleaved, as is indicated by the disappearance of the $M_{\mathrm{r}}=$ $26,000 / 28,000$ doublet and the formation of low molecular weight products migrating with the dye front in the gel.

The immunoblot of the time course of APC-catalyzed inactivation of membrane-bound factor $V_{a} R 506 Q$ (Fig. 3.3B) differs from that of normal factor $\mathrm{Va}$. Inactivation of factor $\mathrm{VaR} 506 \mathrm{Q}$ correlated with the appearance of only two reaction products with $M_{r}=60,000 / 62,000$ and $M_{r}=45,000$, which corresponds with cleavage at $\mathrm{Arg}^{306}$. The immunoblot further demonstrates that eleavage at $\mathrm{Arg}^{679}$ did not significantly contribute to factor $\mathrm{VaR506Q}$ inactivation since no additional bands became visible in the heavy chain or $M_{r}$ $=54,000 / 56,000 \mathrm{kDa}$ region of the immunoblot. This would have been expected if cleavage at $\mathrm{Arg}^{679}$ had occurred.

The immunoblot analysis supports the model for APC-catalyzed proteolysis of factor Va presented in the previous section. The rapid phase of the time course of inactivation of normal factor $\mathrm{Va}$ is associated with cleavage at $\operatorname{Arg} 506$ and the subsequent slow phase is due to cleavage at $\operatorname{Arg} 306$. Inactivation of factor $\mathrm{Va} R 506 \mathrm{Q}$ proceeds via a monophasic reaction which is explained by cleavage at $\mathrm{Arg}^{306}$. 


\section{$A P C$-Catalyzed Inactivation of Factor Va and Factor $V_{a} R 506 Q$ in the Absence of Phospholipids}

In order to quantify the effect of the membrane on the peptide bond cleavages during factor $\mathrm{Va}$ and factor $\mathrm{VaR} 506 \mathrm{Q}$ inactivation by $\mathrm{APC}$ we have also determined time courses of factor $\mathrm{Va}$ inactivation in the absence of phospholipids under pseudo-first order conditions (Fig. 3.4).

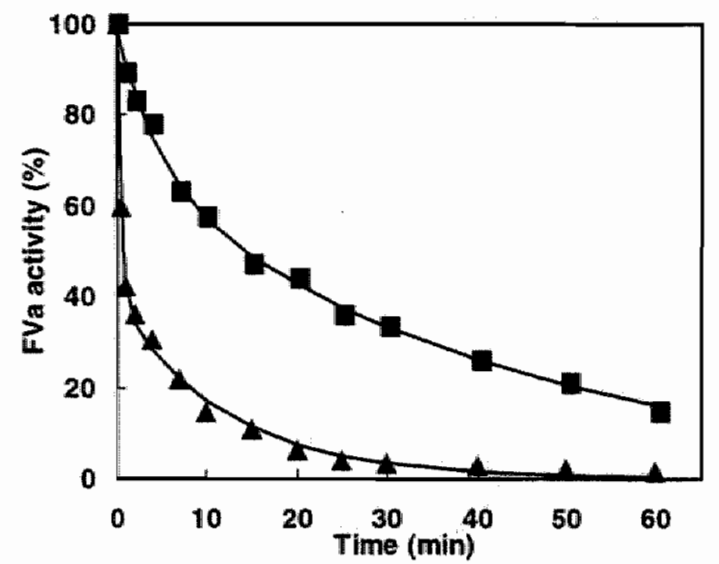

FIG. 3.4 Inactivation of factor $\mathrm{Va}$ and factor VaR506Q by APC in the absence of phospholipids. $19 \mathrm{nM}$ purified human factor $\mathrm{Va}(\boldsymbol{\Lambda})$ or factor VaR506Q (⿻) was incubated with $390 \mathrm{nM}$ APC in $25 \mathrm{mM}$ Hepes (pH 7.5), $175 \mathrm{mM} \mathrm{NaCl}, 3 \mathrm{mM} \mathrm{CaCl}$ and $5 \mathrm{mg} / \mathrm{ml}$ BSA at $37 \mathrm{C}$. At the indicated time points factor Va activity was determined as described in the "Materials and Methods". The solid lines represent exponential curves obtained after fitting the data using equation 3 given in the "Materials and Methods". The rate constants and activity of the reaction intermediate were determined by nonlinear least-squares regression analysis of the data.

It was not possible to fit these time courses of inactivation with a single exponential. For both factor $\mathrm{Va}$ and factor $\mathrm{Va} R 506 \mathrm{Q}$ it was necessary to postulate that inactivation proceeded via a biphasic reaction with a partially active reaction intermediate.

To correlate the loss of cofactor activity with peptide bond cleavages in the heavy chain we analyzed the product generation pattern by immunoblot analysis of samples taken from the inactivation mixture at selected time intervals (Fig. 3.5). 


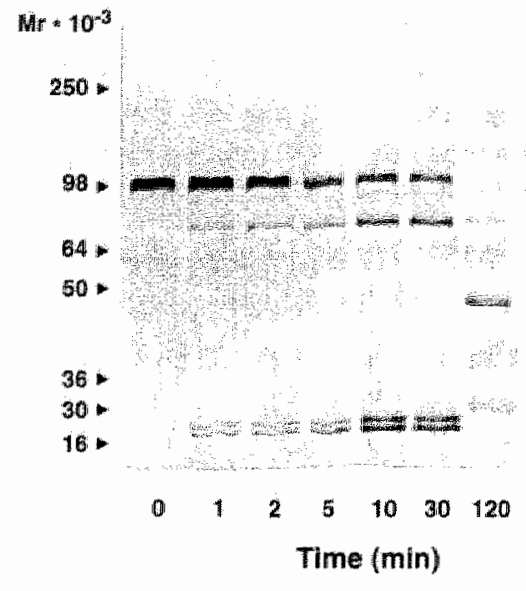

A

FiG. 3.5 Immunoblot analysis of factor Va and factor VaR506Q inactivation by APC in the absence of phospholipids. (A) $40 \mathrm{nM}$ purified human factor $\mathrm{Va}$ and $15 \mathrm{nM}$ APC or (B) 40 $n M$ factor $\mathrm{Va} R 506 \mathrm{O}$ and $500 \mathrm{nM}$ APC were incubated in $25 \mathrm{mM}$ Hepes (pH 7.5), $175 \mathrm{mM}$ $\mathrm{NaCl}, 3 \mathrm{mM} \mathrm{CaCl} z$ and $0.2 \mathrm{mg} / \mathrm{ml} \mathrm{BSA}$ at $37^{\circ} \mathrm{C}$. In the case of normal factor Va (A) the APC concentration was increased to $500 \mathrm{nM}$ APC after $35 \mathrm{~min}$. At the indicated time intervals samples from the inactivation mixture were subjected to SDS-PAGE. After transfer to Immobilon-P membranes, the heavy chain and derived fragments were visualized with a polyclonal antibody directed against the heavy chain of factor Va. The positions of the molecular weight markers are indicated at left of Panels $\mathrm{A}$ and $\mathrm{B}$. The percentages cotactor activity at the indicated time points were (A) 100, 88, 71, 59, 39, 24 and $1 \%$ and (B) 100, 95, 85, 69, 46, 34, 18, and $6 \%$. Further experimental details are described under "Materials and Methoos".

Compared with the peptide bond cleavage pattern of membrane-bound factor $\mathrm{Va}$ a striking difference was observed. In the absence of phospholipids cleavage at $\mathrm{Arg}^{679}$ occurred at appreciable rates in factor $\mathrm{Va}$ R506Q (Fig. 3.5B). This is concluded from time-dependent appearance of an additional band in the heavy chain region of the gel.

Thus, it appears that in the case of factor $\mathrm{VaR506Q}$ inactivation proteolysis at $\mathrm{Arg}^{679}$ and $\mathrm{Arg}^{306}$ contributed to factor $\mathrm{Va}$ inactivation and that cleavage at $\mathrm{Arg}^{679}$ preceded cleavage at $\mathrm{Arg}^{306}$. Fitting the time course of APC-catalyzed factor VaR506Q inactivation (Fig. 3.4, solid lines) to the equation for a biphasic reaction with a partially active intermediate yields rate constants of $8.0 \times 10^{3} \mathrm{M}^{-1} \mathrm{~s}^{-1}$ and $1.0 \times 10^{3} \mathrm{M}^{-1} \mathrm{~s}^{-1}$ for $\dot{k}_{679}$ and $\mathrm{k}_{306}$, 
respectively and $70 \%$ cofactor activity for the reaction intermediate that has been cleaved at $\mathrm{Arg}^{679}$.

Immunoblot analysis (Fig. 3.5A) indicates that during the time courses of normal factor Va inactivation (Fig. 3.4) only peptide bond cleavages at Arg 506 and $\mathrm{Arg}^{306}$ significantly contributed to the loss of factor Va cofactor activity. Inspection of the immunoblot that represents inactivation of normal factor $\mathrm{Va}$ reveals that cleavage at $\mathrm{Arg}^{679}$ had a minor contribution to the loss of factor Va cofactor activity. As a first approximation we have, therefore, also fitted this time course with a biphasic exponential. This fit (Fig. 3.4, solid line) yielded rate constants of $1.3 \times 10^{5} \mathrm{M}^{-1} \mathrm{~s}^{-1}$ and $4.0 \times 10^{3} \mathrm{M}^{-1} \mathrm{~s}^{-1}$ for cleavage at $\mathrm{Arg}^{506}$ and $\mathrm{Arg}^{306}$, respectively and a reaction intermediate with $40 \%$ cofactor activity. It should be emphasized that the values of the latter rate constants may be slightly overestimated due to the assumption that cleavage at $\operatorname{Arg} 679$ did not contribute to inactivation.

\section{Rate Constants for APC-Catalyzed Cleavage of Peptide Bonds During Inactivation of Free and Membrane-Bound Factor Va and Factor $\mathrm{Va} R 5060$}

The rate constants for APC-catalyzed cleavage at Arg $306, \mathrm{Arg}^{506}$ and Arg ${ }^{679}$ in factor $\mathrm{Va}$ and $\mathrm{Va}^{\mathrm{R} 506 \mathrm{Q}}$ are summarized in Table 3.1. It was not possible to calculate rate constants for cleavage at $\mathrm{Arg}^{679}$ in normal factor $\mathrm{Va}$ from the time courses of inactivation presented in Figs. 3.2 and 3.4. However, from the disappearance of the $M_{r}=26,000 / 28,000$ doublet on immunoblots (time points between 10 and $60 \mathrm{~min}$, data not shown) it could be estimated that cleavage at Arg 679 in free factor Va occurred with $k_{679} \approx 5.9 \mathrm{x}$ $10^{3} \mathrm{M}^{-1} \mathrm{~s}^{-1}(\mathrm{t} t / 2=16 \mathrm{~min}$ at $156 \mathrm{nM} \mathrm{APC})$ and that the same peptide bond in membrane-bound factor Va was cleaved with $\mathrm{k}_{679} \approx 7.6 \times 10^{4} \mathrm{M}^{-1} \mathrm{~s}^{-1}(\mathrm{t} / \mathrm{z} \approx$ $30 \mathrm{~min}$ at $50 \mathrm{nM} \mathrm{APC}$ ). 
Table 3.1

\section{Rate constants of APC-catalyzed peptide bond cleavages in factor $\mathrm{Va}$ and factor $\mathrm{Va} \mathrm{R} 506 \mathrm{Q}$}

Rate constants of APC-Catalyzed inactivation of factor Va and factor VaR506Q were obtained by fitting time courses of factor Va or VaR506Q inactivation such as presented in Figs. 3.2 and 3.4 to equation 3 given in the "Malerials and Methods". $k_{679}$ for normal factor Va was calculated from the $t_{1 / 2}$ of disappearance of the $\mathrm{M}_{\mathrm{r}}=26,000 / 28,000$ doublet $\left(\mathrm{k}_{679}=\right.$ in $\left.2 / t_{1 / 2}\right)$ obtained by scanning immunoblots of time courses of APC-catalyzed factor Va inactivation. The rate constants given are averages calculated from at least 10 experiments. The standard error of mean (SE) was $<20 \%$ in all cases.

\begin{tabular}{|c|c|c|c|c|}
\hline & \multicolumn{2}{|c|}{ normal factor $\mathrm{Va}$} & \multicolumn{2}{|c|}{ factor $V a R 506 Q$} \\
\hline & $-P L^{a}$ & $+P L$ & $-P L$ & $+P L$ \\
\hline & \multicolumn{2}{|c|}{$\left(M^{-1} s^{-1}\right)$} & \multicolumn{2}{|c|}{$\left(M^{-1} s^{-1}\right)$} \\
\hline$k_{506}$ & $1.4 \times 10^{5}$ & $4.3 \times 10^{7}$ & & \\
\hline$k_{306}$ & $3.7 \times 10^{3}$ & $2.3 \times 10^{6}$ & $9.4 \times 10^{2}$ & $1.7 \times 10^{6}$ \\
\hline $\mathrm{k}_{679}$ & $\approx 5.9 \times 10^{3}$ & $\approx 7.6 \times 10^{3}$ & $7.5 \times 10^{3}$ & $N D^{\circ}$ \\
\hline
\end{tabular}

PL, $25 \mu \mathrm{M}$ phospholipid vesicles composed of $10 \%$ DOPS and $90 \%$ DOPC

${ }^{\mathrm{ND}}$, not determined

The data presented in Table 3.1 show that phospholipids stimulated the APC-catalyzed peptide bond cleavages in factor $V a$ to a different extent. Phospholipids appeared to have no effect on $\mathrm{k}_{679}$. Furthermore it is ciear that cleavage at $\mathrm{Arg}^{306}$ in free factor $\mathrm{VaR} 506 \mathrm{Q}$ occurred at a lower rate than in normal factor $\mathrm{Va}$. For membrane-bound factor $\mathrm{VaR} 506 \mathrm{Q}$ and factor $\mathrm{Va}$ this difference was annulated. These observations are indicative for specific effects of phospholipids and/or prior cleavage at Arg506 on the cleavages at $\operatorname{Arg}^{306}$ and $\operatorname{Arg}^{679}$ (see discussion).

\section{Kinetic Parameters for APC-Catalyzed Cleavage at Arg 506 and $\mathrm{Arg}^{306}$ in Membrane-Bound Factor Va and Factor VaR506Q}

The differences in rate constants for cleavage at $\mathrm{Arg}^{506}$ and $\mathrm{Arg}^{306}$ in membrane-bound factor $\mathrm{Va}$ must result from differences between the Michaelis-Menten kinetic parameters $\left(k_{c a t}\right.$ and/or $\left.K_{m}\right)$ for these peptide bond cleavages. In order to obtain information on the kinetic basis of the differences we have determined the kinetic parameters, $K_{m}$ and $k_{\text {cat }}$, by measuring the initial rates of factor $\mathrm{Va}$ inactivation (between 0 and $20 \%$ loss of cofactor activity) at varying factor $\mathrm{Va}$ or factor $\mathrm{Va} \mathrm{R} 506 \mathrm{Q}$ concentrations. 
The experiment with normal factor $V a$ yields the $\mathrm{k}_{c a t}$ and $\mathrm{K}_{\mathrm{m}}$ for cleavage at Arg 506 since this peptide bond is preferentially cleaved during the initial phase of inactivation. Michaelis-Menten kinetic analysis of factor $\mathrm{Va} P 506 \mathrm{Q}$ inactivation will give kinetic parameters for cleavage at Arg 306.

The Lineweaver-Burk plots presented in Fig. 3.6 show that cleavage at $\operatorname{Arg}^{506}$ was characterized by a $\mathrm{K}_{\mathrm{m}}$ of $20 \mathrm{nM}$ and a $\mathrm{K}_{\text {cat }}$ of $0.96 \mathrm{~s}^{-1}$. Inactivation of factor $\mathrm{VaR} 506 \mathrm{Q}$, which corresponds with cleavage at $\mathrm{Arg} 306$, had a high $K_{m}(196 \mathrm{nM})$ and a $\mathrm{K}_{\mathrm{cat}}$ of $0.37 \mathrm{~s}^{-1}$.

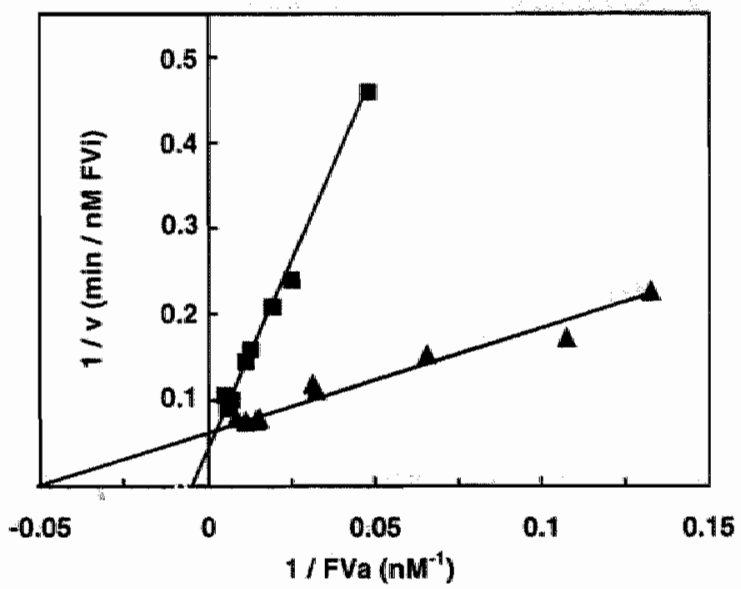

FIG. 3.6 Lineweaver-Burk plots for inactivation of factor Va and factor VaR506Q by APC in the presence of phospholipids. Initial rates of factor Va inactivation were determined at varying concentrations of factor $\mathrm{Va}(\mathbf{\Lambda})$ or factor $\mathrm{Va} R 506 \mathrm{O}$ (m) that were incubated with 0.28

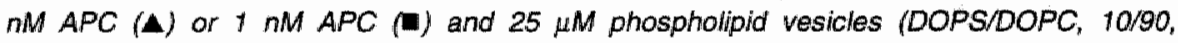
$\mathrm{mol} / \mathrm{mol}$ ) in $25 \mathrm{mM}$ Hepes ( $p H$ 7.5), $175 \mathrm{mM} \mathrm{NaCl}, 3 \mathrm{mM} \mathrm{CaCl} 2$ and $5 \mathrm{mg} / \mathrm{ml} \mathrm{BSA}$ at $37^{\circ} \mathrm{C}$. After different time intervals the factor $V a$ activity was determined as described in the "Materials and Methods" and initial rates of factor Va inactivation were expressed as nM factor Va inactivated/min/nM APC (assuming that normal factor Va is converted into an intermediate with $40 \%$ cofactor activity). The solid lines represent a fit of the data according the MichaelisMenten equation with $K_{m}=20 \mathrm{nM}$ and $V_{\max }=57.6 \mathrm{nM}$ factor $\mathrm{Va}$ inactivated/min/ $/ \mathrm{MM} A P C$ $\left(k_{c a t}=0.96 \mathrm{~s}^{-1}\right)$ for factor $V_{a}(\sigma)$ and $K_{m}=196 \mathrm{mM}$ and $V_{\max }=22.2 \mathrm{nM}$ factor $V_{a} R 5060$ inactivated $/ \mathrm{min} / \mathrm{nM}$ APC $\left(k_{\mathrm{cat}}=0.37 \mathrm{~s}^{-1}\right)$ for factor $\mathrm{Va} R 506 \mathrm{Q}(\mathbf{m})$ ).

Theoretically the $\mathrm{K}_{\mathrm{cat}} / \mathrm{K}_{\mathrm{m}}$ obtained by Michaelis-Menten analysis should equal the second order rate constant calculated from a time course of inactivation determined at low factor Va concentrations (Fig. 3.2). Indeed the $\mathrm{k}_{\text {cat }} / \mathrm{K}_{\mathrm{m}}$ values determined for cleavage at $\operatorname{Arg}^{506}\left(4.8 \times 10^{7} \mathrm{M}^{-1} \mathrm{~s}^{-1}\right)$ and $\operatorname{Arg}^{306}\left(1.9 \times 10^{6} \mathrm{M}^{-1} \mathrm{~s}^{-1}\right)$ closely resemble the rate constants obtained at pseudo first-order reaction conditions (Table 3.1). This shows that the kinetic parameters, $K_{m}$ and $k_{c a t}$, are indeed associated with the indicated peptide 
bond cleavages. The data further demonstrate that the differences between the rate constants of cleavage at $\mathrm{Arg}^{506}$ and $\mathrm{Arg}^{306}$ are mainly dure to differences between the $K_{m}$ values for these peptide bond cleavages.

\section{Cofactor Activity of Factor Va after Cleavage at Arg 506 by APC}

Pseudo first-order time courses of inactivation of normal factor Va (Fig. 3.2 and 3.4) could only be fitted in a reaction model that consisted of two steps with the formation of a reaction intermediate (factor Va cleaved at Arg 506 ) that retained partial cofactor activity.

The actual cofactor activity of factor $\mathrm{Va}$ is dependent on its interaction with procoagulant membranes, factor $\mathrm{Xa}$, prothrombin and on its ability to increase the catalytic activity ( $k_{\text {cat }}$ ) of factor $X^{2-5,40}$. To examine which of these functions was impaired in factor $\mathrm{Va}$ that is cleaved at $\mathrm{Arg} 506$, we have characterized the functional properties of the inactivation intermediate. To this end normal factor Va was inactivated by APC in the absence of phospholipids (cf. Fig. 3.4) and after completion of the first phase of inactivation (Arg506 cleavage) the reaction mixture was diluted and chromatographed on a Mono $S$ column. The reaction intermediate bound to Mono $S$ and eluted in a $\mathrm{NH}_{4} \mathrm{Cl}$ gradient as an overlapping doublet between $700 \mathrm{mM}$ and $800 \mathrm{mM} \mathrm{NH}{ }_{4} \mathrm{Cll}$. These column fractions contained almost pure inactivation intermediate (Fig. 3.7B).

To compare the abilities of factor $\mathrm{Va}$ and the purified inactivation intermediate to assemble with factor $X a$ into a membrane-bound prothrombinase complex we determined initial steady state rates of prothrombin activation at limiting amounts of factor Va or factor Va cleaved at Arg 506 as a function of the factor $X a$ concentration (Fig. 3.7A,B). Low amounts of factor $X a$ were required for full expression of prothrombinase activity in the case of normal factor $\mathrm{Va}\left(\mathrm{K}_{1 / 2} \mathrm{Xa}=0.088 \mathrm{nM}\right)$. With factor $\mathrm{Va}$ that was cleaved at $\mathrm{Arg}^{506}$ much higher factor Xa concentrations $\left(\mathrm{K}_{1 / 2} \mathrm{Xa}_{\mathrm{a}}=\right.$ $3.9 \mathrm{nM}$ ) were needed to obtain maximal prothrombinase activity. 

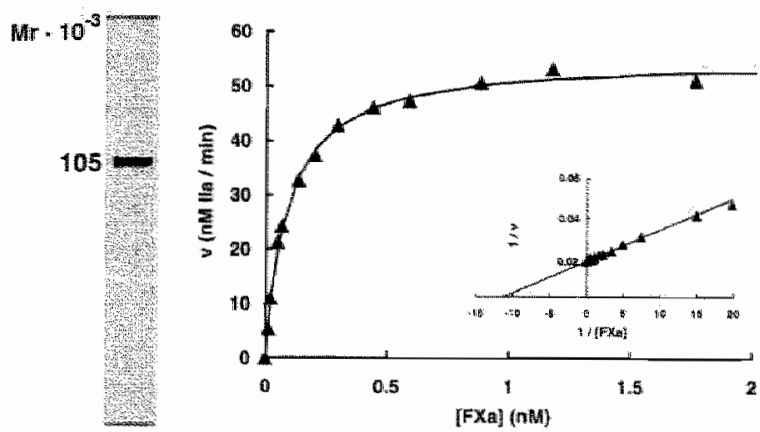

A
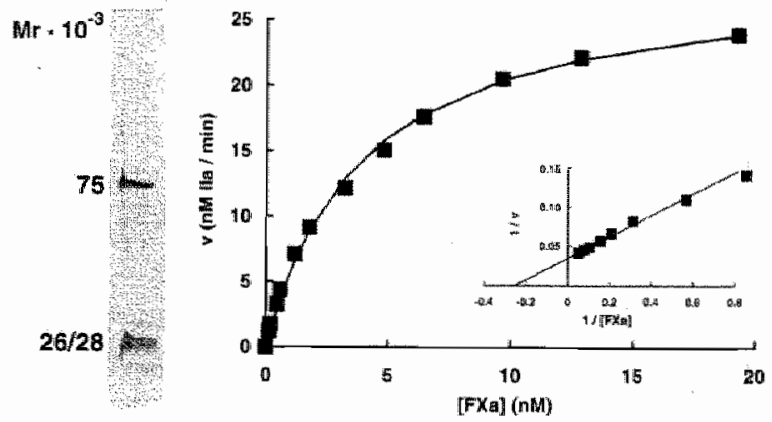

B , concentrations of factor Xa in $25 \mathrm{mM}$ Hepes (pH 7.5), $175 \mathrm{mM} \mathrm{NaCl}, 2 \mathrm{mM} \mathrm{CaCl}$ and $5 \mathrm{mg} / \mathrm{ml}$ BSA at $37^{2} \mathrm{C}$. Rates of prothrombin activation were determined as described under "Materials and Methods' and were corrected for thrombin formed in the absence of factor Va. The solid lines represent hyperbolas obtained after fitting the data with $K_{1 / 2} X_{a}=0.088 \mathrm{nM}$ and $V_{\max }=$ 50.2 nmoles $/ \mathrm{a} / \mathrm{min} / \mu \mathrm{g}$ factor $\mathrm{Va}\left(\mathrm{K}_{\mathrm{cat}}=151 \mathrm{~s}^{-1}\right)$ for factor $\mathrm{Va}(\boldsymbol{\Delta})$ and $K_{1 / 2} X_{a}=3.9 \mathrm{mM}$ and $V_{\text {max }}=28.7$ nmoles $\mathrm{Na} / \mathrm{min} / \mu \mathrm{g}$ protein $\left(k_{\text {cat }}=72 \mathrm{~s}^{-1}\right)$ for the column fraction (factor $V$ cleaved at Arg $^{506}$ ( $\mathbf{m}$ ).

(nset) Double reciprocal plots of the same data.

The $V_{\text {max }}$ of prothrombin activation obtained with the purified inactivation intermediate was lower than that determined for native factor $\mathrm{Va}$. The $\mathrm{V}_{\max }$ values could be converted into $k_{\text {cat }}$ values on basis of the protein contents of 
the titrated fractions. This yielded $k_{\text {cat }}$ values of $153 \mathrm{~s}^{-1}$ and $96 \mathrm{~s}^{-1}$ for native and cleaved factor $\mathrm{Va}$, respectively.

The interaction of the membrane-bound factor $\mathrm{Xa}-\mathrm{Va}$ complex with prothrombin was not affected by cleavage at Arg 506 since the $K_{m}$ values for prothrombin were virtually the same for prothrombinase complexes with normal and cleaved factor $\mathrm{Va}$ (data not shown).

From these data we conclude that APC-catalyzed cleavage at Arg506 of the heavy chain of factor Va results in the formation of a reaction product that has lost part of its cofactor activity mainly because of a reduction of its affinity for factor $\mathrm{Xa}$.

\section{The Effect of the Factor Va Concentration and the Assay Conditions on Observed Time Courses of Inactivation of Membrane-Bound Factor Va and Factor VaR506Q by APC}

The data presented in this chapter demonstrate that differences in rate constants of cleavage at $\mathrm{Arg}^{506}$ and $\mathrm{Arg}^{306}$ are primarily due to differences in the $K_{m}$ for these peptide bond cleavages. This means that at high factor $V a$ concentrations, where the rates of cleavage approach $V_{\max }$, differences in time courses of inactivation of factor $\mathrm{Va}$ and factor $\mathrm{VaR506Q}$ should become less pronounced.

We have also shown (Fig. 3.7) that the relative cofactor activities of native factor $\mathrm{Va}$ and factor $\mathrm{Va}$ cleaved at $\mathrm{Arg}^{506}$ strongly depend on the factor $\mathrm{Xa}$ concentration present in the factor $\mathrm{Va}$ assay. It was demonstrated that factor $\mathrm{Va}$ that is cleaved at $\mathrm{Arg}^{506}$ will exhibit much lower cofactor activity than native factor $\mathrm{Va}$ when assayed at factor $\mathrm{Xa}$ concentrations below $\mathrm{K}_{1 / 2} \mathrm{Xa}_{a}(3.9$ $\mathrm{nM})$.

These observations predict that the observed time courses of factor $\mathrm{Va}$ or factor $\mathrm{VaA506Q}$ inactivation by APC will depend 1) on the factor $\mathrm{Va}$ concentration in the inactivation mixture and 2) on the assay conditions at which the loss of cofactor activity of factor $\mathrm{Va}$ is followed. Compared with factor $\mathrm{Va} R 506 \mathrm{Q}$, normal factor $\mathrm{Va}$ will be more rapidly inactivated at low than at high factor $\mathrm{Va}$ concentrations. The apparent loss of cofactor activity of normal factor $\mathrm{Va}$ will be even more rapid and approach complete loss of activity much faster when samples from the inactivation mixture are assayed at a factor $\mathrm{Xa}$ concentration at which the inactivation intermediate has no activity i.e. [factor $X a]<3.9 \mathrm{nM}\left(\mathrm{K}_{1 / 2} \mathrm{Xa}_{\mathrm{a}}\right)$.

These predictions were confirmed by an experiment in which time courses of factor $\mathrm{Va}$ inactivation were determined at low (Fig. 3.8A) or high concentrations of factor $\mathrm{Va}$ or $\mathrm{VaR} 506 \mathrm{Q}$ (Fig. 3.8B) and in which samples 
from the same inactivation mixture were assayed for the loss of cofactor activity in assay mixtures that contained a low (Fig. 3.8A) or a high factor $\mathrm{Xa}$ concentration (Fig. 3.8B).

As predicted, the differences in APC-catalyzed loss of cofactor activity of normal factor $\mathrm{Va}$ and factor $\mathrm{Va} 506 \mathrm{Q}$ were most pronounced when factor $\mathrm{Va}$ was inactivated at a low concentration and assayed in a prothrombin activation mixture that contained a low factor $\mathrm{Xa}$ concentration (Fig. 3.8A). Differences in time courses of inactivation of factor $\mathrm{Va}$ and factor $\mathrm{VaR}$ R06Q were indeed greatly reduced when high factor $\mathrm{Va}$ concentrations were inactivated by APC and the loss of cofactor activity was monitored in prothrombin activation mixtures that contained a high factor $\mathrm{Xa}$ concentration (Fig، 3.8B).
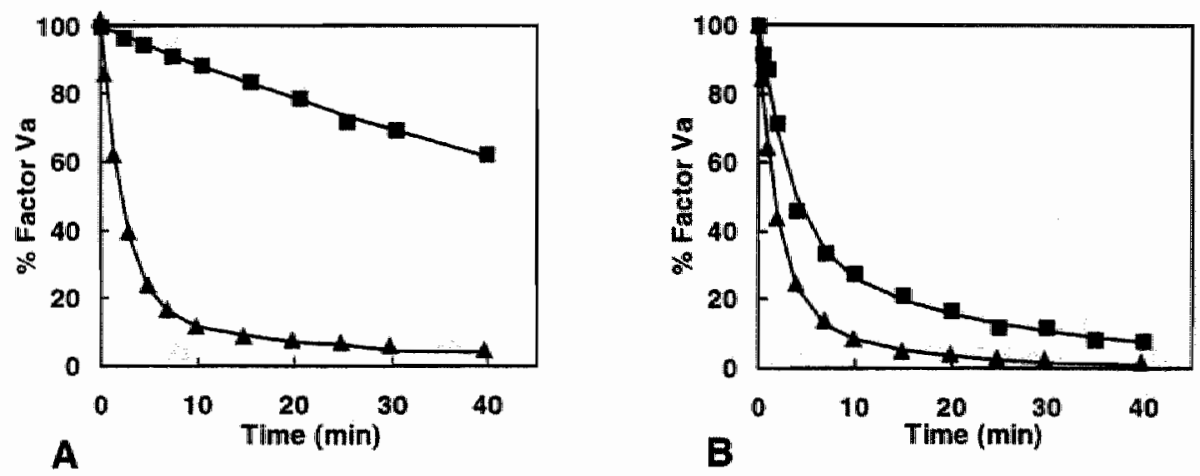

FiG. 3.8 The effect of assay conditions and factor Va concentration on the loss of cofactor activity during factor Va inactivation by APC. Purified human factor Va ( $\mathbf{A}$ ) or factor VaR506Q (m) was incubated with APC and phospholipid vesicles in $25 \mathrm{mM}$ Hepes (pH 7.5), $175 \mathrm{mM} \mathrm{NaCl}, 3 \mathrm{mM} \mathrm{CaCl}$ and $5 \mathrm{mg} / \mathrm{m} / \mathrm{BSA}$ at $37^{\circ} \mathrm{C}$. At the indicated time points factor Va activity was determined as described in the "Materials and Methods" in assay mixtures that contained $10 \mathrm{nM}$ or $0.4 \mathrm{nM}$ factor Xa. (A) Inactivation mixture: $0.8 \mathrm{nM}$ factor Va (4) or $0.8 \mathrm{nM}$ factor VaR506Q (a), 0.15 nM APC, $25 \mu M$ phospholipid vesicles (DOPS/DOPC, 10/90, mol/mol); cofactor assay mixture: $0.4 \mathrm{nM}$ factor $X a(\mathrm{~B})$ Inactivation mixture: $210 \mathrm{nM}$ factor $\mathrm{Va}$ (A) or $210 \mathrm{nM}$ factor VaR506Q (-), 2.7 nM APC, 25 uM phospholipid vesicles (DOPSIDOPC, 10/90, mol/mol); cofactor assay mixture: $10 \mathrm{nM}$ factor $X a$. 


\subsection{Discussion}

Proteolytic inactivation of membrane-bound factor Va by APC requires cleavage of two peptide bonds located at $\mathrm{Arg}^{506}$ and $\mathrm{Arg}^{306}$ in the heavy chain domain of factor Va (Fig. 3.1). At low factor Va concentrations cleavage at Arg 506 occurs at a rate that is approximately 20 -fold higher than the rate of cleavage at $\mathrm{Arg}^{306}$. This results in the accumulation of a reaction intermediate that is cleaved at Arg 506 and that exhibits partial cofactor activity in prothrombin activation (Fig. 3.2). Cleavage at $\mathrm{Arg}^{306}$, which may occur both in the reaction intermediate and in native factor Va (see below), results in a complete loss of cofactor activity.

The cofactor activity of the factor Va derivative cleaved at Arg506 strongly depends on the factor Xa concentration in the prothrombin activation mixture in which factor $\mathrm{Va}$ is assayed. Cofactor activity of the reaction intermediate in prothrombin activation is only observed at high factor $\mathrm{Xa}$ concentrations. Compared with native factor $\mathrm{Va}$, full expression of cofactor activity of factor $\mathrm{Va}$ that is cleaved at $\mathrm{Arg}{ }^{506}$ requires a 45 -fold higher factor Xa concentration. This indicates that cleavage at $\mathrm{Arg}^{506}$ in the heavy chain of factor $\mathrm{Va}$ affects its interaction with factor $\mathrm{Xa}$ and results in a considerable loss of affinity for factor $X a$.

Factor $\mathrm{Va} R 506 \mathrm{Q}$ obtained from factor $\mathrm{V}$ purified from the plasma of a homozygous APC-resistant patient is slowly inactivated by APC (cr. ref ${ }^{12}$ ). This factor $\mathrm{Va}$ molecule lacks the cleavage site at $\mathrm{Arg} 506$, due to replacement of $\mathrm{Arg}$ by $\mathrm{Gln}^{18-21}$. Time courses of inactivation of low concentrations of membrane-bound factor $\mathrm{Va} R 506 \mathrm{Q}$ could be fitted with an equation for a single exponential curve. Immunoblotting experiments (fig. $3.3 \mathrm{~B})$ show preferential cleavage at $\mathrm{Arg}^{306}$ during the inactivation of membrane-bound factor $V a R 506 Q$. These data indicate that APC inactivates factor $V_{a} R 506 Q$ by a single cleavage at position Arg 306 which results in the formation of a reaction product that has virtually lost its cofactor activity in prothrombin activation.

Under the conditions of our experiments (low factor Va concentrations) cleavage at $\mathrm{Arg} 679$ has a negligible contribution to the loss of cofactor activity in the case of APC-catalyzed inactivation of membrane-bound factor Va or factor $\mathrm{VaR} 506 \mathrm{Q}$. This is concluded from the fact that cleavage at $\mathrm{Arg}^{679}$ (i.e. disappearance of the $M_{r}=26,000 / 28,000$ fragment or appearance of doublet bands in the heavy chain or the $M_{r}=54,000 / 56,000$ region of immunoblots) is only observed after time intervals at which more than $90 \%$ of the cotactor activity of factor $\mathrm{Va}$ is already lost. 
These data suggest that inactivation of membrane-bound factor $\mathrm{Va}$ and factor $\mathrm{Va} R 506 \mathrm{Q}$ by $\mathrm{APC}$ proceeds via the pathways depicted below.

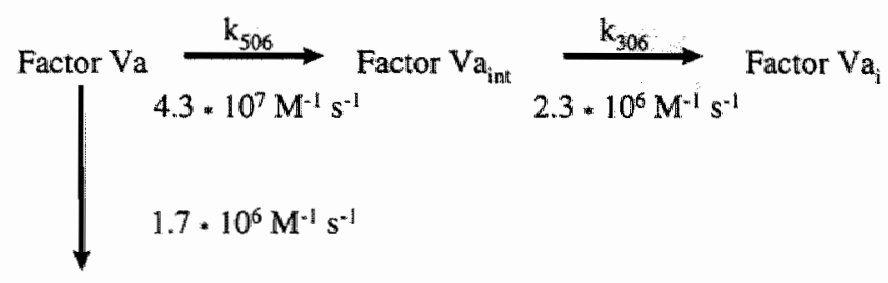

Factor $\mathrm{Va}_{\mathrm{i}}$

Factor $\mathrm{Va}^{\mathrm{R} 506 \mathrm{Q}} \stackrel{\mathrm{k}_{306}}{\longrightarrow}$ Factor $\mathrm{Va}_{\mathrm{i}}$ $1.7 \cdot 10^{6} \mathrm{M}^{-1} \mathrm{~s}^{-1}$

Scheme 3.1

In this scheme 3.1 factor Vaint exhibits partial cofactor activity and factor $V_{a}$ is a reaction product that has no detectable cofactor activity. We propose that APC-catalyzed cleavage at Arg506 and Arg 306 in membrane-bound factor $\mathrm{Va}$ occurs in a random fashion and that cleavage at $\mathrm{Arg}^{306}$ is not affected by prior cleavage at Arg506. This is inferred from the fact that the rate constants for cleavage at $\mathrm{Arg}^{306}$ calculated from time courses of inactivation of normal and APC-resistant factor $\mathrm{Va}$ are approximately the same $\left(k_{306}\right.$ is $2.3 \times 10^{6} \mathrm{M}^{-1} \mathrm{~s}^{-1}$ and $1.7 \times 10^{6} \mathrm{M}^{-1} \mathrm{~s}^{-1}$ for normal $\mathrm{Va}$ and factor $\mathrm{VaR506Q}$, respectively).

Michaelis-Menten analysis provided additional information regarding the mechanism that accounts for the observed difference between $k_{506}$ and $k_{306}$. The kinetic parameters determined for cleavage at $\mathrm{Arg}^{506}$ in normal factor $V a$ were: $K_{m}$ for factor $V a=20 \mathrm{nM}$ and $k_{\text {cat }}=0.96 \mathrm{~s}^{-1}$. The peptide bond at $A \mathrm{Arg}^{306}$ in factor $\mathrm{VaR506Q}$ was cleaved with $\mathrm{K}_{\mathrm{m}}=196 \mathrm{nM}$ and $\mathrm{k}_{\text {cat }}=$ $0.37 \mathrm{~s}^{-1}$. The fact that the calculated catalytic efficiencies $\left(\mathrm{K}_{\mathrm{cat}} / \mathrm{K}_{\mathrm{m}}\right)$ have the same values as the second order rate constants calculated for cleavage at Arg 506 in normal factor $\mathrm{Va}$ and for cleavage at $\mathrm{Arg}^{306}$ in factor $\mathrm{Va} \mathrm{R} 506 \mathrm{Q}$ verifies that the Michaelis-Menten kinetic parameters are indeed associated with the indicated peptide bond cleavages. These data suggest that the differences in rate constants for cleavage at $\mathrm{Arg}^{506}$ and $\mathrm{Arg}^{306}$ mainly result from differences in the $K_{m}$ and explain why at high factor $V a$ concentrations $\left(>K_{m}\right)$ differences between time courses of factor $\mathrm{Va}$ and factor $\mathrm{Va}_{\mathrm{A}} \mathrm{R}$.66Q inactivation are much less pronounced (Fig. 3.8B). 
$A P C$ can also fully inactivate factor $V a$ and factor $V a R 506 Q$ in the absence of a membrane surface (Fig. 3.4). Under these conditions cleavage at Arg679 also contributes to the loss of factor Va cofactor activity. This is particularly observed for factor $\mathrm{Va} R 506 \mathrm{Q}$, in which the peptide bond at $\operatorname{Arg}^{679}$ is even cleaved at a 8-fold higher rate than the site at $\mathrm{Arg}^{306}$ Cleavage at Arg ${ }^{679}$ does not require prior cleavage at $\mathrm{Arg}^{506}$ or $\mathrm{Arg}^{306}$ since immunoblot analysis shows the appearance of a doublet band in the $M_{r}$ $=105,000$ region of the gel, which indicates that cleavage at position Arg 679 can already occur in the intact heavy chain.

Comparison of rate constants obtained for free and membrane-bound factor $\mathrm{Va}$ shows that phospholipids greatly accelerate APC-catalyzed factor Va inactivation. Part of this stimulation will presumably be due to the fact that both the substrate (factor $\mathrm{Va}$ ) and the enzyme (APC) bind to the membrane surface, a condition that promotes their interaction and reaction in a way similar to that of phospholipid-dependent coagulation factor activations ${ }^{4,5,8,40-}$ 42. However, in the case of APC-catalyzed factor Va inactivation, phospholipids do not accelerate the peptide bond cleavages to the same extent (Table 1). Cleavage at Arg 506 and $\mathrm{Arg}^{306}$ in normal factor Va is stimulated 300-600 fold, whereas cleavage at Arg 306 in factor VaR506Q is enhanced 1800 -fold by phospholipids. This is indicative of a specific effect of phospholipids on APC-catalyzed cleavage at $\mathrm{Arg}^{306}$ (cf. ref. ${ }^{11}{ }^{12}$ ). We observed that $k_{679}$ is not significantly increased in membrane-bound factor $\mathrm{Va}$. This demonstrates that after binding of factor $\mathrm{Va}$ to phospholipids the peptide bond at position Arg679 is hardly accessible to cleavage by membrane-bound APC.

Taken together our conclusions seem to contradict earlier observations of Kalafatis et al. ${ }^{11,12}$ who reported that APC-catalyzed cleavages in the heavy chain of membrane-bound factor Va occur in an ordered, sequential fashion in which cleavage at Arg 506 promotes cleavage at $\mathrm{Arg}^{306}$ and $\mathrm{Arg}^{679}$. They also suggested that cleavage at Arg 506 does not affect the cofactor activity of normal factor $\mathrm{Va}$ and that cleavage at position $\mathrm{Arg} 679$ is required for full inactivation of factor $\mathrm{Va}$. These apparent discrepancies may be explained by our obsenvations that 1) the relative rates of peptide bond cleavages in the heavy chain of factor Va depend on the factor Va concentration present in the inactivation mixture (Fig. 3.6) and 2) that the residual cofactor activity of partially active reaction intermediates strongly depends on the reaction conditions at which the functional activity of factor $\mathrm{Va}$ and its degradation products is assayed (Figs. 3.7 and 3.8). In this respect it is essential to mention that Kalafatis et al. ${ }^{11.12}$ collected their data at high factor Va concentrations ( $>200 \mathrm{nM}$ ) and used a factor Va assay system with high 
concentrations of coagulation factors, while our conclusions are based on experiments at low factor $\mathrm{Va}$ concentrations $(<10 \mathrm{nM})$ and assessment of cofactor activity of factor $\mathrm{Va}$ in prothrombin activation mixtures that contained varying concentrations of coagulation factors.

To emphasize the importance of reaction and assay conditions, we demonstrated that the apparent loss of factor $\mathrm{Va}$ cofactor activity during inactivation by APC indeed strongly depends on the concentration at which factor $\mathrm{Va}$ is inactivated and on the prothrombinase conditions at which the loss of cofactor activity is monitored (Fig. 3.8). Time courses of factor Va and factor $\mathrm{VaR506Q}$ inactivation at a high factor $\mathrm{Va}$ concentration, in which the loss of cofactor activity of factor $\mathrm{Va}$ is followed in prothombin activation mixtures that contain a high factor $\mathrm{Xa}$ concentration, show relatively little difference (Fig. 3.8A and ref. ${ }^{12}$ ). However, when factor $\mathrm{Va}$ is inactivated at a low concentration and when its cofactor activity is assayed in a prothrombin activation mixture that contains a low amount of factor $\mathrm{Xa}_{\text {, the differences }}$ between factor $\mathrm{Va}$ and factor $\mathrm{VaR} 506 \mathrm{Q}$ are profound (Fig. 3.8B). This observation may have significant physiological consequences. If thrombotic events result from ongoing coagulation at low concentrations of factor $\mathrm{Xa}$ and factor $\mathrm{Va}$ (the plasma factor $V$ concentration is $-25 \mathrm{nM}$ ), down-regulation of the cofactor activity of factor Va by APC will be most efficient in the case of normal factor $\mathrm{Va}$ and will be maximally impaired in case of factor $\mathrm{VaR} 506 \mathrm{Q}$. This underscores the increased risk for venous thromboembolism in individuals whose plasmas are APC-resistant as a consequence of a factor $\mathrm{V}$ phenotype in which $A r g 506$ is substituted by Gin.

Acknowledgments - We thank Lico Hoekema and Dr. José W.P. GoversRiemslag for technical assistance. 


\section{REFERENCES}

1. Suzuki $K$, Dahlbäck $B$ and Stenflo J. Thrombin-catalyzed activation of human coagulation factor $V$. J Biol Chem 1982; 257,6556-6564.

2. Plosing d, Bakker HM, Thomassen MCLGD, Hemker HC and Tans G. Characterization of two forms of human factor $\mathrm{Va}$ with different cofactor activities. J Biol Chem 1993; 268, 21130-21136

3. Nesheim ME, Taswell JB and Mann KG. The contribution of bovine factor $\mathrm{V}$ and factor Va to the activity of the prothrombinase. J Biol Chem 1979;254, 10952-10962

4. Rosing J, Tans G, Govers-Riemslag UWP, Zwaal RFA and Hemker HC The role of phospholipids and factor Va in the prothrombinase complex. J Biol Chem $1980 ; 255,274-283$

5. van Rijn JLML, Govers-Riemslag JWP, Zwaal RFA and Rosing J. Kinetic studies of prothrombin activation: effect of factor $\mathrm{Va}$ and phospholipids on the formation of the enzyme-substrate complex. Biochemistry 1984; 23, 4557-4564

6. Walker FJ, Sexton PW and Esmon CT. The inhibition of blood coagulation by activated protein $C$ through selective inactivation of activated factor $V$. Biochim Biophys Acta $1979 ; 571,333-342$

7. Suzuki $K_{n}$ Stenflo J, Dahlbäck $B$ and Teodorsson B. Inactivation of human coagulation factor $V$ by activated protein $\mathrm{C}$. J Biol Chem 1983; 258, 1914-1920

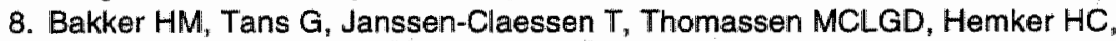
Griffin $\mathrm{JH}$ and Rosing J. The effect of phospholipids, calcium ions and protein $S$ on rate constants of human factor $V a$ inactivation by activated human protein C. Eur J Biochem 1992; 208, 171-178

9. Walker FJ. Regulation of activated protein $C$ by a new protein. A possible function for bovine protein S. J Biol Chem 1980; 255, 5521-5524

10.Solymoss S, Tucker MM and Tracy PB. Kinetics of inactivation of membranebound factor $\mathrm{Va}$ by activated protein $\mathrm{C}$. Protein $\mathrm{S}$ modulates factor $\mathrm{Xa}$ protection. J Biol Chem 1988; 263, 14884-14890

11. Kalafatis $M$, Rand MD and Mann KG. The mechanism of inactivation of human factor $V$ and human factor Va by activated protein C. J Biol Chem 1994; 269, 31869-31880

12. Kalafatis M, Bertina RM, Rand MD and Mann KG. Characterization of the molecular defect in FV R.506Q J Biol Chem 1995; 270, 4053-4057

13.Griffin, J. H., Evatt, B., Zimmerman, T.S. and Kleiss,. A.J. (1981) J. Clin. Invest. 68, 1370-1373

14.Schwarz HP, Fisher M, Hopmeier P, Batard MA and Griffin J. Plasma protein S deficiency in familial thrombotic disease. Blood 1984;64, 1297-1300

15. Comp PC, Nixon RR, Cooper MR and Esmon CT. Familial protein S deficiency is associated with recurrent thrombosis. J Clin Invest 1984; 74, 2082-2088

16.Dahlbäck $B$, Carlsson $M$ and Svensson PJ. Familial thrombophilia due to a previously unrecognized mechanism characterized by poor anticoagulant response to activated protein $\mathrm{C}$ : prediction of a cofactor to activated protein $\mathrm{C}$. Proc Nat Acad Sci USA 1993; 90, 1004-1008

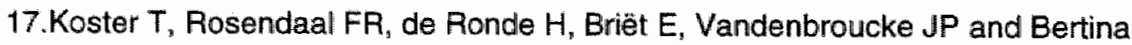
RM. Venous thrombosis due to a poor anticoagulant response to activated protein C: Leiden Thrombophilia Study. Lancet 1993; 342, 1503-1506 
18.Bertina RM, Koeleman BPC, Koster T, Rosendaal FA, Dirven RJ, de Ronde $H_{\text {, }}$ wan der Velden PA and Reitsma PJ. Mutation in blood coagulation factor V associated with resistance to activated protein $C$. Nature 1994;369; 64-67

19.Greengard JS, Sun $X, X u X$, Fernandez JA, Griffin JH and Evatt B. Activated protein $C$ resistance caused by Arg506Gin mutation in human factor $V$. Lancet $1994 ; 343,1361-1362$

20. Voorberg J, Roelse J, Koopman R, Büller $H$, Berends $F_{1}$ ten Cate JW, Mertens $K$ and van Mourik JA. Association of idiopathic venous thromboembolism with single point-mutation at $\mathrm{Arg}^{506}$ of factor $\mathrm{V}$. Lancet $1994 ; 343,1535-1536$

21.Zöller $B_{1}$ and Dahlbäck $B$. Linkage between inherited resistance to activated protein $C$ and factor $V$ gene mutation in venous thrombosis. Lancet $1994 ; 343$, 1536-1538

22.DiScipio RG, Hermodson MA, Yates SG and Davie EW. A comparison of human prothrombin, factor IX (Christmas factor), factor $X$ (Stuart factor) and protein S. Biochemistry 1977; 16,698-706

23.Pletcher $\mathrm{CH}$, and Nelsestuen GL. The rate-determining step of the heparincatalyzed antithrombin/thrombin reaction is dependent of thrombin. $\mathrm{J}$ Biol Chem 1982; 257, 5342-5345

24.Bock PE, Craig PA, Olsen ST and Singh P. Isolation of hurnan blood coagulation alpha-factor $\mathrm{Xa}$ by soybean trypsin inhibitor-sepharose chromatography and its active-site titration with fluorescein mono-pguanidinobenzoate. Arch Biochem Biophys 1989; 273, 375-388

25.Schiffman S, Theodor $J$ and Rapaport SJ. Separation from Russell's viper venom of one fraction reacting with factor $X$ and another reacting with factor $V$. Biachemistry 1969; 8, 1397-1405

26. Gruber A, Griffin JH, Harker L and Hanson SR. Inhibition of platelet-dependent thrombus formation by human activated protein $\mathrm{C}$ in a primate model. Blood $1989 ; 73,639-642$

27. Dahllbäck B. Human coagulation factor $V$ purification and thrombin-catalyzed activation. J Clin Invest 1980; 66, 583-591

28. Tans G, Rosing J, Thomassen MCLGD, Heeb MJ, Zwaal RFA and Griffin JH. Comparison of anticoagulant and procoagulant activities of stimulated platelets and platelet-derived microparticles. Blood 1991; 77, 2641-2648

29.Beauchamp NJ, Daly ME, Hampton KK, Cooper PC, Preston FE, and Peake IR. High prevalence of a mutation in the factor $V$ gene within the UIK population: relationship to activated protein $\mathrm{C}$ resistance and famillal thrombosis. British J. Haematol. 1994; 88, 219-222

30.Smith PK, Krohn Ri, Hermanson GT, Malia AK, Gartner FH, Provenzano MD, Fujimoto EK, Goeke NM, Olsen BJ, and Klenk DC Anal. Biochem. 1985; 150 , 76-85

31. Chase T Jr. and Shaw E. Comparison of the esterase activities of trypsin, plasmin and thrombin on guanidinobenzoate esters. Titration of the enzymes. Biochemistry 1969; 8, 2212-2224

32.Smith RL. Titration of activated bovine factor X. J Biol Chem 1973; 248, 24182423.

33.Sala N, Owen WG and Collen D. A functional assay of protein C in plasma. Blood 1984; 63(3), 671-675

34. Böttcher CJF, van Gent CM, and Pries C. A rapid and sensitive sub-micro phosphorus determination. Anal. Chim. Acta 1961; 24, 203-207 
35.Laemmli, U.K. Cleavage of structural proteins during the assembly of the head of bacteriophage T4. Nature 1970, 227,680-685

36.Blake MS, Johnston KH, Russel-Jones GJ and Gotschlich EC. A rapid, sensitive method for detection of alkaline phophatase-conjugated ant-antibody on Western blats. Anal Biochem 1984; 136, 175-179

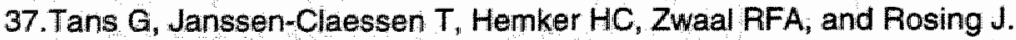
Meizothrombin formation during factor Xa-catalyzed prothrombin activation. Formation in a purified system and in plasma. (1991) J. Biol. Chem. 266, 21864-21873

38. Fersht A, (1985) in Enzyme Structure and Mechanism (Fersht A, ed) pp. 128-

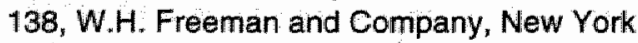

39. Kalafatis $M$, and Mann KG. Role of the membrane in the inactivation of factor Va by activated protein $C$. J Biol Chem 1993; 268, 27246-27257

40.Bakker HM, Tans G, Thomassen MCLGD, Yukelson LY, Ebberink R, Hemker $H C$, and Rosing J. Functional properties of human factor Va lacking the $A_{s p}{ }^{683}$. $\mathrm{Arg}^{700}$ domain of the heavy chain. J Biol Chem 1994; 269, 20662-20667

41.van Dieyen, G., Tans, G., Rosing, J., Zwaal, R.F.A., and Hemker, H.C. (1981) J. Biol. Chem. 256, 3433-3442

42. Mann KG, Nesheim ME, Church WR, Haley $P_{\text {" Krishnaswamy S. Surface }}$ dependent reactions of the vitamin $K$-dependent enzyme complexes. Blood $1990 ; 76,1-16$ 
Chapter' 4

\section{A Prothrombinase-Based Assay for Detection of Resistance to Activated Protein C}




\subsection{Summary}

Iril this chapter we present a new method for the detection of resistance to activated protein $C$ (APC) that is based on direct measurement of the effect of APC on the cofactor activity of plasma factor $V a$. The factor $V$ present in a diluted plasma sample was activated with thrombin and its sensitivity towards APC was subsequently determined by incubation with phospholipids and APC. The loss of factor Va cofactor activity was quantified in a prothrombinase system containing purified prothrombin, factor $\mathrm{Xa}$ and phospholipid vesicles and using a chromogenic assay for quantitation of thrombin formation. The reaction conditions were optimized in order to distinguish normal, heterozygous- and homozygous APC-resistant plasmas. Maximal differences in the response of these plasmas towards APC were observed when factor $V a$ was inactivated by APC in the absence of protein $S$ and when the cofactor activity of factor $\mathrm{Va}$ was determined at a low factor $\mathrm{Xa}$ concentration $(0.3 \mathrm{nM})$.

Addition of $0.2 \mathrm{nM} \mathrm{APC}$ and $20 \mu \mathrm{M}$ phospholipid vesicles to a 1000 -fold diluted sample of thrombin-activated normal plasma resulted in loss of more than $85 \%$ of the cofactor activity factor $\mathrm{Va}$ within $6 \mathrm{~min}$. Under the same conditions, APC inactivated $-60 \%$ and $-20 \%$ of the factor Va present in plasma samples from APC-resistant individuals that were heterozygous or homozygous for the mutation $\mathrm{Arg}^{506} \rightarrow \mathrm{Gln}$ in factor $V$, respectively. Discrimination between the plasma samples from normal and heterozygous and homozygous APC-resistant individuals was facilitated by introduction of the so-called APC-sensitivity ratio (APC-sr). The APC-sr was defined as the ratio of the factor $\mathrm{Va}$ cofactor activities determined in thrombin-activated plasma samples after 6 min incubation with or without $0.2 \mathrm{nM} \mathrm{APC}$ and was multiplied by 100 to obtain integers (APC-sr $=\left\{\right.$ factor $\left.V a_{+A . P C} / f a c t o r V a_{-A P C}\right\} \times$ 100). Clear differences were observed between the APC-sr of plasmas from normal healthy volunteers (APC-sr: $8-20, n=33$ ) and from individuals that were heterozygous (APC-sr: 35-50, n=17) or homozygous APC resistant (APC-sr: $82-88, n=7$ ). There was no mutual overlap between the APC-sr of normal plasmas and plasmas from heterozygous- or homozygous APC resistant individuals $(p<0.0001)$. In all cases our test gave the same result as the DNAbased assay. Since the test is performed on a highly diluted plasma sample there is no interference by conditions that affect APC resistance tests that are based on clotting time determinations (e.g. coagulation factor deficiencies, oral anticoagulation, heparin treatment, the presence of Jupus anticoagulants, pregnancy or the use of oral contraceptives). Furthermore, we show that part 
of the factor Va assay can be performed on an autoanalyzer which increases the number of plasma samples that can be handled simultaneously.

\subsection{Introduction}

In 1993, Dahlbäck et al. ${ }^{1}$ described a hereditary defect in the anticoagulant response to activated protein $C$ (APC) that is associated with an increased risk for venous thrombosis. This abnormality, called APC resistance, was subsequently identified as the most common defect in thromboembolic patients $^{2-6}$ and was found in $20-50 \%$ of patients with venous thrombosis. APC resistance is associated with familial thrombophilia and is inherited as an autosomal dominant trait. The molecular defect responsible for APC resistance is a single point mutation in the gene encoding for coagulation factor $V$. This mutation results in the substitution of $\mathrm{Arg}^{506}$ by Gin in the heavy chain domain of factor $V(a)^{7-11}$. Since Arg506 constitutes one of three $A P C$ cleavage sites in factor $V a^{12}$, the mutated factor $V(a)$, also described as factor $V^{\text {Leiden }}$ or factor $V R 506 Q$, is much less effectively inactivated by APC than normal factor $\mathrm{Va}^{13,14}$. Since APC-catalyzed inactivation of factor $\mathrm{Va}$ is a crucial step in the down-regulation of thrombin formation this likely explains the increased risk for venous thromboembolism in individuals with APCresistant plasma.

The requirement for reliable detection of APC resistance became important when it was discovered that at least 2 to $4 \%$ of the Caucasian population is APC-resistant ${ }^{2,3,6,7}$. Several methods for the diagnosis of APC resistance have been described so far ${ }^{15}$. Most of these methods are based on sequence analysis of genomic DNA ${ }^{7,16}$ or on measurement of the effect of APC on the activated partial thromboplastin time (APTT) ${ }^{4,77,18}$ or on thrombin generation in plasma ${ }^{19}$. APTT-based APC-resistance assays appear to be less reliable in the case of other coagulation disorders ${ }^{17,20-22}$, anticoagulant therapy ${ }^{2,4,6,23}$, pregnancy ${ }^{21}$ or the use of oral contraceptives ${ }^{24,25}$.

In this chapter, we report a different method for the identification of APCresistant plasmas. The method is based on direct measurement of the effect of APC on the activity of factor Va in diluted thrombin-activated plasma samples and subsequent determination of factor Va cofactor activity in prothrombin activation. 


\subsection{Materials and Methods}

\section{Materials and Buffers}

The phospholipids 1,2-dioleoyl-sn-glycero-3-phosphoserine (DOPS) and 1,2-dioleoyl-sn-glycero-3-phosphocholine (DOPC) were obtained from Avanti Polar Lipids, Alabaster, Alabama, USA. The chromogenic substrates D-Phe(pipecolyl)-Arg-pNA (S2238) and L-pyroGlu-Pro-Arg-pNA (S2366) were supplied by Chromogenix, Mölndal, Sweden. Recombinant human APC (rAPC) was a kind gift of Immuno A.G., Vienna, Austria. Human protein $S$ was purchased from Enzyme Research Laboratories, Swansea, United Kingdom. Human prothrombin and human factor $X$ were purified as described by DiScipio et $a{ }^{26}{ }^{26}$. Human factor $X$ was converted into factor $X a$ by incubation with the purified factor $X$ activator from Russel's viper venom and factor $X a$ was isolated from the activation mixture by chromatography on soybean trypsin inhibitor-Sepharose ${ }^{27}$.

All proteins used in the APC resistance test were diluted in buffer $1(25 \mathrm{mM}$ Hepes [pH 7.5], $175 \mathrm{mM} \mathrm{NaCl},\left.3 \mathrm{mM} \mathrm{CaCl}\right|_{2}$ and $5 \mathrm{mg} / \mathrm{ml} \mathrm{BSA}$ ).

\section{Phospholipid Vesicle Preparations}

Small unilamellar phospholipid vesicles composed of a mixture of DOPS/DOPC (10/90, M/M) were prepared as described earlier ${ }^{28}$. Phospholipid concentrations were determined by phosphate analysis ${ }^{29}$.

\section{Protein Concentrations}

APC concentrations were determined with $\$ 2366$ using kinetic parameters reported by Sala et al. ${ }^{30}$. Thrombin concentrations were determined with the chromogenic substrate $S 2238^{34}$. Protein $S$ concentrations were calculated from the $A_{280}$ using an $A^{1 \%}{ }_{280}$ of 9.5 and $M_{r}=70,000$ for protein $S^{32}$. Factor $V$ and factor $\mathrm{Va}$ concentrations were determined by measuring their activity in prothrombin activation ${ }^{14,33}$ under conditions described in the legends to the figures. 


\section{Collection and Handling of Plasma Samples}

Nine parts of blood from normal healthy volunteers or from individuals (both men and women) that were shown to be heterozygous or homozygous for the $\mathrm{Arg}^{506} \rightarrow \mathrm{GIn}$ mutation in factor $\mathrm{V}$ by DNA analysis ${ }^{34}$ were collected in one part of $0.13 \mathrm{M}$ trisodium citrate $(\mathrm{pH} 7.8)$. The blood was centrifuged twice for 15 minutes at $3,000 \times \mathrm{g}$ at room temperature. The platelet poor plasma thus obtained was stored at $-80^{\circ} \mathrm{C}$. The healthy volunteers had a normal APTT and prothrombin time, a normal response to APC and DNA analysis showed that they were not carrying the $\mathrm{Arg}^{506} \rightarrow \mathrm{Gln}$ mutation. A normal plasma pool was obtained by mixing the plasma of 84 different healthy volunteers (both men and women). Coagulation factor concentrations (including protein $\mathrm{S}$ and $\mathrm{C}$ ) of all volunteers were within the normal range.

\section{Chromogenic APC-resistance test}

The procedure that we have developed basically consists of three steps that are performed at $37^{\circ} \mathrm{C}$ :

1) activation of plasma factor $V$ with thrombin

2) incubation of factor $V a$ with or without APC

3) quantification of factor $\mathrm{Va}$ cofactor activity

Step1: to two tubes (sample A en B) with $215 \mu$ of $1 / 1000$ dilutions of the same plasma sample in buffer $\mathrm{I}, 5 \mu \mathrm{l}$ of a mixture of $175 \mathrm{nM}$ thrombin and 1 $\mathrm{mM}$ phospholipid vesicles (10/90 M/M DOPS/DOPC) was added to activate the factor $\mathrm{V}$ present in the plasma sample.

Step 2:. After $10 \mathrm{~min} 10 \mu \mathrm{l}$ buffer I was added to sample A and $10 \mu \mathrm{l}$ purified rAPC ( $4.6 \mathrm{nM})$ was added to sample $B$ and the incubation at $37^{\circ} \mathrm{C}$ was continued.

Step 3: After 6 min incubation with APC, $10 \mu$ prothrombin $(25 \mu \mathrm{M})$ and 10 $\mu \mathrm{l}$ factor Xa $(7.5 \mathrm{nM})$ were added to the samples $A$ en $B$ in order to determine the factor Va cofactor activity present. After $1 \mathrm{~min}$, the amount of thrombin generated in the reaction aliquots was quantitated by transferring a $10 \mu \mathrm{l}$ aliquot into a disposable cuvette with $990 \mu$ l of a buffer containing $235 \mu \mathrm{M}$ S2238 in $50 \mathrm{mM}$ Tris ( $\mathrm{pH} 7.5$ at $\left.37^{\circ} \mathrm{C}\right), 175 \mathrm{mM} \mathrm{NaCl}, 0.5 \mathrm{mg} / \mathrm{ml}$ ovalbumin and $20 \mathrm{mM}$ EDTA. The factor Va concentration in the plasma sample was calculated from the thrombin formed using a calibration curve made with known amounts of purified factor $\mathrm{Va}^{34}$.

The final concentrations of essential reaction components in the different steps were: step 1) $1 / 1000$ dilution of plasma sample, $4 \mathrm{nM}$ thrombin and 22.7 $\mu \mathrm{M}$ DOPS/DOPC (10/90, M/M) vesicles; step 2), $0.2 \mathrm{nM} \mathrm{APC}$ and 
21.7 $4 \mathrm{M}$ DOPS/DOPC (10/90) vesicles; step 3) $0.25 \mu \mathrm{M}$ prothrombin, $0.3 \mathrm{nM}$ factor $\mathrm{Xa}$ and $20 \mu \mathrm{M}$ DOPS/DOPC (10/90) vesicles. The factor Va assay procedure (step 3 ) is essentially the same as reported earlier ${ }^{33}$. However, in this particular application factor Va was assayed at $0.3 \mathrm{nM}$ factor Xa since at this factor $\mathrm{Xa}$ concentration the residual cofactor activity of the reaction intermediate cleaved at $\mathrm{Arg}^{506}$ is negligible compared to native factor $\mathrm{Va}^{14}$. This increased the difference in response between normal and factor $\mathrm{Va}^{\mathrm{R} 506 \mathrm{O}}$ in the test (see Results). Plasma samples were assayed within 1 hour of thawing, although samples, kept at room temperature for 20 hours, could be assayed without loss of assay accuracy. The intra-assay variation of the test was $3 \%(n=17)$, the inter-assay variation is $4 \%(n=20)$.

\section{Semi-automated method for the detection of APC resistance:}

Plasma samples were diluted 750 times in a $25 \mathrm{mM}$ Hepes buffer $(\mathrm{pH} \mathrm{7.5),}$ containing $175 \mathrm{mM} \mathrm{NaCl}, 5 \mathrm{mM} \mathrm{CaCl}$ and $5 \mathrm{mg} / \mathrm{ml} \mathrm{BSA}$, (buffer 1). After prewarming two aliquots of $400 \mu$ of the same plasma sample at $37^{\circ} \mathrm{C}, 16 \mu \mathrm{l}$ of a mixxture of $67 \mathrm{nM}$ thrombin and $667 \mu \mathrm{M}$ phospholipids (10/90 DOPS/DOPC M/M) without (sample A) or with $10 \mathrm{nM} \mathrm{APC} \mathrm{(sample} \mathrm{B)} \mathrm{was}$ added yielding final concentrations of $4 \mathrm{nM}$ thrombin, $20 \mu \mathrm{M}$ phospholipid vesicles with or without $0.39 \mathrm{nM} \mathrm{APC}$, respectively. After 20 min incubation, i.e. activation of plasma factor $V$ (sample $A$ ) or activation and inactivation of plasma factor $V$ (sample $B$ ) the reaction was stopped by the addition of 4500 $\mu$ cold buffer $1\left(4^{\circ} \mathrm{C}\right)$. After dilution of the APC-treated plasma sample APCcatalyzed factor $\mathrm{Va}$ inactivation at $37^{\circ} \mathrm{C}$ is slowed down $\sim 100$-fold and becomes considerably slower than the rate of spontaneous loss of factor $\mathrm{Va}$ cofactor activity $\left(<0.3 \% / \mathrm{min}\right.$ at $37^{\circ} \mathrm{C}$ ). Since spontaneous loss of factor $\mathrm{Va}$ activity occurs both in non-treated and APC-treated plasma samples any loss of factor $\mathrm{Va}$ activity during the preincubation/incubation procedure in the ACL300 will not affect the APC-sr.

The cofactor activity of factor $\mathrm{Va}$ present in the plasma samples was determined on an ACL-300 Research Automated Coagulation apparatus (Instrumentation Laboratory, Milan, Italy). Prothrombin activation was started by mixing $50 \mu \mathrm{l}$ aliquots of the plasma dilutions with $50 \mu \mathrm{l} 2 \mu \mathrm{M}$ prothrombin, $0.6 \mathrm{nM}$ factor $\mathrm{Xa}$ and $40 \mu \mathrm{M}$ phospholipids (10/90 DOPS/DOPC M/M) in 25 mM Hepes $(\mathrm{pH} 7.5), 175 \mathrm{mM} \mathrm{NaCl}$. After $2 \mathrm{~min}$ prothrombin activation was stopped by mixing with $50 \mu$ of $60 \mathrm{mM}$ EDTA in $25 \mathrm{mM}$ Hepes (pH 7.5), 175 $\mathrm{mM} \mathrm{NaCl}, 0.5 \mathrm{mg} / \mathrm{ml}$ ovalbumin and $2.35 \mathrm{mM} \mathrm{S} 2238$ and the thrombin present was assayed by monitoring $\$ 2238$ conversion for 1 minute at 405 $\mathrm{nm}$. Under the conditions described above $\mathrm{S} 2238$ conversion appeared to be proportional with the amount of factor $\mathrm{Va}$ present in the plasma sample. 


\section{Statistics}

Data are presented as ranges of values observed, median values or as mean \pm S.E.M.. The Student's t-test was used to determine the significance of differences between test results of groups of plasmas.

\subsection{Results}

\section{APC-mediated inactivation of factor Va generated in normal-pooled plasma and in plasmas from heterozygous and homozygous APC- resistant individuals.}

The chromagenic method to screen plasmas for APC resistance is actually based on earlier publications from our group concerning a sensitive assay for factor $\mathrm{Va}^{33}$, kinetic analysis of APC-catalyzed inactivation of factor $\mathrm{Va}$ and factor $\mathrm{Va}^{\mathrm{R5060} \text { ref14 }}$ and the effects of protein $\mathrm{S}$ and factor $\mathrm{Xa}$ thereon ${ }^{35}$.

Recently, we have shown ${ }^{14}$ that APC inactivates normal factor Va 20 times faster than factor $\mathrm{Va}^{\mathrm{R5060}}$. The difference between the observed rates of inactivation of factor $\mathrm{Va}$ and factor $\mathrm{Va}^{\mathrm{RSOGQ}}$ was maximal when the loss of cofactor activity of factor $\mathrm{Va}$ was monitored in prothrombin activation mixtures that contained a low factor Xa concentration (e.g. $0.3 \mathrm{nM}$, cf. ref. 14). Furthermore, we reported that differences in the rates of inactivation of factor $\mathrm{Va}$ and factor $\mathrm{Va}{ }^{\mathrm{R} 506 \mathrm{C}}$ were less pronounced or even nullified when factor $\mathrm{Va}$ was inactivated in the presence of protein $\mathrm{S}$ and/or factor $\mathrm{Xa}^{35}$.

Since the plasma of normal healthy volunteers contains $\sim 25 \mathrm{nM}$ factor $V^{36}$ and since our factor Va assay allows quantitation of factor Va as low as 0.2 $\mathrm{pM}$ it is possible to determine the sensitivity of plasma factor Va towards APC at high plasma dilutions (>1000-fold), independent from and unaffected by other plasma components. The procedure that we have developed for distinguishing normall and APC-resistant plasmas basically consists of three steps:

1) activation of the factor $V$ present in a highly diluted plasma sample with thrombin

2) incubation of factor Va in the presence of phospholipids with or without APC

3) quantification of factor Va cofactor activity. 
4) In order to obtain optimal differentiation between plasmas from normal healthy individuals, heterozygous and homozygous APC individuals the inactivation of factor $\mathrm{Va}$ should theoretically be performed in the absence of factor $\mathrm{Xa}$ and protein $\mathrm{S}^{35}$ and the cofactor activity of factor $\mathrm{Va}$ should be assayed at a low factor Xa concentration ${ }^{14}$.

Fig. 4.1 A shows that under these conditions the factor $V a$ formed by thrombin in a normal plasma sample was indeed readily inactivated by $0.2 \mathrm{nM}$ APC whereas the factor $V a$ present in the plasma sample from a heterozygous APC-resistant patient showed intermediate sensitivity and that in plasma from a homozygous APC-resistant patient was very slowly inactivated by APC. The differences in response

towards APC were much less pronounced when protein $S$ was present during factor $\mathrm{Va}$ inactivation (Fig. 4.1B) or when the loss of cofactor activity of factor $\mathrm{Va}$ was assessed in a prothrombinase mixture that contained a high concentration of factor $\mathrm{Xa}$ (Fig. $4.1 \mathrm{C}$ ).

For practical reasons it is preferable that an APC-resistance test is based on measurement of sensitivity of plasma factor Va towards APC at a single time point. Quantitative comparison of the plasma samples was facilitated by expressing their response towards APC in terms of the so-called APC sensitivity ratio (APC-sr, of. ref. 2, 11, 17-18). The APC-sr is defined as the ratio of the factor $\mathrm{Va}$ activities determined after incubation of the plasma factor $\mathrm{Va}$ in the presence and absence of APC and was multiplied by 100 to obtain integers $\left(A P C-s r=\left\{\right.\right.$ factor $V a_{+A P C}$ factor $\left.V a_{-A P C}\right\} \times 100$ ). It appeared that under the reaction conditions of the experiment presented in Fig. 4.1A, clear differences between the APC-sr of the various plasmas were obtained for incubation times between 2 and $15 \mathrm{~min}$. Therefore, in the case of a single time point assay, we have arbitrarily chosen for determination of the APC-sr after 6 min incubation with APC. Under these conditions the APC-sr was 13 for normal pooled plasma and 50 and 81 for heterozygous- and homozygous APC-resistant plasma, respectively. 

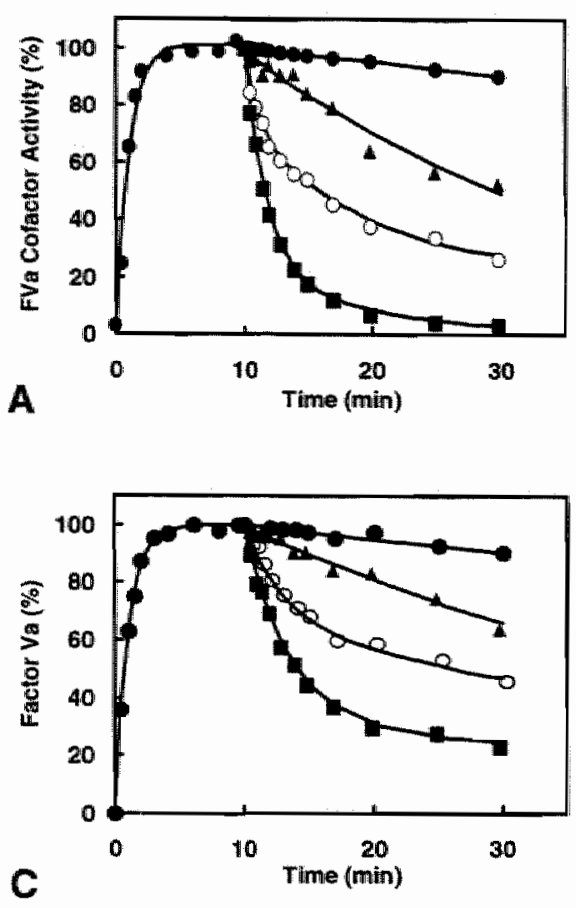

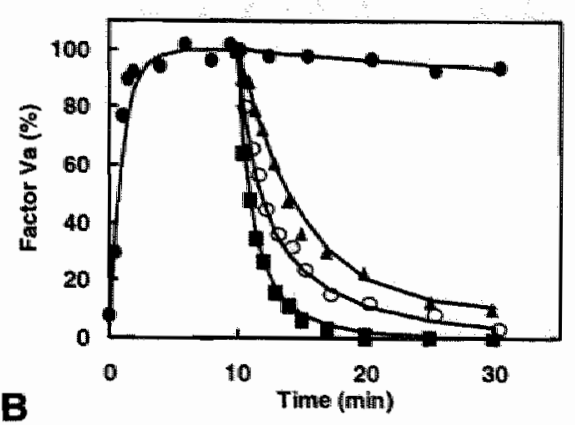

FIG. 4.1 Effect of APC on the activity of factor Va generated in normal plasma and in plasma from heterozygote- and homozygote APCresistant individuals. Normal-pooled plasma (I), plasma from heterozygous (O) or homozygous (4) APC-resistant individual wes diluted 1000 times in buffer I and factor $V$ was activated at $37{ }^{\circ} \mathrm{C}$ with 4 $n M$ thrombin in the pressnce of phospholipid vesicles (10/90 DOPS/ DOPC MMM). After $10 \mathrm{~min}$ $A P C$ with or without protein $S$ was added to

inactivate factor $\mathrm{Va}$. The formation and loss of factor $\mathrm{Va}$ cofactor activity was followed as described in "Materials and Methods". For each plasma sample the factor Va activity is given as \% of its plateau value. Time courses of factor $V$ activation in the different plasmas and the spontaneous loss of factor Wa activity were indistinguishable and are therefore, given in the figure as a single averaged curve ( ) for the three clifferent plasmas. The final concentrations of components during the inactivation and assay procedures were: (A) $0.2 \mathrm{nM}$ APC and 21.7 $\mu M$ phosphofipid vesicles during inactivation and $0.3 \mathrm{nM}$ factor $X a, 1 \mu \mathrm{M}$ prothrombin and 20 $\mu M$ phospholipid vesicles in the factor Va assay mixture; (B) $0.2 \mathrm{MM} A P C, 200 \mathrm{nM}$ protein $\mathrm{S}$ and $21.7 \mu \mathrm{M}$ phospholipid vesicles during inactivation and $0.3 \mathrm{nM}$ factor $X a, 1 \mu \mathrm{M}$ prothrombin and $20 \mu \mathrm{M}$ phospholipid vesicles in the factor Va assay mixture and (C) $0.2 \mathrm{nM} A \mathrm{APC}$ and 21.7 $\mu M$ phospholipid vesicles during inactivation and $10 \mathrm{mM}$ factor $X a, 1 \mu \mathrm{M}$ prothrombin and 20 $\mu M$ phospholipid vesicles in the factor Va assay mixture.

\section{Influence of plasma dilution on the APC-sr}

To establish the range of plasma dilutions at which the APC resistance test can be performed, we have determined the APC-sr as a function of the plasma dilution (Fig. 4.2). 


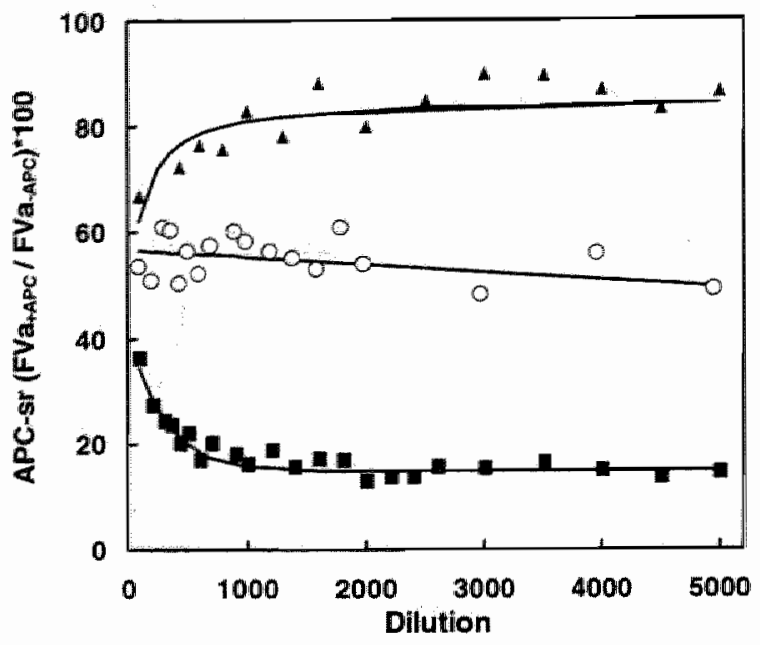

FiG. 4.2 The influence of the plasma difution on the response of the various plasmas to APC. The factor $V$ present in varying difutions of normal-pooled plasma (I) or plasma from a heterozygous (O) or a homozygous APCresistant individual (A) was activated by incubating the plasma dilution during $10 \mathrm{~min}$ with $4 \mathrm{nM}$ thrombin at $37^{\circ} \mathrm{C}$. Factor $\mathrm{Va}$ was further incubated for 6 min with or without 0.2 IM APC in the presence of $21.7 \quad \mu M$ phospholipid vesicles (10/90

DOPSIDOPC MM). The remaining cofactor activity of factor Va was determined in a prothrombinase mixture containing $0.3 \mathrm{nM}$ factor $X a, 1 \mu \mathrm{M}$ prothrombin and $20 \mu \mathrm{M}$ phospholipid vesicles (10/90 DOPS/DOPC MMM). The APC-sr (factor Va $a_{+A P d}$ factor Va.,ApC) was corrected for an assay blank, determined with a reaction mixture that did not contain plasma. For practical reasons, the APC-sr was multiplied by 100 in order to obtain integers. Further experimental details are given under 'Materials and Methods'.

At low plasma dilutions the APC-sr of the different plasmas approached the same value $(-50)$. This may be caused by effects of other plasma proteins (e.g. protein $\mathrm{S}$, cf. ref. 35) on the inactivation of factor Va by APC or by underestimation of the amount of factor Va present in the plasma sample. When too much factor $\mathrm{Va}$ is introduced in the factor $\mathrm{Va}$ assay mixture, factor $X_{a}$ and prothrombin become limiting, which will cause an underestimation of the factor $\mathrm{Va}$ concentration especially in the plasma sample that was not treated with APC.

Reliable differences between the APC-sr of normal and APC-resistant plasmas were obtained when the test was performed on plasma samples that were diluted 500 to 5000 times. At higher dilutions of the plasma samples, the thrombin used to activate factor $V$ in the plasma sample significantlly contributed to the thrombin determined in the factor Va assay. Correction for this contribution (typically $\angle 5 \%$ in the absence of APC, and $5-25 \%$ in the presence of APC) required subtraction of an assay blank in which plasma was substituted with buffer. 


\section{Test results for a population of normal plasmas and plasmas from heterozygous or homozygous APC-resistant individuals.}

Plasmas from a number of normal ( $n=33)$, heterozygous $(n=17)$ and homozygous individuals $(n=7)$, both men and women, were screened using the method described in the previous paragraphs. For all plasmas the presence or absence of the factor $V^{\mathrm{R} 5060}$ mutation was verified by genetic analysis of genomic DNA samples. In agreement with the results presented in previous paragraphs for the single plasmas, clear differences were observed for the three different groups of plasmas (Fig. 4.3).

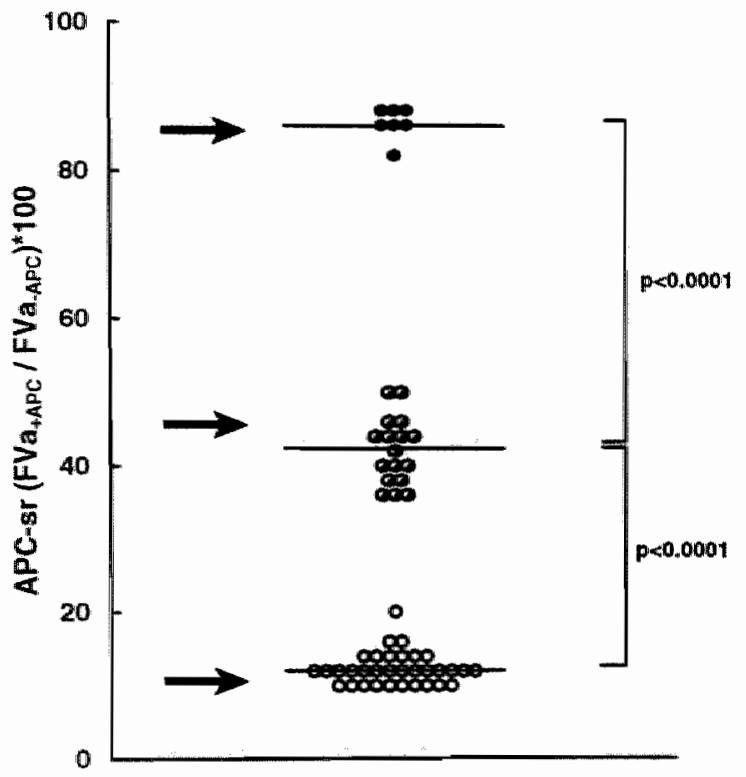

FIG. 4.3 Range of APC-sr of plasmas from healthy volunteers and heterozygous- and homozygous APC-resistant individuals. The effect of APC on the cofactor activity of factor $\mathrm{Va}$ generated in a $1 / 1000$ dilution of the plasma samples was determined as described in the Materials and Methods (cf. Fig. 4.2). The plasma samples were classified as belonging to normal healthy individuals (O), heterozygous APCresistant individuals (O) or homozygous APC-resistant individuals (O) by DNA analysis. The data obtained were plotted as $A P C-s r=$ factor Va $a_{+A P C}$ factor Va.APC multipiled by 100. Median values are indicated per group. P-values are given. The position of the theoretical APC-sr (see Discussion) is indicated per group of plasma samples $(\rightarrow)$.

The APC-sr values of the plasmas actually divided into three populations: $12.3 \pm 0.38$ (mean \pm S.E.M.), for normal plasmas, $42.3 \pm 1.0$ for the plasmas of heterozygous APC-resistant individuals and $85.6 \pm 0.63$ for the plasmas of homozygous APC-resistant individuals. The ranges of APC-sr observed for these three populations were 8-20, 35-50 and 82-88 respectively. There was no overlap between the three groups of plasmas, i.e. the APC-sr of homozygouls APC resistant individuals was significantly higher than the APCsr of heterozygous APC-resistant individuals $(P<0.0001)$. A similar difference was observed between the APC-sir of the plasma of heterozygous APC- 
resistant individuals and the plasma of normal individuals. The outcome of the chromogenic APC resistance test was in full agreement with the results obtained by DNA analysis.

\section{The chromogenic APC resistance test and plasma with coagulation abnormalities}

APC resistance tests that are based on measurement of the effect of APC on the APTT give less reliable results in plasmas with abnormal APTT values e.g. in the case of coagulation factor deficiencies ${ }^{17,20,24}$, anticoagulant treatment with heparin or oral anticoagulants $2,4,6,17,23$, the presence of Lupus anticoagulant $^{22}$, pregnancy ${ }^{21}$ or the use of oral contraceptives ${ }^{24,25}$. Since our test is performed on highly diluted plasma samples it is only dependent on plasma factor $V$ and is not dependent on other plasma components. Hence, it is not surprising that for all "abnormal plasmas" tested the APC-sr values obtained by our assay were within the range of normal plasmas (Table 4.1).

Table 4.1

APC-sr for normal plasmas and plasmas with abnormal coagulation properties

\begin{tabular}{lccc}
\hline Plasma & APC-sr & range & $\mathrm{n}$ \\
\hline Plasma from normal individuals & $12.3 \pm 0.38$ & $8-20$ & 33 \\
Heterozygous APC resistant plasma & $41.9 \pm 1.0$ & $35-50$ & 17 \\
Homozygous APC resistant plasma & $86.0 \pm 0.63$ & $82-88$ & 7 \\
Protein S deficient plasma & $12.8 \pm 0.70$ & $12-14$ & 2 \\
Plasma (oral anticoagulation) & $15.4 \pm 1.20$ & $12-20$ & 8 \\
Plasma (Heparin treatment) & $15.9 \pm 0.74$ & $14-18$ & 4 \\
Plasma (oral contraception) & $13.1 \pm 0.49$ & $10-18$ & 15 \\
Plasma (pregnancy) & $12.6 \pm 0.61$ & $12-14$ & 3 \\
Plasma (Lupus anticoagulans) & $12.0 \pm 0.96$ & $10-14$ & 3 \\
\hline
\end{tabular}

\footnotetext{
"The APC-sr for the different plasmas was determined as described in the legend of Fig. 4.2. Mean \pm S.E.M. are given, $n$ : number of different plasma samples tested. immunodepleted and plasma from a heterozygous protein $S$ deficient patient ( $<5 \%$ free protein $S$ antigen)
} 


\section{Modification of the chromogenic APC resistance test for use on an autoanalyzer.}

Although the test described above is rather easy to perform we have adapted the assay for use on an ACL-300 Research Automated Coagulation Apparatus. In this application the plasma dilution, the activation of factor $\mathrm{V}$ and inactivation of factor Va were performed outside the apparatus but the factor $\mathrm{Va}$ was determined on the autoanalyzer. It appeared possible to activate plasma factor $V$ and inactivate the factor $V a$ with $A P C$ in a single step by incubating the plasma dilution with $20 \mu \mathrm{M}$ phospholipids, $4 \mathrm{nM}$ thrombin in the absence or presence of $0.4 \mathrm{nM}$ APC during $20 \mathrm{~min}$. After this incubation the sample was diluted 12-fold with cold Hepes buffer and stored on ice in order to block further factor $\mathrm{Va}$ inactivation. The factor $\mathrm{Va}$ present in the plasma samples thus obtained appeared to be stable for at least one hour, which allowed a factor Va determination on the autoanalyzer. In the autoanalyzer the treated plasma sample was mixed with a solution containing prothrombin, factor $X a$ and phospholipid vesicles $(t=0 \mathrm{~min})$ and subsequently with a S2338/EDTA mixture $(t=2 \mathrm{~min})$ to stop prothrombin activation and to determine thrombin. Under the chosen assay conditions the thrombin formed was proportional to the amount of factor Va present in the plasma sample. The results obtained with the semi-automated method are shown in fig. 4.4 and are in good agreement with the data shown in Fig. 4.3, they also gave a distinct APC-sr for the normal plasmas and the heterozygous and homozygous APC-resistant plasmas. The differences between the three groups of plasmas tested were highly significant $(p<<0.0001)$. The APC-sr (mean \pm S.E.M.) for the three groups of plasmas tested were $12.2 \pm 0.24$, $45.3 \pm 0.72$ and $77.3 \pm 0.3$ for the plasmas of normal, heterozygous APCresistant and homozygous APC-resistant individuals respectively. 


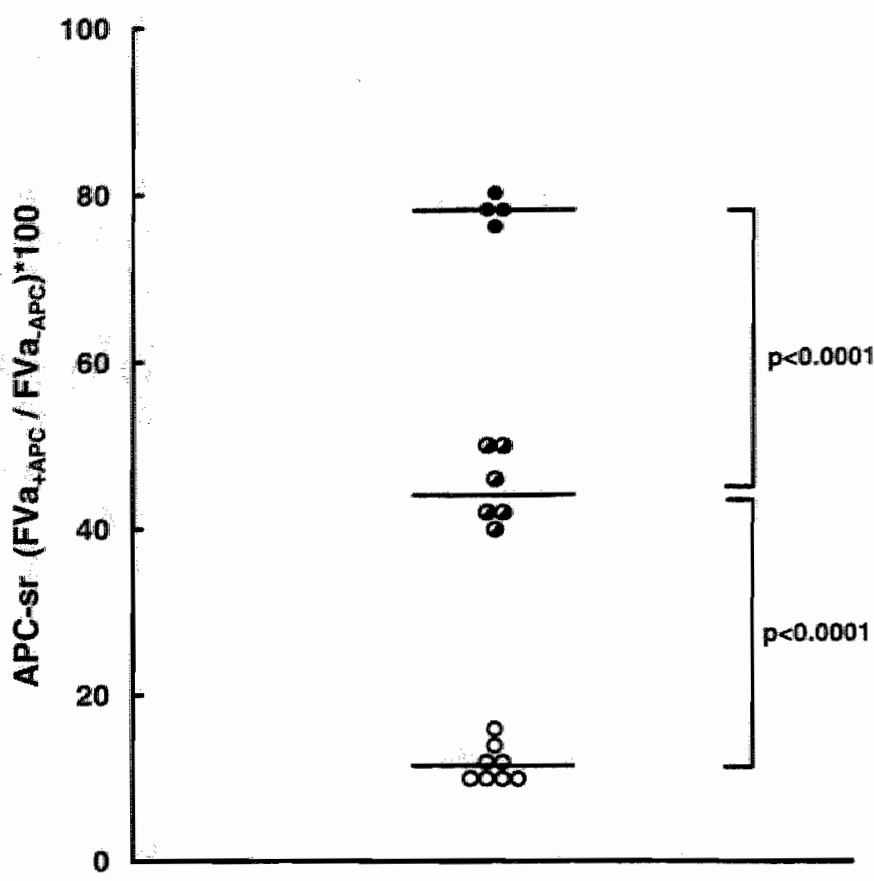

FIG. 4.4 Range of APC sensitivity ratios of plasmas from healthy volunteers and heterozygous- and homozygous APC-resistant individuals determined by a semiautomated method. The APC-sr (factor Va $a_{+A P C}$ factor Va.APC) 100 of various plasmas was determined on a ACL-300 Research Automated Coagulation apparatus as described in the Materials and Methods. The plasma samples were classified as belonging to normal healthy individuals (O), heterozygous APC-resistant individuals $(O)$ or homozygous APC-resistant individuals (O) by DNA analysis. Median values are indicated per group. 


\section{5 Discussion}

In this chapter we present a new functional test for the screening of plasmas for APC resistance that is based on probing the effect of APC on the cofactor activity of factor $\mathrm{Va}$ that is present in a thrombin-activated plasma sample. APC-catalyzed loss of cofactor activity of nomal factor Va is due to proteolytic cleavage of peptide bonds located at $\mathrm{Arg}^{506}$ and $\mathrm{Arg}^{306}$ of the heavy chain of factor Va (ref 12-14). Factor Va from APC-resistant individuals (factor $\mathrm{Va}^{\mathrm{R} 506 \mathrm{Q}}$ ) is much slower inactivated by $\mathrm{APC}^{14}$ since it lacks the cleavage site at $\mathrm{Arg}^{506}$.

In this chapter we show that maximal differences in APC-mediated loss of factor $\mathrm{Va}$ cofactor activities, present in thrombin-activated plasma samples from normal individuals and heterozygous and homozygous APC-resistant individuals, were obtained when 1) factor Va was inactivated by APC in a high plasma dilution in the absence of factor $X a$ and protein $S$ and when 2) the factor $\mathrm{Va}$ cofactor activity was determined in a prothrombinase mixture containing a low factor $X a$ concentration (Fig. 4.1).

This led to a rapid and simple method for the screening of plasmas for APC resistance. Our procedure is based on comparison of the amounts of factor Va cofactor activity present in thrombin-activated plasma samples that were incubated during 6 minutes with phospholipid vesicles either in the absence or presence of $0.2 \mathrm{nM}$ APC. The anticoagulant response of a given plasma sample to APC can be easily quantitated from the so-called APC sensitivity ratio (APC-sr) which is defined as the ratio of amounts of factor $\mathrm{Va}$ present in the APC-treated and the non-treated plasma sample. The chosen reaction conditions allow full distinction between the normal plasmas and the plasmas from individuals that were shown to be heterozygous or homozygous APC resistant by DNA analysis (Fig. 4.3). This is in contrast to results obtained with APTT-based APC-resistance assays, in which borderline zones for the APC response are observed in which it is difficult to distinguish normal heterozygous and homozygous APC-resistant individuals ${ }^{11,15,37}$ unless the plasma sample is diluted in factor $V$-deficient plasma ${ }^{38,39}$ or buffer ${ }^{40}$. The functional method for screening of APC resistance described in this chapter gives results that are fully compatible with those obtained by DNA analysis. This is not surprising since the determination is performed on highly diluted plasma samples which makes the assay independent of other plasima components that may affect inactivation or quantitation of the factor $\mathrm{Va}$ present in the plasma sample. This has the additional advantage that our assay is not affected by conditions that may interfere with coagulation-based tests such as coagulation factor abnormalities ${ }^{20,21}$, the presence of lupus 
anticoagulants ${ }^{22}$, anticoagulant treatment $t^{2,4,6,17,23}$, pregnancy ${ }^{21}$ or the use of oral contraceptives ${ }^{24,25}$ (Table 4.1). A number of the heterozygote and homozygote APC-resistant individuals had been suffering from episodes of venous thromboembolism. In the prothrombinase-based assay they were indistinguishable from healthy APC-resistant individuals.

It should be emphasized that the actual value of the APC-sr is dependent on reaction conditions such as $\mathrm{pH}$, temperature, the concentrations of APC and phospholipid vesicles and the time of incubation with APC. When the reaction conditions are not strictly controlled, different APC-sr may be obtained. Day to day variation of the APC-sr can, however, be minimized by predetermining the APC-sr of a nomal pooled plasma as a function of the incubation time with APC and taking in the actual test an incubation time that yields an $\mathrm{APC}-\mathrm{sr}$ of $10-15$ in the pilot experiment.

Actually, the APC-sr obtained in the experiment presented in Fig.4.3 should equal a theoretical value that can be calculated using rate constants for APC-catalyzed cleavage of the peptide bonds located at Arg ${ }^{506}$ and $\mathrm{Arg}^{306}$ reported in chapter $3^{14}$. Using rate constants of $6.7^{*} 10^{-5} \mathrm{~s}^{-1}$ for the spontaneous loss of factor Va cofactor activity and $4.3^{*} 10^{7} \mathrm{M}^{-1} \mathrm{~s}^{-1}$ for APCcatalyzed cleavages at $\mathrm{Arg}^{505}$ and $2.3^{*} 10^{6} \mathrm{M}^{-1} \mathrm{~s}^{-1}$ for cleavage at $\mathrm{Arg}{ }^{306}\left(\mathrm{ref}^{14}\right.$ ), theoretical APC-sr of 10,46 and 85 are calculated for the plasma of normal individuals, heterozygous (assuming $50 \%$ normal factor $V$ and $50 \%$ factor $V^{A 5060}$ ) and homozygous APC-resistant individuals, respectively. The theoretical values for the APC-sr closely approach the values experimentally obtained (Fig. 4.3).

We have shown that it is possible to use an autoanalyzer in order to increase the number of samples that can be tested simultaneously. In the semi-automated method the activation of plasma factor $V$ by thrombin and the inactivation of factor $\mathrm{Va}$ by APC occur in a single step in a $37^{\circ} \mathrm{C}$ waterbath and the amount of factor Va present in the plasma sample is determined on an autoanalyzer by subsequently mixing the plasma sample with prothrombinase components (phospholipids, $\mathrm{Ca}^{2+}$ ions, prothrombin and factor $X a)$ and with a solution containing the thrombin-specific chromogenic substrate $\$ 2238$ in EDTA (to block further prothrombin activation). When the reaction conditions and the incubation times were chosen properly, the rate of S2238 conversion appeared to be proportional with the amount of factor $\mathrm{Va}$ present in the plasma sample and values for APC-si allowed discrimination between normal, heterozygous and homozygous APC-resistant plasmas (Fig. 4.4).

The combination of reliability, reproducibility and easy performance, together with the fact that the assay is not disturbed in plasmas with abnormal 
coagulation characteristics, make the APC-resistance test that is presented in this chapter an excellent method to screen plasma samples for APC resistance. The test actually gives direct information on the presence of Arg506 $\rightarrow$ Gin mutation and gives distinct results with normal, homozygous and heterozygous APC-resistant plasmas that are fully compatible with those obtained with DNA-based assays. It is to be expected that the test will also recognize other abnormalities related to the factor $V$ gene that can cause APC resistance (e.g. mutations or variable expression of factor $V$ alleles in R506Q heterozygotes).

\section{Acknowledgments}

This work was supported by Program Grant 900-526-192 from the Dutch Organisation for Scientific Research (N.W.O.).

\section{References}

1. Dahlbäck $B$, Carlsson $M$, and Svensson PJ. Familial thrombophilia due to a previously unrecognized mechanism characterized by poor anticoagulant response to activated protein $\mathrm{C}$ : Prediction of a cofactor to activated protein $\mathrm{C}$. Proc Natl Acad Sci USA 1993; 90: 1004-08.

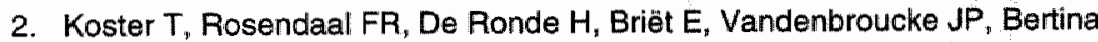
RM. Venous thrombosis due to a poor anticoagulant response to activated protein C: Leiden Thrombophilia Study. Lancet 1993; 342: 1503-06.

3. Griffin JH, Evatt B, Wideman C, Fernandez JA. Anticoagulant protein C pathway defective in a majority of thrombophilic patients. Blood 1993; 82: 1989-93.

4. Cadroy $Y$, Sie $P$, Boneu $B$. Frequency of a defective response to activated protein $C$ in patients with a history of venous thrombosis. Blood 1994; 83: 2008-9.

5. Svensson PJ, Dahlbäck B. Resistance to activated protein $C$ as a basis for venous thrombosis. N Engl J Med 1994; 330: 517-22.

6. Halbmayer WM, Haushofer A, Schön $R$, Fischer $M$. The Prevalence of poor anticoagulant response to activated protein C (APC Resistance) among patients suffering from stroke or venous thrombosis and among healthy subjects. Blood Coagul Fibrinol 1995; 5:51-7.

7. Bertina RM, Koeleman BPC, Koster T, Rosendaal FR, Dirven RJ, De Ronde $\mathrm{H}$, Van der Velden PA, Reitsma PH. Mutation in blood coagulation factor $V$ associated with resistance to activated protein $C_{\text {. Nature }}$. N994; 369:64-7.

8. Voorberg J, Roelse J, Koopman R, Büller H, Berends F, Ten Cate JW, Mertens K, Van Mourik JA. Association of idiopathic venous thromboembolism with single point-mutation at Arg506 of factor V. Lancet 1994; 343: $1535-6$. 
9. Greengard JS, Sun $X, X u, X$, Fernandez JA, Griffin JH, Evatt B. Activated protein C resistance caused by Arg506Gin mutation in factor Va. Lancet 1994; 343: $1361-62$.

10. Alhenc-Gelas M, Gandrille S, Aubry M-L, Emmerich J, Fiessinger J-N, Alach $M$. Unexplained thrombosis and factor $V$ Leiden mutation. Lancet 1994; 344 : $555-6$.

11. Zöller $B$, Svensson $P J$, He X. Dahilbäck $B$. Identification of the same factor $V$ gene mutation in 47 out of 50 thrombosis-prone families with inherited resistance to activated protein C. J Clin Invest 1994; $94: 2521-4$.

12. Kalafatis M, Rand MD, Mann KG. The mechanism of inactivation of human factor $V$ and human factor $V a$ by activated protein $C . J$ Biol Chem 1994; 269: 31869-80.

13. Kalafatis M, Bertina RM, Rand MR, Mann KG. Characterization of the molecular defect in factor VR5060. J Biol Chem 1995: 270: 4053-7.

14. Nicolaes GAF, Tans G, Thomassen MCLGD, Hemker HC, Pabinger I, Varadi K, Schwarz HP, Rosing J. Peptide bond cleavages and loss of functional activity during inactivation of factor $\mathrm{Va}$ and factor $\mathrm{Va} \mathrm{R}^{\mathrm{B}} \mathrm{O6Q}$ by activated protein C. J Biol Chem 1995; 270: 21158-66.

15. Dahlbäck B. Resistance to activated protein $\mathrm{C}$, the $\mathrm{Arg}^{506}$ to $\mathrm{Glin}$ mutation in the factor $V$ gene and venous thrombosis. Thromb Haemost 1995; 73: 739-42.

16. Gandrille S, Alhenc-Gelas M, Aiach M. A rapid screening method for the factor $V$ Arg506-> Gin mutation. Blood Coagul Fibrinol 1995; 6: 245-8.

17. De Ronde $\mathrm{H}$, Bertina RM. Laboratory diagnosis of APC-resistance: a critical evaluation of the test and the development of diagnostic criteria. Thromb Haemost 1994; 72 : 880-6.

18. Rosén $\mathrm{S}$, Johansson K, Lindberg K, Dahlbäck B. Multicenter evaluation of a kit for activated protein $C$ resistance on various coagulation instruments using plasmas from healthy individuals. Thromb Haemost 1994; 72: 255-60.

19. Nicolaes GAF, Thomassen MCLGD, Béguin S, Tans G, Rosing J, Hemker $\mathrm{HC}$. Effect of activated protein $\mathrm{C}$ on thrambin generation and on the thrombin potential in normal and APC resistant individuals. Thromb Haemost, submitted for publication.

20. Kraus $M$, Zander $N$, Fickenscher $K$. Coagulation assay with improved specificity to factor $V$ mutants insensitive to activated protein $C$. Thromb Res 1995; 80: 255-64.

21. Vasse $M$, Leduc $O$, Borg $J-Y$, Chrétien $M H$, Monconduit M. Resistance to activated protein C: evaluation of three functional assays. Thromb Res 1994: 76: $47-59$.

22. Bokarewa MI, Bremme K, Falk $G$, Sten-Linder $M$, Egberg N, Blombäck $M$. Studies on phospholipid antibodies, APC-resistance and associated mutation in the coagulation factor $V$ gene. Thromb Res 1995; 78: 193-200.

23. Cadroy $Y$, Sié $P$, Alhenc-Gellas $M_{2}$, Alach $M$. Evaluation of APC resistance in the plasma of patients with Q506 mutation of factor $V$ (factor $V$ Leiden) and treated by oral anticoagulants. Thromb Haemost 1995; 73: 734-5.

24. Henkens CMA, Bom VJJ, Seinen AJ, Van der Meer J. Sensitivity to activated protein $C_{;}$influence of oral contraceptives and sex. Thromb Haemost 1995; 73: $402-4$ 
25. Olivieri $O$, Friso S, Manzato F, Guella A, Bernardi $F$, Lunghi $B$, Girelli $D$, Azzini $M$, Brocco G, Russo C, Corrocher $R$. Resistance to activated protein $C$ in healthy women taking oral contraceptives. Br J Haematol 1995; 91: 465-70.

26. DiScipio RG, Hermodson MA, Yates SG, Davie EW. A comparison of human prothrombin, factor $\mathrm{XX}$ (Christmas factor), factor $\mathrm{X}$ (Stuart factor), and Protein S. Biochemistry 1977; 16: 698-706.

27. Bock PE, Craig PA, Olsen ST, Singh P. Isolation of human blood coagulation factor $\alpha$-factor $X a$ by soybean trypsin inhibitor-sepharose chromatography and its active site titration with fluorescin mono-p-guanidinobenzoate. Arch Biochem Biophys 1989; 273: 375-88.

28. Rosing J, Bakker HM, Thomassen MCLGD, Hemker HC, Tans G. Characterization of two forms of human factor Va with different cofactor activities. J Biol Chem 1993; 268: 21130-6.

29. Böttcher C.JF, van Gent CM, Pries C. A rapid and sensitive sub-micro phosphorus determination. Anal Chim Acta 1961; 24: 203-7.

30. Sala $N$, Owen WG, Collen D. A functional assay for protein $C$ in human plasma. Blood 1984; 63: 671-5.

31. Rosing J, Tans G, Govers-Riemslag JWP, Zwaal RFA, Hemker HC. The role of phospholipids and factor $\mathrm{Va}$ in the prothrombinase complex. $J$ Biol Chem 1980; 255: 274-83.

32. DiScipio RG, Davie EW. Characterization of protein $S$ a gammacarboxyglutamic acid containing protein from bovine and human plasma. Biochemistry 1979; 18: 899-904.

33. Tans G, Rosing J, Thomassen MCLGD, Heeb MJ, Zwaal RFA, Griffin JH. Comparison of anticoagulant and procoagulant activities of stimulated platelets and platelet-derived microparticles. Blood 1991; 77: 2641-8.

34. Beauchamp NJ, Daly ME, Hampton KK, Cooper PC, Preston FE, Peake IR. High prevalence of a mutation in the factor $V$ gene within the U.K. population: relationship to activated protein $\mathrm{C}$ resistance and familial thrombosis. $\mathrm{Br} \mathrm{J}$ Haematol 1994; 88: 219-22.

35. Rosing J, Hoekema L, Nicolaes GAF, Thomassen MCLGD, Hemker HC, Varadi $K$, Schwarz HP, Tans $G$. Effects of protein $S$ and factor $X a$ on peptide bond cleavages during inactivation of factor $\mathrm{Va}$ and factor $\mathrm{Va}{ }^{\mathrm{Ag} 06 \mathrm{Q}}$ by activated protein C. J Biol Chem 1995; 270: 27852-8.

36. Tracy PB, Eide LL, Bowie EJW, Mann KG. Radioimmunoassay of factor $V$ in human plasma and platelets. Blood 1982; 60: 59-63.

37. Samaha $M$, Trossaert $M$, Conard $J$, Horellou $M H_{3}$ Elalamy I, Samama MM. Prevalence and patient profile in activated protein $\mathrm{C}$ resistance. Am J Clin Pathol 1995; 104:450-4

38. Sun X, Evatt B, Griffin J. Blood coagulation factor Va abnormality associated with resistance to activated protein $C$ in venous thrombophilia. Blood 1994; 11:31120-5

39. Engel $H$, Zwang L, wan Vliet HHDM, Michiels JJ, Stibbe J., Lindemans J. Phenotyping and genotyping of coagulation factor $V$ Leiden. Thromb Haemost $1996 ; 75: 267-9$

40. Le DT, Donnely $K$, Sevilla B, Rapaport. Further experience with the TF-based FV assay for APC resistant Fva. (APC-R). Blood. 1995; 86:202a 
Chapter 5

\section{Effect of activated protein $\mathrm{C}$ on thrombin generation and on the thrombin potential in plasma of normal and APC-resistant Individuals}




\subsection{Summary}

This chapter describes the effect of activated protein C (APC) on thrombin generation initiated in platelet poor plasma via the extrinsic or the intrinsic pathway. Thrombin was determined with a specific chromogenic substrate and quantitated by calculating the time integral of the thrombin generation curve, i.e. the endogenous thrombin potential (ETP). Addition of APC to normal plasma after both extrinsic and intrinsic initiation of coagulation resulted in a dose-dependent inhibition of thrombin generation as reflected by the decrease of the ETP. Data obtained in intrinsically-triggered plasma of normal individuals were subject to rather large variation. Therefore, the effect of APC on thrombin generation in APC-resistant plasmas was only studied in extrinsically-stimulated reaction systems. APC had much less effect on the ETP of plasma from individuals that were heterozygous or homozygous for the mutation $\mathrm{Arg}^{506} \rightarrow \mathrm{Gln}^{506}$ in factor V (APC resistance). There appears to be a linear relationship between the ETP and the amount of $\alpha_{2}$-macroglobulin-thrombin complex $\left(\alpha_{2} \mathrm{M}-1 / \mathrm{l}\right)$ that accumulates in plasma during thrombin formation. Since the $\alpha_{2} M-l l a$ complex possesses amidolytic activity, we measured the effect of APC on thrombin generation via the so-called normalized APC sensitivity ratio (APC-sr). The latter was defined as the ratio of the end levels of amidolytic activity of the $\alpha_{2} \mathrm{M}$-lla complex determined in the presence and absence of $50 \mathrm{nM}$ APC $\left(\alpha_{2} \mathrm{M}-1 \mathrm{l}_{+\mathrm{APC}} /\left(\alpha_{2} \mathrm{M}-\mathrm{Il} \mathrm{a}_{-\mathrm{APC}}\right)\right.$ divided by the ratio of a normal plasma pool. Significant differences $(p<0.001)$ were observed between APC-sr of plasmas from normal individuals (APC-sr: 0.5$1.9, n=25$ ) and of plasmas from individuals that were heterozygous (APC-sr: 2.1-6.7, $n=17$ ) or homozygous APC resistant (APC-sr: 3.9-5.9, $n=5$ ). There was no overlap between APC-sr of normal plasmas and plasma from individuals, bearing the factor $V$ mutation. Abnormal APC-sr in certain plasmas (pregnancy, use of oral contraceptives, anticoagulant therapy, protein $S$ deficiency or Lupus anticoagulant) were corrected by performing the assay on a plasma sample that was diluted 10 -fold in factor $V$-deficient plasma. Our data show that measurement of the effect of APC on the ETP yields valuable information about the (pro)thrombotic status of plasma (e.g. $A P C$ resistance, pregnancy, use of oral contraceptives). 


\subsection{Introduction}

APC-resistance is a hereditary disorder which appears to be associated with an increased risk for venous thrombosis..$^{2-6}$ APC-resistance is caused by a single point mutation ( $\mathrm{G} 1691 \rightarrow \mathrm{A}$ ) in the gene encoding for coagulation factor $V$ which results in the replacement of $\mathrm{Arg}^{505}$ by $\mathrm{Gln}$ in the heavy chain domain of factor $V(a) .^{7-11}$ Since $\mathrm{Arg}^{506}$ is located at a predominant APC cleavage site ${ }^{12}$, the mutated factor $V$ molecule (also called factor $V_{\text {Leiden }}$ or factor $V^{\mathrm{A5060}}$ ) is less efficiently down-regulated by $A P C^{13,14}$ which probably explains the increased risk for venous thromboembolism in APC resistant individuals. Since the prevalence of APC resistance is relatively high (3-5\% in Europe) $)^{2,3,6,7}$ screening for the presence of the mutation is useful and advisable in several clinical situations. ${ }^{15,16}$

The methods that are currently used for the diagnosis of APC resistance are either variations of APTT assays ${ }^{1,17}$ or are based on sequence analysis of genomic DNA. ${ }^{718}$ This chapter, describes an essentially different method. The technique is based on measurement of the effect of APC on the time course of thrombin generation in plasma that is triggered either via the extrinsic pathway or via the intrinsic pathway. As a characteristic parameter we have determined the time integral of thrombin formation, i.e. the endogenous thrombin potential (ETP). ${ }^{9-23}$ The ETP appears to be a good indicator for the pro- or anti-thrombotic condition of a plasma sample and can be used to screen individuals for the presence of congenital and acquired APC resistance.

\subsection{Materials and Methods}

\section{Materials}

The phospholipids 1,2-dioleoyl-sn-glycero-3-phosphoserine (DOPS), 1,2-dioleoyl-sn-glycero-3-phosphocholine (DOPC) and 1,2-dioleoyl-snglycero-3-phosphoethanolamine (DOPE) were obtained from Avanti Polar Lipids, Alabaster, Alabama, USA. D-Phe-(pipecolyl)-Arg-pNA (S2238) and LpyroGlu-Pro-Arg-pNA (S2366) and Coatest ${ }^{\circledR}$ APC ${ }^{\text {TM }}$ Resistance APTT reagent (used to initiate the intrinsic coagulation pathway) were supplied by Chromogenix, Mölndal, Sweden. The extrinsic pathway of coagulation was initiated in plasma samples with relipidated recombinant tissue factor (Innovin ${ }^{\circledR}$ without additives), which was a kind gift of Dr. H. Pelzer, Dade International, Fiorida, USA. Recombinant human APC (rAPC) was a kind gift 
of Immuno A.G., Vienna, Austria. Ancrod ${ }^{\circledR}$ was obtained from the WHO International Laboratory for Biological Standards, Hertfordshire, England. The fibrin polymerization inhibitor Pefabloc $\mathrm{Fg}^{(\mathbb{B})}$ was purchased from Pentapharm, Basel, Switzerland. Immuno-depleted factor $V$-deficient plasma was obtained from Organon Teknika, Durham, NC, USA.

\section{Phospholipid vesicle preparations}

Small unilamellar phospholipid vesicles composed of a mixture of DOPS/DOPE/DOPC (20/20/60, M/M/M) were prepared as described earlier. ${ }^{24}$ Phospholipid concentrations were determined by phosphate analysis. ${ }^{25}$

\section{Protein concentrations}

APC concentrations were determined with S2366 using kinetic parameters reported by Sala et al. ${ }^{26}$ Thrombin concentrations were determined with the chromogenic substrate $\mathrm{S} 2238 .{ }^{27}$

\section{Collection and handling of plasma samples}

Nine parts of blood from normal healthy volunteers or from individuals heterozygous or homozygous for the mutation $\mathrm{Arg}^{506} \rightarrow \mathrm{G} / \mathrm{n}$ in factor $\mathrm{V}$ was collected in one part of $0.13 \mathrm{M}$ trisodium citrate $(\mathrm{pH} 7.8)$. The blood was centrifuged twice for $15 \mathrm{~min}$ at $3,000 \mathrm{~g}$ at room temperature. The platelet poor plasma thus obtained was stored at $-80^{\circ} \mathrm{C}$ until it was used. Plasma defibrination was achieved by adding $1 \mathrm{U} / \mathrm{ml}$ Ancrod ${ }^{(\mathcal{B}}$ to a plasma sample and allowing the fibrin formed to polymerize during $10 \mathrm{~min}$ at $37^{\circ} \mathrm{C}$. The resulting clot was removed from the plasma by winding it out on a plastic spatula.

The normal donors were healthy individuals with a normal APTT and prothrombin time, a normal response to APC and which after DNA analysis were identified as not carrying the mutation $\mathrm{Arg}^{506} \rightarrow \mathrm{Gln}$. The APC-resistant donors were also healthy individuals but they were characterized as heterozygous or homozygous APC resistant by PCR analysis of genomic DNA. ${ }^{28}$ Coagulation factor concentrations (including protein $S$ and $C$ ) were all within the normal range. A pool of plasma from 10 different healthy donors was used in the experiments presented in Figures 5.1 and 5.2. 


\section{Determination of thrombin generation in plasma}

Extrinsically initiated thrombin generation curves ${ }^{19}$ were determined as follows: $240 \mu \mathrm{l}$ of defibrinated plasma was mixed with $60 \mu \mathrm{l}$ of a solution containing $9.0 \mu \mathrm{M}$ of phospholipid vesicles (DOPS/DOPE/DOPC, 20/20/60, $\mathrm{M} / \mathrm{M} / \mathrm{M}$ ) in $25 \mathrm{mM}$ Hepes ( $\mathrm{pH} 7.5$ ), $175 \mathrm{mM} \mathrm{NaCl}, 5 \mathrm{mg} / \mathrm{ml}$ BSA. The mixture was incubated for $3 \mathrm{~min}$ at $37^{\circ} \mathrm{C}$ and thrombin generation was subsequently started by the addition of $60 \mu$ of a prewarmed mixture containing $0.6 \mathrm{ng} / \mathrm{ml}$ relipidated recombinant tissue factor in $25 \mathrm{mM}$ Hepes buffer $(\mathrm{pH} 7.5), 175$ $\mathrm{mM} \mathrm{NaCl}, 5 \mathrm{mg} / \mathrm{ml} \mathrm{BSA}$ and $100 \mathrm{mM} \mathrm{CaCl} 2$ with or without $200 \mathrm{nM} \mathrm{rAPC}$. This resulted in final concentrations of $1.5 \mu \mathrm{M}$ phospholipid, $0.1 \mathrm{ng} / \mathrm{ml}$ relipidated tissue factor, $50 \mathrm{nM}$ rAPC and $8 \mathrm{mM} \mathrm{CaCl}$. At regular time intervals, $10 \mu \mathrm{l}$ samples were withdrawn and the amidolytic activity towards $\$ 2238$ (thrombin plus $\alpha_{2} \mathrm{M}$-thrombin) was determined as described before. ${ }^{23}$

Intrinsically initiated thrombin generation curves were obtained in a similar way: $320 \mu \mathrm{l}$ of defibrinated plasma was mixed with $160 \mu \mathrm{l}$ of the Coatest $t^{(B)}$ APC $^{\text {TM }}$ Resistance APTT reagent (containing purified phospholipids and colloidal silica) and the mixture was incubated for $4 \mathrm{~min}$ at $37^{\circ} \mathrm{C}$. Thrombin generation was started by the addition of $20 \mu \mathrm{l}$ of a prewarmed mixture containing $400 \mathrm{mM} \mathrm{CaCl} 2$ in $25 \mathrm{mM}$ Hepes (pH 7.5), $175 \mathrm{mM} \mathrm{NaCl}, 5 \mathrm{mg} / \mathrm{ml}$ BSA with or without $1250 \mathrm{nM}$ rAPC. Final concentrations of reaction components were $8 \mathrm{mM} \mathrm{CaCl} 2,50 \mathrm{nM} \mathrm{rAPC}$ and $160 \mu \mathrm{l}$ APTT reagent per $500 \mu$ final volume. Sampling and stopping methods, as well as chromogenic determination of thrombin formation were performed as described for the extrinsically initiated thrombin generation tests (TGT). ${ }^{23}$

The thrombin generation curves thus obtained were corrected for the contribution of the $\alpha_{2}$-macroglobulin-thrombin ( $\left.\alpha_{2} M-l l a\right)$ complex to the total amidolytic activity as described earlier. ${ }^{19}$ The resulting curve, representing the free thrombin concentration as a function of time, was used to calculate the ETP. ${ }^{19}$ which was defined as the time-integral of free thrombin concentration in a TGT. ${ }^{19-23}$

\section{Determination of the effect of APC on the ETP of plasmas by measurement of end levels of the $\alpha_{2} M$-lla complex}

Thrombin generation curves generally reach a residual level of amidolytic activity that can be attributed to the $\alpha_{2} \mathrm{M}$-lla complex..$^{19,22,29-31}$ The end level of $\alpha_{2} \mathrm{M}-1 \mathrm{lla}$ is constant in time and is a direct indicator for the ETP in plasmas with the same $\alpha_{2} \mathrm{M}$ levels. ${ }^{22}$ This is particularly the case when the same plasma is tested with and without APC. The relationship between the end 
level of $\alpha_{2} \mathrm{M}$-lla and the ETP of a given plasma sample can be calculated from the rate of formation of the $\alpha_{2} \mathrm{M}$-lla complex le.:

$$
\mathrm{d}\left[\alpha_{2} \mathrm{M}-\| \mathrm{l} \mathrm{a}\right] \mathrm{dt}=\mathrm{k} *[\| \mathrm{a}]_{\mathrm{t}} *\left[\alpha_{2} \mathrm{M}\right]_{\mathrm{t}}
$$

in which $k$ is the second order rate constant for $\alpha_{2} M-11 a$ complex formation and [lla]t and $\left[\alpha_{2} M\right]_{t}$ are the free thrombin (lla) and $\alpha_{2} M$ concentrations at time $t$, respectively. Equation (1) yields:

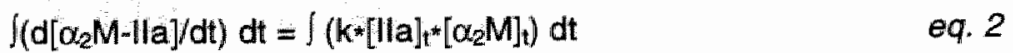

Since $\left[\alpha_{2} M\right]_{0}=\left[\alpha_{2} M-\|\right]_{t},\left[\alpha_{2} M\right]_{0} \approx\left[\alpha_{2} M\right]_{t}$ equation (2) can be rearranged into:

$$
\left[\alpha_{2} M-\| l\right]_{t}=k *\left[\alpha_{2} M\right]_{0} *[\| l a]_{t} d t=k *\left[\alpha_{2} M\right]_{0} *[E T P+c]
$$

in which ETP is the time integral of the free thrombin concentration in the TGT. Since at $t=0,\left[\alpha_{2} M-11 a\right]=0$, it follows that $c=0$ and that

$$
\left[\alpha_{2} M-l \|\right]_{t}=k \star\left[\alpha_{2} M\right]_{0} * E T P
$$

Equation (4) verifies that variations of the ETP in plasma with identical $\left[\alpha_{2} M\right]_{0}$ will result in a proportional variation of the end level of the $\alpha_{2} \mathrm{M}-1$ lla complex. This implies that the effect of APC on the ETP of a given plasma sample can be simply quantitated on the basis of single amidolytic assays of the end levels of $\alpha_{2} \mathrm{M}$-lla in plasma determined in the presence and absence of APC (see below).

\section{APC sensitivity ratio: $A P C-s r$}

Similar to APTT-based diagnostic methods for APC resistance ${ }^{1,2,6,32}$ an APC sensitivity ratio (APC-sr) has been defined, to screen plasmas for the effect of APC on thrombin generation. We have used the so-called normalized APC sensitivity ratio, ${ }^{32}$ defined as the ratio of the endlevels of $\alpha_{2} \mathrm{M}-$ Ila determined in the presence and absence of APC divided by the ratio determined in the normal plasma pool lie:

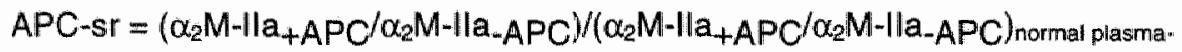

The APC-sr obtained appears to be independent of the plasma levell of antithrombin III due to the fact that the fraction of thrombin that is inhibited by antithrombin III un an individual plasma sample is the same with and without APC.

Since constant end levels of amidolytic activity $\left(\alpha_{2} \mathrm{M}\right.$-lla ) were in almost all cases reached within $10 \mathrm{~min}$ (see figures 5.1 and 5.3), APC-sr were routinely calculated from two amidolytic assays (plasma samples with and without 
APC) performed $15 \mathrm{~min}$ after initiating thrombin formation according the procedure described above ("determination of thrombin generation in plasma").

\section{Statistics}

Data are presented as ranges of values observed, median values or as mean \pm S.E.M. . The Student's t-test was used to determine the significance of differences between test results of different groups of plasmas.

\subsection{Results}

\section{Effect of APC on thrombin generation in normal plasma}

In a first series of experiments, the effect of various amounts of added APC $(0-75 \mathrm{nM})$ on thrombin generation in normal-pooled plasma was determined. Figure 5.1A shows typical thrombin generation curves that were obtained in a thrombin generation test initiated via the extrinsic pathway. ${ }^{19,20}$ During a short interval, thrombin is formed at an increasing rate. After about $2 \mathrm{~min}$ the thrombin concentration in plasma reaches a maximum. The thrombin that has been formed is subsequently irreversibly inhibited, mainly by the action of the plasma inhibitors antithrombin $I I I$ and $\alpha_{2} \mathrm{M}^{19,20}$ The plateau in amidolytic activity that is finally reached represents the amount of $\alpha_{2} \mathrm{M}$-lla complex that is formed. This complex lacks activity on macromolecular substrates but is still capable of cleaving small synthetic substrates. ${ }^{29-31}$

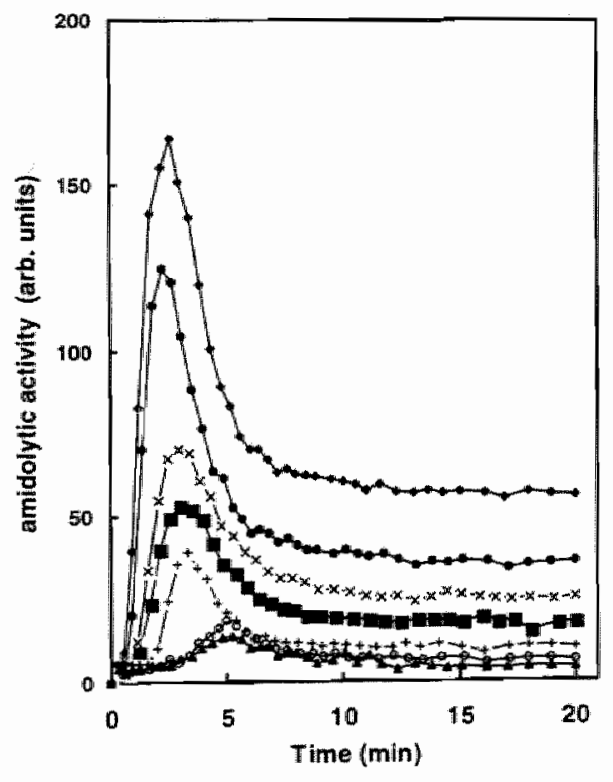

FIG 5.\%. Effect of APC on thrombin generation in normalapooled plasma. Thrombin formation was initiated in plasma with a mixture of varying amounts of $A P C$ and recombinent tissue factor.

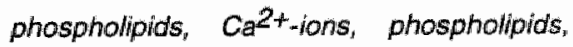
Ca ${ }^{2+}$-jons. The final $A P C$ concentrations in plasma were: (†) no APC added; (•) 2.5 $n M ;(x) 5 \mathrm{nM} ;$ (I) $10 \mathrm{nM}$; (+) $25 \mathrm{nM}$; (O) $37.5 \mathrm{nM}$, (O) $50 \mathrm{nM}$ and (4) $75 \mathrm{nM}$. Formation of thrombin was measured as described in 'Materials and Methods'. 1 arbitrary unit equals $1 \mathrm{~mA} / \mathrm{min}$, determined as described in 'Materials and Methods'. 
The thrombin generation curve obtained after initiation via the intrinsic pathway was somewhat different (Figure 5.1B) and was characterized by a pronounced lag-phase in thrombin generation.

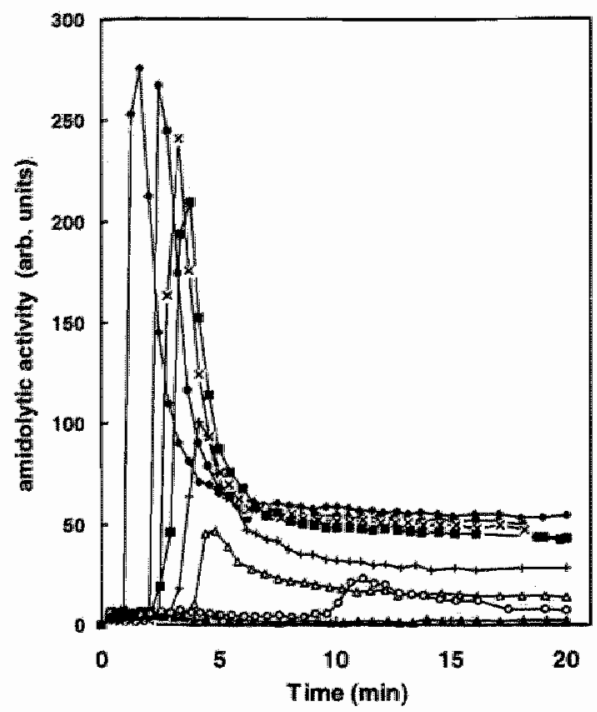

FIG 5.1B Effect of APC on thrombin generation in normal-pooled' plasma. Thrombin formation was initiated in plasma with a mixture of varying amounts of $A P C$ and colloidal silica, phospholipids, $\mathrm{Ca}^{2+}$. ions. The final APC concentrations in plasma were: (\$) no APC added; (-) 2.5 $n M ;(x) 5 \mathrm{mM}$; (D) $10 \cap \mathrm{M} ;$; (+) $25 \mathrm{nM}$; (O) $37.5 \mathrm{nM}$, (O) $50 \mathrm{nM}$ and (4) $75 \mathrm{nM}$. Formation of thrombin was measured as described in 'Materials and Methods: 1 arbitrary unit equals $1 \mathrm{~mA} / \mathrm{min}$, determined as described in Materials and Methads'.

When APC was present in the TGT experiments, thrombin formation was inhibited. At $50 \mathrm{nM} \mathrm{APC}$, inhibition in normal plasma appeared to be more than $90 \%$. From Figure $5.1 \mathrm{~A}, \mathrm{~B}$ it is clear that the presence of APC lowers both the formation of free thrombin and the end level of the $\alpha_{2} \mathrm{M}-11 \mathrm{a}$ complexes in a dose-dependent manner. In intrinsically triggered plasma, APC not only affected the amount of thrombin formed but also prolonged the lag-phase that preceded thrombin generation.

The thrombin generation curves were used to calculate the effect of APC on the ETP ${ }^{19_{2} 23}$ and on the end levels of $\alpha_{2} \mathrm{M}-1 / \mathrm{la}$. At increasing APC concentrations the ETP, calculated from the area under the thrombin generation curve, decreased parallel with the end level of the $\alpha_{2} \mathrm{M}$-Ila complex (Figure 5.2A,B), which confirms the close relation between ETP and the $\alpha_{2} \mathrm{M}$ lla plateau $(r=0.986$ and $r=0.992$ for the extrinsic and intrinsic TGT experiments, respectively) and justifies the approach to quantitate the effect of APC on the ETP via measurement of $\alpha_{2} \mathrm{M}$-lla endlevels (ct. ref 22 and Methods). There appeared to be a marked difference in the APC sensitivity in the two systems: $50 \%$ inhibition of thrombin generation was obtained at $\sim 8$ $\mathrm{nM}$ APC after extrinsic initiation and $\sim 25 \mathrm{nM} \mathrm{APC}$ after intrinsic initiation. 

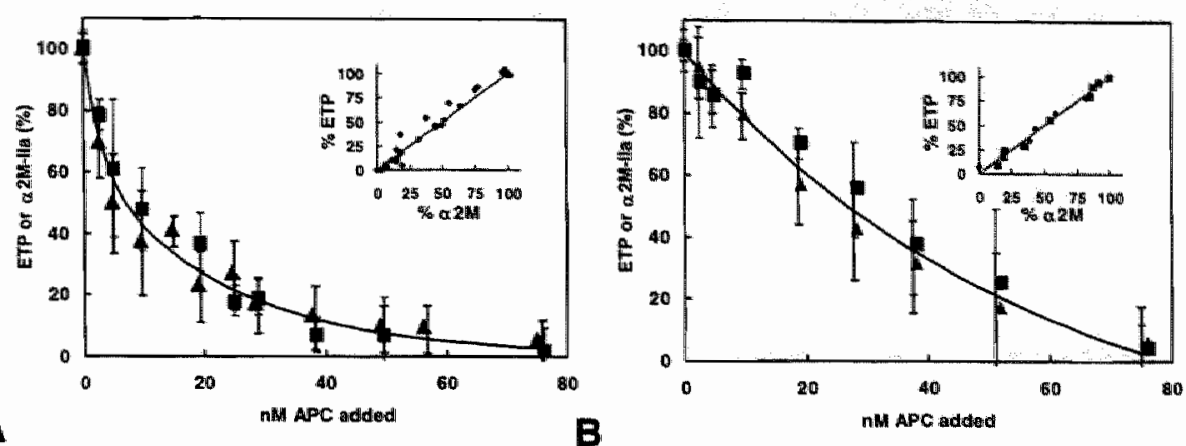

FIG 5.2 Effect of APC on the ETP and the end level of $\alpha_{2} M$-lla generated in normal plasma. ETP values (w, normal error bars) were calculated from thrombin generation curves (cf. Figure 5.1 and ref. ${ }^{23}$ ) and data are given as average $\pm 2 S O(n=3)$. The $\alpha_{2}$ M-lla levels $(A$, bold error bars) were determined $15 \mathrm{~min}$ (panel A) or $20 \mathrm{~min}$ (panel B) after initiation of thrombin formation $(n=10)$. Values are expressed as percentage of the ETP or $\alpha_{2} M$-lla level obtained in the absence of APC. (A) Thrombin formation was initiated with a mixture of recombinant tissue factor, phospholipids, $\mathrm{Ca}^{2+}$ ions containing varying amounts of $A P C$. $(E T P, 100 \%=490 \pm 31 \mathrm{nM} / \mathrm{ll} \cdot \mathrm{min}$ (mean $\pm S D) ; a_{2} M-H a, 100 \%=57 \pm 6 \mathrm{~mA} / \mathrm{min}$ ). (B) Thrombin formation was initiated in plasma with a mixture of colloidal silica, phospholipids, $\mathrm{Ca}^{2+}$-jons containing varying amounts of APC. (ETP, $100 \%=486 \pm 51 \mathrm{nM} \| \mathrm{la}$ min; $\alpha_{2} \mathrm{M}-1 / \mathrm{a}$, $100 \%=65 \pm 7 \mathrm{~mA} / \mathrm{min})$. The insets show the relation between the ETP and $\alpha_{2} M-l l a$ levels calculated from the extrinsically $(r=0.986)$ and intrinsically triggered thrombin generation curves $(r=0.992)(n=3)$.

\section{Effect of assay conditions on ETP measurements with and without $A P C$}

Optimal reaction conditions for APC-induced inhibition of thrombin generation initiated via the extrinsic pathway have been determined. At 1.5 $\mu \mathrm{M}$ phospholipid, the ETP hardly varied at free $\mathrm{Ca}^{2+}$ concentrations between 5 and $25 \mathrm{mM}$ and relipidated tissue factor concentrations between 0.025 and $0.15 \mathrm{ng} / \mathrm{ml}$ (data not shown). At high phospholipid concentrations less APC and at high tissue factor concentrations more APC was required to inhibit thrombin formation. The activity of recombinant APC used in this study was $30 \%$ lower than that of an APC preparation that was purified from human plasma. In our further experiments we have chosen for reaction conditions (50 $\mathrm{nM} \mathrm{APC}$ and $1.5 \mu \mathrm{M}$ phospholipid) that approach those of conventional APTT-based clotting assays. ${ }^{1,17,32}$ 


\section{Inter-individual variation of sensitivity to APC}

The experiments in which the ETP of intrinsically initiated thrombin formation is measured as a function of APC in a plasma pool of healthy volunteers consistently showed an as yet unexplainable scattering (compare Figure 5.2A and Figure 5.2B). Moreover, the inter-individual variation of the sensitivity of thrombin formation for APC in plasmas from normal individuals ( $n=10$ ) appeared to be much larger in the intrinsic system than in the extrinsic system. The residual amidolytic activity determined at $75 \mathrm{nM}$ APC ranged from $2.5-40 \%$ after intrinsic initiation while the same individuals gave a much narrower range $(5-18 \%$ at $50 \mathrm{mM}$ APC) after extrinsic initiation of coagulation. In order to compare normal individuals with carriers of factor $V_{\text {Leiden }}$ we have therefore studied APC-resistant plasma only in extrinsicallystimulated reaction systems.

\section{Effect of APC on thrombin generation in plasma of different factor $V^{A B O S O}$ genotypes}

In the absence of APC there were no differences in thrombin generation in the plasmas from normal healthy volunteers (Figure 5.3A) and from individuals that were heterozygous (Figure 5.3B) or homozygous (Figure $5.3 \mathrm{C}$ ) for the factor $V^{\mathrm{R506Q}}$ mutation. The values calculated for the ETP of these plasmas determined in the absence of APC were virtually the same (Table 5.1).

Clear differences between normal and APC-resistant plasmas were observed when $50 \mathrm{nM}$ APC was present during thrombin formation. In agreement with Figure 5.1A, $50 \mathrm{nM}$ APC strongly inhibited thrombin generation in plasma of the healthy volunteer (Figure 5.3. generation curve corrected for $\alpha_{2} \mathrm{M}-1 / \mathrm{l}$ ) and caused $-90 \%$ reduction of the ETP (Table 5.1). APC had much less effect on thrombin generation in plasma of the individual, who is heterozygous for the factor $\mathrm{V}^{\mathrm{R} 506 \mathrm{O}}$ mutation (Figure $5.3 \mathrm{~B}$ ) and caused $\sim 65 \%$ reduction of the ETP (Table 5.1 ). The effect of APC on thrombin formation in the plasma of the individual who is homozygous for factor $V^{\mathrm{R} 506 \mathrm{Q}}$ mutation (Figure 5.3C) was even less as can be concluded from $-40 \%$ reduction of the ETP (Table 5.1).

In agreement with the data presented in Figure 5.2, the effect of APC on the thrombin formation and on the ETP closely correlated with its effect on the finall levels of the $\alpha_{2} \mathrm{M}$-lla complex (Table 5.1). 

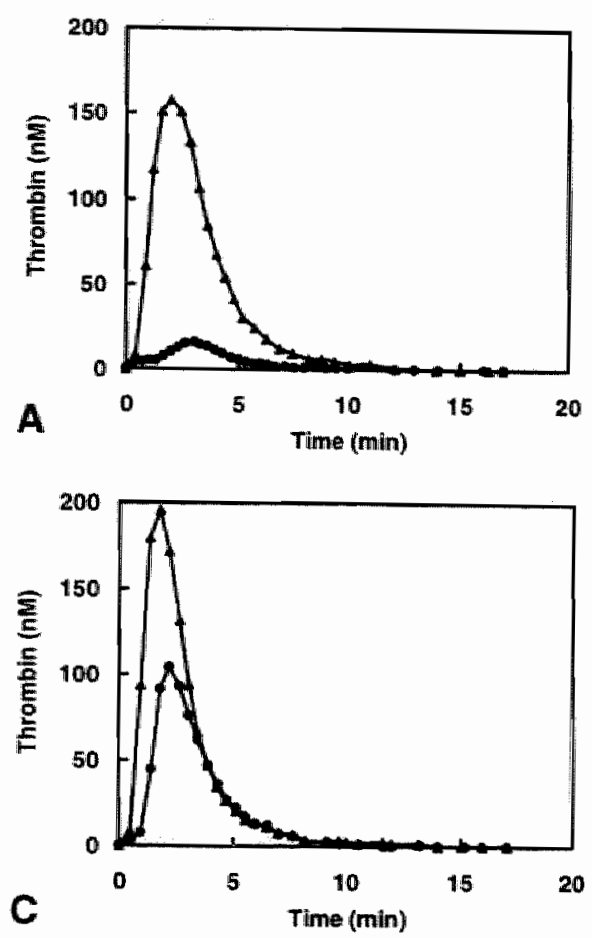

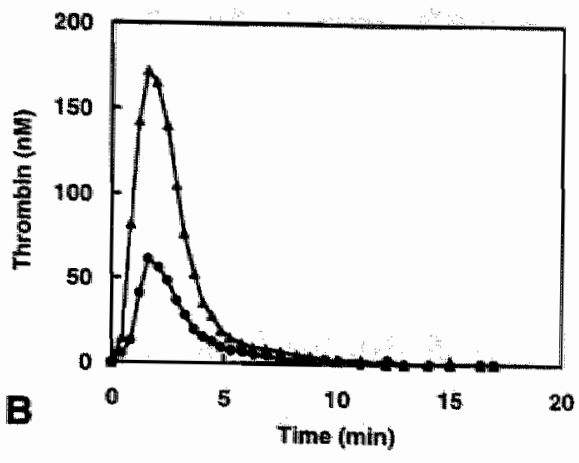

FIG 5.3 Effect of APC on thrombin generation in single normal and APC-resistant plasmas. Thrombin formation was initiated in normal plasma (A), heterozygous APC-resistant plasma (B) or homozygous APC-resistant plasma (C) with a mixture of recombinant tissue factor" phospholipid's, Ca ${ }^{2+}$-ions, without APC (4) or with an amount of $A P C$ ) yielding a final $A P C$ concentration of $50 \mathrm{nM}$ in plasma. Further experimentai details are described in 'Materials and Methods:

Table 5.1

Effect of APC on the ETP and the levels of $\alpha_{2}$ M-lla of plasmas from a normal, a heterozygous and a homozygous APC-resistant individual

\begin{tabular}{|c|c|c|c|c|c|c|}
\hline & $\begin{array}{l}\text { ETP.APC } \\
\mathrm{nM} \cdot \mathrm{min}\end{array}$ & $\begin{array}{l}\mathrm{ETP}_{+\mathrm{APC}} \\
n M^{*} \min \end{array}$ & $\begin{array}{c}\mathrm{ETP}_{+} \mathrm{APC} \\
\%\end{array}$ & $\begin{array}{l}\alpha_{2} M-1 \| a_{-A P C} \\
\text { arb. Units }\end{array}$ & $\begin{array}{l}\alpha_{2} M-11 a_{4 A P C} \\
\text { arb. Units }\end{array}$ & $\begin{array}{c}\alpha_{2} M \| a_{+A P C} \\
\%\end{array}$ \\
\hline normal plasma & 533 & 58 & 11 & 44 & 3.6 & 8.2 \\
\hline heterozygote & 482 & 170 & 35 & 37 & 11 & 29 \\
\hline homozygote & 523 & 312 & 60 & 67 & 38 & 57 \\
\hline
\end{tabular}

ETP = time integral of thrombin formation calculated from Figures 5.3 A,B and $C$ respectively.

$\%$ of value determined in the absence of $A P C$

Corrected for the amidolytic activity of APC on the chromogenic substrate for thrombin 
Test results for a population of plasmas from normal, heterozygous and homozygous APC-resistant individuals

In order to verify whether the different effects of APC on thrombin generation in plasmas from a normal, a heterozygous and a homozygous APC-resistant individual could be used as a diagnostic toal, we have screened groups of healthy individuals $(n=25)$ and individuals that were identified as heterozygous $(n=17)$ and homozygous $(n=5)$ for the factor $V^{\text {R5060 }}$ mutation by genetic analysis of genomic DNA. In order to provide a method that can be easily carried out in any laboratory we assessed the effect of APC on thrombin generation by measuring its influence on end levels of the $\alpha_{2} \mathrm{M}$ lla complex (cf. Figure 5.1A and Figure 5.2A).

The APC sensitivity ratios obtained are summarised in Figure 5.4.

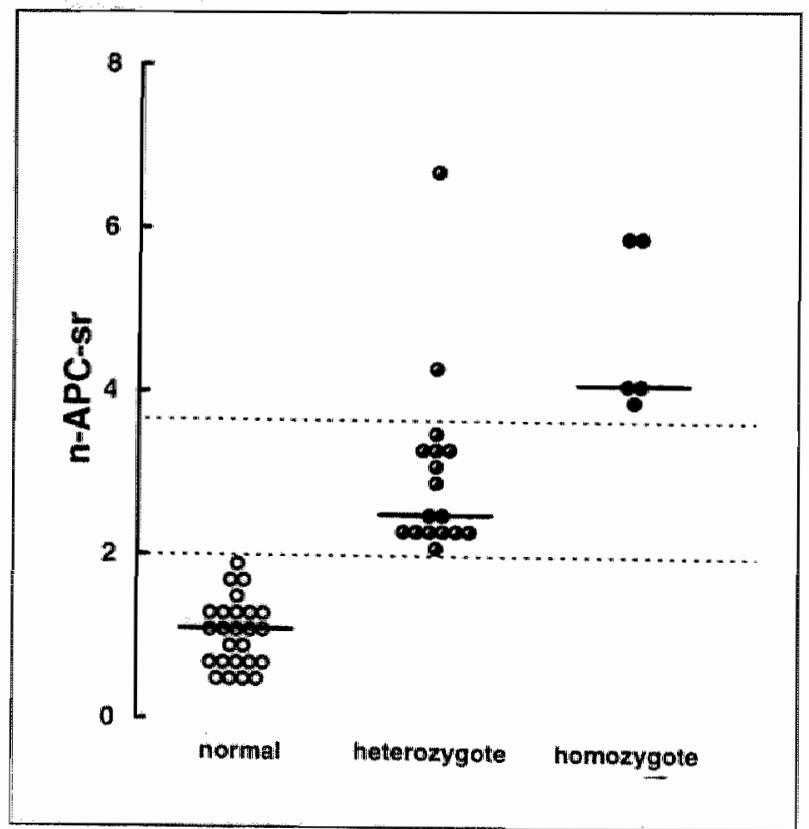

FIG 5.4 APC sensitivity ratios calculated from $\alpha_{2} M-1 / a$ endlevels in plasmas from normal, heterozygous and homazygous APC-resistant individuals. Thrombin formation was initiated in plasma with a mixture of recambinant tissue factor, phospholipids, Ca ${ }^{2+}$-ions with or without APC. In the incubations with APC the final plasma APC concentration was $50 \mathrm{nM}$. After $15 \mathrm{~min}$ the oy thrombin endilevels were determined with 52238 . Further experimental details are given in 'Materials and Method's:

The APC sensitivity ratio is defined as ([c $\left.c_{2} M-l l a\right]_{+A P C}\left(\left\{\alpha_{2} M-\| l a\right)_{-A P C}\right)$ ldivided by

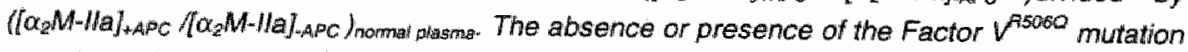
was determined by genetic analysis of genomic DNA samples isolated from peripheral blood. ${ }^{20}$ The solid lines indicate the mean values observed.

As expected there was a clear difference in APC sensitivity ratios for the three groups tested. The APC sensitivity ratios roughly divided into three populations: APC-sr $<1.9$ for normal plasmas, between 2.1 and 3.6 for 
heterozygotes and $\geq 3.9$ for homozygotes, with median values of $1.1,2.5$ and 4.1 , respectively. There was no overlap between the normal and APCresistant populations $(p<0.001$ for the difference between the normal population and either of the APC-resistant populations) and some overlap between the homozygous and heterozygous APC-resistant populations since two of the seventeen heterozygotes had an APC-sr $>3.9(p>0.01)$.

We have also determined APC-sr for part of our population after intrinsic initiation of coagulation. Due to the earlier described large inter-individual variation of APC response in the intrinsic system there was a large overlap between APC-sr of normal individuals (range 0.3-3.3) and heterozygous carriers of factor $V_{\text {Leiden. }}$. Approximately $30 \%$ of the non-carriers of factor $V_{\text {Leiden }}$ fell in the range of heterozygous APC-resistant individuals. This percentage is similar to that observed for the APTT-based assay in nondiluted plasma. ${ }^{36}$

\section{Conditions that affect APC-sr measurements via ETP or $\alpha_{2} M-l l a$ plateau determination}

Reliable diagnosis of APC-resistance with APTT-based assays in undiluted plasma appears difficult for pregnant women, ${ }^{16}$ women using oral contraceptives ${ }^{16,33}$ or for patients that are on oral anticoagulation, ${ }^{2}$ treated with heparin, ${ }^{32}$ diagnosed as protein $S$ deficient $^{32}$ or positive for lupus anticoagulant, ${ }^{34}$ In such plasmas thrombin generation was also affected which hampered the screening for APC resistance via the method presented in this chapter (Table 5.2). 
Table 5.2

APC-sr of various plasma samples after dilution in FV-deficient plasma.

\begin{tabular}{|c|c|c|c|c|c|c|}
\hline \multirow[b]{2}{*}{ Plasma } & \multicolumn{3}{|c|}{ Normal assay } & \multicolumn{3}{|c|}{ Modified assay } \\
\hline & APC-sr & SEM & $n$ & APC-sr & SEM & $n$ \\
\hline normal & 1.04 & 0.08 & 25 & 1.09 & 0.16 & 4 \\
\hline Heterozygous APC resistant & 3.03 & 0.27 & 17 & 2.24 & 0.13 & 3 \\
\hline Homozygous APC resistant & 4.75 & 0.44 & 5 & 3.35 & 0.43 & 4 \\
\hline Protein $S$ deficient & 1.87 & - & 1 & 1.32 & 0.04 & 2 \\
\hline Oral anticoagulation & n.d." & - & 3 & 1.41 & 0.12 & 4 \\
\hline Heparin treatment & n.d." & - & 3 & 1.34 & 0.12 & 5 \\
\hline Lupus anticoagulans & n.d. & - & 2 & 0.94 & 0.24 & 2 \\
\hline Oral contraception & 2.40 & 0.85 & 8 & 1.63 & 0.20 & 3 \\
\hline Pregnancy & 2.81 & 1.10 & 3 & 1.68 & - & 1 \\
\hline
\end{tabular}

Note: mean values of APC-sr were calculated from final levels of $\alpha_{2} M-l l a$ in undiluted plasma samples (normal assay) or in plasma samples diluted 10 -fold in factor $V$-deficient plasma (modified assay).

Not determined. Strongly inhibited thrombin formation in the absence of APC Assays performed in the presence of $40 \mathrm{ng} / \mathrm{mi}$ polybrene. ${ }^{37}$

It has been investiglated whether these interferences can be overcome by modifying the test e.g. by performing the assays on plasma samples diluted in factor-V deficient plasma. ${ }^{35,36}$ Preliminary data, for a limited number of plasma samples are given in Table 5.2. It is clear that dilution in factor $V$-deficient plasma normalized the sensitivity of these plasmas towards APC since APCsr approached the values obtained for normal-pooled plasma.

In all experiments presented thus far the plasma samples were defibrinated by pre-treatment with Ancrod $^{(\mathcal{B})}$, a thrombin-like enzyme purified from the venom of Agkistrodon rhodostoma. It is not necessary, however, to defibrinate the plasma samples when thrombin is formed in the presence of Pefabloc $\mathrm{Fg}^{3}$, an inhibitor of fibrin polymerisation. ${ }^{38}$ At a final concentration of $2 \mathrm{mg} / \mathrm{ml}$ plasma, Pefabloc Fg ${ }^{(i)}$ prevented clot formation and hardly affected the ETP or the $\alpha_{2} M-l l a$ endlevel (data not shown).

It is well documented that chromogenic substrates do not show a unique selectivity towards the specific protease for which they were designed. The thrombin specific substrate used in the experiments presented in this chapter (S2238) is for instance also converted by APC albeit much less efficient. 
Therefore, especially in the case of a normal plasma sample (low $\alpha_{2} \mathrm{M}$-lla levels in the presence of APC) the APC-related amidolytic activity can potentially contribute to the final amidolytic end-level determined. At the APC concentrations used in our experiments $(\sim 50 \mathrm{nM})$ the contribution of APC to the final amidolytic activity in individual normal plasmas $(n=10)$ was $\sim 30 \%$ (range $20-50 \%$ ). For APC-resistant plasmas the contribution of APC to the final amidolytic activity becomes negligible $(<5 \%)$ due to the much higher level of $\alpha 2 \mathrm{M}-11 \mathrm{a}_{+} \mathrm{APC}$. To obtain a correct APC-sr for normal plasma the APC-sr needs to be corrected for the contribution of APC to the amidolytic activity. It should be emphasised, however, that it is not necessary to determine the contribution of APC for each individual plasma. Application of a standard correction (amidolytic activity of APC in non-triggered normal plasma) yields APC-sr close to the value obtained after individual correction and will not interfere with the distinction between normal and heterozygous APC-resistant individuals.

\subsection{Discussion}

Unlike a clotting time, analysis of thrombin generation in plasma provides direct information on the entire blood coagulation process. ${ }^{20-23,39-41}$ The results presented in this chapter show that determination of the effect of APC on the ETP of a plasma sample allows detection of an abnormal anticoagulant response of plasma to APC (APC resistance).

In normal plasma, the presence of $50 \mathrm{nM}$ APC almost completely inhibited thrombin formation initiated via the extrinsic pathway (Figure 5.1A) and reduced the ETP to values that were $\sim 10 \%$ of that observed in the absence of APC, whereas in heterozygous and homozygous APC-resistant plasmas the residual ETP's were $35 \%$ and $60 \%$, respectively. These observations seem to be easily explained by the fact that APC inactivates factor $V a^{\mathrm{PEO} O 6 \mathrm{Q}}$, isolated from APC-resistant plasma, some 10-20 times slower than normal factor $\mathrm{Va} .{ }^{13}$ However, recently we reported ${ }^{14}$ that, dependent on their actual concentrations, factor $\mathrm{Xa}$ and protein $\mathrm{S}$ diminish the difference between the sensitivities of factor $\mathrm{Va}$ and factor $\mathrm{Va}{ }^{\mathrm{A} 506 \mathrm{O}}$ for APC. This was concluded from studies in model systems with purified proteins. The data reported in the present chapter show that care should be taken to simply apply theories developed on the basis of model experiments to plasma systems.

In order to simplify a TGT-based screening method for APC-resistant plasmas, we verified (Figure 5.2A,B) the linear relationship between the ETP and the end level of $\alpha_{2} \mathrm{M}$-lla present in plasma after completion of thrombin generation. ${ }^{22}$ This allows rapid screening for APC-resistant plasmas by 


\subsection{Summary}

Epidemiological studies have shown that women who use thirdgeneration oral contraceptives (OC) containing desogestrel, gestodene or norgestimate have a higher risk of venous thrombosis than women that use second-generation $O C$ containing levonorgestrel. It is also known that a mutation in factor $V$ (factor $V_{\text {Leiden }}$ ), which results in resistance to activated protein C (APC) and which is the most common cause of hereditary thrombophilia, potentiates the prothrombotic effect of $O C$.

Effects of APC on thrombin generation in the plasma of women using OC were compared to the response to APC in non-OC users and in individuals that were heterozygous or homozygous for factor $V_{\text {Leiden. }}$. The response towards APC was evaluated on basis of the ratio (APC-sr) of the time integrals of thrombin formation determined in the presence and absence of APC.

Compared with women not using $O C$, women who used $O C$ exhibited a significantly decreased sensitivity to APC $(P<0.001)$, independent of the kind of $O C$ used. Women who used third-generation monophasic $O C$ were significantly less sensitive to APC than women using second-generation OC $(P<0.001)$ and had APC-sr that did not significantly differ from heterozygous female carriers of factor $V_{\text {Leiden }}$ who did not use OC. Women who were heterozygous for factor $V_{L e i d e n}$ and used $O C$ had APC-sr in the range of homozygous carriers of factor $V_{\text {Leiden. }}$. Two women who started $O C$ therapy had significantly elevated APC-sr within 3 days.

Acquired APC resistance may well explain the epidemiological observation of increased risk for venous thrombosis in OC users, especially in women using third-generation $\mathrm{OC}$. 


\subsection{Introduction}

Since their introduction, the use of oral contraceptives $(O C)$ has been linked to an increased incidence of thromboembolic events'. Compared with non $\mathrm{OC}$ users, women that take $\mathrm{OC}$ have a risk for venous thrombosis that is increased about 4 -fold ${ }^{2}$. Recently, concern has been raised that thirdgeneration $\mathrm{OC}$, which contain the progestagens desogestrel, gestodene or norgestimate, further increase the risk of thromboembolism ${ }^{2,3,4}$. The small but definite increase of the incidence of venous thromboembolism in OC users becomes more manifest when other thrombosis risk factors are present. This is illustrated by reports that women that are resistant to activated protein $\mathrm{C}$ (APC) and that use OC have a considerably increased risk of thrombosis ${ }^{5,6}$.

APC resistance is a hereditary disorder ${ }^{7,8,9}$, that results from a mutation in the gene of blood coagulation factor $V^{10}$ and that renders the activated form of factor $\mathrm{V}$ (factor $\mathrm{Va}$ ) less susceptible to proteolytic inactivation by $\mathrm{APC}^{11}$. Since APC-catalyzed factor $V a$ inactivation is a crucial step in the downregulation of thrombin formation ${ }^{12}$, impaired inactivation of factor $\mathrm{Va}$ likely explains the increased risk for venous thromboembolism in APC-resistant individuals. A remarkable feature of APC resistance is its high prevalence. About $4 \%$ of the West-European population appears to be heterozygous APC resistant ${ }^{9,10,13,14}$ and this abnormality is found in $20-50 \%$ of patients with venous thrombosis $8.9,10,13,14$.

Although the higher risk of idiopathic venous thromboembolic events, deep-vein thrombosis and/or pulmonary embolism in association with the use of $O C$ is well established, no clear causal relations with alterations within the haemostatic system have as yet been reported ${ }^{15,16}$. In general, the effects of $O C$ therapy on coagulation variables are modest and in several reports it has been suggested that the use of $O C$ induces changes in the procoagulant- and anticoagulant pathways that may counterbalance each other ${ }^{15,16}$.

In this chapter we report the change of a haemostatic variable that may be indicative for a substantial disturbance of the haemostatic balance and for the existence of a prothrombotic state in OC users. We have measured the effect of APC on thrombin generation in plasma and show that women who use $O C$ are much less sensitive to APC than non users and that differences in sensitivity to APC between women who use second-and third-generation $\mathrm{OC}$ correlate with the reported higher risk of thrombosis in third-generation OC users. 


\subsection{Materials and Methods}

This study was performed according to a protocol approved by our institutional ethics committee. The participants in this study were selected from general practitioners offices using criteria described below.

\section{Study cohorts}

The following plasmas were used in our study: a normal plasma pool prepared from plasma of healthy volunteers ( 40 females not using $\mathrm{OC}$ and 50 males, mean age 35 years), individual plasma samples from male volunteers $(n=25,18-38$ years old, mean age 28 years), women not using $O C$ ( $n=53$, 19-39 year, mean age 31 years), women using triphasic $O C(n=24,19-37$ year; mean age 28 years, duration of $\mathrm{OC}$ use $0.5-17$ year, average duration $O C$ use 8 year), women using second-generation monophasic contraceptives containing levonorgestrel or lynestrenol $(n=32,20-39$ years, mean age 29 years, duration $O C$ use $0.5-20$ years, average duration $O C$ use 9 years), women using third-generation monophasic contraceptives containing desogestrel, gestodene or norgestimate $(n=40,18-36$ years; mean age 29 years, duration of $O C$ use 1-20 year, average duration $O C$ use 7 years) and women heterozygous for the factor $V_{\text {Leiden }}$ mutation not using $O C$ ( $n=17,16$ 79 year, mean age 41 years).

Women who had ceased OC therapy for more than 6 months were considered as non users. The $\mathrm{OC}$ user group consisted of women that were using the same $\mathrm{OC}$ for more than 3 months. With the exception of carriers of the factor $V_{\text {Leiden }}$ mutation, individuals with a previous episode or a known familial history of venous or arterial thrombosis $(\sim 10 \%$ of our population), having a chronic or intercurrent acute disease, taking medication that may interfere with coagulation, and pregnant women were excluded from our study.

\section{Collection and Handling of Plasma Samples}

Nine parts of blood from consenting volunteers were collected in one part of $0.13 \mathrm{M}$ trisodium citrate $(\mathrm{pH} 7.8)$. Platelet poor plasma was obtained by centrifugation for 25 minutes at $3,000 \mathrm{~g}$ at room temperature followed by centrifugation for $25 \mathrm{~min}$ at $20,000 \mathrm{~g}$ at $4{ }^{\circ} \mathrm{C}$ and was stored in small aliquots at $-80^{\circ} \mathrm{C}$ until analysis. 
The occurrence of heterozygous and homozygous APC-resistance was established by determination of the sensitivity of plasma factor $\mathrm{Va}$ for $A P \mathrm{C}^{17}$ and by DNA analysis ${ }^{18}$.

\section{Determination of Thrombin Generation in Plasma}

Thrombin generation curves were determined at $37^{\circ} \mathrm{C}$ in defibrinated plasma $^{19}$ containing $15 \mu \mathrm{M}$ phospholipid vesicles ${ }^{11,17,20}$ (dioleoylphosphatidylserine/dioleoyl-phosphatidylethanolamine/dioleoylphosphatidylcholine, 20/20/60, M/M/M; Avanti Polar Lipids, USA), $0.1 \mathrm{ng} / \mathrm{ml}$ relipidated tissue factor (Recomboplastin S, Dade, USA). and $15 \mathrm{mM}$ added $\mathrm{CaCl}_{2}$, with or without 5 nM APC (Immuno AG, Vienna, Austria). At regular time intervals, samples were withdrawn to determine the generation of amidolytic activity ${ }^{19}$ (thrombin plus $\alpha 2$-macroglobulin-thrombin complex [o2M-lla]) with D-Phe-pipecolyl-ArgpNA (S2238, Chromogenix, Sweden). Correction of the time course of generation of amidolytic activity for the contribution of $\alpha 2 \mathrm{M}$-lla yielded the free thrombin concentration as a function of time $e^{21}$. These values were used to calculate the ETP, which is defined as the time-integral of free thrombin concentration in a thrombin generation test ${ }^{19,21}$

Since ETP values of a particular plasma sample are directly proportional to the residual levels of amidalytic activity $(\alpha 2 \mathrm{M}-\| \mathrm{la})^{20,22}$, we quantitated the effect of APC on thrombin generation (i.e. on the ETP) by measuring its effect on the final level of $\alpha 2 \mathrm{M}-1 / \mathrm{la}$. The APC sensitivity ratio (APC-sr) was defined as the ratio of $\alpha_{2} \mathrm{M}-1 / \mathrm{la}$ determined in the presence and absence of APC divided by the ratio determined in the normal plasma pool ${ }^{23}$ :

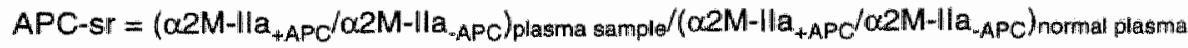

\section{Statistics}

Statistical analysis was performed after logarithmic transformation of the data which resulted in normally distributed APC-sr values. P-values were obtained by pairwise comparison of the groups using Student's t-test and were corrected for comparison of multiple groups according to the Bonferroni procedure ${ }^{24}$. 


\subsection{Results}

\section{Effect of APC on Thrombin Generation}

Fig 6.1 shows thrombin generation curves (closed symbols) obtained after initiating thrombin formation via the extrinsic pathway in plasma pools of women not using $\mathrm{OC}$, women using third-generation $\mathrm{OC}$ and heterozygous APC resistant men and women who did not use OC.

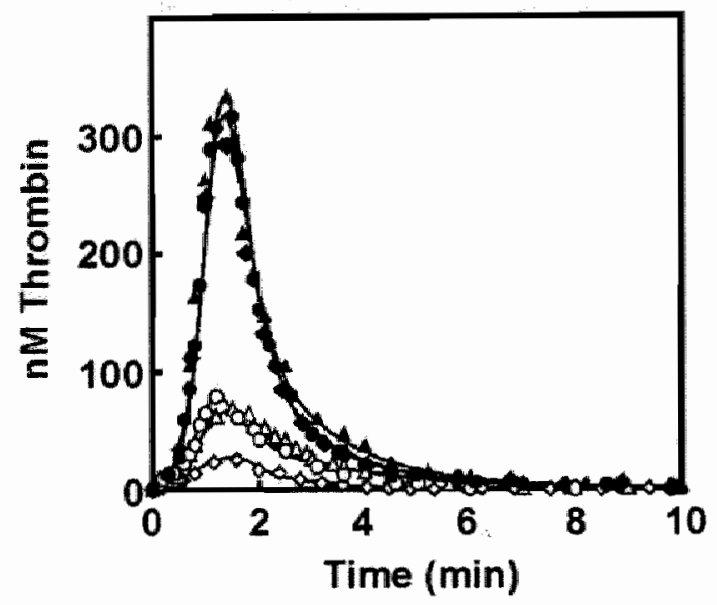

FIG 6.1 Effect of APC on thrombin formation in pooled plasmas. Time courses of thrombin formation were initiated in plasma with a tissue factor/CaCly/phospholipid mixture in the absence (closed symbols) or presence of $5 \mathrm{nM} \mathrm{APC} \mathrm{(open} \mathrm{symbols).} 0$ plasma pool from women not using OC $(n=27) ; 0$ plasma pool from women using third-generation monophasic OC $(n=25)$ and $\Delta, \Delta$ plasma pool from men $(n=8)$ and non OC-using women $(n=15)_{1}$, heterozygous tor the Factor $V_{L \text { taden }}$ mutation.

APC strongly inhibited thrombin formation in the plasma pool of women not taking OC (open symbols) and the residual ETP was $9.5 \%$ of that determined in the absence of APC. Thrombin generation in the plasma pool of woman taking third-generation $O C$ was much less sensitive to APC (residual ETP $=28.0 \%$ ) and exhibited a response towards APC that is similar to that observed in a pool of heterozygous APC-resistant individuals (residual ETP $=29.0 \%$ ). Thrombin formation in the plasma pools of women using triphasic $\mathrm{OC}$ or second-generation $\mathrm{OC}$ was also considerably less affected by APC than in women who did not use OC (Table 6.1). 
Table 6.1

Effect of APC on thrombin generation in pooled plasmas

\begin{tabular}{|c|c|c|c|c|c|}
\hline Pooled plasmas & $n$ & $\begin{array}{c}\text { Mean age } \\
\text { years }\end{array}$ & $\begin{array}{l}\text { ETP.APG } \\
\text { nM.min }\end{array}$ & $\begin{array}{l}\text { ETP } \cdot A P C^{t} \\
\text { nM.min }\end{array}$ & $\begin{array}{c}\text { ETP }+ \text { APC } \\
\%\end{array}$ \\
\hline normal plasma & 90 & 35 & $458 \pm 6$ & $43 \pm 4$ & $9.4 \%$ \\
\hline men & 23 & 28 & $442 \pm 5$ & $39 \pm 1$ & $8.8 \%$ \\
\hline \multicolumn{6}{|l|}{ women } \\
\hline no contraceptive & 27 & 29 & $473 \pm 29$ & $45 \pm 2$ & $9.5 \%$ \\
\hline $\begin{array}{l}\text { triphasic } \\
\text { monophasic }\end{array}$ & 28 & 28 & $533 \pm 10$ & $105 \pm 3$ & $19.7 \%$ \\
\hline 2nd generation & 28 & 29 & $483 \pm 5$ & $85 \pm 1$ & $17.6 \%$ \\
\hline 3rd generation & 25 & 29 & $554 \pm 4$ & $155 \pm 13$ & $28.0 \%$ \\
\hline $\begin{array}{l}\text { heterozygous } \\
\text { Factor V } \text { Leidlen }^{\text {F }}\end{array}$ & 23 & 45 & $486 \pm 5$ & $141=9$ & $29.0 \%$ \\
\hline
\end{tabular}

"Plasma pools were prepared from individual plasma samples described under Materials and Methods'

tThrombin formation was quantified by calculating the time integral of the thrombin generation curve (ETP) as described under 'Materials and Methods.' Values are given as means $\pm S E$.

$¥ \%$ of value determined without APC.

Men $(n=8)$ and women $(n=15)$

\section{Effects of OC therapy and factor $V_{\text {Leiden }}$ on APC-sensitivity ratios}

Since determination of the APC-sr in a large number of plasmas is precluded by the fact that measurement of complete thrombin generation curves is very time consuming, we routinely determined the APC-sr from the residual levels of the $\alpha 2 \mathrm{M}$-lla complex obtained in the presence and absence of APC. This procedure yields APC-sr that are identical to values calculated from the ratio ETP $+A P C / E T P \cdot A P C{ }^{20,22}$. It should be emphasized that $A P C-s r$ calculated by this method exhibit trends that are the reverse of APC-sr determined with APTT-based clotting assays ${ }^{7,9,23}$ (APC-sr $=$ APTT + APC APTT $A P C)$. Since APC inhibits thrombin generation and prolongs the APTT, decreased sensitivity for APC (APC resistance) yields higher APC-sr in ETPbased assays and lower APC-sr in APTT-based assays.

The APC-sr of individual plasma samples of men, women not using $O C$. women on $O C$ therapy and heterozygous carriers of the factor $V_{\text {Leiden }}$ mutation (women not using OC) determined as described above are summarized in Fig 6.2 and Table 6.2. 


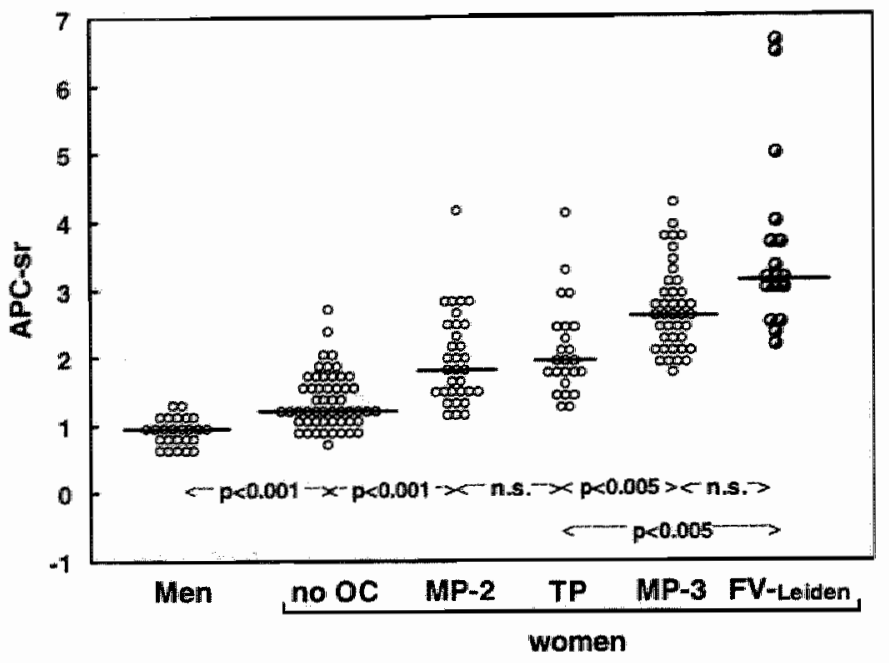

FlG 6.2 APC-sr of men, women, women using OC and female heterozygous carriers of

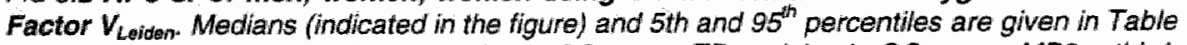
6.2. MP2 = second-generation monophasic OC users, IP = triphasic OC users, MP3 = thirdgeneration monophasic OC users.

It appeared that men had significantly lower APC-sr than women that were not using $O C$, confirming that men are more sensitive to APC than women $^{8,25}$. Plasmas from women using different kinds OC had APC-sr that were considerably higher than those of non $\mathrm{OC}$ users. Independent of the kind of OC used, significant differences were observed between the APC-sr of OC users and of women that were not using OC (Fig 6.2). The APC-sr of plasmas from women who take third-generation monophasic $\mathrm{OC}$ were almost equal to the APC-si" of heterozygous APC-resistant women not using $O C$ and was significantly higher than the APC-sr of women that used triphasic $(P<0.005)$ or second-generation monophasic $O C(P<0.001)$.

For heterozygous APC-resistant women not using OC the APC-sr defined by the $5^{\text {th }}$ and $95^{\text {th }}$ percentile fell in the range 2.09-6.60. No men and $3 / 53(6 \%)$ of the women not using OC had an APC-sr within this range. Among women using OC, 12/32 (37\%) taking second-generation monophasic $\mathrm{OC}_{1} 8 / 24(33 \%)$ using triphasic $\mathrm{OC}$ and $32 / 40(80 \%)$ on third-generation monophasic OC therapy had APC-sr values within the $5^{\text {th }}$ and $95^{\text {th }}$ percentile of the heterozygous APC-resistant population.

During our study we identified five women who were using $\mathrm{OC}$ and were also heterozygous carriers of the factor $V_{\text {Leiden }}$ mutation. These women had an APC-sr (4.52-6.40) of the levels normally observed for homozygous APCresistant individuals (Table 6.2). 
Table 6.2

Effect of OC therapy and factor $V_{\text {Leiden }}$ on APC-sr.

\begin{tabular}{|c|c|c|c|c|}
\hline Group & $\mathrm{n}$ & $\begin{array}{c}\text { Mean age } \\
\text { (yr) }\end{array}$ & $\begin{array}{l}\text { APC-sr } \\
\text { Median }\end{array}$ & $5^{\text {th }}-95^{\text {th }}$ percentile \\
\hline $\begin{array}{l}\text { men } \\
\text { women }\end{array}$ & 25 & 28 & 0.96 & $0.65-1.28$ \\
\hline $\begin{array}{l}\text { no OC } \\
\text { no OC, heterozygous }\end{array}$ & $\begin{array}{l}53 \\
17\end{array}$ & $\begin{array}{l}31 \\
41\end{array}$ & $\begin{array}{l}1.22 \\
3.10\end{array}$ & $\begin{array}{l}0.87-2.15 \\
2.09-6.60\end{array}$ \\
\hline $\begin{array}{l}\text { FV Leiden } \\
\text { no OC, homozygous FV Leiden } \\
\text { triphasic OC } \\
2^{\text {nd }} \text { generation monophasic } \\
3^{\text {rd }} \text { generation monophasic } \\
\text { Heterozygous FV Leiden } \\
\text { using OC }\end{array}$ & $\begin{array}{c}5 \\
24 \\
32 \\
40 \\
5\end{array}$ & $\begin{array}{l}41 \\
28 \\
29 \\
29 \\
31\end{array}$ & $\begin{array}{l}4.75 \\
1.93 \\
1.81 \\
2.59 \\
5.41\end{array}$ & $\begin{array}{l}3.91-6.02 \\
1.26-3.29 \\
1.19-2.87 \\
1.91-3.88 \\
4.53-6.45\end{array}$ \\
\hline
\end{tabular}

\section{Changes of APC-sr after Starting OC Therapy}

The sensitivities to APC of two healthy women, who had not used OC for more than 8 years and who started with OC therapy, were followed over a 4 month period. Prior to the use of OC the women had an APC-sr within the normal range (Fig 6.3).

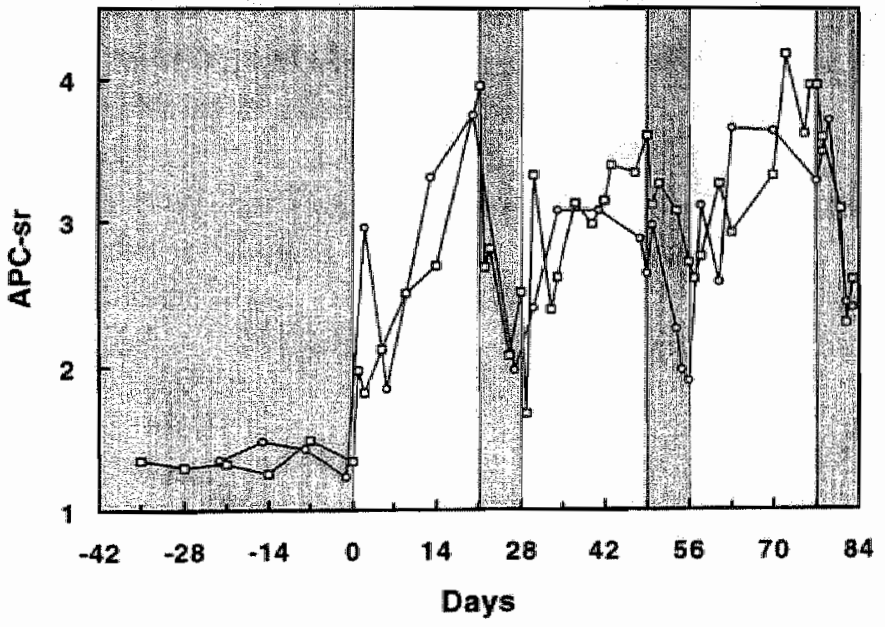

FIG 6.3 Effect of starting OC therapy on the APC-sr. APC-sr were determined in plasma from two healthy women, age 26 years (O) and 34 years (), who had not been taking oral contraceptives for more than 8 years and who started $O C$ therapy on day $O$ with a thirdgeneration monophasic $O C(150 \mu \mathrm{g}$ desogestrel/30 $\mathrm{\mu g}$ ethinylestradial). OC free periods are indicated by shaded bars. 
Within 3 days of starting OC therapy the APC-sr had significantly increased, reaching values $\geq 3$ in the third week of OC use. During the seven OC-free days the APC-sr significantly decreased, rising again during the second and third treatment cycles.

\subsection{Discussion}

In vivo down-regulation of thrombin formation is achieved by plasma protease inhibitors (e.g. antithrombin III and $\alpha_{2}$-macroglobulin) and by the proteins of the anticoagulant pathway (APC and protein S). The physiological importance of these pathways is demonstrated by the association of venous thrombosis with congenital deficiencies in antithrombin $111^{26}$, protein $\mathrm{C}^{27}$ or protein $\mathrm{S}^{28}$ and by the accurrence of hereditary thrombophilia in individuals with a genetic defect ${ }^{7,10}$ that makes factor $\mathrm{Va}$ less sensitive to proteolytic inactivation by APC (APC resistance).

An increased risk for venous thromboembolism has also been associated with the use of $O C$ by healthy women. Although large retrospective and prospective studies have associated $O C$ therapy with a 4-9 fold increased incidence of venous thrombosis ${ }^{2-4}$, the changes in haemostatic parameters in women using OC are minor and generally remain within the normal range ${ }^{15,16}$. In $O C$ users without other thrombosis risk factors, the increased procoagulant activity of the haemostatic system is at least partially compensated by an increased activity of the anticoagulant- and profibrinolytic pathways.

In this chapter we report a substantial change of a haemostatic variable (the APC-sr) in women using OC which appears to be much more sensitive and that may be indicative for the existence of a prothrombotic state in $O C$ users. We have shown that measurement of the effect of APC on thrombin formation in plasma provides information on the sensitivity of an individual to APC. Screening a population of women who use or do not use OC shows that OC therapy induces acquired APC resistance. Significant differences in sensitivities to APC were observed between women not using $O C$ and women on $O C$ therapy, independent of the kind of OC used. Within the group OC users, women taking third generation monophasic. OC were significantly less sensitive to APC than triphasic or second-generation monophasic OC users and exhibit a decreased sensitivity to APC comparable to that observed in heterozygous APC-resistant women who did not use OC (Fig 6.2).

We propose, that decreased sensitivity to APC (acquired APC resistance) in OC users may, at least in part, explain the higher risk of thrombotic disease of women taking OC. The fact that users of OC with third- 
generation progestagens, for whom a higher risk of venous thromboembolism has been reported ${ }^{2-4}$, exhibit significantly lower sensitivities to APC than users of second-generation $\mathrm{OC}_{5}$ reinforces this hypothesis.

Until now, the increased risk for venous thrombosis during $O C$ therapy has always been linked to effects of estrogen on the coagulation system ${ }^{15,16}$. Our study provides a first example of a biological effect of the progestagen component on haemostasis and shows that, with respect to the risk for venous thrombosis, the role of progesterone cannot be ignored.

Whereas women that use third generation $\mathrm{OC}$ have APC-sr similar to heterozygous carriers of factor $V_{\text {Leiden }}$ not using OC (Fig 6.2), the APC response in women that take $O C$ and who also carry the factor $V_{\text {Leiden }}$ mutation is further impaired and similar to that observed in homozygous APC resistant individuals (Table 6.2). Together with the fact that, compared with non-carriers non-users, the increased risk for deep-vein thrombosis of non carriers who use third-generation $O C(7-8 \text { fold })^{2-4}$ is similar to that of heterozygous carriers not using OC $(7 \text {-fold })^{9}$ and that heterozygous carriers of factor $V_{\text {Leiden }}$ who use $O C$ exhibit a risk increase $(50 \text {-fold) })^{6}$ that approaches that of homozygous carriers not using OC (80-fold $)^{5,14}$, this supports our proposal that the increased incidence of venous thrombosis in congenital APC resistant individuals and in women using $O C$ originate from a defect in the same physiological pathway.

The observations that the effect of $O C$ on the APC response takes place within a few days after starting OC therapy and that the APC-sr drops in pillfree periods (Fig 6.3) contains valuable information about the underlying mechanism. Unfortunately, our present data do not allow further conclusions regarding changes in the haemostatic system that may link the impaired APC response and the increased thrombotic risk of OC users. It is unlikely, however, that the decreased sensitivity to APC is due to the reported decreased levels of protein $S$ in OC users ${ }^{15.16}$, since addition of protein $S$ to the plasma of OC users did not normalize the APC-sr (data not shown). We confirmed that measurement of sensitivity for APC in APTT-based clotting assays yields marginal differences between women using and not using $\mathrm{OC}^{25,29}$. The major difference between ETP-based and APTT-based methods is that initiation of coagulation in the case of the ETP occurs via the extrinsic pathway of coagulation (tissue factor/factor VIlla) whereas in APTT-based systems coagulation is initiated via the intrinsic coagulation pathway. This indicates that the basis of the impaired APC response in women using OC may have to be sought in the activity and/or regulation of the extrinsic pathway of coagulation. 
16. Newton JA. (1995) Classification and comparison of oral contraceptives containing new generation progestagens. Human Reproduction Update, 1 , $23 y-263$.

17. Nicolaes GAF, Thomassen MCLGD, van Oerle R, Hamulyák K, Hemker HC, Tans G and Rosing J. (1996) A prothrombinase-based assay for detection of resistance to activated protein $C$. Thromb Haemost, 76, 404-410.

18. Beauchamp NJ, Daly ME, Cooper PC, Preston FE and Peake IR (1994) Rapid two-stage PCR for detecting factor V G1691A mutation. Lancet, 344, 694-695.

19. Hemker HC, Béguin S. (1995) Thrombin generation in plasma: its assessment via the endogenous thrombin potential. Thromb Haemost, 56, 9-17.

20.Nicolaes GAF, Thomassen MCLGD, Tans G, Hemker HC, Rosing J. (1997) effect of activated protein $C$ on thrombin generation and on the thrombin potential in plasma of normal and APC-resistant individuals, Blood Coagulation and Fibrinolysis, 8, 28-38.

21. Hemker HC, Willems GM and Béguin S. (1986) A computer assisted method to obtain the prothrombin activation velocity in whole plasma independent of the thrombin decay processes. Thrombosis and Haemostasis, 56, 9-17.

22. Duchemin J, Pittet $\mathrm{J}$, Tartary $M$. et al. (1994) A new method based on thrombin generation inhibition to detect both protein $\mathrm{c}$ and protein $\mathrm{S}$ deficiencies in plasma. Thromb Haemost, 71, 331-338.

23.de Ronde $\mathrm{H}$ and Bertina FM. (1994) Laboratory diagnosis of APC-resistance: a critical evaluation of the test and the development of diagnostic criteria. Thromb Haemost, 72, 880-886.

24.Altman DG. (1991) Practical statistics for medical research, Chapman \& Hall, London.

25. Henkens CMA, Bom VJJ, Seinen AJ and van der Meer J (1995) Sensitivity to activated protein $\mathrm{C}$; influence of oral contraceptives and sex. Thromb Haemost, 73, 402-404.

26. Hirsch J, Piovella F and Pini M. (1989) Congenital antithrombin III deficiency. Incidence and clinical features. American Joumal of Medicin, 87, 34S-38S.

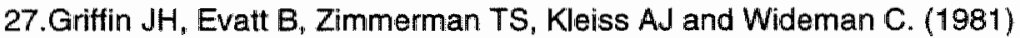
Deficiency of protein $C$ in congenital thrombotic disease. Journal of Clinical Investigation, 68, 1370-1373.

28.Schwarz HP, Fischer M, Hopmeier P, Batard MA and Griffin JH. (1984) Plasma protein $S$ deficiency in familial thrombotic disease. Blood, 64, 12971300.

29.Olivieri O, Friso S and Manzato F. (1995) Resistance to activated protein $\mathrm{C}$ in healthy women taking oral contraceptives. British Journal of Haematology, 91 , 465-470.

30. Greer LA. (1994) Haemostasis and Thrombosis, pp. 1327-1338. Churchill Livingstone, Edinburgh. 
Chapter 7

General Discussion and Conclusions 
In this general discussion the results, described in the previous chapters, will be put in the context of surveys performed by other research groups. Where possible, connections between chapters are made and the mechanistic and physiological implications of our findings will be discussed.

\subsection{Meizothrombin-catalyzed activation of Factor $V$}

Activation of the inactive procofactor of human FV is essential for the expression of FVa cofactor activity in prothrombin activation. The pivotal role of FVa in the prothrombinase complex, and hence for the process of thrombin formation is well-established and undisputed. Under in vitro conditions it has been shown that activation of $\mathrm{FV}$ is the rate-limiting factor during the initiation of plasma prothrombin activation". However, both in in vitro experiments in plasma and in blood and in the in vivo situation the activation of FV has for long been somewhat of a paradox since efficient activation of $F V$ requires thrombin ${ }^{2-6}$ - whereas thrombin is only formed in sufficient amounts when FVa is present. However, in 1990 it was shown by Monkovic and Tracy ${ }^{7}$ that in the presence of phospholipids, FXa can also serve as an efficient activator of human FV. Given the kinetic parameters determined in the latter study, FXa is $\sim 2$ times less efficient than thrombin in activating plasma concentrations of $F V$. It should be emphasized however, that FV activation by FXa may be a temporary process since in the presence of procoagulant membranes $\mathrm{FXa}$ forms a tight complex with FVa and not with FV. This will reduce the free FXa concentration available for FV activation. Together these data indicate that the physiologic activation of FV is a complex process, which is probably initiated via minute amounts of extrinsically formed FXa, but which is rapidly shifted to activation by thrombin and/or meizothrombin (see below).

In chapter 2 we describe that meizothrombin, an active reaction intermediate in the activation of PT, can activate FV in a model system. Meizothrombin is a potent activator of $F V$ in the presence of phospholipids which activates FV with rate constants that exceed those of thrombin and FXa -4 fold.

In doing so, meizothrombin must act exclusively at a phospholipid/cell surface (Table 2.1). Binding of meizothrombin to a membrane surface then opens a possible role for meizothrombin in the activation of protein $C$ as well. This activation can be thought to occur together with another membraneassociated protein, thrombomodulin,. Meizothrombin thus 'fits' well within the concept of 'the catalytic surface', a general concept within haemostasis ${ }^{8-10}$. 
It should be emphasized however, that it is possible that the amounts of meizothrombin formed in vivo are insufficient to activate FV. Although it has been shown that, in model systems containing purified proteins, meizothrombin is the preferred PT activation intermediate when FVa is present and the PT concentration is high ${ }^{11-15}$, it was observed that meizothrombin formation on cultured endothelial cells ${ }^{16,17}$ or in plasma systems $^{15,18,19}$ is rather low or even undetectable. Formation of intact meizothrombin in plasma experiments may be limited for two reasons. First, it has been reported that meizothrombin rapidly converts itself into meizothrombin-desF1 via autocatalysis ${ }^{20,21}$. This form of meizothrombin hardly activates FV (see chapter 2) since it does not bind to phospholipids due to the fact that it lacks the Gla-containing fragment 1 domain. Secondly, formation of meizothrombin in plasma experiments may also be low because the bulk of prothrombin is activated in plasma at a very high factor $\mathrm{Xa}-\mathrm{Va}$ concentration. From thrombin generation curves, determined during thromboplastin-induced clotting of plasma (chapter 6,7 , refs. ${ }^{22,23}$ ) it can be calculated that the factor $\mathrm{Xa}-\mathrm{Va}$ concentration during the burst of thrombin formation exceeds $300 \mathrm{pM}$. At such conditions prothrombin activation can become a diffusion-limited process ${ }^{24}$ and despite the fact that the bulk prothrombin concentration is high, the local PT concentration, in the vicinity of the factor Xa-Va complex, will approach zero. This condition enables rapid conversion of locally-formed meizothrombin into thrombin. The current data do not rule out, however, that meizothrombin may be the physiological FV activator during the early phase of $P$ T activation, i.e. at conditions at which the amount of factor Xa-Va complex is still low.

More data are needed in order to fully comprehend the physiological value of meizothrombin. Close examination of the forms of FVa, which are formed in vivo (i.e. presence of the $280,000 \mathrm{kD}$ activation fragment, fig. 2.5 ) might proof helpful.

\subsection{Inactivation of FVa and FVa $a_{L e d e n}$ by APC in model systems}

The inactivation of human FVa by APC in reaction systems containing purified coagulation proteins has been described by many laboratories ${ }^{14,25-28}$ already before 1993. After having overcome the difficulties of purification of the clotting factors used, these first publications showed the essential characteristics of APC-catalyzed FVa inactivation: a) inactivation occurs by multiple clleavages of the heavy chain domain of factor $\mathrm{Va}$, that lead to loss of cofactor activity ${ }^{30.31}$ b) inactivation occurs preferably at a phospholipid 
surface $e^{25_{*} 26,32}$ c) inactivation is stimulated by the presence of protein $S^{29,32,33}$ d) Factor $X a$ can protect factor Va from inactivation by $\mathrm{APC}^{25,26,34}$.

In 1994, Kalafatis et al. ${ }^{30}$ reported the exact locations of the APC-cleavage sites in the heavy chain domain of human FVa and in the FV molecule. The discovery of the $\mathrm{R} 506 \mathrm{Q}$ mutation in $\mathrm{FV}_{\text {Leiden }}$ patients $^{35}$ has however been a major incentive for the detalled analysis of FVa inactivation by APC.

Chapter 3 describes a study that was performed to elucidate the order and rates of peptide bond cleavages during the APC-catalyzed inactivation of $\mathrm{FVa}$ and FVa Leiden. In reaction systems containing 0-5 nM of $\mathrm{FVa}$ and $0.05-5 \mathrm{nM}$ APC time courses of FVa inactivation were obtained in the presence or in the absence of phospholipid vesicles. Under these conditions, reaction kinetics were first-order, both with respect to FVa and APC, which allows calculation of apparent second-order rate constants for $\mathrm{FVa}$ inactivation. By the use of the mathematical technique of curve fitting, we were able to obtain rate constants for the peptide bond cleavages that eventually annihilate the cofactor activity of the FVa molecule in prothrombin activation. Identification of cleavage sites was performed by combination of the kinetic analyses with immuno-blotting experiments. Our experiments resulted in a model for the inactivation of human factor Va by APC that is given in figure 7.1 below:

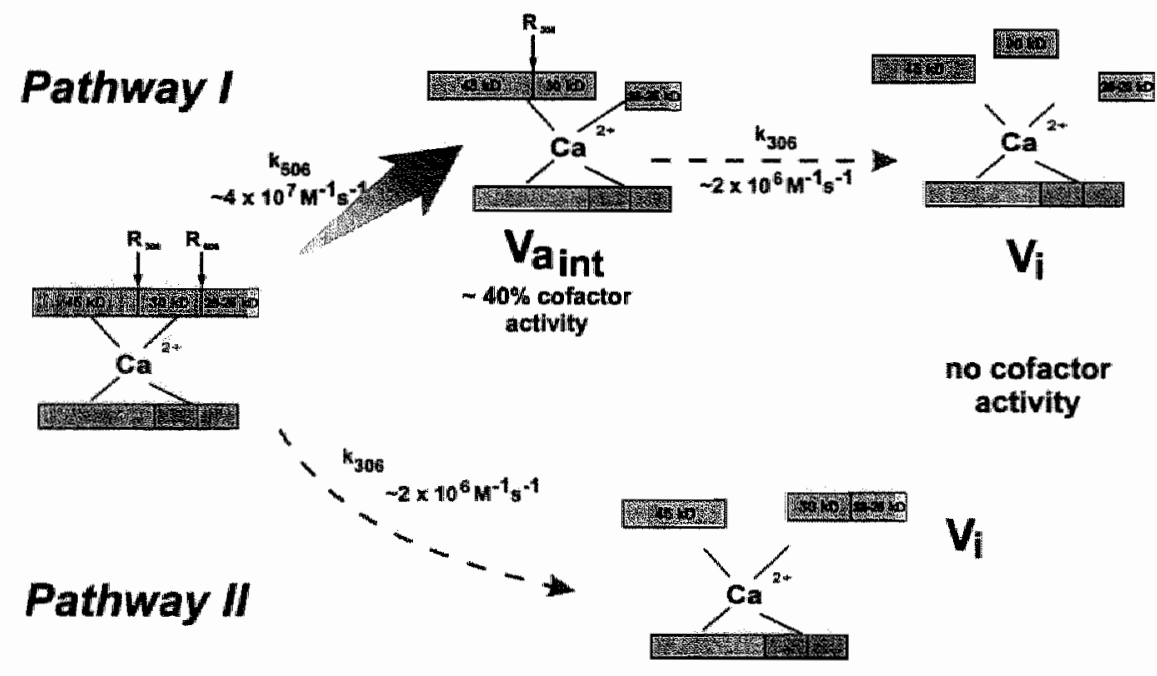

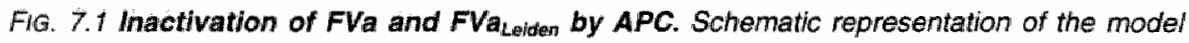
for inactivation of FVa and FValaition by activated protein C in the presence of phospholipids. Molecular masses of fragments and rate constants of cleavages are indicated. For explanation of the wo alternative pathways, see text below. 
In this model, inactivation of membrane-bound FVa can occur via two independent pathways. In pathway I, FVa is initially cleaved at $\mathrm{Arg}^{506}$ "yielding a partilally active reaction intermediate ( $\left.F V a_{i n t}\right)$ that loses its cofactor activity after cleavage at $\mathrm{Arg}^{306}$. Cleavage at $\mathrm{Arg}^{506}$ is much faster than cleavage at $\operatorname{Arg}^{306}$, which causes the $75 \mathrm{kD}$ intermediate $\left(F V a_{\text {int }}\right)$ to accumulate during FVa inactivation. FVa inactivation via pathway II occurs after initial cleavage at $\mathrm{Arg}^{306}$ and causes the direct loss of all cofactor activity. The slow rate at which cleavage at Arg ${ }^{306}$ occurs is similar in both the pathways I and 11 . Since in $\mathrm{FV}_{\text {Leiden, }}$ the Arg at amino acid position 506 is mutated into Gln, inactivation of FVa Leiden can only occur via the (slow) pathway II. For normal FVa, the distribution of FVa over both pathways is largely governed by the concentration of FVa that is present. We have shown that inactivation at $\operatorname{Arg}^{506}$ has $K_{m}$ and $K_{\text {cat }}$ values that are $\sim 10$ times lower and -3 times higher, respectively, than the corresponding parameters for inactivation at $\mathrm{Arg}^{306}$. This implies that differences between normal FVa and FVaLeiden are most pronounced at low concentrations of FVa.

This model contradicts reports by Kalafatis and coworkers in which it is stated that inactivation of FVa is sequential and that cleavage at $\mathrm{Arg}^{506}$ is necessary to expose the cleavage sites at $\mathrm{Arg}^{306}{\text { and } \mathrm{Arg}^{679} \text { rets } 30,31}^{31}$. However, these studies are performed at very high FVa concentrations ( -20 times higher than the plasma FV concentration) in combination with a FVa cofactor assay that contains a high amount of FXa (see below).

To unquestionably elucidate this mechanism however, kinetic studies of APC-catalyzed inactivation of mutant FVa molecules with mutations at the APC-cleavage sites, will be necessarily.

At the time of preparation of this thesis, a preliminary study was presented by Egan et al. ${ }^{36}$ who used site-directed mulagenesis to mutate human factor $V$ at positions 306 and 506. Their findings show that in the absence of 306 and 506 there is no inactivation and that cleavage at 306 and/or 506 are required for efficient factor $V a$ inactivation. $A$ detailed kinetic analysis of these mutants are not provided, however.

Upon cleavage of the $\mathrm{Arg}^{506}$-Gly ${ }^{507}$-bond the resulting FVa intermediate possesses a partial FVa cofactor activity in prothrombin activation. We have shown that the partial loss of cofactor activity is particularly due to diminished interaction with $\mathrm{FXa}$, whereas the affinities of $\mathrm{FVa}_{\mathrm{int}}$ for PT and phospholipid vesicles were virtulally the same as for FVa. This finding has important implications for functional assays for APC resistance that are based on measurement of the loss of APC-mediated FVa activity, and which involves determination of the remaining cofactor activity of $\mathrm{FVa}$ and $\mathrm{FV} \mathrm{a}_{\text {Leiden }}$ in prothrombin activation. In order to obtain maximal differences between FVa 
and FVaLeiden, the determination of FVa cofactor activity in such assays should be performed at low FXa concentration (see section 7.4 below).

The rate constants for APC-catalyzed cleavage of peptide bonds in the

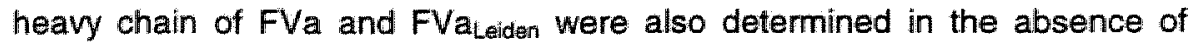
phospholipid vesicles. These experiments showed that two cleavages, at $\mathrm{Arg}^{506}$ and $\mathrm{Arg}^{306}$, are stimulated by the presence of phospholipid vesicles. The order of stimulation is different however, and is $\sim 300$-fold and $\sim 625$-fold respectively, under the conditions tested. This implies that a shift can occur in the relative amounts of FVa that are inactivated via pathway I or II. What is more important though, is that in the absence of phospholipid vesicles the rate of cleavage at $\mathrm{Arg}^{306}$ is of the order of magnitude as the cleavage-rate at $\mathrm{Arg}^{678}$. Especially in the case of inactivation of $\mathrm{FVa}_{\text {Leiden, where the fast }}$ cleavage at $\mathrm{Arg}^{506}$ can not occur, cleavage at $\mathrm{Arg}^{306}$ and at $\mathrm{Arg}^{679}$ will both contribute to inactivation in the absence of a membrane surface, which was confirmed by immunoblotting experiments.

Despite the careful explanation of the kinetics approach, it is somewhat surprising to note that Kalafatis et al. ${ }^{37}$ question our kinetic data. According to their comment, the differences in inactivation rates reported in their and our studies is most likely due to the use of a non-bioactive APC, and to the, relative to $\mathrm{FVa}$, high APC concentrations in our experiments. The concentrations used in our kinetics experiments, however, never exceeded $1.5 \mathrm{nM}$, which is well below the limit of $5 \mathrm{nM}$ that was ascertained by us for the first-order kinetics under our experimental conditions. Furthermore, the kinetic parameters, $K_{m}$ and $K_{\text {cat }}$ and the $k_{c a r} / K_{m}$ values that were obtained from Michaelis-Menten kinetic analysis (an analysis that is essentially different from the second-order kinetic analysis based on curve-fitting of time courses of FVa inactivation) were in complete agreement with the rate constants obtained from the curve fitting experiments as well as with published kinetic data by Solymoss and coworkers ${ }^{29}$. We therefore have full confidence in the kinetic data as were obtained by us and reject this unfounded critique.

Discussion about the quality of an APC preparation would however indeed be helped if it were possible to uniformly define the activity of a preparation. Like in case of thrombin, a consensus on the definition of 1 international unit of APC (e.g. the amount of APC in $\mathrm{nM}$ that reduces the APTT of a nomal pooled plasma from normal to $90 \%$ of its normal value) would be very meaningful. Expression of concentration in IU, possibly in parallel with a unit

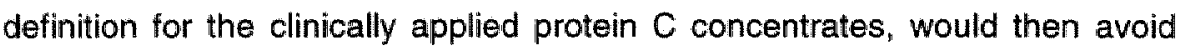
the disagreements about the functionality of an APC preparation.

Shortly after the publication of the work that is described in chapter 3 we published a paper in which we further extended the model as is presented in 
figure 7.1. In this study we reported that FXa and protein $S$ have very specific effects on the inactivation of FVa by APC. Protein $S$ accelerates FVa inactivation by selectively enhancing the slow cleavage at $\operatorname{Arg}^{306}$ (20-fold), whereas FXa protects FVa from inactivation by selectively blocking cleavage at $\mathrm{Arg}^{506}$. The assignment of these target sites were confirmed in experiments with $\mathrm{FVa}_{\text {Leiden. }}$. Due to the lack of the cleavage site at $\mathrm{Arg}^{306}, \mathrm{APC}$-mediated $F V a_{\text {Leiden }}$ inactivation is not inhibited by $\mathrm{FXa}$, while the effect of protein $\mathrm{S}$ on the loss of cofactor activity of FVa Leiden is much more pronounced than in the case of normal FVa. The implications of these observations, which are of great importance for APC resistance tests and for the inactivation of FVa in plasma, will be discussed in the next section.

\subsection{Inactivation of FVa and FVa Leiden by APC in plasma systems}

Inactivation of FVa by APC in plasma systems is complicated by several factors that are absent in model systems that utilize purified proteins. Among these are a) the presence of such "interfering" coagulation factors as FXa, PT and protein $\mathrm{S}, \mathrm{b}$ ) protease inhibitors that inhibit the proteolytic activity of APC, c) FVIII(a), which are also substrates for APC, d) non-activated FV, which forms a pool of procofactor that constantly replenishes $\mathrm{FVa}$ activity and that itself is a substrate for APC, e) anticoagulants, which in most experiments are used to prevent clotting of blood, $f$ ) fibrinogen, which can easily form fibrin clots that hamper sample handling.

Interference by all these factors was lost in the APC resistance test that we devised (chapter 4). Although the test uses a plasma sample, the $100 \%$ specificity and sensitivity that is obtained is largely attributable to the $>750$ fold dilution that was used. Inactivation of FVa in diluted plasma samples resembles inactivations in model systems more than those in full plasma. This was underscored by the good correlation between the rate constants for FVa inactivation obtained from time courses of $\mathrm{FVa}$ inactivation in diluted plasma samples of normals, heterozygous and homozygous APC resistant individuals and those determined in model systems. In agreement with observations in the model systems, we showed that differences between APC-mediated loss of FVa cofactor activity in plasma samples from normal individuals and $\mathrm{FV}_{\text {Leiden }}$ carriers were maximal when $\mathrm{FVa}$ is inactivated at low protein $\mathrm{S}$ concentrations and when the loss of FVa cofactor activity is probed at a low FXa concentration.

Studies on the inactivations of FVa, responsible for the inhibition of thrombin formation by APC in tissue-factor triggered full plasma (chapters 5 and 6 ), occur under conditions that are hampered by interference by the 
factors that are mentioned at the beginning of this section. A simple description of how FVa is inactivated in full plasma is therefore not possible. It is likely the relative rates of activation and inactivation of $\mathrm{FV}(\mathrm{a})$ that determine the effect of APC on thrombin generation in plasma. As reported in chapters 2 and 3 , the catalytic efficiencies $\left(k_{\mathrm{cat}} / \mathrm{K}_{\mathrm{m}}\right)$ of both activation and inactivation are similar. This means that at the low concentrations of activating and inactivating enzymes, as presumably present during the onset of in vitro coagulation, both processes can balance each other. When APC concentrations are sufficiently high, the balance is shifted in favour of inactivation and thrombin generation (clot formation) will be inhibited. In that situation APC directly cleaves the heavy chain of FVa (generated after activation by (meizo)thrombin and/or FXa), thereby preventing formation of thrombin, that is necessary for further FV activation through positive feedback reaction. As a result, a shift towards inactivation will cause a lengthening of clotting times.

Interesting in this context are reports by Kalafatis and coworkers ${ }^{37,38}$ who observed that APC can also inactivate the non-activated procofactors FV and FV Leiden. Furthermore, it is shown that addition of low amounts of APC to FV Leiden results in transient accumulation of a FV molecule containing a heavy chain like fragment of amino acids 1-679 which possesses potential cofactor activity. Following cleavage at $\mathrm{Arg}^{306}$, the cofactor activity of this FV derivative is lost. At higher concentrations of APC ( $>5.5 \mathrm{nM}$ ) cleavage at $\mathrm{Arg}^{306}$ is believed to occur much faster than cleavage at $\mathrm{Arg}^{679}$, preventing accumulation of the 1-679 heavy chain-like fragment with procoagulant

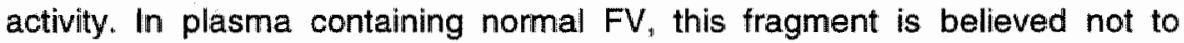
accumulate due to fast inactivation at $\mathrm{Arg}^{506}$. The blotting data that are provided in this study are however hampered by the fact that they were performed in 10-fold diluted plasma. This dilution might have consequences for the reaction kinetics that occur and may therefore not reflect the conditions that occur in full plasma.

Not included in this discussion so far are recent observations by Shen et al. ${ }^{39}$, Varádi et al. ${ }^{40}$ and Lu et al. ${ }^{41}$ who reported a cofactor function for FV in the inactivation of FVIIIa and FVIII by APC. This will possibly influence FVa inactivation in plasma. The former study ${ }^{39}$ showed that when assembled on phospholipid membranes, FV acts in synergy with protein $S$ in the downregulation of FVIlla by APC. The authors showed in model systems that it is an intrinsic ability of FV, and not FVa, to enhance the APC-catalyzed inactivation of FVIIla.

This latter observation is seemingly in contradiction with the observations by Lu et al. ${ }^{41}$ who observed that APC- or thrombin-treated FV, and not single 
chain intact FV, is able to stimulate the inactivation of the procofactor FVIII by APC in the presence of protein $S$. Western blot analysis showed that upon addition of APC to mixtures of FVIII and FV, in the presence of phospholipids and protein S, FV was completely cleaved by APC at the beginning of the inactivation process. From combination of these experiments with data from experiments using thrombin-treated FV (=FV heavy and light chains + activation peptides), it was concluded that a portion of the $B$ region of $F V$ is involved in the FV cofactor function for FVIII inactivation. Since membranebound FVIIla showed a spontaneous rapid loss of cofactor activity and APCcatalyzed inactivation of the procofactor FVIII was relatively slow compared to inactivation of $F V$, it is concluded that FV and $F V a$, rather than FVIII and FVIIla are the physiological substrates for APC. The difference in FV-cofactor activities between refs 39 and 41 may be explained by a difference in quantitation of FVIlla activity: whereas the first group used a well-defined model system containing purified clotting factors to assess FVIIla cofactor activity, the latter group used a one-stage clotting assay. Apart from these observations in model systems, Varádi et al. ${ }^{40}$ confirmed in plasma-based reaction systems that both $F V$ and protein $S$ are required for optimal inactivation of FVIII by APC. It was observed that at a low protein $S$ concentration (2.42 nM) neither FVa, nor thrombin-treated FV or RVV-treated FV, expressed cofactor activity. The most remarkable observation was however, that, $F V_{\text {Leiden }}$ almost totally lacked cofactor activity in APC-catalyzed inactivation of FVIII in the presence of protein S.

Down-regulation of thrombin formation in plasma (chapters 5 and 6) is a complex process in which down-regulation of $\mathrm{FVa}$ activity plays an equally important role as down-regulation of FV activation: inactivation of FVIlla will result in reduced $\mathrm{FXa}$ and thrombin formation, which in turn reduces $F V$ activation. Therefore, thrombin formation can be controlled by preventing the activation of any factor that can activate $F V$, or by slowing down the formation of these factors, so that their activities can be down-regulated by plasmainhibitors. The kinetics of activation of FX may in particular be of importance since APC must compete with FXa for complexation with FVa, when FV becomes activated. Once bound to $\mathrm{FXa}, \mathrm{FVa}$ is protected against inactivation by APC, especially when FVa is incorporated into PTase complex. Thus, an integrated view of several clotting factors is required when considering limitation of thrombin formation. To what extent FVIIla contributes to the tissue factor-triggered thrombin generation, as described in chapters 5 and 6 , is presently under investigation.

Figure 7.2 below summarises and illustrates in a simplified way the complex reactions that can occur following the addition of tissue factor to 
plasma in vitro, that were discussed in this section. The reactions may partly represent the reactions that occur in vivo after tissue damage.

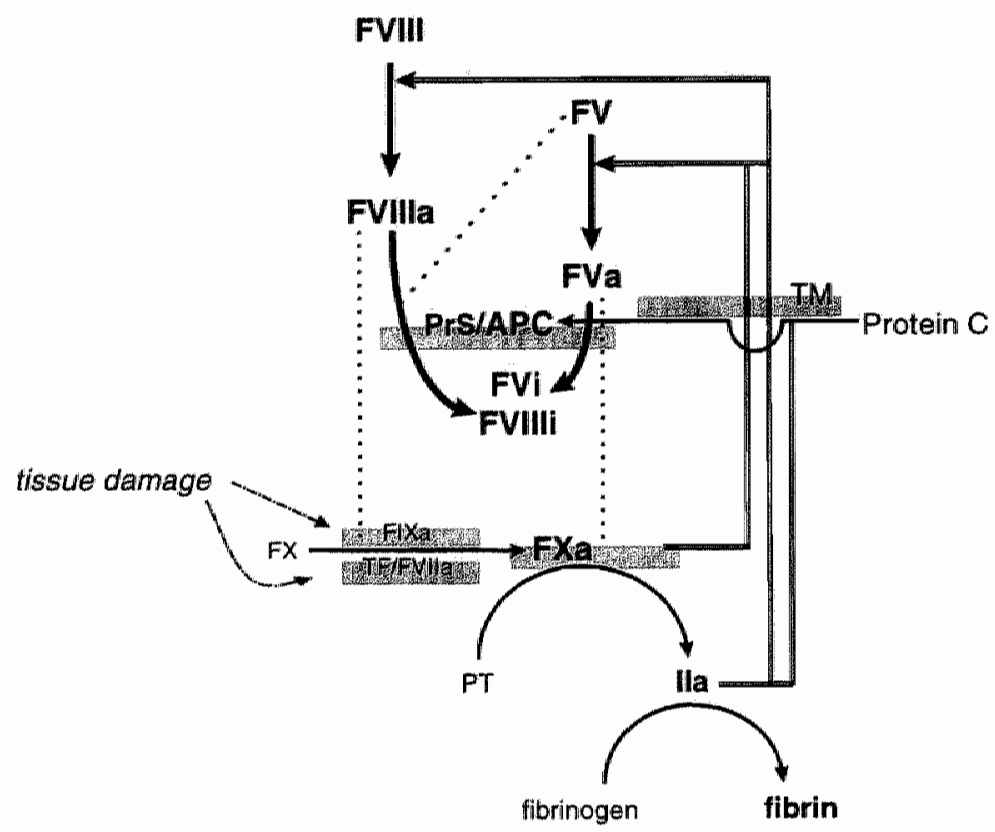

FiG. 7.2 Schematic representation of reactions in the pro- and anticoagulant pathways that are initiated after occurrence of tissue damage. The presence of tissue factor will elicit both a procoaguiant response, eventually leading to fibrin deposition, and a anticoagulant response after thrombin-catalyzed protein $C$ activation. Solid arrows indicate clotting factor conversions, dotted lines indicate participation of respective proteins as a cofactor, double lines denote positive feedback reactions. Grey horizontal bars indicate surface dependent reactions. FVi=inactivated FVa, FVIIli=inactivated FVIlla, TM=thrombomodulin, TF=tissue factor, PrS protein S

Future research is needed to estimate the physiological values of all the in vitro APC-related interactions that have been published so far.

\subsection{Current view on hypercoagulable states: APC resistance and its assessment in the hematological laboratory}

If the inactivation of $\mathrm{FVa}$ is not the sole determinant for the downregulation of thrombin generation, then what determines in a plasma sample the in vitro APC resistance assay outcome and what is the outcome's value? 
Likewise, what are the causative conditions for the occurrence of thrombophilia as is observed in vivo in APC resistant individuals?

In chapters 5 and 6 we have shown that tissue factor triggered thrombin generation, and its inhibition by exogenously added APC, embodies a sensitive assay system for the detection of hypercoagulability. The mechanistic explanation for the power of the assay system in the detection of the tested hypercoagulable states, is possibly different for the groups of plasmas (carriers of $F V_{\text {Leiden }}$ mutation and women using $O C$ ) tested in chapters 5 and 6 respectively. In chapter 5 , the FV mutation will most likely contribute to observed differences between normals and plasmas from individuals carrying the $\mathrm{Arg}^{506} \rightarrow$ Gin mutation. Also, plasmas, presenting different APC-sr had no differences in standard laboratory parameters (coagulation factor concentrations, APTT, PT) other than the presence of the FV Leiden mutation. For the experiments described in chapter 6 , this explanation cannot account for the observed differences between the groups of plasmas, since all plasmas were tested for the presence of the FVLeiden mutation and only groups of similar FV Leiden-genotypes were compared. Differences in coagulation parameters, as have been reported in users of oral contraceptives and pregnant women, e.g. decreases in protein $S$ levels, antithrombin III and increases in prothrombin, FX, FVII and protein $\mathrm{C}^{42-44}$ may contribute to the observed hypercoagulability in these plasmas. Notably, not only are the responses to APC in the plasmas tested in both chapters 5 and 6 different from nomal plasmas, also the thrombin generations in the absence of APC are significantly enhanced in these plasmas (in particular in case of FV Leiden: $O C$ use and pregnancy). This may reflect a possible contribution of endogenously formed $A P C$, and thus the protein $C$ pathway, during the thrombin generation experiment. Also other factors such as diminished plasma inhibitor concentrations or altered coagulation factor levels could contribute to this enhanced in vitro thrombin formation.

Since October 1995, when the United Kingdom Committee on Safety of Medicines recommended that women should use oral contraceptives containing desogestrel or gestodene only if prepared to accept an increased risk of thromboembolism, an increasing amount of papers have been published that focus on the relationship between venous thromboembolic disease and use of oral contraceptives. None of these papers has found a so clear difference in laboratory test outcome between groups of plasmas from users of different generations of contraceptives as was found in our experiments, described in chapter 6 . The reason for this is at present unclear, but the possible explanation for why in our system these differences are more marked than in other assay systems may very well give a clue to the 
14.Krishnaswamy S, Mann KG, Nesheim ME. The prothrombinase-catalyzed activation of prothrombin proceeds through the intermediate meizothrombin in an ordered, sequential reaction. J Biol Chem 1986; $261: 8977-8984$.

15.Tans G. Janssen-Claesen T, Hemker HC "Zwaal RFA, Rosing J. Meizothrombin formation during factor Xa-catalyzed prothrombin activation. Formation in a purified system and in plasma. J Biol Chem 1991; $266: 21864-$ 21873.

16.Tijburg PN, Van Heerde WL, Leenhouts HM, Hessing M, Bouma BN, De Groot $P G$. Formation of meizothrombin as intermediate in FXa-catalyzed prothrombin activation on endothelial cells. The influence of thrombin on the reaction mechanism. J Biol Chem 1991; 266: 4017-4022.

17.Sugo T, Nakamikawa $C$, Tanabe $S$, Matsuda $M$. Activation of prothrombin by factor Xa bound to the membrane surface of human umbilical vein endotheliall cells: Its catalytic efficiency is similar to that of prothrombinase complex on platelets. J Blochem (Tokyo) 1995; 117: 244-250.

18.Bovill EG, Tracey RP, Hayes TE, Jenny RJ, Bushan FH, Mann KG. Thromb Haemostas 1993; 69: 779

19.Bovill EG, Tracy RP, Hayes TE, Jenny RJ, Bhushan FH, Mann KG. Evidence that meizothrombin is an intermediate product in the clotting of whole blood. Arterioscler Thromb Vasc Biol 1995; 15: 754-758.

20.Côtě HCF, Stevens WK, Bajzår L, Banfield DK, Nesheim ME, MacGillivray RTA. Characterization of a stable form of human meizothrombin derived from recombinant prothrombin (R155A, R271A, and R284A). J Biol Chem 1994; 269: $11374-11380$.

21.Stevens WK, Côté HCF, MacGillivray RTA, Nesheim ME. Calcium ion modulation of meizothrombin autolysis at Arg 55 -Asp 56 and catalytic activity. J Biol Chem 1996; 271: 8062-8067.

22. Hemker HC, Willems GM, Bëguin S. A Computer Assisted Method to Obtain the Prothrombin Activation Velocity in Whole Plasma Independent of Thrombin Decay Processes. Thromb Haemost 1986; 56(1): 9-17.

23. Hemker HC, Beguin S. Thrombin Generation in Plasma: Its Assessment Via the Endogenous Thrombin Potential. Thromb Haemostas 1995; 74(1): 134138.

24. Giesen PLA, Willems GM, Hermens WT. Production of thrombin by the Prothrombinase Complex is Regulated by Membrane-mediated Transport of Prothrombin. J Biol Chem 1991; 266: 1379-1382.

25.Walker FJ, Sexton PW, Esmon CT. The inhibition of blood coagulation by activated protein $\mathrm{C}$ through selective inactivation of activated factor $\mathrm{V}$. Biochim Blophys Acta 1979; 571: 333-342.

26.Suzuki K, Stenflo J, Dahlbäck B, Teodorsson B. Inactivation of human coagulation factor $V$ by activated protein $C$. J Biol Chem 1983; 258: 1914-1920.

27. Guinto ER, Esmon CT. Loss of prothrombin and of factor Xa-factor Va interactions upon inactivation of factor $V$ a by activated protein $C . J$ Biol Chem 1984; 259 : 13986-13992.

28. Odegaard B, Mann KG. Proteolysis of Factor Va by Factor Xa and Activated Protein C. J Biol Chem 1987; 262:23: 11233-11238.

29.Solymoss S, Tucker MM, Tracy PB. Kinetics of inactivation of membranebound factor $\mathrm{Va}$ by activated protein $\mathrm{C}$. Protein $\mathrm{S}$ modulates factor $\mathrm{Xa}$ protection. J Biol Chem 1988; 263; 14884-14890. 
30.Kalafatis $M$, Rand MD, Mann KG. The mechanism of inactivation of human factor $V$ and human factor Va by activated protein $C$. J Biol Chem 1994; 269: 31869-31880.

31. Kalafatis $M$, Bertina $R M$, Rand MD, Mann KG. Characterization of the molecular defect in factor $V^{R 5080}$. J Biol Chem 1995; 270: 4053-4057.

32. Esmon CT. Jackson CM. Thromb Res 1974; 2: 509-524.

33.Bakker $H M$, Tans $G$, Janssen-Claesen $T$, et al. The effect of phospholipids, calcium ions and protein $S$ on rate constants of human factor Va inactivation by activated human protein C. Eur J Biochem 1992; 208: 171-178.

34. Walker FJ. Regulation of activated protein $C$ by a new protein. A possible function for bovine protein S. J Biol Chem 1980; 255: 5521-5524.

35. Comp PC, Esmon CT. Activated protein C inhibits platelet prothrombinconverting activity. Blood 1979; 54: 1272-1281.

36. Bertina RM; Koeleman BP; Koster T; Rosendaal FR; Dirven RJ; de Ronde H; van der Velden PA; Reitsma PH. Mutation in blood coagulation factor $V$ associated with resistance to activated protein $C$. Nature 1994; 369:64-67.

37.Egan JO, Kalafatis $M$, Mann KG. Activated protein $C$-mediated inactivation of recombinant human factor $\mathrm{Va}$. Circulation 1996; $94: 1566$

38. Kalafatis M, Haley PE, Lu DS, Bertina RM, Long GL, Mann KG. proteolytic events that regulate factor $V$ activity in whole plasma from normal and activated protein $\mathrm{C}$ (APC)-resistant individuals during clotting: an insight into the APC-resistance assay. Blood 1996; 87:11: 4695-4707.

39. Kalafatis M, Bertina RM, Mann KG. The Generation of Factor Va Activity During the APC Resistance Assay. Blood 1995; 86: 2445

40.Shen L, Dahlbäck B. Factor $V$ and protein $S$ as synergistic cofactors to activated protein $C$ in degradation of factor VIlla. J Biol Chem 1994; 269 ; $18735-18738$.

41. Váradi K, Rosing J, Tans G, Pabinger I, Keil B, Schwarz HP. Factor V enhances the cofactor function of protein $S$ in the APC-mediated inactivation of factor VIII: influence of the Factor $\mathrm{V}^{\mathrm{R} 5060}$ mutation. Thromb Haemostas 1996; 76(2): 208-214.

42. Lu DS, Kalafatis M, Mann KG, Long GL. comparison of activated protein $\mathrm{C} /$ protein S-mediated inactivation of human factor VIII and factor V. Blood $1996 ; 87: 11: 4708-4717$.

43. Forbes CD, Greer IA, Lowe GDO, et al. Haemostasis and Thrombosis in Obstetrics and Gynaecology. London: Chapman \& Hall, 1992;

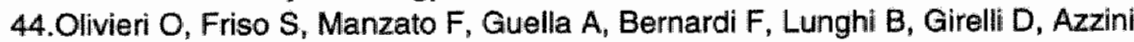
$M, B r o c c o G_{1}$ Russo $C$. Resistance to activated protein $C$ in healthy women taking oral contraceptives. $\mathrm{Br} J$ Haematol 1995; $91: 465-470$.

45. Winkler UH, Holscher T, Schulte H, Zlerleyn JP, Collet W, Schindler AE. Ethinylestradiol 20 versus $30 \mu \mathrm{g}$ combined with $150 \mu \mathrm{g}$ desogestrel: A large comparative study of the effects of two low-dose oral contraceptives on the hemostatic system. Gynecol Endocrinol 1996; 10: 265-271.

46. Simioni P; Scarano L; Gavasso S; Sardella C; Girolami B; Scudeller A; Girolami $A$. Prothrombin fragment $1+2$ and thrombin-antithrombin complex levels in patients with inherited APC resistance due to factor $V$ Leiden mutation. Br J Haematol 1996; 92: 435 441. 
47.Zöller B, Holm J, Svensson PJ, Dahlbäck B. Elevated levels of prothrombin activation fragment $1+2$ in plasma from patients with heterozygous Arg 506 to Gin mutation in the factor $V$ gene (APC-resistance) and/or inherited protein S deficiency. Thromb Haemost 1996; 75: 270-274.

48. Rintelen C, Mannhalter C, Ireland H, Lane DA, Knobl P, Lechner K, Pabinger I. Oral contraceptives enhance the risk of clinical manifestation of venous thrombosis at a young age in females homozygous for factor $\mathrm{V}$ Leiden. $\mathrm{Br} \mathrm{J}$ Haematol 1996; 93 : 487-490.

49. Koeleman BP, Reitsma PH, Allaart CF, Bertina RM. Activated protein C resistance as an additional risk factor for thrombosis in protein $\mathrm{C}$-deficient famillies. Blood 1994; 84: 1031-1035.

50.Eschwège-Gufflet V, Aillaud MF, Verdy E, Barthet MC, Juhan-Vague 1, Robert A. The assessment of the ACV test in the screening of defects in the anticoagulant protein $C$ pathway: a prospective study. Haemostasis $1996 ; 26$ : 215

51. Siegemund A, Engelhardt W, Kraus M. Pilot evaluation of a new assay for determination of APC sensitivity. Haemostasis 1996; $26: 486$

52. Hafner G, Niemann F, Erbes H, Prellwitz W, Noah M, Kraus M. Proc Global: a new functional screening assay sensitive for defects of protein $\mathrm{C}$, protein $\mathrm{S}$ and factor V. First clinical data. Haemostasis 1996; 26: 499

53.Kalafatis $\mathrm{M}$. The effect of factor Va phosphorylation on cofactor inactivation. Circulation 1996; $94: 1270$

54.Bajzăr $L$, Kalafatis $M$, Simioni $P$, Tracy $P B$. Prothrombotic tendencies associated with factor $V$ Leiden: an antifibrinolytic mechanism. Circulation $1996 ; 94: 2683$

55.Nichols WC, Amano K, Cacheris PM, Figueiredo MS, Michaelides K, Schwaab $R$, Hoyer $L$, Kaufman RJ, Ginsburg D. Moderation of hemophilia A phenotype by the factor V R506Q mutation. Blood 1996; 88: 1183-1187.

56.Brenner $B$, Mandel $H_{1}$ Lanir $N$. Activated protein $C$ resistance can be associated with recurrent fetal loss. Haemostasis 1996; 26: 415 


\section{Summary}

Haemostasis and thrombosis are two closely rellated processes with a common origin. Haemostasis is a physiological process in which blood loss from damaged blood vessels is limited and stopped by formation of a thrombus. In the case of thrombosis, a pathological condition, the haemostatic balance is disturbed. This can lead to formation of thrombil at locations in the body where, and at times when no thrombus formation is needed. Unwanted formation of thrombi can lead to obstruction of the circulation which can have many consequences. Chapter 1 reviews the general hypotheses for the formation of blood clots under both physiologicaland pathophysiological conditions. Several components of the haemostatic system are described which function in the formation and regulation of thrombin, a serine protease that plays a pivotal role in haemostasis. Furthermore, the structure, activation, function and inactivation of $\mathrm{FV}$, a nonenzymatic protein cofactor which is required for efficient generation of thrombin, is discussed. Particular attention is given to APC-mediated downregulation of $\mathrm{FVa}$ cofactor activity in individuals with a $\mathrm{Arg} \rightarrow \mathrm{Gln}$ amino acid replacement at position 506 in the FV molecule (FV Leiden, APC resistance). Acquired APC resistance, a phenomenon that has arisen since the gleneral acceptance of screening for APC resistance by functional methods, is discussed in the last part of this chapter.

Chapter 2 describes the activation of $\mathrm{FV}$ by meizothrombin, a reaction intermediate formed during prothrombin activation. In this study, a recombinant meizothrombin (R155A meizothrombin) was used in which $\mathrm{Arg}^{155}$ was replaced by Ala. This mutation prevents autocatalytic removal of the fragment 1 domain and allows studies on the functional activity of intact meizothrombin. In the presence of negatively charged phospholipid vesicles R155A meizothrombin was a potent activator of FV which activated FV with rate constants similar to those obtained for activation of $\mathrm{FV}$ by thrombin. Gel electrophoretic analysis of R155A meizothrombin- and thrombin-catalyzed activation of FV showed differences in the rates of cleavage of the susceptible peptide-bonds of FV by these two activators. However, FVa molecules obtained after full activation by R155A meizothrombin and thrombin were identical. It is concluded that during the initial phase of prothrombin activation, meizothrombin may play an important role in in vivo FV activation.

In chapter 3 , the kinetics of inactivation of purified normal plasma FVa and FVa from an individual homozygous for the $\mathrm{Arg}^{506} \rightarrow$ GIn were studied. To this end, functional assays, probing the FVa cofactor activity, as well as immunoblot analysis were used. This study resulted in a model for the inactivation of FVa in which FVa loses its cofactor activity by APC-catalyzed 
cleavage in the heavy chain domain of FVa in the presence of phospholipid vesicles via random cleavages of peptide bonds at positions $\mathrm{Arg}^{306}$ and $\mathrm{Arg}^{506}$. Cleavage at $\mathrm{Arg}^{506}$ is, however, characterized by a $\sim 25$ times higher second order rate constant $\left(\mathrm{K}_{\mathrm{ca}} / \mathrm{K}_{\mathrm{m}}\right)$. This implies that at low $\mathrm{FVa}$ concentrations the peptide bond at $\mathrm{Arg}^{506}$ is cleaved at a $\sim 20$ times faster rate than cleavage at $\mathrm{Arg}^{306}$. Likewise, initial cleavage of a low concentration of FVa by APC is $\sim 20$ times faster in normal FVa than in FVa ${ }^{\mathrm{A} 5060}$ since in the latter FVa, $\mathrm{Arg}^{508}$ is not present and cleavage occurs only at $\mathrm{Arg}^{306}$. It also demonstrates that $\mathrm{FVa}^{\mathrm{RE}}{ }^{\mathrm{B} 0 \mathrm{O}}$ is not fully resistant to inactivation by $\mathrm{APC}$. Cleavage at $\mathrm{Arg}^{506}$ in normal $\mathrm{FVa}$ yields a reaction intermediate that possesses $40 \%$ cofactor activity in prothrombin activation mixtures containing $5 \mathrm{nM} \mathrm{FXa}$. It is shown that the expression of cofactor activity of the intermediate is a function of the FXa concentration present in the FVa assay system that is used to monitor the loss of cofactor activity in prothrombin activation. This demonstrates that $\mathrm{Arg}^{506}$-cleaved $\mathrm{FVa}$ is impaired in its ability to interact with FXa. Similar kinetic analyses were performed for reaction systems that did not contain phospholipid vesicles. In these systems it was observed that most prominently in case of $\mathrm{FVa}^{\mathrm{P} 506 \mathrm{Q}}$, cleavage at $\mathrm{Arg}^{679}$ also contributes to the observed loss of cofactor activity upon incubation with APC.

The knowledge about the mechanism of APC-catalyzed inactivation of $\mathrm{FVa}$, obtained from the experiments presented in chapter 3 was used for the design of a chromogenic prothrombinase-based assay for the detection of APC-resistance (chapter 4). In this method, FV present in 1000-fold diluted plasma sample was activated with thrombin and subsequently incubated with phospholipids in the absence or presence of APC. After a fixed time interval FVa is quantified via determination of its cofactor activity in the prothrombinase complex. The percentage of remaining FVa cofactor activity, in the incubation with $A P C$, relative to the incubation without $A P C$, enables discrimination between plasma samples obtained from normal, heterozygousor homozygous APC-resistant individuals. The test was optimized for the detection of normal, heterozygous- or homozygous APC-resistant individuals and the sensitivity and specificity obtained were both $100 \%$, implying full correlation with DNA-based methods. The observed residual FVa activities for the different plasmas tested corresponded well with residual activities that were calculated on basis of rate constants of inactivation, presented in chapter 3. The test can be performed on any sample, provided that a sufficient amount of FV is present. Moreover, conditions that are known to hamper or influence functional detection of APC-resistance by clotting timebased methods (such as heparin treatment, oral anticoagulation, coagulation 
factor deficiencies, pregnancy, use of oral contraceptives or the presence of lupus anticoagulants) do not interfere with the outcome of our test.

In chapter 5 the focus of research shifts from the study of the anticoagulant function of APC in model systems, to systems which contain platelet poor plasma. The effect of APC on the extrinsic and intrinsic pathways of coagulation in plasma from normal and APC-resistant individuals was studied by measuring the time integral of thrombin generation (endogenous thrombin potential, ETP) determined via chromogenic methods. It is shown that the reduction of the ETP by APC can be inferred from the ratio of endlevels of $\alpha_{2}$-macroglobulin-thrombin complexes, in the presence and absence of $50 \mathrm{nM}$ APC: $\alpha_{2} M-\left\|l a_{+A P C} / \alpha_{2} M-\right\| l a_{A P C}$. Since the $\alpha_{2} M-l l a$ complex possesses amidolytic activity on small chromogenic substrates, the ratio, called APC-sensitivity ratio can be determined from two amidolytic measurements of the final levels of $\alpha_{2} \mathrm{M}$-lla complex, both in the presence and in the absence of APC. Division of the obtained ratio by the same ratio as determined for a normal plasma resulted in the normalized APC sensitivity ratio (nAPC-sr). Significant differences $(p<0.001)$ were observed between APC-sr of plasmas from normal individuals (nAPC-sr: $0.5-1.9, n=25$ ) and of plasmas from individuals that were heterozygous (nAPC-sr: $2.1-6.7, n=17$ ) or homozygous APC resistant (nAPC-sr: $3.9-5.9, n=5$ ). There was no overlap between APC-sr of normal plasmas and plasma from individuals, bearing the FV mutation. The data show that measurement of the effect of APC on the ETP yields valuable information about the (pro)thrombotic status of a plasma (e.g. APC resistance, pregnancy or the use of oral contraceptives).

In chapter 6 the effect addition of APC on the ETP of a plasma sample, as is described in chapter 5 , was further evaluated with plasma samples from women who were using oral contraceptives $(\mathrm{OC})$ and from women not using OC. Compared with women not using OC, women who used OC exhibited a significantly decreased sensitivity to APC $(P<0.001)$, independent of the kind of $O C$ used. Furthermore, it was shown that women who used thirdgeneration monophasic $O C$ were significantly less sensitive to APC than women using second-generation $O C(P<0.001)$ and had $A P C-s r$ that did not differ significantly from heterozygous female carriers of $F V_{\text {Leiden, }}$ not using $O C$. During the research, five women were identified who used $O C$ and were heterozygous carrier for the FV Leiden mutation. These women had an nAPC-sr in the range of homozygous carriers for the $\mathrm{FV}_{\text {Leiden }}$ mutation. Two women were included into the research that started $O C$ therapy. Within 3 days after start of OC therapy the APC-sr was significantly elevated. We propose that the observed acquired resistance to APC may well explain the 
epidemiological observation of the increased risk for venous thrombosis in $\mathrm{OC}$ users, especially in women using third-generation $O C$.

Chapter 7 gives a general discussion of the data that are presented in the chapters 2 to 6 and puts these data in the context of experiments that were performed by other research groups. The different chapters are linked to each other " where possible. Chapter 7 ends with a discussion on hypercoagulable states, such as APC resistance and acquired factors such as use of oral contraceptives or pregnancy.

\section{Samenvatting}

Dit proefschrift beschrijt het onderzoek dat gedurende de periode van 1 maart 1993 tot 1 maart 1997 door de auteur is uitgevoerd binnen de vakgroep Biochemie van de Faculteit der Geneeskunde van de Universiteit Maastricht. De vakgroep Biochemie vormt een onderdeel van CARIM, het Cardiovasculair Research Instituut Maastricht. Binnen dit instituut wordt vanuit verschillende wetenschappelijke disciplines onderzoek verricht dat betrekking heeft op de veelheid van processen die met het functioneren van hart- en bloedvaten te maken hebben. Belangrijk onderdeel van deze processen zijn de hemostase en trombose.

Hemostase en trombose zijn twee nauw aan elkaar verwante mechanismes die eenzelfde oorsprong hebben. Hemostase (bloedstolling) is een fysiologisch proces dat als doel heeft bloedverlies uit beschadigde bloedvaten te beperken en te stoppen. Hierbij wordt het beschadigde vat door een bloedpropje afgesloten. Van trombose spreken we wanneer er sprake is van een pathofysiologische toestand ('ziekte') waarin de hemostase niet meer onder controle is. Het gevolg hiervan is dat er bloedpropjes ontstaan in het lichaam op plaatsen en op tijdstippen waarop dit niet noodzakelijk is. Deze ongewenste vorming van bloedpropjes kan leiden tot verstopping van bloedvaten, waardoor de normale bloedcirculatie wordt gehinderd. Trombose kan in verschillende vormen, met ieder verschillende consequenties, voorkomen.

Hoofdstuk 1 geeft een samenvatting van de huidige theorieën over de vorming van bloedstolsels, zowel onder normale, als onder pathofysiologische condities. Verschillende bouwstenen van het hemostasesysteem worden besproken. Centraal staat echter de functie van het enzym trombine (behorend tot de serine protease klasse). 
Verder wordt de struktuur, de activering, de functie en inactivering van de stollingsfactor $V^{4}$ besproken. Factor $V$ is een niet-enzymatisch cofactor molecuul dat essentieel is voor de effectieve vorming van trombine.

In het bijzonder wordt er aandacht geschonken aan het ongedaan maken van de activiteit die ontstaat wanneer de niet-actieve factor $V$ is omgezet in het actieve FVa. Onderzoek naar de regulatie van FVa activiteit in personen waarbij als gevolg van een genetische afwijking een verandering in het gen voor factor $V$ heeft plaats gevonden (de arginine op positie 506 is vervangen door een glutamine) neemt een bijzondere plaats in. Deze

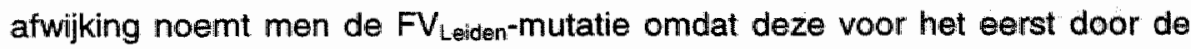
onderzoeksgroep van Prof. Bertina uit Leiden is beschreven (synoniem is de term $F^{R .506 Q}$ ). Mensen met $F V_{\text {Leiden }}$ worden APC-resistent genoemd aangezien de regulatie van $\mathrm{FVa}$ activiteit in deze individuen sterk belemmerd is en het factor Va ongevoelig is geworden voor APC, het enzym dat onder normale omstandigheden FVa inaktiveert.

Door in het laboratorium te testen of het bloedplasma van een individu wel of niet gevoelig is voor APC kan men bepalen of iemand APC-resistent is. Gebleken is echter dat APC resistentie niet alleen voorkomt bij mensen die

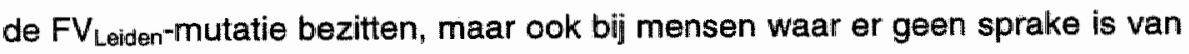
een bekende afwijking aan het stolsysteem. In die gevallen wordt gesproken van verworven APC resistentie. Verworven APC-resistentie, besproken in het laatste deel van hoofdstuk 1; komt onder andere voor bij vrouwen die zwanger zijn of die anticonceptie-pillen gebruiken.

Hoofdstuk 2 beschrijt de aktivering van FV door meizotrombine, een reactie-tuusenprodukt bij de protrombine-aktivering. In deze studie is een recombinante vorm van meizotrombine gebruikt, R155A meizotrombine. Voor de constructie van deze mutant werd het arginine residue op aminozuurpositie 155 veranderd in een alanine; wat tot gevolg had dat autokatalytische afsplitsing van het fragment 1 domein onmogelijk werd gemaakt. In aanwezigheid van negatief geladen fosfolipide-oppervlakken was R155A meizotrombine een sterke activator van $F V$, gekarakteriseerd door een tweede orde snellheidsconstante voor de activering van FV die van dezelfde grootte-orde is als die voor de activering van FV door trombine.

- Volgens afspraak worden een aantal verschillende stolfactoren met Romeinse ciffers aangeduid. Een hoofdletter ' $F$ ' is de afkorting voor stolfactor. Wanneer een stolfactor niet aktief is staat er enkel een Romeins cijfer, bijwoorbeeld FV. Wanneer men de aktieve vorm van een stolfactor bedoeld, dan wordt deze aangeduid door de letter 'a' bij te plaatsen. bijvoorbeeld $\mathrm{FVa}$. 
Gelelectroforetische analyse van FV-activeringen door R155A meizotrombine of trombine toonden aan dat er verschillen zijn in de snelheden waarmee de verschillende peptide-bindingen gesplitst worden tijdens de activering van FV. $\mathrm{Na}$ volledige activering van $\mathrm{FV}$ door $\mathrm{R} 155 \mathrm{~A}$ meizotrombine of trombine worden echter FVa moleculen verkregen die identiek zijn. De conclusie wordt getrokken dat gedurende de initiele fase van de protrombineactivering, meizotrombine een belanigrijke rol kan spelen in de in vivo activering van FV.

In hoofdstuk 3 wordt de inactivering van FVa door APC beschreven voor zowel normaal FVa als voor FVa gezuiverd uit het plasma van iemand die homazygoot voor de $\mathrm{Arg}^{506} \rightarrow$ Gin mutatie is. Hierbij is gebruik gemaakt van een assay waarmee de functionele activiteit van FVa getest wordt en waarbij peptide-band splitsingen in de zware keten van FVa worden bestudeerd met behulp van immunoblot-analyse. Een model voor de inactivering van FVa door APC wordt voorgesteld, waarbij in aanwezigheid van een fosfolipideoppervlak de cofactor-activiteit van FVa verdwijnt, na splitsing van de peptidebindingen achter de aminozuren $\mathrm{Arg}^{306}$ en $\mathrm{Arg}^{506}$ (in willekeurige volgorde) in de zware keten van FVa. Splitsing op positie $\mathrm{Arg}^{506}$ wordt echter gekarakteriseerd door een ongeveer 25 maal grotere reactiesnelheidsconstante $\left(\mathrm{k}_{\text {cat }} / \mathrm{K}_{\mathrm{m}}\right)$ dan splitsing op positie $\mathrm{Arg}^{306}$. Dit verschil wordt met name veroorzaakt door een 10-voudig verschil in de $\mathrm{K}_{\mathrm{m}}$ voor de splitsing van beide peptide-bindingen. Dit houdt in dat bij lage FVa concentraties, zoals die in de beschreven experimenten zijn gebruikt, de splitsing achter Arg $^{506} 20$ keer sneller gaat dan die achter $\mathrm{Arg}^{305}$. Dit betekent dat $\mathrm{FVa}_{\text {Leiden, niet volledig }}$ resistent is tegen inactivering door $A P C$ en via splitsing van de peptideband achter Arg $^{306} 20$ keer langzamer dan FVa kan worden geinactiveerd.

Splitsing achter $\mathrm{Arg}^{506}$ van normaal $\mathrm{FVa}$ levert een reactietussenproduct dat $40 \%$ van de initiele cofactor activiteit bezit in protrombineactiverings mengsels die $5 \mathrm{nM}$ FXa bevatten. Aangetoond wordt dat de expressie van cofactor activiteit van het reactie-tussenproduct een functie is van de FXa concentratie die aanwezig is in de FVa cofactor assay. Dit toont aan dat $\mathrm{Arg}^{506}$-gesplitst $\mathrm{FVa}$ belemmerd is in zijn interactie met $\mathrm{FXa}$.

Soortgelijke kinetische analyses als voor de fosfolipide-bevattende reactie-mengsels zijn uitgevoerd voor reactie-mengsels die geen fosfolipide vesikels bevatten. Experimenten in deze systemen toonden aan dat met name in geval van de inactivering van $\mathrm{FVa}^{\mathrm{R} 506 \mathrm{Q}}$, de splitsing achter $\mathrm{Arg}^{679}$ ook bijdraagi aan het waargenomen verlies van cofactor-activiteit tijdens incubatie met APC.

Het model woor de door APC gekatalyseerde inactivering van $\mathrm{FVa}_{4}$ dat in het vorige hoofdstuk 3 werd voorgesteld is gebruikt bij het ontwerpen van een chromogene test, op basis van protrombinase-activiteit, voor de detectie van 
APC-resistentie. Deze methode wordt beschreven in hoofdstuk 4. In deze methode wordt een plasmamonster sterk verdund (1000 keer) in een fosfolipide-bevattende buffer en het aanwezige $\mathrm{FV}$ wordt met trombine geactiveerd. De resulterende FVa activiteit wordt vervolgens bepaald in een protrombinase-assay, nadat er een incubatiestap met- of zonder APC heeft plaatsgevonden. Het restpercentage FVa activiteit, in het reactiemengsel met daarin APC, ten opzichte van het reactiemengsel zonder APC, wordt gebruikt als een maat om te bepalen of het plasma sample afkomstig was van een normaal individu ofwel van een heterozygoot of homozygoot APC resistent individu. De methode is geoptimaliseerd en zowel de specificiteit als de sensitiviteit van de test waren $100 \%$, wat inhoudt dat er een volledige correlatie bestaat met methoden die op DNA analyse zijn gebaseerd. De waargenomen FVa restactiviteiten voor de verschillende plasma's correspondeerden goed met restactiviteiten die op grond van de kinetische parameters die in hoofdstuk drie zijn gegeven worden berekend voor de verschillende inactiveringen. De test kan worden uitgevoerd op ellk plasma monster, op voorwaarde dat er voldoende FV aanwezig is. Bovendien is de test uitvoerbaar in plasmas die via methodes die gebaseerd zijn op de bepaling van stoltijden moeilijk of niet te bepalen zijn (bijvoorbeeld bij aanwezigheid van heparine of lupus anticoagulantia, bij gebruik van orale anticoagulantia of oral contraceptiva of bij zwangerschap).

In hoofdstuk 5 verschuift het onderzoek naar de anticoagulante functie van APC van een basaal onderzoek in model-systemen maar een meer toegepaste vorm, in systemen die bloedplaatjes-arm plasma bevatten. Het effect van de toevoeging van APC aan plasmamonsters waarin de stolling zowel intrinsiek- als extrinsiek gestart is wordt bestudeerd voor plasma's van normale, gezonde individuen en van APC-resistente individuen. Kwantitering van dit effect van APC wordt uitgevoerd via verlaging van de tijdsintegraal van trombinevorming (endogene trombine potentiaal, ETP) die wordt geregistreerd via een chromogene methode. Aangetoond wordt dat een verlaging van de ETP door APC eenvoudig kan worden afgeleid uit een simultane vermindering van de eindniveau's van de $\alpha_{2}$-macroglobulinetrombine complexen, zowel in aan- als in afwezigheid van APC: $\alpha_{2} M-\| l a_{4 . A P C} /$ $\alpha_{2} \mathrm{M}$-lla.APC. Aangezien het $\alpha_{2} \mathrm{M}$-lla complex amidolytische activiteit bezit t.o.v. kleine chromogene substraten, kan de voorgenoemde ratio van $\alpha_{2} \mathrm{M}-l \mathrm{la}$ niveau's worden berekend uit twee amidolytische bepalingen van de eindniveau's van $\alpha_{2} \mathrm{M}$-lla complex, één in aanwezigheid, en één in afwezigheid van $A P C$.

Deling van de verkregen ratio van activiteiten van het $\alpha_{2} \mathrm{M}$ - 1 la complex voor een willekeurig plasmamonster door een soortgelijke ratio die bepaaid is 
voor een gedefinieerd normaal plasma geeft de genormaliseerde APCsensitiviteits ratio (nAPC-sr). Tussen de plasma's van normale individuen (nAPC-sr: $0.5-1.9, n=25$ ) en heterozygote (nAPC-sr: $2.1-6.7, n=17$ ) en homozygote APC-resistente (nAPC-sr: $3.9-5.9, n=5$ ) personen zijn significante verschillen $(p<0.001)$ in $A P C-s r$ waargenomen. Er was geen overlap tussen de APC-sr van normale plasma's en plasma's van personen die drager van de $F V_{\text {Leiden }}$-mutatie zijn. Onze data tonen aan dat bepaling van het effect van APC-toevoeging op de ETP waardevolle informatie oplevert over de (pro)trombotische status van een plasmamonster (bijvoorbeeld in geval van APC-resistentie, zwangerschap of gebruik van orale contraceptiva).

Hoofdstuk 6 beschrijft het effekt van toevoeging van APC op de ETP van plasma-monsters, volgens de methode zoals beschreven in hoofdstuk 5 , voor een serie van monsters van vrouwen die wel of niet orale contraceptiva (OC) gebruiken. Vergeleken met vrouwen die geen OC gebruiken, vertoont het plasma van vrouwen die $O C$ gebruiken een significant verminderde gevoeligheid voor APC ( $p<0.001)$, onafhankelijk van het soort $O C$ dat wordt gebruikt. Bovendien was het plasma van vrouwen die een derde-generatie monofasische OC gebruiken, significant ongevoeliger voor APC dan het plasma van wrouwen die een tweede-generatie $O C$ gebruiken $(p<0.001)$ en waren de APC-sr niet significant verschillend van de APC-sr voor een groep vrouwelijke heterozygote draagsters van de $\mathrm{FV}_{\text {Leiden-mutatie die geen } O C}$ gebruiken. Vijf vrouwen die aan het onderzoek als bloeddonor deelnamen en die OC gebruikten bleken heterozygote draagster voor de $\mathrm{FV}_{\text {Leiden-mutatie. }}$ Deze vrouwen hadden een APC-sr in de orde van grootte van die welke behoort bil homozygote dragers van de FV Leiden-mutatie.

Twee vrouwen, starters van OC-gebruik, werden bij het onderzoek betrokken. Binnen een tijjdsbestek van drie dagen na aanvang van de $O C$ theraple was de APC-sr in het plasma van deze vrouwen significant verhoogd. Wij stellen dan ook de hypothese dat de waargenomen verworven APC-resistentie mogelijk een verklaring geeft voor het toegenomen risico op veneuze trombose bij het gebruik van $O C$ en met name derde-generatie $O C$, zoals dat uit epidemiologisch onderzoek wordt geconcludeerd.

Hoofdstuk 7 bediscussieert in algemene zin de data die in de hoofdstukken 2 tot en met 6 worden gepresenteerd en stelt deze in een context van data die door andere onderzoeksgroepen werden gepubliceerd. Verbanden tussen de verschillende hoofdstukken worden, waar mogelijk, gelegd. Hoofdstuk 7 eindigt met een uiteenzetting over hypercoagulabele toestanden (dat zijn condities waarbij om de één of andere reden er sprake is van een trombotiseneiging) zoals APC- resistentie en verworven factoren zoals bij gebruik van orale contraceptiva of zwangerschap. 


\section{Curriculum Vitae}

De auteur van dit proefschrift werd op 12 mei 1969 geboren te Maastricht. Na het succesvol doorlopen van de kleuterschool, alwaar een eerste proeve van bekwaamheid werd afgelegd in de vorm van het schoenstrikexamen, ging hij naar de basisschool, de John F. Kennedyschool en later de Petrus en Paulusschool te Wolder-Maastricht. Met een verkeersen een EHBO-diploma op zak ging Gerry vervolgens naar de brugklas van het Stedelijk Lyceum in Maastricht, alwaar hij zijn opleiding vervolgde in het Gymnasium. Op 27 mei 1987 werd het examen Gymnasium-B met veel ijver behaald en in augustus van datzelfde jaar ging Gerry naar de grote stad Utrecht om er Scheikunde te studeren aan de lokale Rijksuniversiteit.

$\mathrm{Na}$ een vlotte propaedeuse en een verplicht basisprogramma werden twee bijvakken gekozen, Biochemie van de Erfelijke Metabole Stoornissen (in het Wilhelmina Kinderziekenhuis te Utrecht onder begeleiding van Dr. M. Duran en Dr. L. Dorland) en een bijvak Klinische Chemie (in het Academisch Ziekenhuis Utrecht onder begeleiding van Dr. M.A. Blankenstein en Prof. Dr. J.H.H. Thijssen). Vervolgens werd Gerry hoofdvakstudent bij de vakgroep Enzymology en Protein Engineering binnen het Centrum voor Biomembranen en Lipide Enzymologie van de Universiteit Utrecht (onder begeleiding van Dr. R.B. Lugtigheid en Prof. Dr. H.M. Verhey). Na een geslaagde afstudeerscriptie over het ondenwerp "HIV-infecties en de mogelijke chemotherapeutische waarde van HIV-protease inhibitors' werd het hoofdvakexamen Biochemie afgenomen door de professoren Prof. Dr. L.L.M van Deenen ${ }^{\dagger}$ en Prof. Dr. B. de Kruijff. Direkt gevolg van dit examen was het verkrijgen van de doctorandus-titel alsmede een keuze uit twee AlOopleidingsplaatsen, waarvan één in Maastricht. Op 25 januari 1993 ontving Gerry, gehesen in een nieuw pak, zijn bul van de Universiteit Utrecht.

Vanaf 1 maart 1993 was Gerry met veel genoegen werkzaam als Assistent In Opleiding bij het Cardiovasculair Research Instituut in het geliefde Maastricht (CARIM). Binnen het CARIM, onderdeel van de Rijksuniversiteit Limburg, een universiteit in beweging, ze heet inmiddels Universiteit Maastricht, werkte hij onder begeleiding van zijn promotor Prof. Dr. H.C. Hemker en de copromotoren, Dr. J. Rosing en Dr. G. Tans aan hetgeen er in dit proefschrift beschreven staat. 


\section{List of Publications}

1. Acylation of porcine pancreatic PLA $\mathrm{A}_{2}$ influences penetration and substrate headgroup binding, depending on the position of the acylated lysine in the enzyme molecule.

Lugtigheid RB, Nicolaes GAF, Veldhuizen EJA, Slotboom Ad, Verheij HM, de Haas $\mathrm{GH}$. (1993) European Journal of Biochemistry 216(2), 519-525

2. Activation of human factor $V$ by meizothrombin.

Tans G, Nicolaes GAF, Thomassen MCLGD, Hemker HC, van Zonneveld A-J, Pannekoek H, Fosing J. (1994) Journal of Biological Chemistry 269, 15969-15972

3. Peptide bond cleavages and loss of functional activity during inactivation of factor $\mathrm{Va}$ and factor $\mathrm{Va} \mathrm{a}^{\mathrm{R506}}$ by activated protein $\mathrm{C}$ Nicolaes GAF, Tans G, Thomassen MCLGD, Hemker HC, Pabinger I, Váradi K, Schwarz HP, Rosing J. (1995) Journal of Biological Chemistry 270, 21158-21166

4. Effects of protein $S$ and factor $X a$ on peptide bond cleavages during inactivation of factor $\mathrm{Va}$ and factor $\mathrm{Va}{ }^{\mathrm{R5} 66 \mathrm{Q}}$ by activated protein $\mathrm{C}$.

Rosing J, Hoekema L, Nicolaes GAF, Thomassen MCLGD, Hemker HC, Våradi K, Schwarz HP, Tans G. (1995) Joumal of Biological Chemistry 270, 27852-27858

5. A prothrombinase-based assay for detection of resistance to activated protein $\mathrm{C}$

Nicolaes GAF, Thornassen MCLGD, van Oerle R, Hamulyák K, Hemker HC, Tans G, Rosing J. (1996) Thrombosis and Haemostasis 76(3). 404-410

6. Effect of activated protein $\mathrm{C}$ on thrombin generation and on the thrombin potential in the plasma of normal and APC resistant individuals

Nicolaes GAF, Thomassen MCLGD, Tans G, Rosing J, Hemker HC. (1997) Blood Coagulation \& Fibrinolysis 8 , 28-38

7. Oral Contraceptives and venous thrombosis: different sensitivities to activated protein $\mathrm{C}$ in women using second and third generation oral contraceptives.

Rosing J, Tans G, Nicolaes GAF, Thomassen MCLGD, Van Oerle R, Van der Ploeg PMEN, Heijnen P, Hamulyák K, Hemker HC. (1997) British Journal of Haematology 97, 233-238

8. Human factor Va1 and Va2: Properties in the procoagulant- and anticoagulant pathways.

Hoekerna L, Nicolaes GAF, Tans G, Hemker HC, Rosing J. (1997) Biochemistry, $36(11), 3331-3335$

9. Regulation of thrombin formation by activated protein $\mathrm{C}$ : effect of the FV Leiden mutation.

Tans G Nicolaes GAF, Rosing J. (1997) Seminars in Hematology, accepted for publication 


\section{Abstracts}

1. Detection of APC resistance by measurement of the effects of APC on the endogenous thrombin potential and on plasma factor Va cofactor activity

Nicolaes GAF, Thomassen MCLGD, Hemker HC, Tans G, Rosing J. (1996) Haemostasis 26 (suppl 3 ), 444

2. Human factor Va1 and Va2: different sensitivities for activated protein $C$ (APC) results in different procoagulant activities.

Nicolaes GAF, Hoekema L, Tans G, Rosing J., accepted as oral presentation at the Congress of the International Society on Thrombosis and Haemostasis, Florence, 6 12 June 1997

3. Use of two new functional assays to detect inherited and acquired APC-resistance.

Nicolaes GAF, Thomassen MCLGD, Hemker HC, Tans G, Rosing J. accepted as poster presentation at the Congress of the International Society on Thrombosis and Haemostasis, Florence, 6-12 June 1997

4. APC-mediated regulation of factor Va activity in plasma.

Hoekema L. Nicolaes GAF, Tans G, Rosing J. accepted as poster presentation at the Congress of the International Society on Thrombosis and Haemostasis, Florence, 612 June 1997

5. Different sensitivities to activated protein $C(A P C)$ in women using second and third generation oral contraceptives.

Tans G, Nicolaes GAF. Thomassen MCLGD. Hamulyàk K, Hemker HC, Rosing J. accepted as poster presentation at the Congress of the International Society on Thrombosis and Haemostasis, Florence, 6-12 June 1997 


\section{Dankwoord}

Wie dit proefschrift, of althans delen ervan, gelezen heeft en vervolgens denkt dat die Gerry dat toch mooi voor elkaar heeft gekregen in zijn eentje, die heeft het mis. Want zoals wel eens vaker gezegd wordt, is de research zoals die is uitgevoerd ten behoeve van dit proefschrift een echte teamsport. Zonder de medewerking van zovelen was dit alles dan ook niet tot stand gekomen en ik vind het dan ook op zijn plaats om in dit dankwoord een aantal mensen te bedanken die een bijzondere bijdrage hebben geleverd.

Als eerste bedank ik alle medewerkers van de vakgroep Biochemie waarvan ik, in meer of mindere mate, de hulp heb mogen inroepen. Wanneer ik hierbil niet alle mensen bij naam noem doe ik dat alleen maar omdat ik niemand tekort will doen en ieders hulp en gezelschap bijzonder op prijs heb gesteld gedurende de periode dat ik als AlO aanwezig was.

Een bijzonder woord van dank gaat verder uit naar mijn begeleiders, Prof. Coen Hemker, Guido Tans en last but not least Jan Rosing. Prof. Hemker, $\bigcup$ will ik graag bedanken omdat ik mede dankzij $U$ in de vakgroep heb kunnen werken en wel zodanig dat ik het idee heb dat de enige zorg van uw AlO's onderzoek doen en promoveren is, op andere plaatsen is dat wel eens anders. Guido, ij was altijd met een waakzaam oog aanwezig, soms als het geweten van de groep, wanneer de ethiek van het onderzoek ter sprake kwam. Het was aanvankelijk een vreemde ervaring om te merken dat wetenschap zelfs met het Maastrichts dialect kan worden bedreven. Voorwaar een genoegen om met jou samen te werken. Tensilotte Jan. Jij bent een verhaal apart "van Dr. Rosing naar meneer Rosing naar Jan. Ik heb ontzettend veel van jou geleerd, en dan bedoel ik niet alleen de wetenschappelijke zaken. Altijd stond je deur open en kon ik even binnenlopen, wat ik dan ook veelvuldig deed. Toch liet je nooit merken dat je geen tijd had. Dit waardeer ik erg. Onderzoek doen en dan het liefst in een team dat het onderling goed met elkaar kan vinden, daar is jou veel aan gelegen; een wijze les.

Stella, jou wil ik toch ook met naam noemen want jij was het die in het begin mij wegwijs maakte in het lab. In de periode daarna, ik was al wat eigenwijzer, bleef jii steeds die fijne collega. Ik denk dan ook dat ik met geen betere analiste had kunnen werken, ik bewonder jou inzet. Om nou niet totaal euforisch te worden wil ik toch graag kwijt dat ik wel soms compleet nerveus werd van de CD-tjes die jij meenam, wilde je iedereen zo graag het lab uit hebben? Lico, jij was de stille kracht uit het noorden, ondanks dat het je nog steeds niet spijt dat de Friezen, de heilligen uit het zuiden de schedell hebben ingeslagen, hebben we plezierig samen kunnen werken. Met name jouw fysisch/mathematische inbreng kwam vaak van pas. José, 'slechts' part-time aanwezig weet jij toch, een stempel op het lab te drukken. Als een soort moeder van het lab en met jouw rustgevende uitstraling krijg jij, als het moet, overal alles voor elkaar. Ook als bliksem-afleider (ik zal geen namen noemeni heb jij prima diensten bewezen. Joyce, nog maar pas bezig, ben je nu al zo nadrukkelijk en gezellig aanwezig in het lab dat ik denk dat we van jou nog veel zullen horen.....

Als laatste bedank ik Silvie. Jij hebt de laatste tijd heel wat met mij te stellen gehad. Als ik weer eens niet laat thuis was, dan liet ik jou well alleen in de huiskamer zitten om zelf achter de computer plaats te nemen. Wanneer het ook maar even kon heb jij me gesteund. Een beter maatje bestaat er niet. 